\title{
Towards a Flexible Plant Breeders' Rights System in Kenya
}

\author{
Peter G. Munyi
}

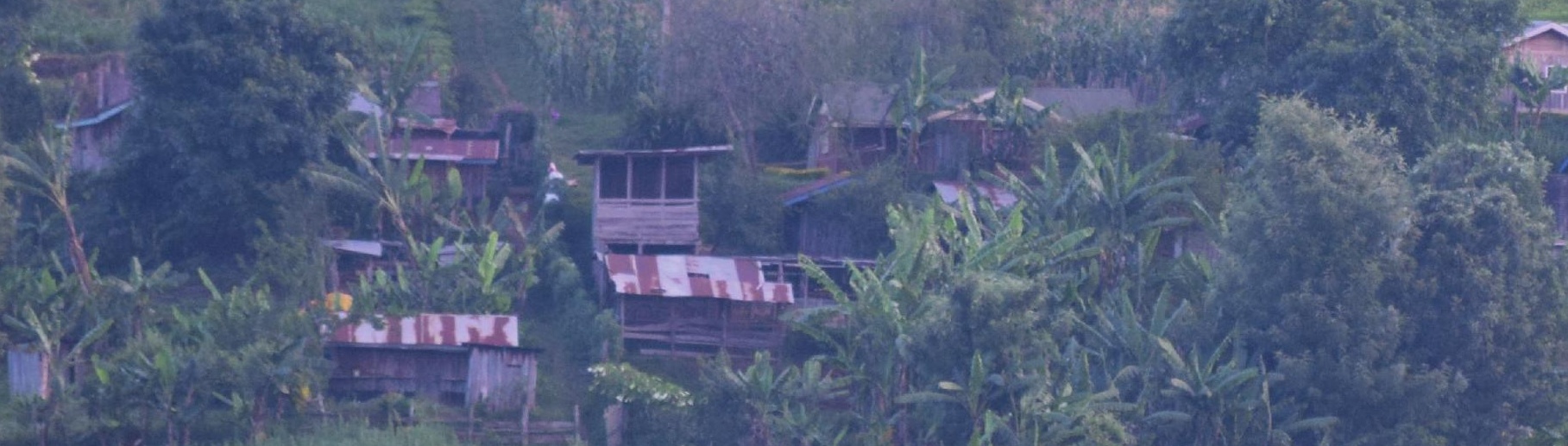

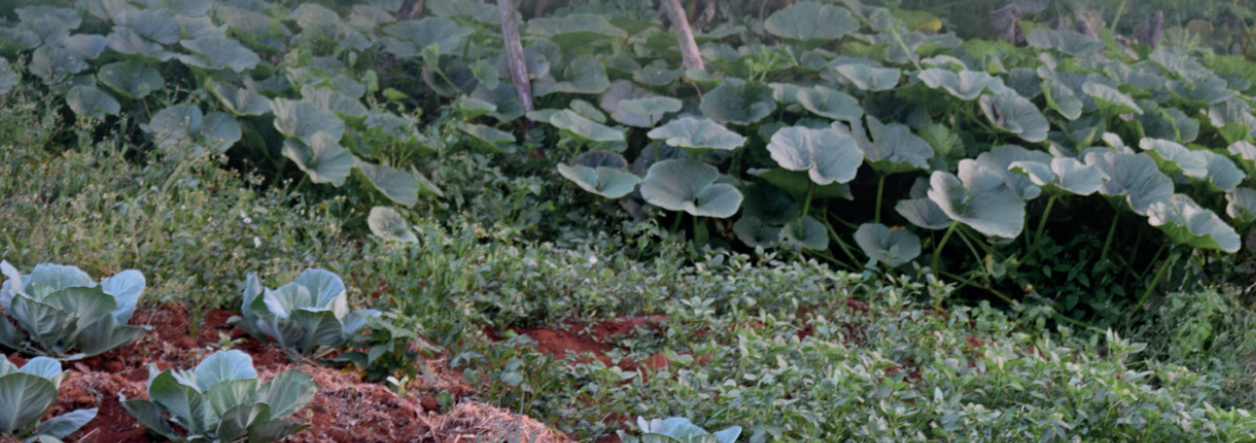

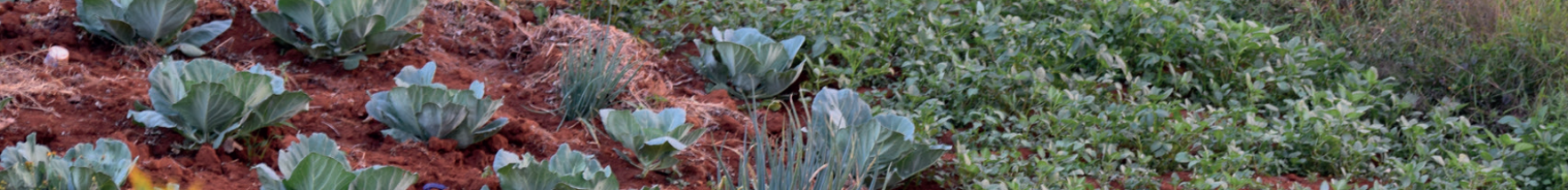

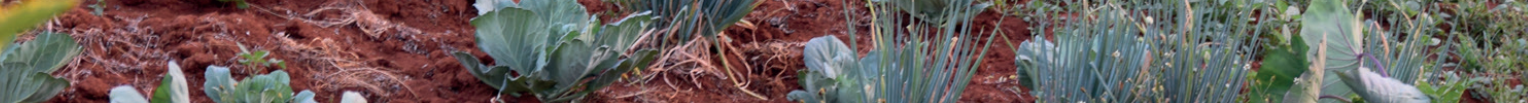


Towards a Flexible Plant Breeders' Rights System in Kenya

Peter Gitahi Munyi 


\section{Thesis committee}

\section{Promotor}

Prof. Mr Dr B.M.J. van der Meulen

Professor of Law and Governance

Wageningen University \& Research

\section{Co-promotors}

Dr N.P. Louwaars

External staff member, Law and Governance Group

Wageningen University \& Research

Dr B. Visser

Policy advisor, Centre for Genetic Resources, the Netherlands

Wageningen University \& Research

Dr B. de Jonge

Postdoc researcher, Law and Governance Group

Wageningen University \& Research

\section{Other members}

Prof. Dr S.W.F. Omta, Wageningen University \& Research

Prof. P. Kameri-Mbote, University of Nairobi, Kenya

Prof. J. Kinderlerer, University of Cape Town, Republic of South Africa

Prof. Dr C.M. Correa, University of Buenos Aires, Argentina

This research was conducted under the auspices of Wageningen School of Social Sciences (WASS) 
Towards a Flexible Plant Breeders' Rights System in Kenya

Peter Gitahi Munyi

\section{Thesis}

submitted in fulfilment of the requirements for the degree of doctor at Wageningen University

by the authority of the Rector Magnificus,

Prof. Dr A.P.J. Mol,

in the presence of the

Thesis Committee appointed by the Academic Board

to be defended in public

on Thursday 23 November 2017

at 11 a.m. in the Aula. 
Peter Gitahi Munyi

Towards a Flexible Plant Breeders' Rights System in Kenya, 217 pages.

PhD thesis, Wageningen University, Wageningen, the Netherlands (2017) With reference, with summary in English

ISBN: 978-94-6343-216-0

DOI: https://doi.org/10.18174/424869 


\section{Table of Contents}

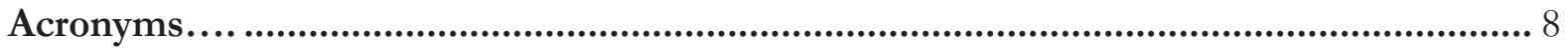

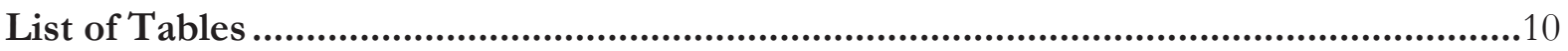

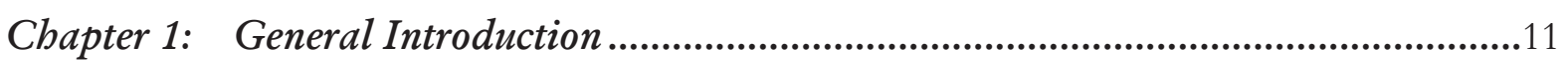

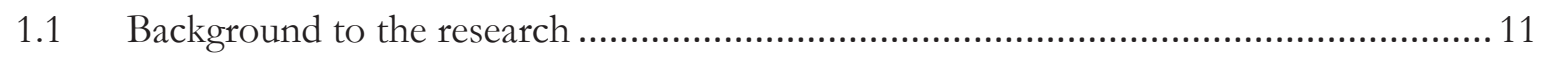

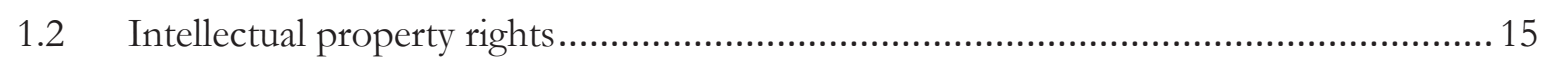

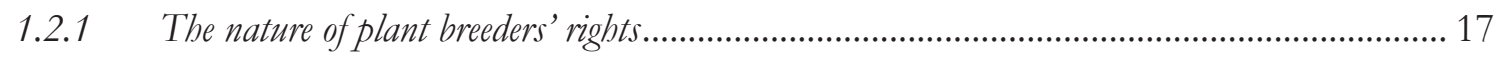

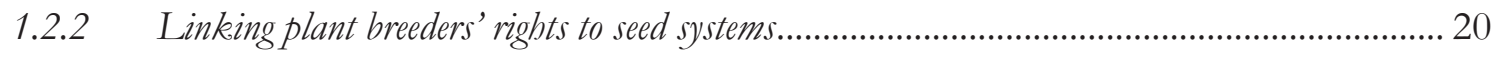

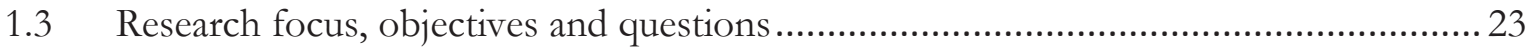

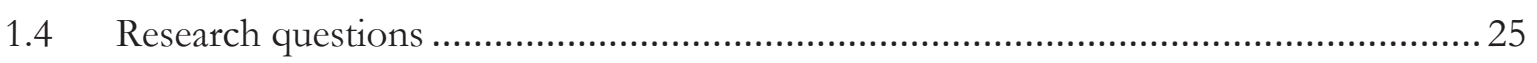

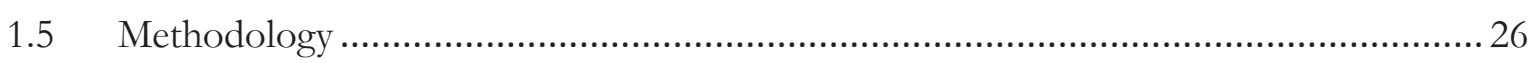

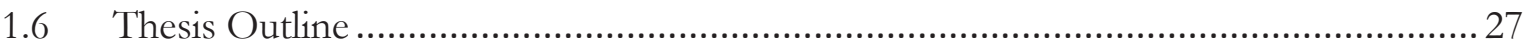

Chapter 2: Seed systems support in Kenya: consideration for an Integrated Seed Sector Development approach ..........................................................................................................31

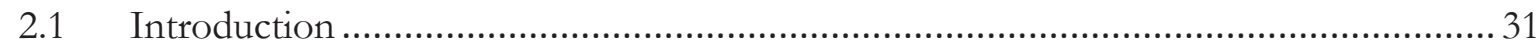

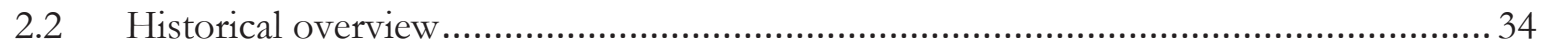

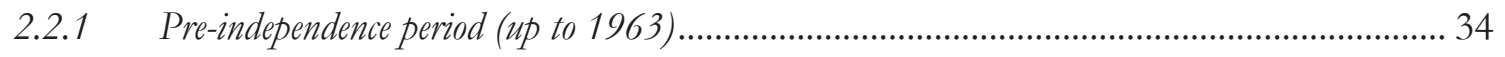

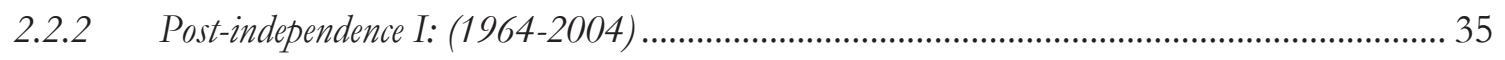

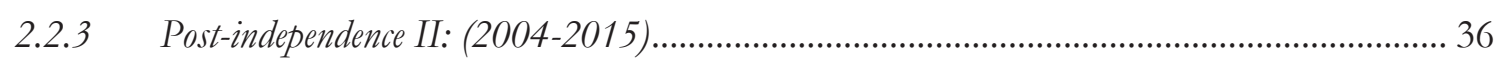

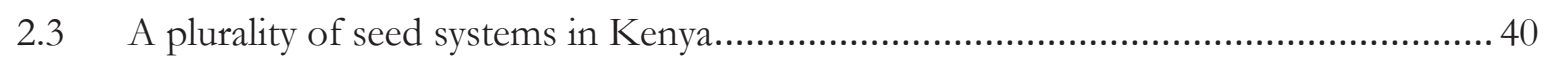

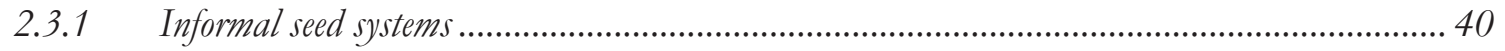

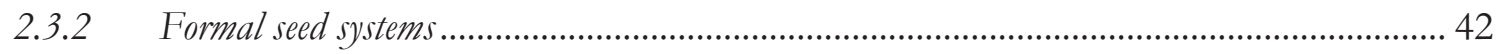

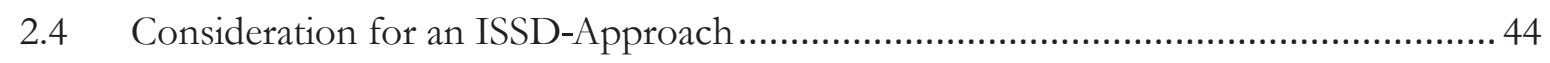

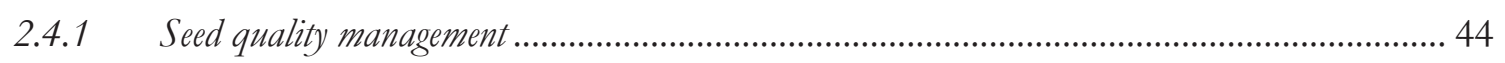

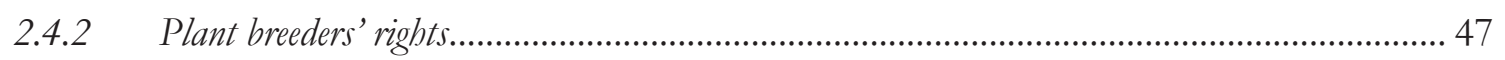

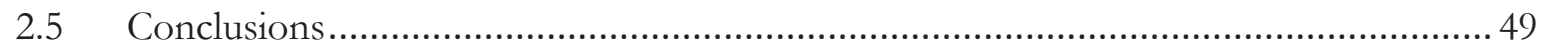

Chapter 3: Plant breeders' rights regime in relation to relevant international obligations: implications for smallbolder farmers in Kenya ..................................................................51

3.1 International plant breeders' rights obligations and domestication dilemmas ............... 51

3.2 Global PBRs architecture of relevance to Kenya ....................................................... 54

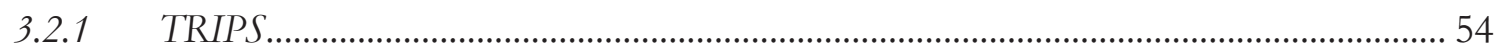

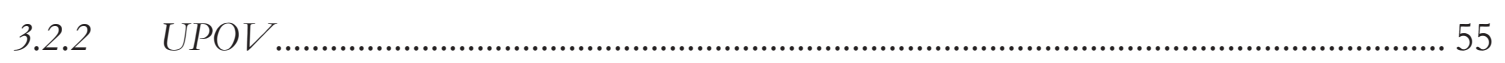

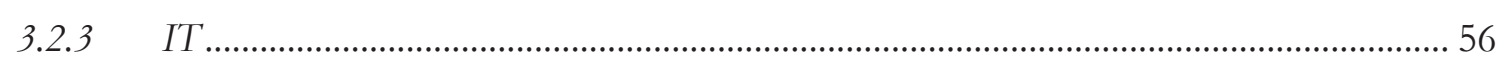

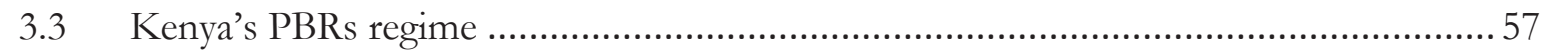

3.3.1 Historical development and landscape of PBRs legislation and PBRs applications ................... 57

3.3.2 Constitutional dimensions of PBRs: anchorage and inclusion of international obligations......... 59

3.3.3 The 1972 SPV A and the 2012 SPV A Amendment: analysis of changes ........................... 62

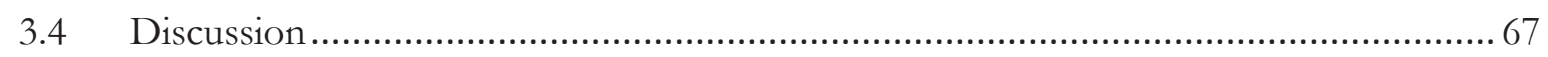




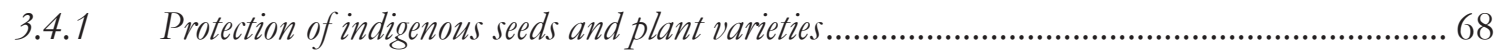

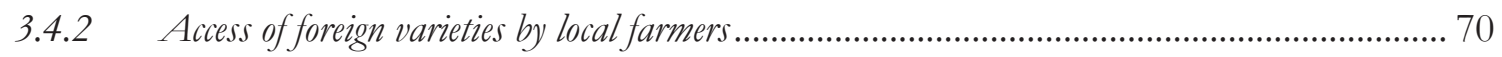

3.4.3 Meeting UPOV 1991 standards: conditions for grant of PBRs.......................................... 71

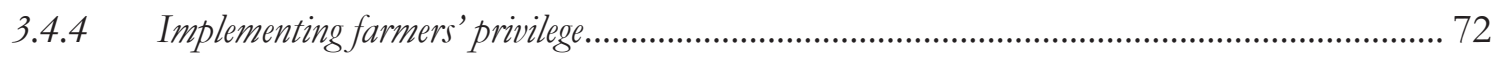

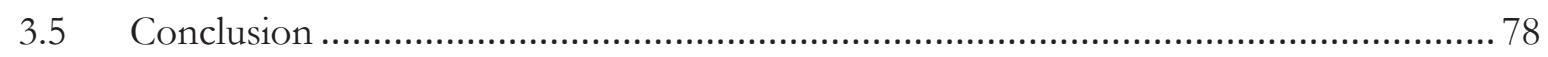

Chapter 4: Opportunities and threats to harmonization of national plant breeders' rights legislations through regional agreements: $A R I P O$ and $S A D C$.........................................81

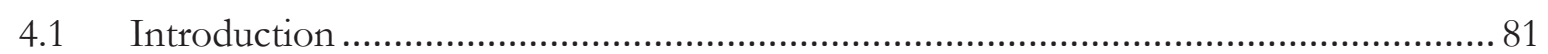

4.2 Uncertainty on whether the Arusha Protocol and the SADC Draft are intended to have a direct legal effect.....

4.3 Difficulties arising from intended uniformity application and prohibition of cumulative protection 89

4.4 Challenges in implementation of the farmers' privilege ...........................................92

4.5 Challenges in the implementation of farmers' rights ................................................ 95

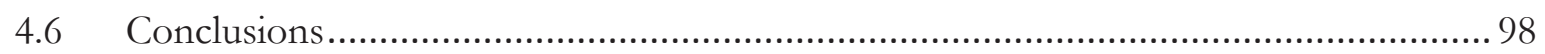

Chapter 5: Plant breeders' rights licensing as a tool to facilitate access of seed for smallbolder farmers: observations from Kenya .............................................................103

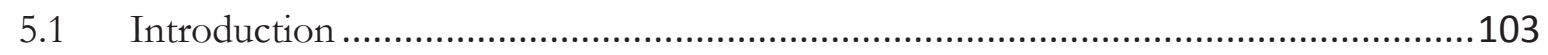

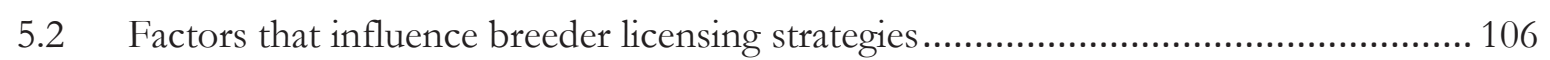

5.2.1 The general legal structure of the national plant breeder's right system ..................................... 106

5.2.2 Source of, and policies attendant to the income for the breeder ............................................... 109

5.2.3 Type and market of crop, including the seed system operating................................................ 112

5.2.4 Royalties collection mechanisms that may be available to the breeder ...................................... 114

5.3 Examples of PBRs licensing and smallholder farmers' access to seeds in Kenya ....... 118

5.3.1 Maize- The Water Efficient Maize for Africa project (WEMA)....................................... 118

5.3.2 Potato-HZPC, Kisima Farm and Syngenta Foundation for Sustainable Development......... 120

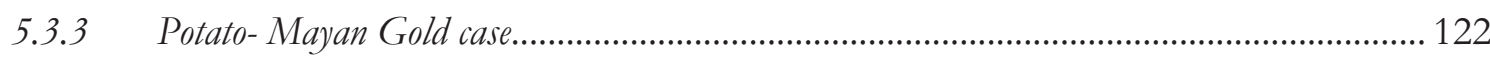

5.4 Reflections on licensing as a tool to facilitate access to seeds for smallholder farmers

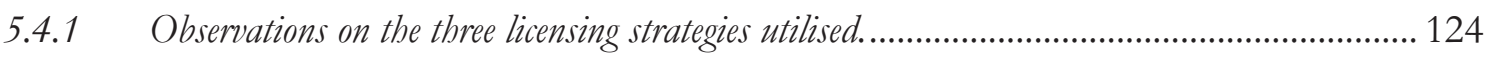

5.4.2 Advantages and disadvantages of the main PBRs licensing strategies ................................... 127

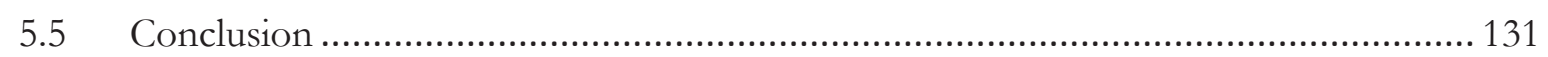

Chapter 6: A differentiated approach to plant breeders' rights in Africa .......................133

6.1 Introduction - Plant Breeders' Rights in Africa ........................................................... 133

6.1.1 An ISSD perspective on plant breeders' rights in Africa .................................................... 135

6.2 Incentivising Plant Breeding Through PBRs ...................................................... 138

6.2.1 The incentive function of plant breeder's rights differ amongst formal seed systems ................... 140

6.2.2 Rights and obligations of commercial farmers: the farmers' privilege...................................... 143 
6.3 The Potential Impact of PBRs on Farmer Managed Seed Systems: The Informal Sector .144

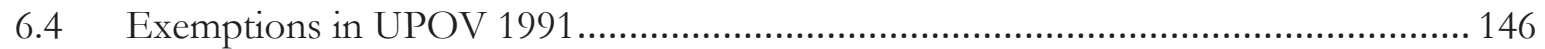

6.5 Creating legal space for smallholders' farming practices.......................................... 149

6.6 Defining Different Categories of Farmers ............................................................ 151

6.6.1 Subsistence farmers, smallholder farmers and commercial farmers ........................................ 151

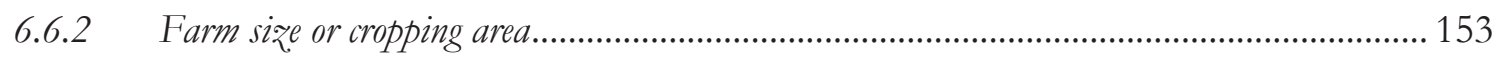

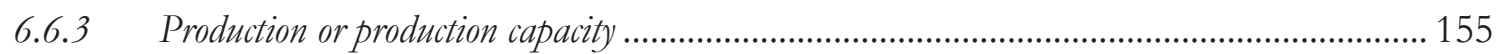

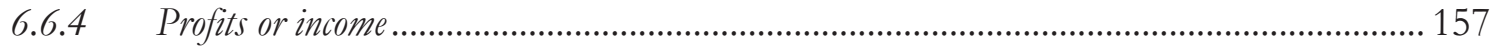

6.6.5 Separating commercial from smallholder farmers ................................................................ 158

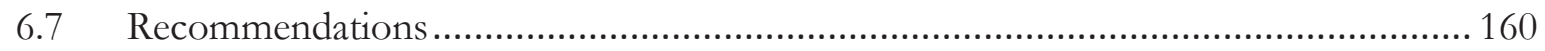

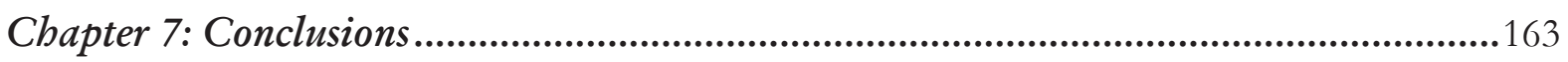

7.1 Plant breeders' rights framework in Kenya and their implications for smallholder

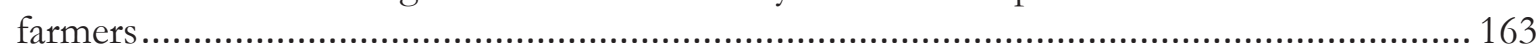

7.2 Harmonization of plant breeders' rights frameworks at the regional level: risks, concerns and opportunities for smallholder farmers in Kenya.......................................... 169

7.3 Existing legal spaces within the current national plant breeders' rights frameworks to facilitate access to seeds for smallholder farmers ............................................................. 171

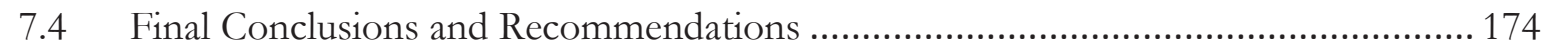

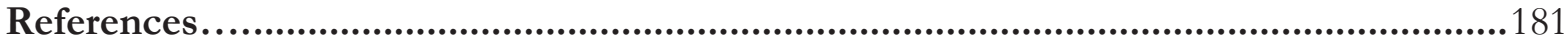

Appendix: Date and place of interview of anonymous informants................................201

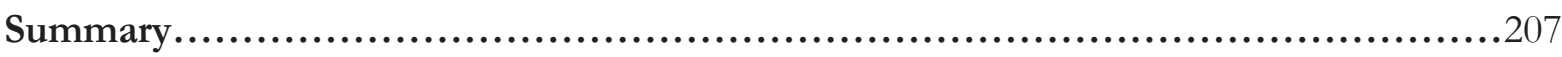




\section{Acronyms}

AATF

AFFA

AFSA

AGRA

APBREBES

ARIPO

ASBP

ASDS

CBD

CBSD

CIMMYT

CMD

COMESA

CRS

CAADP

CGIAR

EPR

ERS

FAO

GDP

GLCI

GOK

IFAD

ISSD

IT

KALRO

KARI
African Agricultural Technology Foundation

Agriculture, Fisheries and Food Authority

Alliance for Food Sovereignty in Africa

Alliance for a Green Revolution in Africa

Association for Plant Breeding for the Benefit of Society

African Regional Intellectual Property Organization

Africa Seed and Biotechnology Programme

Agricultural Sector Development Strategy

Convention on Biological Diversity

Cassava Brown Streak Disease

International Maize and Wheat Improvement Centre

Cassava Mosaic Virus Disease

Common Market for Eastern and Southern Africa

Catholic Relief Services

Comprehensive Africa Agriculture Development

Programme

Consultative Group on International Agricultural

Research

End Point Royalties

Extended Royalties System

Food and Agriculture Organization of the United Nations

Gross Domestic Product

Great Lakes Cassava Initiative

Government of Kenya

International Fund for Agricultural Development

Integrated Seed Sector Development

International Treaty on Plant Genetic Resources for Food and Agriculture

Kenya Agriculture and Livestock Research Organization

Kenya Agricultural Research Institute 
KEPHIS

LDC

MDGs

NPGRC

OAPI

OPVs

PBAK

PBRs

PGRFA

PVP

QDS

SADC

SANSOR

SPVA

TRIPS

UNDP

USAID

UPOV

VPCs

WEMA

WTO
Kenya Plant Health Inspectorate Service

Least Developed Country

Millennium Development Goals

National Plant Genetic Resources Centre

Organisation Africaine de la Properité Intellectuelle

Open Pollinated Varieties

Plant Breeders Association of Kenya

Plant Breeders' Rights

Plant Genetic Resources for Food and Agriculture

Plant Varieties Protection

Quality Declared Seed

Southern African Development Community

South African National Seed Organization

Seeds and Plant Varieties Act

Agreement on Trade Related Aspects of Intellectual

Property Rights of the WTO

United Nations Development Programme

United States Agency for International Development

International Union for the Protection of New Varieties of Plants

Vegetatively Propagated Crops

Water Efficient Maize for Africa

World Trade Organization 


\section{List of Tables}

Table 1

Table 2

Table 3

Table 4

Table 5

Table 6

Table 7

Table 8 page 39

page 43

page 46

page 76

page 101

page 153

page 155

page 177 


\section{Chapter 1: General Introduction}

\subsection{Background to the research}

For a long time, the world has been facing a food security problem. As the world's population has grown, so has the challenge to supply it with food using existing resources. According to the Global Food Index 2015 volatility in agricultural production and also lower urban absorption capacity, are among the constraints to food security progress in almost every region. According to the estimates by the Food and Agriculture Organization of the United Nations (FAO), the International Fund for Agricultural Development (IFAD) and the World Food Programme (WFP), ${ }^{1}$ close to 1 billion people are chronically undernourished. Developing countries bear the brunt of food insecurity. This matter is evidenced by the fact that these countries lagged behind in the fulfilment of the hunger target of the United Nation's Millennium Development Goal 1c (MGD 1c) - of halving the proportion of undernourished people in developing countries by 2015.

Nowhere else more than in Africa where none of the countries are classified as developed, are agricultural activities most important. In Africa agriculture provides employment to more than $70 \%$ of the continent's population and over $30 \%$ of its gross domestic product (GDP). ${ }^{2}$ Yet, almost one in every four Africans lacks adequate food for a healthy and active life, with increasing food prices and drought pushing more people into poverty and hunger. ${ }^{3}$ By 2050, the continent's population is expected to more than double, to 2.4 billion. ${ }^{4}$ At the same time Africa's farm sizes are expected to decrease as farmers subdivide agricultural land for their children. ${ }^{5}$ Even though increased urbanisation may lead to an increase in farm size average, it is likely to leave fewer individuals to undertake farming activities. Food security problems in the continent will only exacerbate.

\footnotetext{
${ }^{1}$ FAO, IFAD and WFP. 2014. The State of Food Insecurity in the World 2014. Strengthening the enabling environment for food security and nutrition. Rome, FAO.

${ }^{2}$ http://climate-l.iisd.org/guest-articles/the-challenge-of-africas-transformation-issues-of-food-security-andclimate-change/ [accessed in November 2015].

${ }^{3}$ FAO. The State of Food Insecurity in the World-Addressing Food Insecurity in Protracted Crises (Rome: Food and Agriculture Organization of the United Nations, 2010).

${ }^{4}$ United Nations, Department of Economic and Social Affairs, Population Division (2015). World Population Prospects: The 2015 Revision, Key Findings and Advance Tables. Working Paper No. ESA/P/WP.241.

5 Jason Bremmer (2012). Population and Food Security: Africa's challenge. Population Reference Bureau, Policy Brief. February 2012.
} 
Viewed from a national level, food security problems are even more manifest. Kenya is an example from this standpoint. According to the 2014 United Nations Development Programme (UNDP) Human Development Index, the country ranked 147 out of 187 countries in all measured indices, putting it in the low human development cluster. It suffers from chronic food shortages with less than $20 \%$ of its land being arable. ${ }^{6}$ The agricultural sector in the country is important as it contributes to about $25 \%$ of the GDP and employs $75 \%$ of the population. ${ }^{7}$ Most of food production in Kenya is through rain-fed agriculture and current climate change trends increasingly cause unpredictable weather patterns, which have a profound impact on crop yields and food supply. The country's population is expected to almost double to 97 million by $2050 .^{8}$ Yet, investments in the agricultural sector to increase yields and food production appear not to match population growth. It is therefore not surprising that despite the country being the leading economy in East Africa, it is unable to eradicate extreme poverty and hunger.'

The Institution of Mechanical Engineers estimates that between 30-50\% of global food production is lost before reaching a human stomach. ${ }^{10}$ This loss is attributed to poor harvesting, storage and transportation practices and well as market and consumer wastage. ${ }^{11}$

There are numerous proposals on strategies to combat food security problems. Some proposals offer suggestions on ways to increase food production while others on how to curb waste of the food produced. For example, Cargill, a multinational agricultural commodities trading company, offers a raft of proposals in dealing with food security challenges. These include honouring comparative advantage by growing crops well suited to local conditions, enabling open markets, supporting smallholder farmers, fostering cooperation between the public and private sectors, encouraging investment, harmonizing food safety standards and reforming biofuels mandates. ${ }^{12}$

On its part, the African Union has since 2003 championed the Comprehensive African Agricultural Development Programme (CAADP). CAADP seeks to drive the agricultural

\footnotetext{
${ }^{6}$ Langinger, N., 2011. School Feeding Programs in Kenya: Transitioning to a Homegrown Approach. Stanford Journal of international Relations, 13(1), pp. 30-37.

${ }^{7}$ Waithaka, M., Nelson, G., Thomas, T., and Kyotalimye, M., 2013. Kenya. In: East African Agriculture and Climate Change. Washington, D.C.: International Food Policy Research Institute.

${ }^{8}$ AFIDEP and PAI. 2012. "Population, Climate Change, and Sustainable Development in Kenya", Nairobi and Washington, DC: African Institute for Development Policy (AFIDEP) and Population Action International (PAI).

${ }^{9}$ Government of Kenya, 2011. National Food and Nutritional Security Policy. Nairobi: Agricultural Sector Coordination Unit.

${ }^{10}$ Institution of Mechanical Engineers, 2013. Global Food: Waste Not, Want Not. A Report. Available at http://www.imeche.org/docs/default-source/reports/Global Food Report.pdf?sfvrsn=0 [accessed in November, 2015]

11 Ibid.

${ }^{12}$ http://www.cargill.com/wcm/groups/public/@ccom/documents/document/na3059569.pdf [accessed in November 2015].
} 
revolution of the continent by increasing investment in agribusinesses and agri-food value chains, improving national and regional agricultural markets, fostering Africa's collective food security and improving management of natural resources. ${ }^{13}$ Through national CAAPD Compact Agreements, countries commit to integrate CAADP programmes into their national agricultural transformational strategies. Kenya as an example has through a 2010 agreement committed to implement the CAADP Compact through the national Agricultural Sector Development Strategy (ASDS), a process that involves matching CAADP thematic areas to the ASDS. ${ }^{14}$

The quest to contribute to finding solutions to global food security problems has also brought about non-state actors to undertake various roles in the agricultural sector. For example, through the Consultative Group on International Agricultural Research (CGIAR) 15 international agricultural research centres, which collaborate with national and regional centres in agricultural research for development, aim at tackling hunger, nutritional imbalances and other food related issues in developing regions of the world. In recent years, non-governmental organisations with specific regional focus or mandates in contributing to solutions to the problem have also emerged in Africa. Through partnerships and collaboration, the Alliance for a Green Revolution in Africa (AGRA) a non-governmental organization funded by the Gates Foundation, undertakes programs aimed at improving market access, policies, soil health and Africa's seed systems. ${ }^{15}$ Similarly, the African Agricultural Technology Foundation (AATF), a not-for-profit organization facilitates and promotes public-private partnerships for the access and delivery of appropriate agricultural technologies for sustainable use by smallholder farmers along the entire value chain for some cereal crops (maize and rice), legumes (cowpea and peanuts) and tuber crops (banana and cassava). ${ }^{16}$

All these efforts have had various results. The 2014 State of Food Insecurity of the World Report ${ }^{17}$ succinctly sums up the solutions and efforts to this problem by observing, "there is no "one-size-fitsall" solution. Interventions must be tailored to conditions, including food availability and access, as well as longerterm development prospects." In other words, the solution to global food security problems requires multifaceted approaches, focussing on all areas of the value chain from crop production, transport and distribution, marketing, processing and storage.

\footnotetext{
${ }^{13}$ African agriculture, transformation and outlook. NEPAD, November 2013, $72 \mathrm{p}$.

${ }^{14}$ Government of Kenya, 2011. The Kenya CAADP Compact. Implemented through the Agricultural Sector Development Strategy.

${ }^{15}$ Progress Report 2007-2014. Alliance for a Green Revolution in Africa (AGRA). March 2015.

${ }^{16} \mathrm{http}$ ://aatf-africa.org/files/files/publications/AATF-brochure.pdf [accessed in November 2015]

${ }_{17}$ FAO, IFAD and WFP. 2014. The State of Food Insecurity in the World 2014. Strengthening the enabling environment for food security and nutrition. Rome, FAO.
} 
Obviously, increasing food availability through crop production will contribute towards the solution to the food security challenges present. Crop production is at the very foundation of food security, whether for increasing food availability or for securing livelihoods. One of the basic components of crop production is seed, a term used to include grains, tubers, cuttings and any part of a plant used as propagating material for crop reproduction.

Seeds perform various functions in society. In agriculture, as the carrier of the genetic makeup of the plant seeds are key tools for technology transfer. ${ }^{18}$ In this sense, seeds are widely considered a focal point in agricultural progress ${ }^{19}$ a matter that became particularly clear during the Green Revolution. ${ }^{20}$ In some societies, seeds are inextricably linked with the culture of the people that develop, select, conserve and use them. ${ }^{21}$ This matter is acknowledged in the International Treaty on Plant Genetic Resources for Food and Agriculture (IT or the Plant Treaty), which in its preamble affirms the past contributions of farmers in among others, conserving and making available plant genetic resources for food and agriculture which invariably, include seeds. In this sense, seeds are the very foundation of life and livelihoods. Finally, seeds also have commercial value and hence scientific and commercial investments are made to increase yields, and reduce disease and pest attacks, all with a view to generate commercial returns on the investments made.

Investment in seed improvement activities started off as a public sector activity although in Europe, the same emerged as a business in the late $18^{\text {th }}$ century. ${ }^{22}$ Concurrent with this development was advancement in scientific methods in plant breeding - from 'Mendelism' to early genetics. As a result, advancement in plant breeding techniques including through use of biotechnology has led to seeds over the years becoming carriers of proprietary genetic information. The need to recoup investments made in breeder research and discoveries through commercialisation of new varieties has brought about the quest to protect the intellectual creations of the breeder. This intellectual property protection of improved varieties of seed has not taken away the fact that many local seeds are an embodiment of communities' traditions, cultures and indigenous knowledge arising from efforts by farmers and communities to conserve and improve them over the years. The intellectual property protection conferred over improved

\footnotetext{
${ }^{18}$ Louwaars, N.P. 2007. Seeds of Confusion: The Impact of Policies on Seed Systems. PhD dissertation, Wageningen, The Netherlands. ISBN 978-90-8504-793-3.

${ }^{19}$ McMullen, N. 1987. Seeds and World Agricultural Progress. Washington DC, National Planning Association, $263 \mathrm{p}$.

${ }^{20}$ Borlaug, N.E. 1968. Wheat breeding and its impact on world hunger. In: K.W. Finlay \& K.W. Shepherd (Eds): Proc. $3^{\text {rd }}$ Int. Wheat Genetics Symposium. Canberra, Australian Academy of Science, pp 1-36.

${ }^{21}$ Supra, note 18.

22 Louwaars, N., et al. Intellectual property rights in plant sciences and development goal in agriculture: a historical perspective. In Arapostathis, S and Dutfield, G (2013). Knowledge Management and Intellectual Property: Concepts, Actors and Practices from the Past to the Present. Edward Elgar, Cheltenham, UK.
} 
seed of a variety of crops, and at the same time the aim to maintain the traditional and cultural embodiments of seed has brought forth tensions between breeders' commercial interests and unrestricted access to seed by smallholder farmers. Intellectual property protection over seed has brought about concerns that it is a double edged sword, by not only incentivising breeding, but also blocking access to private sector seed for smallholder farmers and breeders, and by destroying traditional farming practices.

In the developed parts of the world, patent rights on inventions have been applied to plants as a result of the application of advanced biotechnological knowledge and information to seeds and planting materials. The nature of patent rights like all intellectual property rights is that they bestow upon their holder, the right to prevent others to do certain things with the protected inventions without their permission. In the context of protected seeds, the nature of these rights necessarily affects smallholders who are also users of proprietary seeds. However, this thesis does not focus on patent rights as the application of these rights to plant materials in Kenya especially food crops, is very limited as yet. Plant breeders' rights which provide intellectual property protection to the work of a plant breeder upon fulfilment of conditions different to those in patents are the predominant mechanisms for the protection of breeders' creations in Kenya. This thesis thus focuses on plant breeders' rights, a subset of intellectual property rights and the effects these rights have on access to seeds by smallholder farmers in Kenya. Access to seeds invariably affects food availability and security and ultimately, the right to food.

In light of the above, a general introduction to intellectual property rights and a subset thereof, i.e., plant breeders' rights, follows in the sub-section below. Thereafter the conceptual framework for this thesis based on the nature of plant breeders' rights and seed systems in which these rights operate is laid out.

\section{I.2 Intellectual property rights}

One of the functions of intellectual property rights is to incentivise innovation. This function rests on a hypothesis that in the absence of intellectual property protection, innovators would find difficulties in appropriating the returns from their intellectual creations, with obvious 
negative consequences in terms of the creation of innovations. ${ }^{23}$ This provides the basis for granting an exclusive right although limited in time and scope, on commercialisation.

Historically, intellectual property rights were granted principally to mechanical inventions and artistic creations. ${ }^{24}$ Over time, systems for protection of intellectual property have extended in scope- to include living things, and also geographically, to developing and least developed countries. The Agreement on Trade Related Aspects of Intellectual Property Rights of the World Trade Organisation (TRIPS Agreement), aptly captures this in its Article 27.1. In this article, it is provided that "patents shall be available for any inventions whether products or processes, in all fields of technology...". The requirement to also extend intellectual property protection to innovations relating to plants is no more pronounced again than in Article 27.3(b) of the TRIPS Agreement. In this article WTO member states are obliged to provide for the intellectual property protection of plant varieties either by patents or by an effective sui generis system or by any combination thereof.

As a subset of intellectual property rights, plant breeders' rights otherwise known as plant variety protection or plant variety rights are a sui generis system of protecting innovations, specifically developed for plant breeding. Over the years, innovations in plant breeding have contributed to agricultural development, and will continue to do so in the future given challenges related to among others, population growth and climate change.

The object of protection in plant breeders' rights is plant varieties. Plant varieties are defined as 'a plant grouping within a single botanical taxon of the lowest known rank, which grouping, irrespective of whether the conditions for the grant of a breeder's right are fully met, can be (i) defined by the expression of the characteristic resulting from a given genotype or combination of genotypes (ii) distinguished from any other plant grouping by the expression of at least one of the said characteristics, and (iii) considered as a unit with regard to its suitability for being propagated unchanged. ${ }^{25}$ Plant breeders' rights concern the protection of a plant variety that is, a grouping of plants as long as the grouping is within a single botanical taxon of the lowest known

\footnotetext{
${ }^{23}$ Fabio Pammolli and Maria Alessandra Rossi (2005), Intellectual Property, Technological regimes and market Dynamics, Economia e Politica Industriale, 2/2005. Accessed from http://www.who.int/intellectualproperty/submissions/IP-tech-reg-final.pdf [November 2015].

${ }^{24}$ Integrating Intellectual Property Rights and Development Policy. A report of the Commission on Intellectual Property Rights, London, September 2002.

${ }^{25}$ Article 1, 1991 Act of the International Convention for the Protection of New varieties of Plants (UPOV 1991). The International Treaty on Plant Genetic Resources for Food and Agriculture closely follows this definition. It is notable that while the definition referred to in this thesis is that of UPOV, countries are not restricted to following this definition as UPOV is only one example of a sui generis system for protection of innovations relating to plants as required by the TRIPS Agreement.
} 
rank. Plant varieties fall within a species. ${ }^{26}$ It is the varieties that are adapted to the environment in which they are grown and suited for cultivation practices employed and for culinary or other use preferences, and also the subject matter of protection through plant breeders' rights.

Rights granted to a breeder through plant breeders' rights are private in nature inasmuch as the state acquires innately, powers to transfer, rescind or amend these rights, should a request to do so be made by another party, and the legal conditions set being met. If it is not an inherent policy to support innovation in plant breeding, the need to adhere to international trade rules such as those laid in Article 27.3(b) of the TRIPs Agreement of the WTO and bilateral trade agreements among others, is likely to cause a country to consider providing for a system for granting plant breeders' rights. Article 27.3(b) notwithstanding, the TRIPS Agreement contains special and differentiated provisions which provide that Least Developed Countries (LDCs) most of which are African, do not have to comply with this and other provisions of the same Agreement until 2021. This explains in part why over the years, most African countries have not had plant breeders' rights legislation. However, this situation is changing as several countries and regional organizations are working towards the enactment of plant breeders' rights in their territories.

\subsubsection{The nature of plant breeders' rights}

Intellectual property is protected by legal rights with a view to principally exclude others from using the protected subject matter commercially. In other words, the primary right of the holder of intellectual property is not to positively use the intellectual property for own benefit, but rather to exclude others. Drahos ${ }^{27}$ attributes the negative nature of these rights to the fact that they are granted for a limited period of time (which varies depending on the intellectual property protected), within which period the owner of the intellectual property in the public interest, may recoup the investments made. It is notable that recouping investments made is a purely discretional activity of the right holder. A right holder may not want to recoup investments on an invention (for whatever reason), but may want to exercise the right to exclude others from using the protected invention, while the right holder engages in a different activity altogether, not necessarily directly related to the invention. This negative nature of rights is not restricted to certain types of intellectual property rights, but extends to all, including plant breeders' rights.

\footnotetext{
${ }^{26}$ Moore, G. and Witold, T. (2003). The Explanatory Guide to the International Treaty on Plant Genetic Resources for Food and Agriculture. The World Conservation Union (IUCN). IUCN Environmental Policy Law Paper Number 57. 2005

${ }^{27}$ Drahos, P (1996). A philosophy of intellectual property, Dartmouth. Aldershot, England.
} 
As far as plant breeders' rights are concerned, Articles 5(1) of the 1961, 1972 and 1978 Acts of the International Union for the Protection of New Varieties of Plants (UPOV) ${ }^{28}$ together with Article 14(1) of the 1991 Act of UPOV confirm this fact. ${ }^{29}$ All these articles are explicit in pronouncing that the effect of the right granted is to require a breeder's prior authorisation in performing certain acts on a protected variety during the duration of the right.

This negative nature of all intellectual property rights (including plant breeders' rights) - which Drahos also refers to as the right not to have possessions interfered with, brings into focus the veracity of intellectual property rights as mechanisms for the transfer of knowledge and information in society, including in the seed sector. The right to restrain, regulate or control the use of knowledge and information in society possesses potential to create asymmetries in society more so between those in possession of the knowledge and information and those in need of the same. Concerns about asymmetries in knowledge and information that may be created by the negative nature of intellectual property rights become real when they relate to products that concern public health such as life-saving medicines. Indeed, the TRIPS Agreement recognizes that by their (negative) nature, intellectual property rights have the potential to be abused by the right holders or lead to practices that unreasonably restrain trade or adversely affect international transfer of technology. ${ }^{30}$ This agreement therefore enables WTO members to intervene in this asymmetry with a view to protect public health and nutrition, and to promote public interest in sectors of vital importance to their socio-economic and technological development. ${ }^{31}$

It is notable that intellectual property rights as designed contain in-built mechanisms to balance the aforementioned asymmetries between the knowledge producers and the users. These in-built mechanisms are known as exceptions and limitations. In the 20 years following the adoption of the TRIPS Agreement, it has emerged that notwithstanding various moral justifications of the nature of intellectual property rights on the basis either of natural law, ${ }^{32}$ personality

\footnotetext{
${ }^{28}$ Article 5 (1) of the 1961, 1972 and 1978 Acts of UPOV provide that the effect of the right granted to the breeder is that his prior authorisation shall be required for the production for the purposes of commercial marketing; the offering for sale; and the marketing of the reproductive propagating material, as such of the variety.

29 The first part of Article 14(1) of the 1991 Act of UPOV is worded largely in similar terms as the first parts of Articles 5(1) of the previous UPOV Acts. The only difference is that the scope of the acts for which authorization of the breeder is required expands to include reproduction or multiplication, conditioning for the purposes of propagation; exporting; importing; and stocking, for these aforementioned purposes.

${ }^{30}$ TRIPS Agreement, Article 8.1.

${ }^{31}$ Ibid, Article 8.2.

32 Hughes, J. (1988) 'The Philosophy of Intellectual Property' The Georgetown Law Journal, Vol. 77, pp. 287366. Also see Bouckaert, B. (1990) 'What is Property?' Harvard Journal of Law and Public Policy, Vol. 13, pp.275-816.
} 
development, ${ }^{33}$ just reward ${ }^{34}$ or social welfare ${ }^{35}$, exceptions and limitations to intellectual property rights have a profound effect on their utility and in balancing the transfer of knowledge between its producers and users. Commonly referred to as flexibilities, ${ }^{36}$ exceptions and limitations operationalize intellectual property rights in an antithetical manner to their negative nature, thus diminishing the right to have intellectual property possessions not interfered with. In other words, exceptions and limitations in principle enable intellectual property possessions to be interfered with by third parties whether justifiably due to public interest considerations ${ }^{37}$ or otherwise. The specificity of these public interest considerations varies across different realms of intellectual property rights. For example, under patents, rights based on prior use, acts done privately and for non-commercial purposes and acts done for experimental purposes are in some jurisdictions allowable exceptions and limitations to the patent right. Under copyright, reproduction of speeches by the press and broadcasters, quotations and press summaries, and of publications (to a limited extent) for teaching purposes, are some of the exceptions and limitations to the rights granted to authors of literary works. ${ }^{38}$ In plant breeders' rights, these exceptions and limitations include the use of protected material for private and non-commercial or experimental purposes, acts done for the purposes of breeding other varieties, and the re-use of seeds by farmers (farmers' privilege). ${ }^{39}$

The requirement for least developing countries and developing countries members of the WTO to initially comply with some of the provisions of the TRIPS Agreement by 2000 and by 2005 respectively ${ }^{40}$ heightened the awareness and debate on the risks posed by intellectual property

\footnotetext{
${ }^{33}$ Richards, D.G. (2002) 'The Ideology of Intellectual Property Rights in the International Economy', Review of Social Economy, Vol. IX, No.4, pp.521-620.

${ }_{34}$ Machlup, F. and Penrose, E. (1959) 'The Patent Controversy in the Nineteenth Century' Journal of Economic History, Vol.x, No.1, pp. 1-29. 1959:11

${ }^{35}$ Rayan, A. (1987) Property, Milton Keynes: Open University Press.

${ }^{36}$ The use of the term 'flexibilities' to include exceptions and limitations to intellectual property rights appears to gave gained notoriety following the adoption of the WTO Doha Declaration on TRIPS and Public Health in 1999. However, the term 'flexibility' as used in the TRIPS Agreement, has limited meaning with reference to need to exempt Least Developed Countries from applying specific provisions of the Agreement due to their economic, financial and administrative constraints and their need to create a viable technological base.

${ }^{37}$ Daniel Gervais, (2008) The TRIPS Agreement: Drafting History and Analysis, Sweet \& Maxwell, UK.

${ }^{38}$ Berne Convention, Article 10.

${ }^{39}$ UPOV 1991, Article 15. Farmers privilege refer to the right of a farmer, within reasonable limits, and subject to the safeguarding the legitimate interests of the breeder, to permit the farmer to use for propagating purposes, on his own holdings, the product of the harvest which the farmer has obtained by planting on his own holding, the protected variety.

${ }^{40}$ Under Article 66.1 of the TRIPS Agreement, least developed countries were not required to comply with the provisions of the TRIPS Agreement (other than Articles 3,4 and 5) for a period of 10 years. This transition period was later extended to 1 July 2013 and thereafter to 1 July 2021. See WTO documents IP/C/40 dated 30 November 2005 and IP/C/64 dated 12 June 2013. As for developing countries, Articles 65.1 and 2 of the TRIPS
} 
rights in the creation of knowledge and information asymmetries. Legal problems that were then posed by the provisions of the TRIPS Agreement in enabling countries with little or no manufacturing capacity to import generics of life saving HIV/AIDS medicines from those with capacity to manufacture or import generic medicines in cases of life threatening emergencies were classical examples of these risks. This awareness also brought into the fore the clamour for the application of the public interest principles as stated in the objectives of the TRIPS Agreement (Article 8) and the use of exceptions and limitations to the intellectual property right in bringing about necessary societal balance in knowledge and information asymmetries. Thus with respect to public health, lack of access to life-saving HIV/AIDS medicines in least developing and developing countries due to assertion of patent rights by the right holders mainly in developed countries precipitated the affirmation by the WTO Ministerial Declaration on the TRIPS Agreement and Public Health that the 'TRIPS Agreement does not and should not prevent members from taking measures to protect public health. ${ }^{41}$ This declaration was a watershed moment in buttressing the proposition that intellectual property rights are subservient to the right to health and other related rights such as the right to food.

An effect that intellectual property rights could have on other rights is that of limiting access to these other rights. In the context of the right to health, patents rights have been seen to limit access to life saving medicines, a matter that has even been the subject of litigation in many countries. As far as the right to food is concerned, there are similar concerns that patents and plant breeders' rights could have an effect of stifling access to seed for farmers, especially in developing countries with respect to protected varieties. This in turn could contribute to insufficient food production and exacerbate hunger. The relevance and potential of utilizing the exceptions and limitations in plant breeders' rights with a view to facilitate ultimately, access to seed for food security purposes, falls squarely in this debate.

\subsubsection{Linking plant breeders' rights to seed systems}

Innovations in plant breeding take place in complex systems that make use of local, national and international networks of knowledge and resources, and involve different sectors. Seed systems are an integral part of these innovation processes. Seed systems have been defined simply as the

Agreement, granted them the option to delay application of the provision of the Agreement for five years, that is, up to 1 January 2000.

${ }^{41}$ WTO document WT/MIN(01)/DEC/2 of 20 November 2001. 
means through which farmers access seed. ${ }^{42}$ World over, the characteristics of farmers vary from pure commercial to smallholder subsistence farmers, and so do the seed systems they operate in.

Seed systems are guided by national and international policies and regulations. Intellectual property rights such as plant breeders' rights are a component of such policies and through exclusive rights to commercialisation of innovations are intended to create incentives for investment in research and development, and for the uptake of new varieties in formal seed production. Protection of intellectual property rights can be very important for a seed company to invest in multiplication and promotion of a new variety, i.e. to facilitate farmers' access the innovation. Yet, uncertainties and debate have arisen about the social benefits and possible negative consequences of intellectual property protection in plant breeding ${ }^{43}$ and more so with respect to least developed and developing countries ${ }^{44}$ where commercial returns for the incentive function in plant breeding are rare. Questions have been raised whether there is an incentive for plant breeding in developing countries as the farmers - mostly smallholders mainly depend on informal rather than formal seed supply sources or systems for many crops every planting season. ${ }^{45}$ Informal seed systems which cover methods of local seed selection, production and diffusion are said not to offer sufficient markets for seeds of protected varieties for a number of crops, thus not incentivising plant breeding. ${ }^{46}$

Informal seed systems which operate for most crops in Africa have also brought about controversy and doubt into the usefulness of plant breeders' rights because plant breeders' rights tend to conflict with farmers' rights. Farmers' rights relate to the recognition of the enormous contribution that local and indigenous communities and farmers particularly those in the centres of origin and crop diversity have made, and will continue to make for the conservation and

\footnotetext{
42 Muthoni, J. and Nyamongo, D.O. (2008) Seed Systems in Kenya and Their Relationship to On-Farm Conservation of Food Crops, Journal of New Seeds 9: 4, 330-342.

${ }^{43}$ Louwaars, N., et al. (2009). Breeding business. The future of plant breeding in the light of developments in patent rights and plant breeders' rights (Centre for Genetic Resources, the Netherlands, CGN Report 2009-14).

${ }^{44}$ Bellman, C., et al. (2003) Trading in Knowledge: Development Perspectives on TRIPS, Trade and Sustainability Earthscan Publications $357 \mathrm{p}$.

${ }^{45}$ Also referred to as farmers' seed supply systems, informal seed sources cover methods of local seed selection, production and diffusion whereas formal seed supply systems cover seed production and supply mechanisms operated by public or private sector specialists in different aspect of seed supply and ruled by well defined methodologies, control stages of multiplication, and in most cases regulated by the national legislation and international standardization of methodologies. See Almekinders, C.J.M., N.P. Louwaars \& G.H. de Bruijn, 1994. Local seed systems and their importance for an improved seed supply in developing countries. Euphytica 78: $207-216$.

${ }^{46}$ Ibid.
} 
development of plant genetic resources. ${ }^{47}$ They include any rights that farmers have to save, use, exchange and sell farm-saved seed/propagating material subject to national law and as appropriate. ${ }^{48}$ While the primary objective of a holder of breeders' rights is to prevent others from making commercial use of the protected variety, farmers' rights to the opposite explicitly allow farmers to save, use, exchange and sell farm-saved seed and propagating material. The exercise of farmers' rights (without explicit legal and policy support) is deeply engrained in Africa's farming practices. Africa's farming practices for most food crops are informal seed systems-led.

\section{The Plant 'Treaty and Farmers' Rights}

Over the years, the absence of legal and policy frameworks in most countries in Africa for the assertion of proprietary rights over breeders' innovations and the existence of informal seed systems for most crops is seen as not to impede but rather to support the exercise of farmers' rights. The adoption at the international level in 2001 of the International Treaty on Plant Genetic Resources for Food and Agriculture (the Plant Treaty), a treaty that affirms Farmers' Rights and which later entered into force in 2004, only complements this situation. 46 African countries have ratified this treaty. Furthermore, the Governing Body to this treaty is constantly urging parties to take active initiatives to implement farmers' rights at the national level. Another feature related to the Plant Treaty is that its adoption has also brought about debate on the interrelationship between UPOV and this treaty. While both treaties have different objectives, two shared aims are to support plant breeding activities and to encourage the development of new varieties of plants. ${ }^{49}$ However, these two treaties go about achieving these shared aims differently. The Plant Treaty does so by providing a system for conservation, sustainable use and fair and equitable sharing of benefits arising from utilisation of plant genetic resources for food and agriculture whereas UPOV does so by establishing a system for protection of new varieties of plants through plant breeders' rights. ${ }^{50}$ The difference in approach by these two international conventions brings about policy conflicts at the national level for countries seeking to implement both conventions especially in the context of smallholder farmers.

\footnotetext{
${ }^{47}$ International Treaty on Plant Genetic Resources for Food and Agriculture (IT), Article 9.1

${ }^{48}$ Ibid, Article 9.3

${ }^{49}$ http://www.upov.int/about/en/faq.html\#Q16 [accessed in February 2016]

50 Ibid.
} 


\section{Regional harmonization}

Until 2006 very few African countries had plant breeder's rights legislation in place. However, the adoption of Annex X by OAPI in 2006 brought on board 16 more countries in the continent. Other countries have followed suit. Regional processes such as those driven by the African Regional Intellectual Property Organization (ARIPO) and the Southern Africa Development Community (SADC) will continue putting in place plant breeders' rights frameworks for use by countries which have in the past acquiesced to the exercise of farmers' rights. Taking into account proliferation of plant breeders' rights regimes in the absence of explicit policy and legal frameworks to support farmers' rights, the debate about the interrelationship between UPOV and the Plant Treaty will only exacerbate the controversy between informal seed systems, smallholder farmers and plant breeders' rights.

\subsection{Research focus, objectives and questions}

Globalisation, international trade obligations especially those brought about by the WTO and bilateral trade agreements continue to require developing countries to provide for intellectual property protection of inventions in all fields of technology, including provision of protection for plant varieties. In sub-Saharan Africa regional plant breeders' rights systems are under development in compliance with the standard set by the 1991 Act of UPOV. A few African countries already have had national plant breeders' rights in place for some years. As such plant breeders' rights are becoming a component of seed policies in many African countries. Policy tensions brought about by these rights could exert pressure on seed systems, which in turn may affect the right to food and thus exacerbate hunger.

This thesis is a study of the relationship between plant breeders' rights on the one hand and access to seed and planting material on the other hand for smallholder farmers in Kenya with a view to ultimately enquire whether the legal spaces that exist within plant breeder' rights legislation can enable smallholder farmers to positively contribute towards the country overcoming food security problems. Kenya is selected as the study area because agriculture provides the bulk of employment and livelihoods in the country yet most of the famers are smallholders, obtaining seed and planting material from informal sources and therefore they do not provide a market for protected varieties of seed. Kenya has had a plant breeders' rights system since 1995 and in 2016, ratified the 1991 Act of the International Convention for the 
Protection of New Varieties of Plants, thus further signifying explicit interest to fully comply with this instrument.

This research also aims to contribute to advancing the existing body of scholarly work on plant breeders' rights in relation to access to seeds.

The uniqueness of this research lies in the combination of all its objectives. The objectives are informed by the problems the research seeks to confront. The overarching objective is to investigate whether the current plant breeders' rights system in Kenya is designed in a manner that enables smallholder farmers to access seed and planting material of protected varieties and in so doing enables them to positively contribute to Kenya overcoming its food security problems. In order for this objective to be investigated in detail, it is then broken down into three sub-objectives as follows: The first in this research is to identify how plant breeders' rights operate in Kenya and their implications for different seed systems in the country. This subobjective is informed by the notion that there have not been in-depth studies about how legal and policy frameworks on plant breeders' rights influence the seed systems operating in Kenya. A natural starting point therefore is an investigation on the seed systems operating in Kenya. The second research sub-objective is to map out legal frameworks governing plant breeders' rights and their implications for smallholder farmers taking into account international treaties and regional processes. This sub-objective is necessitated by the fact that international obligations and regional processes influence national legal plant breeder's rights frameworks, which have implications for smallholder farmers. Furthermore, the various international obligations and regional processes underway bring about legal uncertainties to countries that have, through ratification, taken on board these international obligations and are at the same time participating in the regional processes. The final sub-objective is enquiring into whether there are any existing legal spaces within the current national plant breeders' rights frameworks for rights holders and policy makers that could facilitate access to seeds and planting material for smallholder famers with a view to enabling them to positively contribute towards Kenya overcoming its food security problems. With plant breeders' rights frameworks already in place, it is only logical to examine whether there are any legal spaces in them that could facilitate access to protected varieties for smallholder farmers. 


\subsection{Research questions}

The main research question in this thesis is the following: is the current plant breeders' rights system designed in a manner which enables smallholder farmers to access seeds and planting material of protected varieties? In order to give guidance to the research objectives, the thesis addresses the following sub-questions:

With regard to identifying seed systems operating in Kenya and understanding how legal and policy frameworks have evolved to support these, the following have been formulated:

(i) What is the historical evolution of legal and policy frameworks affecting seed systems in Kenya?

(ii) Which seed systems operate in Kenya?

(iii) Which seed policy components influence smallholder farmers' access to new varieties of seed?

With regard to mapping out the legal frameworks governing plant breeders' rights in Kenya and their implications for smallholder farmers taking into account international treaties and regional processes, the following have been formulated:

(i) Which legal frameworks govern plant breeders' rights in Kenya?

(ii) What is Kenya's legal frameworks' approach towards exceptions and limitations to plant breeders' rights?

(iii) How do Kenya's international obligations in plant breeders' rights and plant genetic resources for food and agriculture influence smallholder farmers' access to seeds and planting material?

(iv) Which risks and concerns that affect smallholder farmers arise from the processes to harmonize plant breeders' rights in sub-Saharan Africa?

(v) Which legal uncertainties arise for national plant breeders' rights legislation from the regional harmonization processes?

With regard to enquiring into whether there are any existing legal spaces within the current plant breeders' rights frameworks for right holders and policy makers that could facilitate access to seeds and planting material for smallholder farmers with a view to enabling them to contribute towards Kenya overcoming food security problems, the following can be asked: 
(i) Can licensing of plant varieties facilitate access to seeds and planting material to smallholder farmers in Kenya?

(ii) What space within the exceptions and limitations to plant breeders' rights as provided in UPOV 1991 can African countries use to balance the needs on behalf of different categories of farmers in the continent?

(iii) How can African countries implement plant breeders' rights systems that incentivise investment in breeding and seed production without creating impediments for access to improved seed for smallholder farmers?

\subsection{Methodology}

This research aims to enrich knowledge in the legal arena. Qualitative research methods were used in undertaking research in this thesis. The research is legal in nature. It is therefore carried out in conformity with legal sciences standards. Legal science methods are not quantitative but qualitative. ${ }^{51}$ With Kenya being a common law country, doctrinal approaches such as canons of construction of law are used in interpreting and giving meaning to statutes and legal instruments. While no judicial interpretation of law in question has been made, predictions of interpretation of law is made by looking at comparable interpretation of law in other jurisdictions with similar or related laws; sources of laws (from international to customary laws); opinions of legal scholars; and legal reasoning. A case study method to complement legal science standards was used in the fifth chapter of this study. The case study method is used in order to give the opportunity to study the real-life context of application of plant breeders' rights.

Primary and secondary data sources have been used throughout this research. Primary data was obtained from interviews; international conventions and treaties; national statutes and regulations; proposed laws; and, policy documents. The secondary sources of data informing the research are academic journals; published books; conference and workshop reports; reports of previous studies and other media. Interviews were conducted in structured and semi-structured manner with 102 informants in Kenya, Italy, South Africa and the Netherlands comprising the following groups of actors: breeders; seed multipliers; smallholder famers; policy makers; and non-governmental organizations. Interviews were carried out in the Netherlands between June and July 2014, and in Kenya variously between August 2011 and November 2015. These interviews were guided by structured open-ended questionnaires. Unstructured interviews were

\footnotetext{
${ }^{51}$ Ulen, T.S.A. Nobel Prize in Legal Science: Theory, Empirical Work, and the Scientific Method in the Study of the Law, University of Illinois Law Review, 2002.
} 
also undertaken at three workshops with relevant actors. The first was in a workshop, $A$ differentiated intellectual property rights system for Africa, that took place in Nairobi on 2 October 2012. The second occurred at an expert workshop held from 29 to 31 January 2013 in Rome, Italy titled, The International Treaty and the Nagoya Protocol: Mutually Supportive Implementation. The third was at a workshop, High Level Round-Table Meeting on Plant Variety Protection in Africa, on 27 and 28 November 2014 in Cape Town, South Africa. This method was employed with a view to confirm facts and positions of inquiry and also to expose the research to unanticipated themes ${ }^{52}$ and perspectives in the subject matter of research. A list of the informants interviewed which is anonymized is included as an appendix to this thesis. The results of this research have also been disseminated in three workshops, during which feedback on the outcomes of research has also been received. These workshops are (1) ISSD Africa National Seminar-Kenya on 24 February 2016 in Nairobi, Kenya, (2) The Impact of Seed Laws on Smallholder Farming Systems in Africa: Challenges and Opportunities from 16-17 March 2016 in Cape Town, South Africa, and (3) Towards Flexibilities in Plant Breeders' Rights Regimes on 30 March 2016 in Nairobi, Kenya.

\subsection{Thesis Outline}

This thesis consists of this introduction, five chapters either published or submitted in peer review journals, and the conclusion. Each chapter deals with at least one research question outlined in section 1.4 above with the net result being that all research questions are addressed.

Chapter 2 is a description of the evolution of Kenya's seed policies and regulatory frameworks from the pre-independence era. It deals with research questions relating to the historical evolution of legal and policy frameworks that affect seed systems in Kenya. Using the integrated seed sector development approach, this chapter identifies the seed systems operating in Kenya and exposes a continuous support for the formal seed sector while support given to the informal sector has merely shown the intention to transform it to formal. Seed policy components that influence smallholder farmers' access to new varieties of seed are exposed as well.

Chapter 3 focuses on Kenya's fulfilment of its international obligations in relation to plant breeders' rights and implications for smallholder farmers. In the process, legal frameworks in Kenya that govern plant breeders' rights and the approaches by these frameworks towards exceptions and limitations to the rights are discussed. It is found that the quest to fulfil

\footnotetext{
${ }^{52}$ Zhang, Y., \& Wildemuth, B. (2009). Unstructured interview. In B. Wildemuth (Ed.), Applications of Social Research Methods to Questions in Information and Library Science (pp.222-231). Westport, CT: Libraries Unlimited.
} 
international obligations has an obvious influence on the legal frameworks' approach towards exceptions and limitations to plant breeders' rights. This quest to fulfil international obligations is oblivious to other related international commitments in place such as those in relation to conservation, sustainable use and fair and equitable sharing of benefits arising from utilization of plant genetic resources for food and agriculture. Furthermore, this quest appears not to fit in with the smallholder farming systems in place, as well as the constitutional requirements in the country.

Chapter 4 builds upon the fulfilment of international obligations and examines two African regional plant breeders' rights initiatives. This chapter deals with questions relating to risks and concerns that arise for smallholders from the processes to harmonise plant breeders' rights in sub-Saharan Africa. It also addresses the question about legal uncertainties that arise in national plant breeders' rights legislation from the regional harmonization processes. The analysis in this chapter reveals that several challenges in relation to implementation of these regional instruments exist and if adopted, the intended outcome may be very different from what is envisioned.

Chapter 5 takes a case study approach examining whether licensing of plant breeders' rights could facilitate access to seeds and planting materials for smallholder farmers in market conditions prevailing in Kenya. Taking into account that licensing is a private activity, it is observed that where breeders are unlikely to recover their costs of investments, licensing can take a humanitarian form of use and third party technology facilitators emerge to, among others, absorb some of the licensing costs involved.

Chapter 6 explores how through utilization of spaces within the exceptions and limitations to plant breeders' rights as provided in UPOV 1991, African countries can balance the needs for different categories of farmers in the continent. Furthermore the chapter explores how African countries can implement plant breeders' rights systems that incentivise investment in breeding and seed production without creating impediments for access to improved seed for smallholder farmers. It is found that such a balance can be established through a differentiated approach to plant breeders' rights. A differentiated approach to plant breeders' rights by making use of the exemptions contained to the breeders' rights, sets different levels of protection for different crops in relation to different categories of farmers.

Chapter 7 provides an overall conclusion from the main findings in the preceding chapters, focusing on disconnections that exist between international commitments on plant breeders' 
rights, national policies legislation and smallholder farmers' practices. These disconnections influence whether smallholder farmers access seed and planting material and therefore enable them to contribute towards a country overcoming its food security problems. While questions for further research are elucidated, the research also makes some policy recommendations particularly in relation to utilisation of any legal spaces in plant breeders' rights legislation.

The field of law that this thesis concerns is intellectual property law, primarily plant breeders' rights. However, it also traverses other fields of law in relation to seeds and plant breeders' rights: seed laws issues in chapter two; some aspects of public international law in chapters three and four; and, contract law in chapter five. 


\title{
Chapter 2: $\quad$ Seed systems support in Kenya: consideration for an Integrated Seed Sector Development approach ${ }^{53}$
}

\begin{abstract}
The threats of climate change and rising food prices have stirred renewed attention for seed and food security in Africa, inviting new thinking on the role of seed sector development in coping with these concerns. One conceptual framework that has gained attention is the Integrated Seed Sector Development (ISSD) approach. The ISSD approach has evolved as a response to the almost exclusive focus on formal seed systems in seed sector development programs. Instead, ISSD aims to recognize and support all the diverse seed systems that exist in a particular country. An analysis of the evolution of seed policies and regulatory frameworks in Kenya since independence indeed exposes a continuous support for the formal seed sector while support given to the informal sector has merely been intended to transform it into formal. In reality, however, the formal and informal sectors appear to be made up of a plurality of seed systems, with the informal seed systems being the main source of seed for most crops. The chapter continues with analysing some of Kenya's recent policy shifts in order to explore how its new seed policy and legislative framework may fit within ISSD principles, and concludes with some recommendations on how the variety of seed systems that exist on the ground and in particular local seed systems can be supported.
\end{abstract}

\subsection{Introduction}

In most of Africa, agriculture is the main activity providing incomes and livelihoods (World Bank, 2008). Yet, the continent remains one of the most food insecure regions of the world. Kenya is a good example. While agriculture contributes $24 \%$ directly to its GDP and $80 \%$ of its rural population relies on agriculture as their primary source of livelihood (Government of Kenya $(\mathrm{GOK}, 2010)$ ) at the same time 30\% of the country's total population suffers from chronic food and nutrition insecurity (FAO, 2012). Seed sector development plays a crucial role in fighting food insecurity, both at global, national and local levels. Because the quality of seed determines the success of crops in terms of yield and product quality (Louwaars, 2007), seed quality and availability are crucial elements in securing food security.

A country's seed sector is made up of different seed systems. A seed system may include any individual or institution undertaking breeding research, selection, development, production,

\footnotetext{
${ }^{53}$ This Chapter is based on the article published as: Munyi Peter and Bram De Jonge (2015). Seed Systems Support in Kenya: Consideration for an Integrated Seed Sector Development Approach. Journal of Sustainable Development (Vol.8, No. 2 (2015)).
} 
multiplication, processing, storage, diffusion, distribution and marketing of seeds. All these components are interrelated (Thiele, 1997). In simplistic terms: a seed system incorporates the different ways by which farmers can access seed, including the different actors involved in the seed chains (Muthoni \& Nyamongo, 2008). Farmers, particularly smallholder farmers, are involved in multiple seed systems, which help them obtain the seed they need. These multiple systems are often broadly divided into two types: the formal (Kloppenburg, 1988) and informal (Cromwell, 1996). When the various components of the seed chain (e.g. breeding, seed production, distribution) are organized and undertaken by public or commercial actors, one normally refers to the formal system. Its opposite, the informal system, is usually defined as the total of farmers' seed production, selection and seed exchange activities (Almekinders \& Louwaars, 1999).

Global food security concerns in the light of climate change and rising food prices have in recent years led to an increased interest in seed sector development in Africa, inviting new thinking on the role of seed in defraying these concerns. One conceptual framework that is rapidly gaining attention is the Integrated Seed Sector Development (ISSD) approach. This approach is based on work by Louwaars \& van Marrewijk (1996), and has more recently been elaborated upon in Louwaars \& De Boef (2012) and Louwaars, De Boef \& Edeme (2013). In comparison to more traditional approaches to seed sector development, the ISSD approach can be characterized by three distinctive features: 1) The ISSD approach has evolved as a response to the predominant and exclusive focus on formal seed systems in seed sector development programs, which operate with a linear perspective expecting that informal seed systems will gradually evolve into formal and commercial systems. 2) The ISSD approach instead, emphasizes the plurality of seed systems that exist in a particular country or region, recognizing that farmers typically gain access to seed from different seed systems. 3) In order to strengthen the seed sector in a given country, ISSD aims to support all the different seed systems since all have their own benefits and limitations and require a unique approach in strengthening. As such, the ISSD approach aims to foster pluralism and guide seed policies and programs in their design to strengthen multiple seed systems (Louwaars, De Boef \& Edeme, 2013).

Under the auspices of the African Union's led Africa Seed and Biotechnology Programme (ABSP), ISSD has emerged as an approach for creating coherence among seed practices, programs and policies in Africa. ISSD programs have run in at least nine countries ${ }^{54}$ as a basis to

\footnotetext{
${ }^{54}$ Burundi, Ethiopia, Ghana, Malawi, Mali, Mozambique, Tanzania, Uganda and Zimbabwe.
} 
improve the effectiveness of a plurality of both formal and informal seed systems, through parallel interventions that may target different crop seeds and different farming systems (Africa Union, 2011). Next to the ISSD country programs, a continental 'ISSD Africa' program was launched in Nairobi in September 2014. This program aims to address complex challenges that hamper seed sector development at local or national levels, but by their specific nature need to be tackled at the continental level (ISSD, 2014).

No ISSD country program has been launched in Kenya. This does not mean that seed sector development is not on the (political) agenda in the country, on the contrary. Since 2004, Kenya has progressively made some major policy shifts in the agricultural sector and in the process among others, overhauled more than 131 pieces of legislation in the sector. In 2010, the country adopted a new overarching national seed policy. Subsequently, agricultural sector legislation has been reviewed and repealed in relation to among others, crop research systems; plant breeders' rights; and, seed quality systems. All these policy shifts are intended to lead the country towards food sufficiency and security (Poulton \& Kanyinga, 2014). Without any doubt, the changes made in the agricultural sector generally and the national seed policy in particular will have an impact on the functioning of the seed systems in place and affect farmer practices relating to seed.

This chapter investigates how the current and past policy frameworks that aim to support seed sector development in Kenya relate to this new ISSD approach. For this purpose, a brief analysis of the seed policies and regulatory frameworks in Kenya that have evolved since prior to Kenya's independence to the present policy and legislative frameworks is made. Three main periods of development of seed policies and regulatory frameworks are examined. This overview will expose a division of the seed sector in two domains, the formal and informal, with government support being almost exclusively targeted to the formal seed sector while support given to the informal sector has merely been intended to transform it into formal. When taking the ISSD approach into account, a brief analysis indeed shows the existence of multiple seed systems within both the formal and informal domains. Furthermore, it becomes clear that the formal domain constitutes a very small part of the totality of seed systems in Kenya as most farmers obtain their seed from informal sources such as the saving, exchange or local trade of seed.

The ISSD approach aims to foster pluralism and build programs to support this diversity of seed systems. In order to explore some of the implications the ISSD approach would have for Kenya's current policy framework on seed sector development, two important components of that framework that is, seed quality management and plant variety protection will be discussed in 
more detail. These two areas have been identified by Louwaars, De Boef \& Edeme (2013) as being amongst the most critical in ISSD guided policy development. The chapter concludes with some recommendations on what changes could be made to the existing policy and statutory framework in Kenya in order to support the diversity of seed systems that exists on the ground, in particular seed systems in the informal domain, which provide seed to the vast majority of Kenyan farmers.

\subsection{Historical overview}

This section analyses three main periods of development of seed policies and regulatory frameworks in Kenya since prior to Kenya's independence until the present. The first period is the pre-independence era. Kenya's independence in 1963 marked the end of this era as well as the beginning of the second era. The second era commences in 1964 (up to 2004) and was marked by gradual adoption of policies and frameworks in the agricultural sector centralized around a post-independence agenda that sought to have resources directed towards activities where productivity would be highest. The third period (from 2004 to 2015) was precipitated by a new government's quest to revitalize the agricultural sector.

\subsubsection{Pre-independence period (up to 1963)}

Pre-independence agriculture in Kenya was characterised by traditional tribal farming, which had developed to cater for subsistence needs. However, the declaration of the East Africa Protectorate by the British Government in 1895 and the subsequent construction of the East Africa Railways had an immediate effect on Kenya's agriculture (Pereira, 1996). The railway was an incentive to invite settlers with capital to develop commercial export agriculture, and importation of farm inputs (seeds and machinery) and exportation of agricultural produce was now possible.

In the lead to independence in 1963, the dominant policy in the agricultural sector that has influenced and shaped seed systems in Kenya is the Swynnerton Plan (Colony of Kenya, 1954). This policy laid the basis for organizing African smallholder farmers to have them produce high value export cereal and cash crops through provision of improved planting material. It also set in motion policies that sought intensification of African agricultural development through land consolidation, assurance of land title and tenure. However, the importance of food crops such as wheat, rice, maize and pulses was not overlooked. To facilitate the development and marketing of these crops, the government increased financial and technical support to crop-specific 
research institutions. Co-operative societies were reinvigorated and transformed and their members educated in co-operative principles and business methods with a view to turn these societies to conduits for providing farm inputs and to organise markets for produce.

Implementation of the Swynnerton Plan led to there being at the dawn of Kenya's independence in 1963, a vibrant commercial agriculture sector well supported by policies, institutions and structures. However, this commercial system of agriculture did not replace subsistence agriculture and traditional methods. Communal grazing, shifting cultivation, fragmentation of land holdings and lack of individual land tenure throughout the country still characterised subsistence agriculture (Pereira, 1996). Acquisition and distribution of farm inputs such as fertilizer and seeds, as well as marketing of farm produce was mainly driven through the Kenya Farmers Association, which served the interests of the colonial commercial farmers (Matanga \& Oehmke, 1996). Contrary to the expectations regarding implementation of the Swynnerton Plan, by independence co-operative societies were not strong enough to serve as farm input conduits as earlier anticipated. The informal acquisition, saving and exchange of farm inputs such as seeds remained therefore a vibrant practice amongst farmers.

\subsubsection{Post-independence I: (1964-2004)}

The main policy framework behind Kenya's post-independence development strategy was the 1965 Sessional Paper No. 10 on African Socialism and its Implications to Planning in Kenya (GOK, 1965). This policy emphasized the following principles: political equality, social justice, and human dignity based on state control of the economy, and it defined the state as the entity that not only should maintain law and order but also outline and implement social and economic programs in a bid to remedy historical and social inequities (Nyangito \& Okello, 1998).

The government, as an example of African socialism at work earmarked the seed sector. As the Sessional Paper No. 10 stated, "almost every form of organization will be utilized in this sector including national farms, co-operatives, companies, partnerships and individual farms." State farms were targeted as the main producer of hybrid seed. The principles contained in Sessional Paper No.10 gave credence to the state's control of the seed chain for the important food crops from plant breeding to multiplication and distribution. Legislation was thereafter crafted to fit with these principles. Thus, through the 1972 Seeds and Plant Varieties Act (1972 SPVA), the state was given the power to regulate seed testing and certification; imposition of regulation on introduction and importation of seeds and new varieties; and, to grant plant breeders' rights. Implementation of various aspects of the 1972 SPVA was progressive starting with seed testing 
and certification. It was not until 1995 that regulations to give better effect to the plant breeders' rights provisions in the 1972 SPVA were put in place, leading to the first grant of such rights being made in 1999.

A number of exogenous factors also led to the shaping of the seed sector policies and programs from the 1970s to the 1990s. For example, food shortages experienced in the late 1970s and early 1980s led to the adoption of the Sessional Paper No. 4 of 1981 on National Food Policy (GOK, 1981), which increased emphasis on breeding programmes, aimed at providing farmers with improved varieties. In Sessional Paper No. 1 of 1986 on Economic Management for Renewed Growth (GOK, 1986), which implemented the World Bank's structural adjustment programmes some food crops (maize, beans, wheat and sorghum) were identified as key for which policy was proposed to increase productivity and self-sufficiency. Finally, the decline of the global market for export crops-tea and coffee in the late 1990s led to the adoption of Sessional Paper No. 2 of 1999 (GOK, 1999) on the Liberalization and Restructuring of the Tea Industry and Sessional Paper No. 2 of 2001 on Liberalization and Restructuring of the Coffee Industry (GOK, 2001). These two policies sought to separate breeding research and marketing functions with respect to tea and coffee, on the assumption that such separation would yield market efficiencies.

Sessional Paper No. 10 of 1965 as well other post-independence policies responding to exogenous issues all similarly intensified support for the formal sector and in particular a few select food crops- mainly cereals, and cash crops. However, informal seed sources continued to provide the bulk of seed for most food crops particularly legumes and vegetatively propagated crops such as cassava, banana and sweet potato.

\subsubsection{Post-independence II: (2004-2015)}

In 2004, the government adopted the Strategy for Revitalization of Agriculture (SRA) "with a view to transform agriculture into a more competitive and commercial sector" (GOK, 2004). This policy was largely driven by a new government that came to power in 2002, which held the view that the agricultural sector required revival. The strategy also sought to limit the government's role in the sector to only providing a limited range of public goods and services, and to regulate in those aspects where private self-regulation was not possible or codes of conduct appeared insufficient. Furthermore, the strategy sought to improve delivery of research and to increase access to farm inputs (Odame \& Muange, 2010), and also reinvigorated financing of agricultural research through donor funding. 
The SRA was the basis for the development of the 2010 National Seed Policy (GOK, 2010). It also laid the foundation for the overhauling of over 131 pieces of legislation in the agricultural sector and the amendment of the 1972 SPVA through the 2012 Seeds and Plant Varieties (Amendment) Act (the 2012 SPVA Amendment); the enactment of the 2013 Crops Act; and, the 2013 Kenya Agriculture and Livestock Research Act. The National Seed Policy and these three legislations are now the designated policy instruments to steer agricultural development activities in Kenya. Invariably, all these four instruments affect seed sector issues, directly or indirectly. These policy instruments are briefly described below.

\subsubsection{2010 National Seed Policy}

The National Seed Policy outlines interventions that aim to address constraints in the seed sector with a view to contribute to agricultural productivity. From the outset, the description of seed systems in the policy follows the formal/informal dichotomy. The formal component is served by government initiated research programmes for some benefactor food and cash crops. Lumped within the informal seed system component are farm-saved seed, seeds purchased, multiplied or marketed locally between farmers and, seed accessed through civil society organizations, or imported by unregistered seed dealers, and relief agencies. The description of the informal seed system in the National Seed Policy is not followed by any policy detail on whether the system either requires attention or support or to be abolished.

Use of farm-saved seed, and seed obtained either through farmer-to-farmer exchange and local markets is identified as a problem. Whereas the specific problem presented by these seeds is not pointed out in the policy itself, it is apparent from the SRA that the quality of these seeds is the perceived problem. Seed certification is presented as the main tool effecting quality control. To enhance certification the policy proposes registration of all actors in the seed value chain (including relief seed suppliers) and prescription of stiffer penalties for those flouting certification procedures. There is also a call for the continued support of public breeding institutions to maintain varieties and produce seed for those varieties not attractive to the private sector. Targeting informal seed systems is a proposed policy on 'provision of advisory services with a view to transform it to the formal sector' (National Seed Policy, 2010). While the nature of advisory services are not expounded, the policy calls for strengthening of farmer extension and advisory services with a view to make farmers appreciate the benefits of using good quality seed. It is expected that through these services this transformation to formal will occur. 


\subsubsection{2012 SPVA Amendment}

The principal objective of the 2012 SPVA Amendment was to amend the 1972 SPVA, albeit not in its entirety. As such, the 1972 SPVA is still operative although in the form amended by the 2012 SPVA Amendment. One key amendment is to upgrade the plant breeders' rights system in Kenya from it being based on the 1978 Act of the International Convention for the Protection of New Varieties of Plants (UPOV 1978) to being framed under the stricter 1991 Act of UPOV (UPOV 1991). Plant breeders' rights, their limitations and exceptions are now largely based on UPOV 1991 principles with the expectation that this will stimulate breeding as well as the introduction of foreign varieties into the country, and that ultimately this will bring more varieties to the market. Under UPOV 1991, farmers are only allowed to save and re-use seed of a protected variety "on their own holding" and "within reasonable limits and subject to safeguarding the legitimate interests of the breeder" which may imply that farmers have to pay a royalty to remunerate the breeder. The exchange and sale of farm-saved seed, as is common practice amongst farmers in informal seed systems, is now prohibited for protected varieties (De Jonge, 2014).

\subsubsection{2013 Crops Act}

The primary novelty of the 2013 Crops Act regarding seeds is the classification of crops as either scheduled or non-scheduled. 112 crops varying from food crops, cash crops, vegetable crops to fruit trees are listed as scheduled crops with the Minister responsible for agriculture having power to increase the number of these crops. The difference between scheduled and nonscheduled crops lies in the requirement for government authorities to assist the development and market promotion of each scheduled crop. As laid out in section 8 of this statute, these measures include establishing experimental stations and seed farms for suitable varieties, facilitating marketing and distribution of the produce of these crops, and devising strategies for value addition for export crops.

Virtually, all food crops grown in Kenya are listed as scheduled crops. While the rationale for this classification is not clear, it is likely to induce the market structures that will be prevalent for these crops and influence farmer options and choices, as it obliges the government to not only set seed quality standards but also to determine the cost of farm inputs, and provision of markets for produce. It requires active participation by government in the crop value chain for virtually all crops, and shows the intention of the government to formalise the entire seed sector. 


\subsubsection{2013 Kenya Agricultural and Livestock Research Act}

The 2013 Kenya Agricultural and Livestock Research Act seeks to overhaul the structure of the agricultural research system in Kenya, by merging various agricultural research institutions in the food crop, cash crop and livestock sectors. ${ }^{55}$ From the outset, section 5 of this statute emphasizes that the principal function of the restructured organization is regulation, promotion, streamlining and coordinating agricultural research. Unlike in the past scenario where some of the agricultural research institutes such as KARI were carrying out plant breeding as well as seed multiplication and distribution, the intended focus of these public institutions under the new structure appear limited to undertaking research only. Any actions of the organization in dissemination of research outcomes appear limited to training and building capacity of users, and activities for demonstration purposes. This may have implications for smallholder farmers, as it removes KARI from participating in downstream seed activities, which is important in terms of ensuring that there is downstream support for improved varieties for crops that may not be attractive to the private sector.

Table 1: Overview of main agricultural sector policy drivers in Kenya

\begin{tabular}{|c|c|}
\hline Era & Main Policy Drivers \\
\hline $\begin{array}{l}\text { Pre-independence } \\
\text { (up to 1963) }\end{array}$ & $\begin{array}{l}\text { - } 1895 \text { Declaration of East Africa Protectorate } \\
\text { - } 1954 \text { Swynnerton Plan }\end{array}$ \\
\hline $\begin{array}{l}\text { Post-independence } \\
\text { I: } 1964-2004\end{array}$ & $\begin{array}{l}\text { - } 1965 \text { Sessional Paper No. } 10 \text { on African Socialism and its Implications } \\
\text { to Planning } \\
\text { - } 1981 \text { Sessional Paper No. } 4 \text { on National Food Policy } \\
\text { - } 1986 \text { Sessional Paper No. } 1 \text { on Economic Management for Renewed } \\
\text { Growth } \\
\text { - } 1999 \text { Sessional Paper No. } 2 \text { on the Liberalization and Restructuring of } \\
\text { the Tea Industry } \\
\text { - } 2001 \text { Sessional Paper No. } 2 \text { on Liberalization and Restructuring of the } \\
\text { Coffee Industry }\end{array}$ \\
\hline Post-indepen & - 2004 Strategy for Revitalization of Agriculture \\
\hline
\end{tabular}

${ }^{55}$ The following research institutions are merged: Kenya Agricultural Research Institute; Kenya Marine and Fisheries Research Institute; Kenya Trypanosomiasis Research Institute; Kenya Forestry Research Institute; Agricultural Science Advisory Council; Coffee Research Foundation; Tea Research Foundation of Kenya; and, Kenya Sugar Research Foundation. 
From the above, it is apparent that policy programmes and reforms adopted in the agricultural sector before and after independence (Table 1) have had the effect of rendering support for the formal seed sector while support given to the informal sector has merely been intended to transform it into formal. This policy fixation on the formal sector at the expense of recognition for the diversity of seed systems on the ground has been a raison d'être for the ISSD approach. As explained above, the ISSD approach has evolved as a response to the exclusive focus on formal seed systems in seed sector development programs as this traditional policy approach neglects the value of non-formal seed systems while it appears to be ignorant of the limitations of the formal sector. While it is questionable whether intensification of support for formal seed systems will lead to alleviation of food security problems (Louwaars \& De Boef, 2012), it also emerges that there is very little understanding of the various seed systems in place in Kenya. In order to strengthen seed sector development, a comprehensive understanding of the various seed systems that exist on the ground is needed (Sperling, Osborn \& Cooper, 2004). Sperling, Osborn and Cooper (2004) also observe that farmers, particularly smallholder farmers, are involved in multiple kinds of sometimes overlapping seed systems which help them produce and obtain the seed they need. This is true for Kenya as will be shown in the next section.

\subsection{A plurality of seed systems in Kenya}

In this section, a general overview is provided of the diversity of seed systems that exist within both the informal and formal domains. This general overview shows the main categories in which the various seed systems in Kenya can be divided.

\subsubsection{Informal seed systems}

The informal seed sector in Kenya can be divided in at least three different categories: farmerbased seed systems, community-based seed system, and relief seed systems. These categories are not absolutely distinct but sometimes overlap depending on the types of crops and seed value chains operating.

Farmer-based seed systems are characterised by individual farmers saving seed from harvests, exchanging seed with their neighbours or purchasing grain from the local market and using the 
same as seed (Almekinders \& Louwaars, 1999). In many cases, it also involves individual farmers selling excess farm produce to other farmers as seed. The bulk of seed and planting material for vegetatively propagated crops- sweet potato $(96 \%)$, cassava $(93 \%)$ and bananas $(80 \%)$ is mostly obtained from farm-saved sources (Ayieko \& Tschirley, 2006). For legumes and small-grain cereals Ayieko \& Tschirley (2006) have found the scenario as similar, as $80 \%$ of bean seed, $75 \%$ of cowpea seed, $90 \%$ of millet seed and $87 \%$ sorghum seed is obtained from farm-saved sources. Hybrid maize is the least, with only 15\% of seed being farm-saved (Ayieko \& Tschirley, 2006). Ayieko and Tschirley (2006) estimate that for all crops cultivated in Kenya, 78\% of seed used comes from informal seed sources. Smallholder farmers, whose farm size averages 0.2-3 hectares, account for $75 \%$ of the total agricultural output and $70 \%$ of marketed agricultural produce (GOK, 2010). As such, seed from farmer-based seed systems contributes substantially towards the total agricultural output in Kenya.

Community-based seed systems involve associations of individuals, often organized as a group or co-operative through the support of non-governmental organizations or state agents that assist them in entrepreneurial forms of seed multiplication and the marketing of seeds. These systems are established either to support other farming systems recovering from systemic stress such as drought, pests or diseases or to strengthen farmer-based systems with improved varieties or seed quality enhancing techniques. Unregulated (informal) seed quality control mechanisms are usually found in these systems. One of the results of the Great Lakes Cassava Initiative (GLCI), a collaborative project between Catholic Relief Services (CRS) and national agricultural research institutes in Kenya and other countries is the establishment of a community-based seed system for cassava in western Kenya. Through this system, some farmers have been organized and trained by KALRO (then KARI) to produce and distribute Cassava Brown Streak Disease (CBSD) and Cassava Mosaic Disease (CMD)-free cassava planting material to other small-holder farmers.

Relief seed composes another critical seed system. Like other countries in the Horn of Africa, Kenya experiences drought from time to time (Sperling, Remington, Haugen \& Nagoda, 2004). Seed aid programmes to assist the afflicted famers overcome acute stress emerged as early as the 1990s. Seed aid programmes have been carried out by the government in certain areas as a result of drought or internal displacement of farming populations. Non-governmental organizations such as CRS have also been engaged in seed aid activities since 1992, distributing both certified and farmer-produced seed. Official and unofficial maize seed aid, followed by vegetable seed aid 
(tomatoes, kale and onions) has dominated in relief seed recipient areas. Sperling et al (2004) have found that seed aid has been delivered on a fairly large scale about every other season, and across a large number of districts in Kenya.

\subsubsection{Formal seed systems}

The formal seed sector in Kenya is also composed of multiple seed systems. Here, three main categories that can be discerned are the public formal seed systems, mixed public private seed systems, and closed value chains.

Public formal seed systems refer to seed systems wherein the public sector undertakes all the activities in the seed value chain - from breeding to seed distribution. The wheat seed system in Kenya is one example of a public formal seed system. While it is not the only mode of delivery of seed to farmers for this crop, public formal sources are the second most important source of seed for wheat after farmer-based seed sources (Mahagayu, Ndiema, Njeru, Macharia \& Rengine, 2010). Currently, all wheat-breeding activities are undertaken by KALRO, which also undertakes seed production, multiplication and distribution through its own Seed Unit and contracted seed growers. Furthermore, KALRO also contracts the Agricultural Development Corporation (ADC), a state agent for seed multiplication. Besides wheat seed distribution being undertaken through ADC and KALRO's own Seed Unit, wheat seed distribution is also undertaken through the National Cereals and Produce Board, another government agent.

Mixed public private seed systems are characterized by participation of both the public and private sector in the seed value chain. The public sector usually undertakes breeding research while the private sector, multiplies and distributes seed to farmers. Private sector participation in seed value chains in Kenya is vibrant albeit to varying degrees. There are around 100 registered seed companies in Kenya. Most of these companies undertake seed multiplication and distribution, leaving plant-breeding research, which is capital intensive and risky to KALRO. Thus, most seed companies obtain breeder material, mainly maize but also beans and other legumes, from KALRO and these are multiplied under supervision by the Kenya Plant Health Inspectorate Service (KEPHIS). ${ }^{56}$

\footnotetext{
56 KEPHIS is the state agency responsible for seed sector regulatory activities- plant breeders' rights registration; seed quality control; and, variety release regulation.
} 
Closed value chain seed systems refer to those seed systems that are entirely controlled by the private sector from plant breeding through to distribution of seed to farmers and the marketing (and processing) of their produce. They are characterized by minimal government involvement in the value chain except in seed quality control and certification, mainly to prevent introduction of pests and diseases. In Kenya, fruit crops, vegetable crops, flowers and tobacco dominate this system. These value chains are dominant in utilizing plant breeders' rights. For example, in the 2010/2011 financial year, of the 69 applications for plant breeders' rights made in Kenya 30 were in respect of roses (KEPHIS, 2011).

Table 2: Plurality of seed systems in Kenya

\begin{tabular}{|c|c|c|}
\hline Seed system & Description & $\begin{array}{l}\text { Examples of crops in the } \\
\text { system }\end{array}$ \\
\hline Farmer-based & $\begin{array}{l}\text { Seed saved, used, exchanged and sold } \\
\text { between individual farmers. }\end{array}$ & $\begin{array}{l}\text { Sweet potato; Irish potato; } \\
\text { bananas; beans; cowpea; } \\
\text { millet; sorghum }\end{array}$ \\
\hline Community- based & $\begin{array}{l}\text { Seeds produced, multiplied and either sold } \\
\text { or shared within a community }\end{array}$ & Cassava \\
\hline Relief seed & $\begin{array}{l}\text { Civil society organisations, non- } \\
\text { governmental organisations and relief } \\
\text { agencies purchase seed either from the } \\
\text { public and private sector and distribute to } \\
\text { farmers }\end{array}$ & $\begin{array}{l}\text { Hybrid maize; OPV maize; } \\
\text { tomatoes; kale; onions }\end{array}$ \\
\hline Public formal & $\begin{array}{l}\text { Breeding, seed production, multiplication } \\
\text { and distribution by public sector only }\end{array}$ & Wheat; hybrid maize \\
\hline $\begin{array}{l}\text { Mixed } \\
\text { public/private }\end{array}$ & $\begin{array}{l}\text { Breeding undertaken by public sector; seed } \\
\text { production, multiplication and distribution } \\
\text { by private sector }\end{array}$ & $\begin{array}{l}\text { Hybrid maize; OPV maize; } \\
\text { beans }\end{array}$ \\
\hline Closed value chains & $\begin{array}{l}\text { Breeding, seed production, seed } \\
\text { multiplication and seed distribution all } \\
\text { undertaken by private sector only. }\end{array}$ & $\begin{array}{l}\text { Pineapples; } \\
\text { tobacco }\end{array}$ \\
\hline
\end{tabular}

Source: adapted from Sperling, Remington, Haugen \& Nagoda (2004); Ayieko \& Tschirley (2006); Mahagayu, Ndiema, Njeru, Macharia \& Rengine (2010) 
From the above one can discern a wide range of seed systems operating in Kenya (Table 2). This is in contrast with the National Seed Policy, which frames seed systems to narrowly fit into formal and informal dichotomies without exploring the diversity or plurality of seed systems within each domain. In addition, a perception has existed and continues to exist that only formal seed systems may be able to deliver better quality seeds to farmers. However, these seed systems have not delivered the perceived outcomes over the years and there is no evidence that they will do so in future. Even more importantly, this notion neglects the importance and benefits of informal seed systems, which may be quicker to respond to external stresses and farmers' needs (Louwaars \& De Boef, 2012). The next section will explore some potential changes that could be made to the existing policy framework on seed sector development in Kenya in order to support the diversity of seeds systems that exists on the ground and in particular, those seed systems in the informal domain, which provide seed to the vast majority of Kenyan farmers.

\subsection{Consideration for an ISSD-Approach}

The goal of the ISSD approach is to enhance farmers' access to quality seed of superior varieties, with superior varieties referring to both improved and local varieties most preferred by farmers (ISSD, 2014). Two important policy components that can strongly influence smallholder farmers access to quality seed of superior varieties are seed quality management and plant variety protection (Louwaars, De Boef \& Edeme, 2013). This section will discuss some of the implications the ISSD approach would have for Kenya's current policy framework in these two policy fields.

\subsubsection{Seed quality management}

Seed certification and quality control guarantee varietal identity and purity as well as physiological, physical and sanitary quality. However, compulsory certification has its limitations (Tripp \& Van der Burg, 1997). Investments and running costs for seed certification and testing schemes are usually high. Even where seed producers cover the costs of these schemes, capacity in the seed quality and testing organizations is often limited.

Kenya's approach to seed certification and seed quality is by strengthening seed certification rules through the 2010 National Seed Policy (section 2.2.3.1). The policy proposes registration of all actors in the seed value chain (regardless of their nature, and the seed systems they operate in) 
and aims to ensure that specific crops are certified with severe legal punishment being visited upon those found flouting the regulations. Of the 37 crops (Table 3) for which certification is either mandatory or voluntary as enumerated under the 2013 Crops Act, 21 are food crops. Under the new legislation, any person who contravenes any provision of the 2012 SPVA Amendment and is found guilty may be liable to a fine not exceeding Kenya Shillings Two Million (approximately USD 22,000) or may be imprisoned for a term up to two years. Previously, anyone found guilty for having committed similar offences under the 1972 SPVA was only liable to a fine not exceeding KSh. 3,000 (approximately USD 35) or imprisonment for a period not exceeding three months. Under the 2012 SPVA Amendment, the rules relating to dealing with uncertified seed are broad enough to include control over smallholder farmers' practices, particularly those engaging in seed trading at local markets.

The policy also aims to ensure that the private sector may participate in seed certification and testing procedures. Obviously, the private sector will only get involved in such practices where it will have a positive effect on profits. With respect to food security crops for which certification is mandatory, the private sector is not likely to offer certification services at cost or subsidized rates as is the government. Unless there is increased competition in the private sector certification services, private certification is not likely to lead to a decrease, but rather to an increase of costs for seed testing and certification of these crops. These increased costs will in turn be passed on to the farmer with the resultant effect being increase of the cost of access to seed.

In an ISSD framework, seed certification and testing may not be necessary for some seed systems, e.g. closed value chain systems where the seed producer has a direct interest in delivering the right type of seed, while it may not be feasible for others, e.g. farmer-based seed systems where farmers save and exchange seed amongst themselves. The burden of full certification can be lessened through the adoption of a 'quality declared seed' (QDS) system. This is useful particularly where seed is produced by farmers or farmer groups for the local markets and in small quantities. QDS is a quality assurance scheme for seed production, which is less demanding than full quality control systems and, thus, can be more easily implemented in situations where resources are limited (FAO, 2010). The scheme involves seed sampling in fields and/or the inspection of whole seed lots. QDS procedures also involve lesser numbers of field inspections, thus decreasing seed quality management costs, and ultimately reducing the price of seed for the farmer while ensuring a certain standard of seed quality. 
According to Granqvist (2006) a QDS system should not be perceived as a competitor to existing seed trade, nor designed to replace a fully developed seed certification program. In itself, a QDS system may facilitate the growth and sustainable development of the seed trade by creating local entrepreneurs, leading to a robust seed sector (De Boef, Dempewolf, Byakweli \& Engels, 2010). The parameters within which a QDS system should operate may be outlined in national legislation. In Tanzania, for example, a QDS system has been incorporated in the 2003 Seeds Act, and guidelines for control of QDS production were introduced in 2007 specifying the production process, the criteria that the farmer producer must meet, and the crops whose seeds may be produced in this manner.

Applying the ISSD approach to seed certification to the current policy framework in Kenya, one finds that the list of crops for which certification is mandatory does not take into account the seed systems these crops operate in. For example, most of seed for Irish potato and beans for which mandatory certification is now a requirement is accessed through informal sources. Whereas a case could be made for the need to have improved varieties of these crops being available, it is questionable whether the formal sector alone will be able to satisfy the demand for quality seed anywhere soon, and the current policy framework does not provide space for alternative mechanisms through which the production of quality seed could be enhanced. A QDS framework, for example, could support the production and multiplication of quality seed of Irish potato and beans by small businesses at the local level. To create space for such farmer or community-based seed businesses, the current legislation will have to be amended by introducing the QDS system and specifying the crops for which this type of certification will be allowed, which should include food security crops, such as hybrid and OPV maize, wheat, sweet potatoes and millets. For crops such as sunflower, which operate in closed value chains, emphasizing on use of certified seed may not be necessary since the value chain structure itself is able to regulate this issue.

Table 3: Food crops for which seed certification is either mandatory of voluntary

\begin{tabular}{|c|c|}
\hline $\begin{array}{l}\text { Food crops for which certification is } \\
\text { mandatory }\end{array}$ & $\begin{array}{l}\text { Food crops for which certification is } \\
\text { voluntary }\end{array}$ \\
\hline $\begin{array}{l}\text { (1) Irish potatoes (2) Sunflower (3) Soya beans } \\
\text { (4) Beans (5) Barley (6) Finger millet (7) Maize } \\
\text { hybrid and OPV (8) Pearl millet (9) Rice (10) }\end{array}$ & $\begin{array}{l}\text { (1) Bananas (2) French beans (3) Cassava (4) } \\
\text { Sweet potato (5) Sesame (6) Ground nut (7) } \\
\text { Pigeon pea (8) Dolichos bean (9) Cow pea (10) }\end{array}$ \\
\hline
\end{tabular}


\begin{tabular}{|l|l|}
\hline Sorghum (11) Wheat & Chick peas \\
\hline
\end{tabular}

Source: adapted from Schedule to the Crops Act, 2013.

\subsubsection{Plant breeders' rights}

Plant breeders' rights (PBRs) aim to encourage plant breeding by granting breeders of new plant varieties an exclusive right on the commercialisation of their varieties. Many breeders and breeding companies consider an effective PBR system a prerequisite for developing and marketing new varieties in a particular country. The 2012 SPVA Amendment seeks to steer Kenya towards compliance with UPOV 1991, which currently provides the strongest, internationally recognized PBR system. The potential benefits of such a system are that it may incentivize public and private breeding and facilitate the introduction of foreign-bred varieties. This would ultimately provide farmers access to a wider range of improved varieties. However, the UPOV system is mostly aimed at supporting formal seed systems. Furthermore, UPOV 1991 is likely to affect the informal sector as it does not allow for the exchange of farm-saved seed of protected varieties through the sales of seed surpluses on the local market (De Jonge, 2014).

It is not in doubt that compliance with UPOV 1991 will be beneficial to some of Kenya's sectors such as horticulture, which utilize this system the most. However, this might not be the case for other crops, food crops especially (with the exception of hybrid maize). A key issue is that a UPOV 1991 framework may not provide a sufficient balance between the exclusive rights of breeders and the rights of farmers to save, exchange and trade protected planting material, which is an essential ingredient in ISSD.

In an ISSD framework, differentiation between rights and limitations for different categories of farmers and crops could be introduced. This will ensure that a blanket implementation of plant breeders' rights does not result in negative impact on smallholder farmers, and a pluralistic approach to seed sector development is supported (Louwaars, De Boef \& Edeme, 2013). One way of doing this is by incorporating different levels of protection for different crops and/or with respect to different categories of farmers (De Jonge, 2013). For example, certain categories of farmers and crops - especially those operating in farm-saved seed systems (Table 2), could be allowed to save, sell and exchange seed of protected varieties amongst themselves. A key challenge of such differentiated PBR system is to regulate structures and boundaries between the 
different levels of farmers and crops. One possible example is provided by the Ethiopian draft PBR Proclamation, which creates three levels of rights. For the commercial export crops, such as flowers, breeders get full protection with no rights for farmers to save seed. For food crops, breeders get protection but farmers have the right to reproduce seed on their own holding. Yet, for all crops, smallholder farmers have the right to exchange and sell seed amongst themselves. This draft Proclamation defines a smallholder farmer in terms of income levels, with total earnings from sales of farm-saved seed not exceeding the average household income (De Jonge, 2013).

In theory, UPOV 1991 itself could provide for a differentiated PBR system through its exemption for private and non-commercial use. Since UPOV 1991 does not define private and non-commercial use member countries are free to define the farming practices, which they considered to fall within the scope of this exception (ISSD, 2015). Remarkably, Kenya's 2012 SPVA Amendment, which was implemented with the aim to make Kenya's PBR law compliant with UPOV 1991 does not include the private and non-commercial use exemption as required by UPOV. The 2012 SPVA Amendment leaves, as such, little room for smallholder farmers to be allowed to freely use farm-saved seed of protected varieties. To implement an ISSD approach to PBRs in Kenya's current legal framework would require at least two things: first, an amendment of the 2012 SPVA Amendment with a view to include the private and non commercial use exemption. The second would be differentiation in the implementing regulations to the current PBRs framework, of farmers and crops that could be allowed to save, sell and exchange seed of protected varieties amongst themselves.

In sum, infusing an ISSD approach to seed quality management and PBRs in the current policy framework on seeds is likely to have a positive impact on how smallholder farmers access seed. A QDS system will lead to better quality seed for certain crops being available and at a lesser cost. Introducing provisions that recognize certain rights or exemptions for smallholder farmers in the PBR system will achieve a similar result by allowing such farmers to freely use protected varieties. These ISSD elements are not likely to negatively affect the already thriving commercial seed sector. The set of farmers and crops for which this sector caters for does not farm for survival and subsistence purposes. Given the many Kenyan farmers that depend on the informal sector for their seed security, policy support for all the various seed systems that can be found on the ground may well be the only way to achieve food security and economic development in the country. 


\subsection{Conclusions}

This chapter reveals that from the pre-colonial era until today, the Kenyan government has continuously offered support to the further development of formal seed systems. Any agricultural policy change that has taken place over the years has had the intention of intensifying this support. Any support and recognition given to other seed systems, which have neither been defined nor analysed in detail in any policy frameworks so far, has been intended to transform these systems into formal systems. Yet, formal seed systems are the basis for provision of only a minor fraction of seeds of a limited number of crops to farmers. Notwithstanding policy change access to seed problems have continued to exist, making it necessary for alternative approaches to be considered and elaborated. As an alternative approach, ISSD offers opportunities to develop seed policies for the simultaneous and parallel development of various seeds systems that together cater for the diversity of demands related to different crops, farming systems and farmers (Louwaars, De Boef \& Edeme, 2013).

The seed quality management procedures currently in place in Kenya are designed for formal seed systems only. They do not provide flexibility to accommodate the functioning of other seed systems besides those operating in the formal domain. Alteration of these procedures through introduction of quality declared seed programmes with a view to accommodate the plurality of seed systems in place and to even recognize diversity of use within crops is likely to lead to an increase of the quality of seeds available to farmers and spur local seed businesses, which supports sustainable and robust seed systems.

As currently designed, plant breeders' rights as incorporated under the 2012 SPVA Amendment prohibit farmers from exchanging or selling farm-saved seed of protected varieties. Noting that smallholder farmers access seed predominantly through these channels, this provision locks out many farmers from accessing quality seed and planting material. It is therefore important that more flexibilities be introduced in the plant breeders' rights regulations to allow that certain categories of farmers or for certain crops may save, exchange and sell farm-saved seeds of protected varieties in local markets so that current seed access channels are not stifled.

All the proposed considerations above fall within the ISSD framework and follow from its concept. The current policy and legislative framework in Kenya does not recognize these flexibilities and opportunities. For it to fully recognize the crucial importance of the diversity of seed systems and, in particular, of the informal seed systems on which the vast majority of Kenyan farmers depend for their seed security, such amendments are highly recommended. 


\title{
Chapter 3: Plant breeders' rights regime in relation to relevant international obligations: implications for smallholder farmers in Kenya $^{57}$
}

\begin{abstract}
Together with other laws affecting agriculture, Kenya's plant breeders' rights legislation was radically amended in 2012. The amendments were mainly driven by the quest to comply with international obligations, principally the 1991 UPOV Convention. However, the country is also a contracting party to other international treaties affecting seeds such as the International Treaty on Plant Genetic Resources for Food and Agriculture and the WTO Agreement on Trade Related Aspects of Intellectual Property Rights. Moreover, the national Constitution obligates statutory recognition and protection of the ownership of indigenous seeds and plant varieties, their genetic and diverse characteristics and their use by the communities of Kenya. The obligations deriving from all these international agreements must be fulfilled against a backdrop of farming systems that are predominantly smallholder farmer-based. This chapter discusses how the amendments in the new Kenya plant breeders' rights law depart from the former legal regime and analyses whether the current regime is compliant with international obligations, and the implications for smallholder farmers.
\end{abstract}

\subsection{International plant breeders' rights obligations and domestication dilemmas}

In the area of intellectual property protection, globalization and the correspondent development of international instruments defining relations among nations has become a catalyst to proliferation of legislation governing intellectual property rights (IPRs), in particular to developing countries such as Kenya. Adopted in 1994, the World Trade Organization (WTO) Agreement on Trade Related Aspects of Intellectual Property Rights (TRIPS) stands out in this context, foremost because it constitutes part of an international legally binding agreement to which an enforcement mechanism is available. National compliance with its provisions is therefore one of the key pillars of the implementation of TRIPS. The requirement under TRIPS that intellectual property protection must be provided for plant varieties provided a logical opportunity for the International Union for Protection of New Varieties of Plants (UPOV) to present itself as the obvious de facto sui generis mechanism for protection of plant breeders' rights

\footnotetext{
57 This Chapter is based on the article published as: Munyi, P. (2015), Plant Variety Protection Regime in Relation to Relevant International Obligations: Implications for Smallholder Farmers in Kenya. World Intellectual Property, 18: 65-85.
} 
(PBRs). Seen in the broader context of IPRs, contention exists on whether PBRs promote industrial enterprise, enabling innovation and ultimately providing farmers and gardeners more choice and varieties of better yield and quality. ${ }^{58}$ Mooney (1979) argues that PBRs among other effects (1) encourage economic concentration, (2) threaten traditional agriculture and food security, (3) constrain free exchange of germplasm, (4) contribute to genetic erosion, (5) threaten biodiversity and (6) lead to appropriation of what is otherwise common heritage for mankind.

This debate was at the heart of the negotiations throughout the 1980s and 1990s that culminated in the adoption of Convention on Biological Diversity (CBD), and the International Treaty on Plant Genetic Resources for Food and Agriculture (IT) under the auspices of the Food and Agriculture Organization of the United Nations (FAO) (De Jonge, 2011). The IT brought farmers, particularly smallholder farmers, into sharp focus for their role in conserving plant genetic resources for food and agriculture (PGRFA), however without recognition or claim for ownership rights. Besides, the IT also laid bare the fact that countries are interdependent on germplasm for food and agriculture and as such, no country exists in a vacuum.

Countries that are contracting parties to these agreements are faced with the dilemma how to conform to these international obligations at the national level. Kenya became a member of the WTO in 1995, the UPOV in 1999 and the IT in 2003. In observing international agreements and domesticating them, the country has to contend with local realities. In the context of agriculture, these realities are characterized by among others, farming systems and rural economies that are largely smallholder farmer based. In Kenya, agriculture provides employment to $75 \%$ of the total labour force, and contributes close to $25 \%$ of the national gross domestic product (Devarajan and Kasekende, 2011). Over 75\% of the total agricultural outputs are produced by smallholder farmers with farm sizes of 2.5 hectares on average, producing mainly for home consumption, and using traditional technologies (FAO, 2009). There is also a significant commercial horticultural sector, producing mainly for export. This statistical information demonstrates that the smallholder farmer plays a significant role in provision of employment, income and food at the national level. This means that the nationalization of these international regimes should support, or at least not counteract the interests of these farming systems.

58 (1970) "Statement of Allenby L. White, Chairman Breeders' Rights Study Committee, American Seed Trade Association." In U.S. Senate, 1970. Washington, DC: USGPO. 
Whereas they mainly produce for home consumption, smallholder farmers are not substantial participants in formal seed markets, which are characterized by among others certified seeds or seeds protected with some form of IPR. Indeed, with a few exceptions, mainly maize and wheat, significant portions of seed and planting material in Kenya are accessed from farmer-based sources. Ayieko and Tschirley (2006) have found that for bananas, beans, cassava, ground-nut, millet, pigeon pea, sorghum, soybean, Irish potato and sweet potato, over $80 \%$ of seed is accessed from farm-saved sources. Maize is the exceptional cereal crop mainly because of the hybrid nature of the high yielding varieties whose offspring does not breed true-to-type once saved, leading to lower yields in the next generation.

PBRs provide the breeder commercial benefits, and are thus not primarily geared to affect nonmarket seed systems. Yet the country is littered with a diversity of farming and seed systemsfarmer based seed systems, community based seed systems, public formal seed systems, mixed public private seed systems, pure private value chains and relief seed systems (Munyi and De Jonge, 2015). The architecture of PBRs at the global level and its domestication at the national level appears not designed to equally address these different seed systems and especially bypasses the needs of the smallholder farmer. Each of these seed systems takes place in specific agroecosystems, with specific goals, objectives and production needs.

Below is an examination of the global PBRs architecture of relevance to Kenya. In this context, a brief introduction to some of the main features of TRIPS, UPOV and the IT is undertaken. This is followed by an examination of the Kenya PBRs regime juxtaposed against the international regimes aforementioned. In undertaking this examination, the main departures between the Seeds and Plant Varieties Act of 1972 ('the 1972 SPVA') and the Seeds and Plant Varieties (Amendment) Act of 2012 ('the 2012 SPVA Amendment') are identified, particularly in how these two statutes conform to and depart from the UPOV system, as well as how they contribute to the fulfilment of TRIPS and IT obligations. Subsequently, a discussion on the following four issues follows: (1) the extent to which indigenous seeds and plant varieties are protected given the constitutional requirement for their protection; (2) access to foreign germplasm by local farmers, having been identified as a key policy objective of the PBRs system; (3) whether the PBRs legislation now meets UPOV '91 standards given that Kenya has joined UPOV 1991; and, (4) implementation of farmers' privilege in line with IT obligations. 


\subsection{Global PBRs architecture of relevance to Kenya}

Kenya has participated in the global intellectual property debates at least since 1965 when it acceded to the Paris Convention on Industrial Property. The design and review of its domestic intellectual property regimes has been influenced by its international obligations and its PBRs system is not an exception. A number of international instruments, which Kenya has ratified, are relevant to its national PBRs regime. In this chapter three of these: TRIPS, UPOV and the IT are examined. Below is a brief overview of these instruments focusing on their key provisions.

\subsubsection{TRIPS}

Adopted in 1994, TRIPS unlike previous IP agreements ${ }^{59}$ brought about significant changes in international approaches towards IP protection in all fields of technology. With respect to plant varieties, TRIPS through its Article 27.3(b) brought forth the mandatory requirement that IP protection must be provided 'either by patents or by an effective sui generis system or by a combination thereof.' TRIPS does not aid countries by providing template treaties or a sui generis framework and it is therefore upon each country to define what an 'effective sui generis system' is for itself, taking into account national interests and concerns to the extent that these are not inconsistent with TRIPS. ${ }^{60}$ The sui generis option presents a wide policy choice and with it possibilities for disharmony between systems developed by countries (Rangnekar, 2013). Regardless, for a sui generis system to remain 'effective' it must at the very least, provide for an IPR and also be consistent with the national treatment and most-favoured nation principles of TRIPS (Rangnekar, 2013).

Despite the flexibility offered to craft an 'effective sui generis system', the UPOV system has emerged as the de facto sui generis system to extend IP protection to plant varieties in developed and developing countries. UPOV's membership continues to grow amongst developing countries. Through regional PBRs systems such as that adopted by the Organisation Africaine de la Propriété Intellectuelle (OAPI), many more countries have also adopted UPOV as the sui generis system without necessarily seeking its membership. In the not too distant future Africa is likely to be enveloped by the UPOV system due to the OAPI system already in place, a similar regional

\footnotetext{
${ }^{59}$ E.g. the 1883 Paris Convention for the Protection of Industrial Property and the 1886 Berne Convention for the Protection of Literary and Artistic Works both administered by WIPO.

${ }^{60}$ Article 8.1 of TRIPS is instructive herein: It provides that, "Members may, in formulating or amending their laws and regulations, adopt measures necessary to protect public health and nutrition, and to promote the public interest in sectors of vital importance to their socio-economic and technological development, provided that such measures are consistent with the provisions of this Agreement."
} 
protection mechanism already adopted under the aegis of the African Regional Intellectual Property Organization (ARIPO), and a third under development by the Southern Africa Development Community (SADC). ${ }^{61}$

Kenya became a member of the WTO in 1995. At the time, a sui generis system for protection of plant varieties was already in place (although not implemented), since the 1972 SPVA contained PBRs provisions. Moreover, the patent law in place in $1995^{62}$ excluded plant varieties from patents, thus clarifying Kenya's solution to its obligations under TRIPS. Measures that were taken around the time such as enactment of the Seeds and Plant Varieties (Plant Breeders' Rights) Regulations in 1994 can thus be seen as having been intended to make the system for granting of PBRs 'effective' as part of the fulfilment of TRIPS obligations.

\subsubsection{UPOV}

As a sui generis system specifically designed for PBRs, UPOV was the outcome of efforts by European seed producers and plant breeders to have their IP creations over plants protected. Initially adopted in 1961, the UPOV Convention has been revised three times: in 1972 (UPOV 1972), in 1978 (UPOV 1978) and in 1991 (UPOV 1991). Originally, its membership was largely ${ }^{63}$ drawn from industrialised countries very keen to protect the interests of their breeding industry both in their domestic and foreign markets mainly and initially in Europe. Currently, membership for new countries is only open to UPOV 1991. However, UPOV 1978 is still operative to UPOV members who have not acceded to UPOV 1991.

A number of commonalities and variations exist between the two UPOV systems that are presently operative. One of these variations is the farmers' privilege concept. ${ }^{64}$ Explicitly provided in UPOV 1991 as an optional exception to the rights conferred, this concept operates by providing that subject to safeguarding of the legitimate interests of the breeder, a farmer is permitted to use for propagating purposes, on his own holdings, the product of the harvest that

\footnotetext{
${ }^{61}$ In July 2015, ARIPO adopted the Arusha Protocol for the Protection of New Varieties of Plants. The Protocol is yet to come into force.

62 The Industrial Property Act (Cap 506) (repealed).

63 Of the 74 members of UPOV, 48 are industrialized countries.

${ }^{64}$ Farmers' privilege under the UPOV system does not include such elements as the rights of participation or right to benefit sharing. The privilege the UPOV aims to provide to farmers, generally as an exemption to the rights of plant breeders is meant enable farmers to save seeds harvested from proprietary crops planted in the previous season and use them in their own holdings during the next planting season.
} 
he has obtained by planting, on their own holdings, the protected variety. ${ }^{65}$ Implicitly included in this provision is a prohibition for farmers to sell and exchange seeds. The clause that the privilege is subject to the legitimate interests of the breeder is translated in Europe in a payment to the breeder on the use of seed of a protected variety saved by the farmer. UPOV 1978 does not make any mention of the privileges or rights of farmers to exchange, sell or re-sow seeds harvested from proprietary plant varieties. However, some authors claim that since the breeder's authorization is required only for production with commercial purposes, farmers can then use saved seed of protected varieties for replanting on their own lands, as well as non-commercial exchange among themselves (Santilli, 2012).

Kenya became a party to UPOV 1978 in 1999 following a review of its legislation for compliance with the convention by UPOV. It has remained an active member of the convention since, and in 2016, acceded to UPOV 1991 following revisions undertaken to its national legislation.

\subsubsection{IT}

The IT was adopted at the Food and Agriculture Organization (FAO) in 2001, and entered into force in 2004. It aims to contribute to the conservation and utilization of plant genetic resources for food and agriculture (PGRFA), and to this end attempts to strike a careful balance between the sovereign rights of states over biological diversity and global food security, requiring facilitated access to genetic resources.

One way in which the IT strikes this balance is through recognition of farmers' rights. Andersen (2005) and Fowler (1994) trace farmers' rights back to the work of Jack R. Harlan (1919-1988) who spoke of farmers as the 'amateurs' who have in fact created the genetic diversity that had become subject to controversies on ownership. It was not however, until the early 1980s that the term gained political momentum and evolved with the negotiations towards the conclusion of the IT as a catch-phrase to highlight the valuable but unrewarded contributions of farmers to PGRFA (Fowler, 1994) and as a counterforce to PBRs which were already institutionalized through UPOV.

Albeit in a non-exhaustive manner, farmers' rights are enumerated in the IT to include protection of traditional knowledge relevant to PGRFA, the right to participate in sharing of

\footnotetext{
${ }^{65}$ Article 15(2) of UPOV 1991.
} 
benefits arising from their utilization, and the right to participate in making decisions on matters related to the conservation and sustainable use of PGRFA. ${ }^{66}$ The responsibility to realize farmers' rights is vested upon national governments including taking decisions to not limit any rights that farmers have to save, use, exchange and sell farm-saved seed and propagating material, subject to national law and as appropriate. ${ }^{67}$ Vesting realization of farmers' rights upon national governments, and subjecting the same to national law has led to one of the main criticisms of the IT: that farmers' rights are not given the same recognition in law and protected at the same level as PBRs. Nonetheless, the more detailed encapsulation of farmers' rights by the IT appears to be a better reflection of smallholder farmers' agricultural practices, as compared to the farmers' privilege exception to PBRs under UPOV 1991.

Kenya acceded to the IT in 2003. At the time, PBRs legislation (the 1972 SPVA) was already in place. Similar to UPOV 1978, this legislation did not explicitly allow or prohibit saving, selling and exchange of seed by farmers from their own harvests, a practice that was already in place. Therefore the 1972 SPVA de facto, allowed saving, selling and exchange by farmers of seed from their own harvests. Accession to the IT did not lead to immediate changes in the 1972 SPVA with a view to reflect implementation of obligations under the IT, particularly with respect to farmers' rights as these obligations were already being put in practice, and appeared permissible under the 1972 SPVA.

\subsection{Kenya's PBRs regime}

\subsubsection{Historical development and landscape of PBRs legislation and PBRs applications}

Formal plant breeding in Kenya can be traced to as far back as the early twentieth century when Lord Delamere, a settler farmer, employed a wheat breeder to cross Australian and Italian varieties following devastation of his crop by yellow rust (Dixon, 1960). Government entry into plant breeding activities was through taking over Lord Delamere's breeding ventures and in 1927, the then Department of Agriculture established the Wheat Breeding Station (Pinto and Hurd, 1970). Legislation to either regulate plant breeding activities or protect PBRs did not follow immediately thereafter. In fact, throughout the colonial period (up to 1963) no legislation explicitly regulated plant breeding activities or protected PBRs inasmuch as policies and plans

\footnotetext{
${ }^{66}$ Article 9.2 of the IT.

${ }^{67}$ Article 9.3 of the IT.
} 
were put in place to provide technical support to crop-specific research institutions. ${ }^{68}$ This is not surprising considering that as a British Colony, no similar legislation existed in Britain or its colonies that could be extended to Kenya. ${ }^{69}$

In 1972 the SPVA was enacted. ${ }^{70}$ Some components of this legislation that dealt with PBRs lay dormant until 1993 when the government adopted Sessional Paper No. 3 of 1993 on National Food Policy. This policy invigorated implementation of PBRs by recognizing that they could facilitate farmers in acquiring new varieties from external sources. To render this policy better effect, the Seeds and Plant Varieties (Plant Breeders' Rights) Regulations (PBRs Regulations) were enacted in $1994 .{ }^{71}$ In 1996, the establishment of the Kenya Plant Health Inspectorate Service (KEPHIS) as the competent authority to receive and grant applications for $\mathrm{PBRs}^{72}$ set the stage for applications for PBRs to be received in Kenya. ${ }^{73}$

For a decade, the 1972 SPVA remained unchanged, and was the principal legislation regulating registration and enforcement of PBRs. A complementary legislation enforcing IPRs, the AntiCounterfeit Act, was however, enacted in 2008. ${ }^{74}$ The Anti-Counterfeit Act extends counterfeiting to include taking certain actions without authority of the owner of PBRs granted under the 1972 SPVA. $^{75}$ The 1972 SPVA was radically amended in 2012 through the enactment of the 2012 SPVA Amendment. The 2012 SPVA Amendment has not repealed the 1972 SPVA in its entirety. Rather it contains provisions either introducing new principles to the PBRs regime

\footnotetext{
${ }^{68}$ The Swynnerton Plan (1954) and the East African Royal Commission Report (1955) are examples of these policies. Implementation of the former led to an increased financial and technical support to the East African Agricultural Research Institute. The latter was a catalyst to the revision of the Agriculture Ordinance (1955) 'with a view to promote...maintain...and stimulate the development of agricultural land in accordance with accepted practices of good land management and good husbandry'.

${ }^{69}$ Britain enacted the Plant Varieties and Seeds Act in 1964, a year after Kenya became independent. The UK thereafter became a party to UPOV in 1968.

${ }^{70}$ The 1972 SPVA was modeled on the UK Plant Varieties and Seeds Act (1964), which mirrored UPOV 1961.

${ }^{71}$ Published on 25 November 1994 in the Official Kenya Gazette Supplement No. 73 of 25 November 1994.

${ }^{72}$ KEPHIS was established as a state corporation by the Presidential Order, the Kenya Plant Health Inspectorate Service Order, 1996 (Legal Notice No. 305 of 1996). In 2012, KEPHIS was re-established under a statute, the Kenya Plant Health Inspectorate Service Act (No. 54 of 2012). The statute is yet to enter into force.

${ }^{73}$ The first applications for PBRs were made on 22 January 1996 and all related to rose flowers.

${ }^{74}$ Act No. 13 of 2008

${ }^{75}$ Section 2 of the Anti-Counterfeit Act (2008) defines counterfeiting broadly to include taking the following actions without the authority of the owner of IPRs (which are defined to include PBRs) subsisting in Kenya or elsewhere: "(a) the manufacture, production, packaging, re-packaging, labelling or making whether in Kenya or elsewhere, of any goods whereby those protected goods are imitated in such a manner and to such a degree that those other goods are identical or substantially similar copies of the protected goods; (b) the manufacture, production or making, whether in Kenya or elsewhere, the subject matter of that intellectual property, or a colourable imitation thereof so that the other goods are calculated to be confused with or to be taken as being the protected goods of the said owner or any goods manufactured, produced or made under his licence;..."
} 
or amending others in the SPVA thus altering the landscape of Kenya's PBRs regime. The principal body of law now that constitutes PBRs legislation in Kenya is thus the 1972 SPVA and the 2012 SPVA Amendment.

The trigger to the enactment of the 2012 SPVA Amendment appears to be two fold. The first is the aspiration to comply with UPOV 1991 requirements. This is evidenced by the memorandum of objects and reasons to the 2012 SPVA Amendment Bill which for example, stated that the amendment of the definition of the breeder and also protection of all plant species and genera was required to be in line with UPOV $1991 .^{76}$ Further, during the second reading of the 2012 SPVA Amendment Bill in Parliament, the then Minister for Agriculture stated that the proposed amendments to the 1972 SPVA were intended to bring the legislation in "conformity with...the Union for the Protection of New Varieties of Plants, 1991..."77 The second trigger was the need for the protection and recognition of indigenous seeds and plant varieties. This need stems from the Constitution whose Article 11(3)(b) provides that "Parliament shall enact legislation to recognize and protect the ownership of indigenous seeds and plant varieties, their genetic and diverse characteristics and their use by the communities of Kenya." Hence under section 27A(1)(a) of the 2012 SPVA Amendment, the National Plant Genetic Resources Centre (NPGRC) is bestowed with the function of providing the protection intended under Article 11(3)(b) of the Constitution. The manner in which protection is sought to be given to indigenous seeds and plant varieties is visited in greater detail in this chapter.

\subsubsection{Constitutional dimensions of PBRs: anchorage and inclusion of international obligations}

In 2010, a new Constitution was promulgated heralding a platform for improved governance, political stability and economic prosperity in Kenya. ${ }^{78}$ It portends a radical shift in the governance framework, introducing, anchoring and clarifying rights to citizenry that were not institutionalized in the repealed Constitution. These include IPRs and domestication of international obligations.

\footnotetext{
${ }^{76}$ Memorandum of Objects and Reasons to the Seeds and Plant Varieties (Amendment) Bill, 2011 dated 28 November, 2011.

${ }^{77}$ Kenya Parliament Hansard, 15 August 2012.

78 Commission for the Implementation of the Constitution. 2012-2013 Annual Report. Three years after promulgation: Tracking devolution.
} 
To begin with, Article 260 of the Constitution defines property to include among others, intellectual property (IP). ${ }^{79}$ This gives a purposeful direction at least in the Kenyan context, to the philosophical question whether rights granted by the state as a result of creation of IP amount to property notwithstanding that IPRs confer a negative (exclusive) right in character whose assigned function is not the enjoyment of the right itself but prevention of others from enjoying the same (Torremans, 2008). Clear designation of IP as property in the Constitution has extended profoundly the application of constitutional principles that apply to classical understandings of property in Kenya into the IP arena. Of prominence is the right to privacy of a person, which includes the right not to have the person's property searched, since this now arguably extends to a person's IP. Except for trade secrets whose regulation under Kenyan law is through contract and imported doctrines of equity law of England, this right is not relevant for most other IPRs, especially patents, copyrights and PBRs, given that disclosure is necessary for the IPR to be granted. Secondly, arbitrary deprivation of property (including IP) is prohibited. Prompt full payment or just compensation to the person must follow deprivation. ${ }^{80}$ In IPRs, where deprivation occurs through compulsory licences, compensation by royalties must follow. This requirement already flows in Kenya's patent legislation-the Industrial Property Act, 2001, wherein there is a requirement to compensate a patent holder where the patent is utilized pursuant to a government use licence or compulsory licence.

Besides extension of the aforementioned classical principles of property into the realm of IPR, the Constitution also contains several express provisions referring to IPRs one of which-article 69 (1)(c), is of direct relevance to PBRs. This article provides that the State shall "protect and enhance intellectual property in, and indigenous knowledge of, biodiversity and the genetic resources of communities." ${ }^{81}$ Given that seeds are genetic resources and also constitute part of biodiversity then arguably, the Constitution recognizes IPRs used to protect genetic resources, for which PBRs are one.

The other constitutional dimension to PBRs discussions relates to the recognition as a source of law 'any treaty or convention ratified by Kenya' in Article 2(6) of the Constitution. This recognition is a significant departure from the repealed constitutional order. Under the repealed constitutional order, Kenya was explicitly a dualist state. The then Constitution only pronounced

\footnotetext{
${ }^{79}$ Article 260 of the Constitution provides that, "In this Constitution, unless the context requires otherwise"property" includes any vested or contingent right to, or interest in or arising from...intellectual property..."

${ }^{80}$ Article 40, The Constitution of Kenya (2010).

${ }^{81}$ Article 69(1)(c), The Constitution of Kenya (2010).
} 
itself as the supreme law and the statutory elaboration of this supremacy- the Judicature Act, set out in detail sources of law in Kenya of which treaties and conventions ratified by Kenya were none.

In theory, the provision recognizing any treaty and convention ratified by Kenya as a source of law implies that all treaties that Kenya had ratified as at 27 August 2010 when the Constitution was promulgated can be considered part of national law, and so will those ratified later such as UPOV 1991. It is an accepted norm of international law under the Vienna Convention of the Law of Treaties (1969) that every treaty in force is binding upon the parties and must be performed by them in good faith. Some of the treaties, which are then binding upon Kenya include the IT, TRIPS and UPOV 1991, given that they have been ratified by Kenya. At the same time, it is also trite law that inasmuch as some treaties are binding upon member states, they are not always enforceable in national courts. Legal jurisprudence arising from Kenyan courts on this matter is still scanty. Nonetheless, courts have been quick to jump and find that almost every treaty placed before them to which Kenya has ratified or acceded to is enforceable, implying that it creates a private right of action. None of the courts decisions have so far considered whether treaties that Kenya has ratified are self-executing, ${ }^{82}$ creating a private right, or a private right of action. ${ }^{83}$ Article $2(6)$ of the Constitution is yet to receive a robust interpretation by the courts with a view to understand the domestic status of international treaties in Kenya and how international legal commitments "come home". Whereas the IT, TRIPS, UPOV 1978 and UPOV 1991 have not been the subject of any litigation in the court, it is safe to say that they are at the very least binding on Kenya within the meaning of the Vienna Convention and prima facie, under Article 2(6) of the Constitution. Whether they are enforceable in Kenyan national courts is another matter altogether.

\footnotetext{
82 The United States Supreme Court has defined a self-executing treaty as one for which no domestic legislation is required to give it the force of law. See Trans World Airlines, Inc. v. Franklin Mint Corp., 466 U.S. 243,252 (1984). Where the treaty is silent as to its self-executing character, account must be taken of any statement by the President in concluding the agreement or in submitting it to the Senate for consent or to the Congress as a whole for approval, and of any expression by the Senate or by Congress in dealing with the agreement. See RESTATEMENT (THIRD) OF THE FOREIGN RELATIONS LAW OF THE UNITED STATES § 111(4) (1987).

${ }^{83} \mathrm{~A}$ private right is a right that accrues to an individual. A private right of action allows an individual to seek a remedy from a court for the violation of a private right provided by a treaty. For a detailed distinction between a private right and a private right of action, see David Sloss, When Do Treaties Create Individually Enforceable Rights? The Supreme Court Ducks the Issue in Hamdan and Sanchez-Llamas, 45 COLUM.J.TRANSNAT'L L. 20, 101-102(2006).
} 


\subsubsection{The 1972 SPVA and the 2012 SPVA Amendment: analysis of changes}

The 1972 SPVA, the 2012 SPVA Amendment and arguably, the IT, TRIPS and UPOV 1991 now constitute the principal body of legislation on PBRs. Enactment of the 2012 SPVA Amendment has altered the PBRs registration regime in several areas. This analysis focuses on several of these areas: (1) protection of ownership of indigenous seeds and plant varieties; (2) conditions for grant of PBRs; (3) subject matter for protection; (4) scope of protection; (5) breeder's exemption; and, (6) farmers' privilege.

\section{Protection of ownership of indigenous seeds and plant varieties}

One of the innovations of the 2012 SPVA Amendment is the provision for protection of indigenous seeds and plant varieties, something that was not addressed explicitly in the 1972 SPVA. The genesis to these provisions as already mentioned is the Constitution which calls for this action. None of the UPOV systems require this action to be taken. Besides protection, the Constitution also requires that the genetic and diverse characteristics and use of indigenous varieties by communities be recognized. No hint is given on how this recognition and protection is to be achieved. No illusion is created that the protection referred relates to granting of PBRs or that PBRs contain the appropriate tools to achieve this objective. In fact the 2012 SPVA Amendment approaches this issue by creating a body-the NPGRC, separate from KEPHIS to fulfill this objective. ${ }^{84}$ The relationship between the NPGRC in terms of addressing 'conservation and sustainable utilization' on the one hand and KEPHIS in dealing with grant of PBRs on the other hand is not addressed. Arguably then, the protection of indigenous seeds and plant varieties contemplated in this legislation is separate and different from PBRs.

In providing the protection sought, what qualifies as 'indigenous seeds and plant varieties' is not defined. An open and perhaps ambiguous understanding of what would constitute indigenous seeds and plant varieties exists. Further, the Minister responsible for agriculture is granted extensive powers to make regulations for the better functioning of the NPGRC, which would include inter alia activating the NPGRC function to provide protection to the ownership if indigenous varieties. However, these powers are yet to be exercised and as matters now stand, this protection though intended is yet to be extended to these varieties.

\footnotetext{
${ }^{84}$ Section 27A of the Seeds and Plant Varieties (Amendment) Act, 2012.
} 


\section{Conditions for granting PBRs}

The conditions for granting PBRs as contained in the 1972 SPVA mainly mimicked the UPOV 1978 provisions. Thus, for a variety to be protectable it must be sufficiently distinct; sufficiently uniform or homogeneous; stable in its essential characteristics; and, new. With respect to distinctness, the requirement that the variety has to fulfil is that it must be clearly distinguishable from any other variety whose existence is a matter of common knowledge at the time of filing of the application. ${ }^{85}$ Common knowledge may be established by reference to various factors such as: cultivation or marketing already in progress, entry in an official register of varieties already made or in the course of being made, inclusion in a reference collection, or precise description in a publication. ${ }^{86}$ The homogeneity requirement essentially means that for a variety to be protected it must be sufficiently homogenous, having regard to the particular features of its sexual reproduction or vegetative propagation. ${ }^{87}$ In other words, the requirement here is that the variety must breed true through subsequent reproduction or propagation (Llewelyn and Adcock, 2006). For a variety to meet the requirement for stability, it must remain stable in its essential or relevant characteristics after repeated propagation, or in the case of a particular cycle of propagation, at the end of such cycle. ${ }^{88}$ Novelty refers to the availability or otherwise of the variety for sale or marketing. To fulfil the novelty condition, the variety must not have been offered for sale or marketed for longer than one year, with the consent of the breeder, in Kenya ${ }^{89}$ Besides, it must not have been offered for sale or marketed, either with the agreement of the breeder, in the territory of any other states for longer than 6 years in the case of vines, forest trees, fruit trees, and ornamental trees, or for longer than 4 years in the case of all other plants (Santilli, 2012).

The 1972 SPVA introduced an additional enveloping condition that is not in accordance with UPOV- that the variety's "agro-ecological value must surpass, in one or more characteristics that of existing varieties according to results obtained in official tests." ${ }^{90}$ However, the legislation does not give a hint of how the 'agro-ecological value' is measured and the measure by which it must surpass the characteristic(s) of the existing varieties.

\footnotetext{
${ }^{85}$ Article 7 of UPOV 1991 and Article 6 of UPOV 1978.

${ }^{86}$ Article 6 (1)(a) of UPOV 1978.

${ }^{87}$ Article 6(1)(c) of UPOV 1978.

${ }^{88}$ Article 6(1)(d) of UPOV 1978.

${ }^{89}$ Article 6 of UPOV 1978.

${ }^{90}$ Schedule 4 Part II of the Seeds and Plant Varieties Act (1972).
} 
The 2012 SPVA Amendment has not altered the conditions for granting PBRs as contained in the 1972 SPVA. Retained includes the definition of common knowledge in determining distinctness in UPOV 1978.

\section{Subject matter for protection}

The 1972 SPVA provided that PBRs may be granted in respect of plant varieties of such species or groups as may be specified by a scheme made by the Minister responsible for agriculture. ${ }^{91}$ In making the scheme, the Minister was required to consult constituencies of those deemed to have a substantial interest in the matter to be regulated. As a result, different provisions for different species or groups of plant varieties could be made. Power to make schemes detailing species to which PBRs may be applied, as immense and potent as it portends was exercised mainly in 2001 when ten schemes were prescribed. These schemes covered fruit, nut and tree crops; vegetables; trees and woody climbers; roots and tuber crops; maize; ornamental and herbaceous plants; oil and fibre crops; cereals such as sorghum, millet, barley, rice and wheat; pulses; and, pasture plants and grasses. Interestingly, there was no reference in the 1972 SPVA to the requirement for gradual extension approach contained in UPOV 1978.

With the enactment of the 2012 SPVA Amendment now "rights may be granted... in respect of varieties of all plant genera and species". ${ }^{92}$ Ostensibly, this conforms to UPOV 1991 which requires states already members of UPOV to extend PBRs to all plant genera and species, within five years of acceding to UPOV 1991. However, while the UPOV requirement is couched in mandatory terms, the requirement for extension to all plant genera and species under the 2012 SPVA Amendment is phrased in discretionary terms. Using 'may' in describing the extent to which these rights should extend denotes flexibility on application of PBRs across plant genera and species. However, whereas under the 1972 SPVA the Minister was the designated authority in determining the plant species that would be the subject matter of PBRs, under the 2012 SPVA Amendment the authority to exercise that discretion is not vested in any institution or individual.

\section{Scope of protection}

Akin to other IPRs PBRs are limited rights. Through the law users of protected varieties and seeds may undertake permissible activities on the protected material without infringing upon the

\footnotetext{
${ }^{91}$ Section 17(1) of the Seeds and Plant Varieties Act (1972).

92 Section 14 of the Seeds and Plant Varieties (Amendment) Act (2012).
} 
rights of the holder of PBRs. The scope of protection and exceptions to PBRs therefore impinges upon other users of plant varieties and seeds (Rangnekar, 2013).

In addressing the scope for protection, the 1972 SPVA took the UPOV 1978 approach allowing the breeder control of production for purposes of commercial marketing of the reproductive or vegetatively propagating material, and for offering for sale or marketing of such material. ${ }^{93}$ However, limited extended protection to include their products, was granted to ornamental plants or cut flowers. ${ }^{94}$ The right therefore, was to prohibit others from commercially using the protected material, the notion of what is commercial being limited to the act of selling or marketing in the sense of holding the material out as being available for sale (Llewelyn and Adcock, 2006). This preserved the right to use the material non-commercially.

All this has changed with the enactment of the 2012 SPVA Amendment. The scope of rights now mirrors those under UPOV 1991 with the plant breeder having an exclusive right to permit others to produce or reproduce; condition for propagation; offer for sale; sell or other marketing; export; import; or, stock for the above purposes, the plant variety. ${ }^{95}$ In addition these rights are extended to harvested material and products unless the breeder has had a reasonable opportunity to exercise his right in relation to either the propagating material or harvested material, as well as to essentially derived varieties, varieties not clearly distinguishable from the protected variety and others whose production requires the repeated use of the protected variety. Essentially derived varieties are defined in consonance with UPOV 1991 provisions.

The breadth of breeders' rights is now much wider than it was earlier provided for under the 1972 SPVA. The preserved right to use material non-commercially, a de facto interpretation of part of farmers' rights, is severely diminished and has been replaced by more explicit provisions. Freedom of farmers to deal with their harvests and products has been removed. Activities such as seed saving which were previously allowable with no restrictions, now have to be undertaken subject to some conditions.

The scope of rights contains several limitations two of which- breeder's exemption and farmers' privilege are discussed below.

\footnotetext{
${ }^{93}$ Section 20 (1)(a) of the Seeds and Plant Varieties Act (1972).

${ }^{94}$ Fifth Schedule of the Seeds and Plant Varieties Act (1972).

${ }^{95}$ Section 17 of the Seeds and Plant Varieties (Amendment) Act, 2012.
} 
The breeder's exemption permits any breeder to use protected material for research purposes even where there is a defined commercial objective to that research. Llewelyn and Adcock (2006) argue that it is the more important derogation of the scope of rights as it purposely allows plant breeding to be incremental recognizing that a protected variety may be the foundation for other varieties. To a large extent, the 1972 SPVA followed UPOV 1978 in providing for the breeder's exemption. Under section 20 of the 1972 SPVA, production and stocking for production of propagating material of a protected variety undertaken solely for research purposes or for developing new varieties in the breeder's own nursery is deemed not to be at variance with the exclusive right of the breeder, and thus not constitute infringement on the PBRs granted to the protected variety. The point of departure between the 1972 SPVA and UPOV 1978 was with respect to instances where a protected variety has to be used repeatedly for the commercial production of the other variety. No similar provision existed in the 1972 SPVA and therefore it appears that even repeated use for commercial production fell within the ambit of the breeder's exemption.

Related to breeder's exemption is the question of dual protection of plant material by PBRs and patents, as this materially affects how breeder's exemption operates. To begin with, neither the 1972 SPVA nor the 2012 SPVA Amendment addresses this issue. Rather it is addressed in the principal legislation dealing with patents, the Industrial Property Act, 2001. Section 26 of the Industrial Property Act states that non-patentable inventions include plant varieties as provided for in the 1972 SPVA. However, 'parts thereof or products of biotechnological processes' fall outside this exclusion, and are therefore patentable. Previously, Rangnekar (2006) was of the view that the phraseology of section 26 renders plant varieties not provided for in the 1972 SPVA to constitute patentable subject matter, which may include those plant varieties that are of species or genera that the Minister had not specified under the schemes gazetted in 2001. However, given that under the 2012 SPVA Amendment the authority of the Minister to make schemes has been done away with since all plant genera and species must be granted protection, then this view is now moot. The logical argument now must be that all plant varieties per se are not patentable, except 'parts thereof' and in sum, dual protection as allowed under UPOV 1991 is possible. The case seems to be that where a variety is protected by PBRs, and a component of that variety (e.g. a trait) falls under the scope of a patent, breeders are not allowed to exercise the breeder's privilege. In some countries explicit exemptions have been made in patent law to introduce a breeder's exemption (and a farmers' privilege) in such cases (Prifti, 2013). 
A new optional exception introduced in the 2012 SPVA Amendment is the so-called farmers' privilege. Derived from UPOV 1991, this exception was not previously contained in the 1972 SPVA, the only exception to the scope of rights being the breeder's exemption discussed above. As such with the restricted act being commercial marketing, the right by third parties such as farmers to use the material for non-commercial purposes was preserved (Llewelyn and Adcock, 2006). This enabled farmers to exercise the freedom to save, exchange or re-use seed or harvested material without restriction. While UPOV 1978 did not expressly allow this practice, it was also a reflection of the reality in most farming communities whereby seed saving, and exchanging is rampant amongst farmers as a means to guarantee availability of seed for every planting season and to experiment with new seeds. Seed saving is widely practiced in Kenya for most crops and provides over $95 \%$ of seed for some crops such as Irish potato and cassava. ${ }^{96}$

The farmers' privilege in the 2012 SPVA Amendment is provided for in mandatory terms that "within reasonable limits and subject to safeguarding the legitimate interests of the breeder, farmers may use the product of the harvest which they have obtained by planting, on their own holdings, the protected variety." Under this provision, Kenyan farmers are henceforth prohibited from exchanging farm-saved seed for all crops with other farmers. Selling farm-saved seed for all crops is equally prohibited. However, these two practices are engrained in the smallholder farmer systems in Kenya, given that they guarantee availability of seed unlike supply by the formal seed system, which is often subject to systemic failures and disruptions along the distribution chain. The only allowable practice for farmers is saving and re-using the seed on their own farms. Since the legitimate interests of the breeder have to be protected, when farmers are saving and re-using farm-saved seed then breeders have to be compensated usually by a royalty payment.

\subsection{Discussion}

The PBRs regulatory landscape in Kenya as it currently stands, consists of a mix of provisions heavily influenced by TRIPS and UPOV 1978 and 1991, and much less by the IT. UPOV 1978 and 1991 principles have now been embraced and its provisions domesticated in a mixed fashion as shown in Table 4 below on the salient features and variations between these two instruments

\footnotetext{
${ }^{96}$ From author's field research.
} 
and the Kenya legislation. However, the process and outcome of embracing these principles invites discussion on several issues.

\subsubsection{Protection of indigenous seeds and plant varieties}

It is arguable that the protection intended for extension to indigenous seeds and plant varieties is different and apart from PBRs for the following reasons: The 2012 SPVA Amendment provides that PBRs may be extended to varieties of all genera and species. Potentially, this includes indigenous seeds and plant varieties. With this social, economic and ecological concerns and special difficulties that would otherwise have been available to the Minister for consideration under UPOV 1978, in making decisions on which crops to avail for protection are now lost. Included in this basket of lost considerations are also those available under TRIPS, necessary to protect public health and nutrition, and to promote the public interest in sectors of vital importance to the socio-economic and technological development. ${ }^{97}$ The availability of these considerations from TRIPS arises from the fact that UPOV as a sui generis system of protection of plant varieties, is subject to other provisions of TRIPS. This notwithstanding, the statute goes ahead to make specific and explicit provisions on protection of indigenous seeds and plant varieties.

It would appear that the explicit provision for protection of indigenous seeds and plant varieties is in itself tacit recognition of local farming realities in Kenya. These are characterized by a diversity of seed systems including farmer-based systems dominated by smallholder farmers wherein indigenous seeds and plant varieties are key. However, the legislation as presently framed is deficient in two ways. In the first, no clarity is given on which species qualify as indigenous and in the second, no suggestion is given on what additional protection may be extended to these species and more so. Nonetheless, this situation presents immense flexibility and opportunities for protection of indigenous species.

A widest possible definition of 'indigenous seeds and plant varieties' is now feasible in the regulations implementing the 2012 SPVA Amendment. This definition could be crafted to include landraces, which form a major component of farmers' plant genetic resources, local varieties, modern farmer varieties and conservation varieties (Salazar et al, 2007). Innovative approaches to protect these varieties could then be anchored on the existing provisions. These approaches may include legal recognition of their origin and establishment of special registration

${ }^{97}$ Article 8 of TRIPS. 
procedures for their inclusion in national seed catalogues (Salazar et al, 2007). According to Bocci (2009) these special procedures may include requirement for seeds of these varieties to be produced in their place of diversification; quantity restrictions; and, establishment (if possible) of a traceability system to prevent abuse from non-qualifying varieties. Already similar provisions exist in other jurisdictions such as the European Union. ${ }^{98}$

A consequent question arising from this discussion is whether protection of indigenous seeds and plant varieties in a manner separate and different from PBRs, is compatible with the UPOV systems in place, and embraced under the 1972 SPVA and the 2012 SPVA Amendment. For one, under UPOV protection is granted to those varieties that meet the set conditions for grant: novelty, distinctness, homogeneity or uniformity, and stability. If indigenous seeds and plant varieties are subjected to the UPOV protection conditions, they are unlikely to fulfil these conditions. By their nature, indigenous seeds and plant varieties are not bred and maintained with these protection conditions in mind. Thus, indigenous seeds and plant varieties are protectable to the extent that conditions that they must fulfil for protection are separate and different from those set out under UPOV. If all plant varieties (including indigenous seeds and plant varieties) are made available for PVP protection smallholder farmers may stand ill cushioned to withstand economic hardships such as price, attendant to accessing protected varieties as they mainly cultivate these crops for subsistence purposes. Also protection of indigenous plant varieties through PBRs may also disenfranchise smallholder farmers where legal ownership would be lost from them, particularly those who have been conserving them over the years.

Since the boundaries of such protection are not yet defined, it is impossible to analyse whether such protection of indigenous seeds and varieties would create a positive or negative effect on various local seed systems. Strong rights of communities may limit access to such materials by smallholder farmers that are not part of that particular community.

One way through which the boundaries for protection could be defined is by linking the 2012 SPVA Amendment insofar as protection of indigenous seeds and plant varieties are concerned to Kenya's legislation on protection of traditional knowledge and cultural expressions ${ }^{99}$ and that

\footnotetext{
${ }^{98}$ EU Commission Directive No. 2008/62/EC of 20 June 2008 providing for certain derogations for acceptance of agricultural landraces and varieties which are naturally adapted to the local and regional conditions and threatened by genetic erosion and for marketing of seeds and seed potatoes for those landraces and varieties. ${ }^{99}$ The Protection of Traditional Knowledge and Cultural Expressions Act, 2016.
} 
regulating benefit sharing of genetic resources ${ }^{100}$. However, these two pieces of legislation do not mention seeds at all moreso the former which among others seeks to implement Article 11 of the Constitution. Explicitly providing in the 2012 SPVA Amendment that access to indigenous seeds and plant varieties is also subject to prior informed consent and mutually agreed terms between their indigenous custodians and the recipient, could provide clarity on protection mechanisms contemplated. Thus even where PBRs may be taken out in respect of indigenous varieties, it would so occur with the consent of those who have conserved the same for years. Through the National Environmental Management: Biodiversity Act, 2004, ${ }^{101}$ South Africa has defined what constitutes indigenous biological resources and genetic resources thus providing a level of differentiation between these and other resources. This statute goes further to also provide for the steps required prior to its access.

Another way through which boundaries for protection of indigenous seeds and plant varieties could be set is by explicitly defining these indigenous varieties and providing for criteria for protection different from that used in the protection of new varieties of plants. India has provided for a criteria for protection of extant varieties-defined to include farmer's varieties; varieties about which there is common knowledge and in the public domain. ${ }^{102}$ This criterion for protection is different from that which other new plant varieties are subjected to. Whereas India is not a party to UPOV, it offers examples of how indigenous seeds and farmer's varieties may be protected and the boundaries that could be set between protection of these and other varieties.

\subsubsection{Access of foreign varieties by local farmers}

One of the objectives of the PBRs system is to facilitate farmers in accessing better quality, high yielding varieties from foreign sources. It is therefore necessary to discern whether this objective has been fulfilled so far.

Since the PBRs registration system became operative as at May 2016, 1,458 applications for grant of PBRs had been filed. Ornamental crops account for about $60 \%$ of the applications. On the

\footnotetext{
100 the National Environmental Management and Co-ordination (Conservation of Biological Diversity, Access to Genetic Resources and Benefit Sharing) Regulations, 2006.

${ }^{101}$ Act 10 of 2004

102 Indian Protection of Plant Varieties and Farmers' Rights of 2001
} 
other hand, food crops account for $34 \%$ of all applications filed. ${ }^{103}$ Roses account for $81 \%$ of applications received for ornamental crops. Maize takes $40 \%$ of the food crops share of PBRs applications, and $10.6 \%$ of the total number of all applications filed. It is also notable that over 99\% of PBRs applications for ornamental crops are from foreign sources. With respect to food crops, the situation is as follows: for maize public breeding institutions (Kenya Agriculture and Livestock Research Organization (KALRO) and Kenya Seed Company (KSC)) account for over 90\% of the PBRs applications. Only 10\% of the PBRs applications for maize are from private or foreign entities. With respect to beans, French beans account for $56 \%$ of the PBRs applications for all bean varieties that have been lodged for grant, with only one application for French beans emanating from a national public research institution. The rest of the French beans applications for PBRs are either from foreign entities or their local subsidiaries. This can be attributed to the fact that French beans are an export crop. All PBRs applications for the locally consumed bean varieties-dry bean, mung bean and runner bean are from public institutions- KALRO and KSC confirming that the local beans market is of little if any interest to foreign entities. ${ }^{104}$

Although being a heavy user of the PBRs system, little floriculture plant breeding is taking place at the domestic level. Virtually all the plant breeding is done in foreign countries (Louwaars et al, 2005) and the same case applies to French beans. PBRs registration for floricultural products appears driven by the fact that Kenya is a major production source for these products for foreign markets. In itself Kenya offers an insignificant market for floricultural products and French beans. The extent to which local farmers other than the commercial horticultural farmers, courtesy of the PBRs system have accessed foreign varieties is therefore questionable. If this objective has been met, it has been so met only partially and within a few crops, mostly those in the commercial sector dominated by floriculture, which is a forte of closed value chain systems, not those farming systems in which smallholder farmers participate.

\subsubsection{Meeting UPOV 1991 standards: conditions for grant of PBRs}

As they are currently framed the conditions for granting PBRs under Kenyan legislation appear to be more strict than those intended under UPOV 1991. This is in two ways. The first lies in the manner in which distinctness is proven. In determining whether a plant variety is distinct, the 1972 SPVA adopted the UPOV 1978 standards to establish common knowledge. Thus common

\footnotetext{
${ }^{103}$ Author's own analysis.

${ }^{104}$ Author's own analysis.
} 
knowledge may be established by reference to various factors such as: cultivation or marketing already in progress, entry in an official register of varieties already made or in the course of being made, inclusion in a reference collection, or precise description in a publication. The standards for establishing common knowledge under UPOV 1991 are different. Under UPOV 1991, common knowledge is established in either of these two ways: the filing of an application for a grant of PBRs or for the entering of another variety in the official register of varieties. Common knowledge therefore is narrower under UPOV 1991 than under UPOV 1978 meaning that establishing distinctiveness under UPOV 1991 requires a lower degree of threshold. Thus the Registrar of PBRs is required to evaluate this condition from a broader reference base of other varieties than he would otherwise do in carrying out a similar examination under UPOV 1991 conditions.

The second way in which conditions for grant of PBRs appear to be stricter than those under UPOV 1991 lies in the agro-ecological valuation test which candidate varieties have to undergo, in addition to fulfilling the NDUS criteria. For a variety to qualify for protection it must offer a useful characteristic beyond what is otherwise available. Given that the statute is silent on how the 'agro-ecological value' is measured and the measure by which it must surpass the characteristic(s) of the existing varieties, this potentially presents an opportunity for farmer and indigenous varieties to be considered, in determining the agro-ecological value of candidate varieties for PBRs. Given that farmer and indigenous varieties may be protected in other ways other than PBRs, and their agro-ecological value may not be a factor for consideration in their mode of protection, this may create the impression that the protection system is designed in favour of farmer and indigenous varieties.

The PBRs legislation as currently framed does not meet UPOV 1991 standards as the current conditions for protection in the PBRs legislation are more and different than otherwise intended under UPOV 1991. This view notwithstanding, it is notable that in 2016, the legislation was found to pass muster for Kenya to accede to UPOV 1991.

\subsubsection{Implementing farmers' privilege}

Farmers' privilege is an optional exception and it is a matter for each country a member of UPOV to decide whether it is appropriate to incorporate this provision in its national 
legislation. ${ }^{105}$ Through the 2012 SPVA Amendment, Kenya has taken the decision to incorporate farmers' privilege into its national legislation. The manner in which this provision is incorporated appears to not take cognizance of several issues that affect both farmers and breeders.

The first is the diversity of farming systems and practices in Kenya, which are mainly dominated by farmer-based seed systems in which seed saving and exchange between farmers is rampant. Because formal seed systems are often inefficient both in time and costs in providing seed to smallholder farmers, they tend to save their own harvests, exchange with their neighbours and also purchase seed from local markets as a result. This is the case for most crops especially tuber crops such as Irish potato, sweet potato and cassava, which are bulky and perishable. Ayieko and Tshirley (2006) have found that over 95\% of planting materials for these crops are obtained from farm-saved sources.

Secondly, the farmers' privilege provision as domesticated in the 2012 SPVA Amendment appears oblivious to the recommendation given by the 1991 Diplomatic Conference for the Revision of the International Convention for the Protection of New Varieties of Plants on its implementation. In the Conference, it was recommended that the farmers' privilege provision, "should not be read so as to be intended to open the possibility of extending the practice ... to sectors of agricultural or horticultural production in which such as privilege is not a common practice on the territory of the Contracting Party concerned." 106 The UPOV Council in its explanatory notes has interpreted the recommendation of the Diplomatic Conference to mean that farmers' privilege was aimed at those crops where, for the member of the Union concerned, there was a common practice of farmers saving harvested material for further propagation. This implies that where the farmers' privilege provision is adopted in a legislation it is possible to limit the extent and manner of its applicability. In fact, the farmers' privilege provision as worded in UPOV 1991 connotes that where the restriction is in place this may be in relation to any crop, not on all crops. Countries therefore have a choice to at the very least, determine the varieties to which this provision may apply, as confirmed by the UPOV Explanatory Note. ${ }^{107}$

\footnotetext{
${ }^{105}$ UPOV/EXN/EXC/1. Explanatory Notes on Exceptions to the Breeder's Right Under the 1991 Act of the UPOV Convention.

106 International Union for the Protection of New Varieties of Plants, (1992) Records of the Diplomatic Conference for the Revision of the International Convention for the Protection of New Varieties of Plants, UPOV, Geneva.

${ }^{107}$ Author's own analysis.
} 
Further to the above, the first limb of the farmers' privilege provision in the UPOV 1991 text and also imported into the 2012 SPVA Amendment requires that where this privilege is adopted, that it must be within reasonable limits and also subject to the safeguarding of the legitimate interests of the breeder. While UPOV 1991 does not provide a yardstick measure of what may constitute reasonable limits and also how the legitimate interests of the breeder may be protected, UPOV Council has given some explanation on the issue. The Council has proposed a list of considerations that a country could make in safeguarding the legitimate interest of the breeder. These include type of variety; size of holding/crop area/crop value; proportion or amount of harvested crop; changing situations and evolution of farming practices; and the remuneration to the breeder. ${ }^{108}$

A number of countries have put some of these considerations into their legislations in implementing farmers' privilege. For example in the European Union, farmers are permitted to use protected material (other than hybrid or a synthetic variety) for propagating purposes on their own holdings for some fodder plants, cereals, potatoes and oil and fibre plants. ${ }^{109}$ Besides, the farmer must pay an equitable remuneration sensibly lower that the amount originally charged-the common figure across the European Community is $50 \%$ of the original price (Llewelyn and Adcock, 2006). Small farmers who are equally defined in the Community Regulation are exempted from paying any remuneration to the breeder. With the average land size for Kenyan farmers being two and half hectares, and over $98 \%$ of farm holdings being small (under ten hectares) (Society for International Development, 2006) certainly the country is a candidate to consider size of holding and crop area in implementing farmers' privilege provision.

Some farming practices in Kenya also fall aptly within the ambit of the considerations provided for by the UPOV Council (UPOV, 2009). In potato farming, non-intentional saving of seed onfarm occurs is in volunteer cropping. Because potato harvesting techniques by many farmers are not automated, there is a tendency to leave some potato tubers non-harvested. After harvesting it is not in the practice of these farmers to apply glyphosate or other herbicide with a view to eliminate the non-harvested tubers. When the un-harvested tubers germinate, farmers tend not to uproot this volunteer potato crop depending on the other crop planted. The volunteer crop is seen as an additional source of food and income. Given that this saving of seed is a by-effect of harvesting practices and does not lead to marketing at any serious scale at the present, the

\footnotetext{
108 Author's own analysis.

${ }^{109}$ Article 14 of Council Regulation (EC) No. 2100/94 on Community Plant Variety Rights.
} 
practice should be considered to be in line with the farmers' privilege. However, because the 2012 SPVA Amendment as currently drafted does not give any specific consideration to any farming practices then this practice would constitute infringement of PBRs if protected varieties are involved.

Finally, is the question of balancing the farmers' privilege provision with farmers' rights obligations under the IT. As at the time Kenya acceded to the IT in 2003 the 1972 SPVA was already in place. At the time practices such as saving, selling and exchange of seed between farmers were already taking place and not explicitly prohibited under the 1972 SPVA as long as it was not on a commercial scale. The fact that the 1972 SPVA was not amended to prohibit these activities with respect to protected varieties can be assumed to have been an implicit recognition and implementation of its farmers' rights obligations under the IT. Now some aspects of farmers' rights such as exchange and selling of seed from protected material are expressly prohibited. This prohibition can only be seen as a limitation of farmers' rights and not only with respect to seed selling and exchange, but also in other areas. This argument is amplified by the fact that of the list of farmers' rights practices that are enumerated under Article 9 of the IT, only protection of indigenous knowledge associated with indigenous species is specifically mentioned in the 2012 SPVA Amendment as one of the core functions of the NPGRC. The right to equitably participate in sharing benefits arising from utilization of PGRFA and the right to participate in making decisions, at the national level on matters related to the conservation and sustainable use of PGRFA are specifically not addressed in the 2012 SPVA Amendment. While sharing of benefits arising from utilization of genetic resources generally is addressed in the biodiversity legislation, ${ }^{110}$ the fact PGRFA specific legislation regulating access has now been put in place puts in doubt the extension and application of the biodiversity legislation to PGRFA matters. The Indian PBRs legislation again may provide inspiration to Kenya in seeking ways of balancing farmers' privilege and farmers' rights. Section 39 of the Indian PBRs legislation allows farmers to save, use, sow, resow, exchange, share and sell farm produce of a protected variety except sale of branded seeds under a commercial market arrangement. Further, farmers are not only protected from innocent infringement, but can also through the legislation claim for compensation where a protected variety fails to give the expected yield under given conditions, as may be claimed by the breeder of the variety.

\footnotetext{
${ }^{110}$ Environmental Management and Co-ordination (Conservation of Biological Diversity, Access to Genetic Resources and Benefit Sharing) Regulations, 2006.
} 
Table 4 below is summary of the salient features and variations between UPOV 1978, UPOV 1991 and the Kenya PBRs legislation.

Table 4

\begin{tabular}{|c|c|c|c|}
\hline Issues & UPOV 1978 & UPOV 1991 & $\begin{array}{l}\text { Kenya PBRs legislation } \\
\text { Assessment }\end{array}$ \\
\hline $\begin{array}{l}\text { Subject matter } \\
\text { for protection }\end{array}$ & $\begin{array}{l}\text { Number of genera or } \\
\text { species required for } \\
\text { protection to be } \\
\text { increased gradually from } \\
5 \text { at the time of entry } \\
\text { into force to } 24 \text { eight } \\
\text { years later }\end{array}$ & $\begin{array}{l}\text { Increasing number } \\
\text { of genera or species } \\
\text { required to be } \\
\text { protected, from } 15 \text { at } \\
\text { time of entry into } \\
\text { force to all genera } \\
\text { and species } 10 \text { years } \\
\text { later (5 years for } \\
\text { members of UPOV } \\
1978 \text { or earlier } \\
\text { UPOV Acts). }\end{array}$ & $\begin{array}{l}\text { PBRs may be extended to } \\
\text { varieties of all plant genera } \\
\text { and species. The } \\
\text { graduated approach of } \\
\text { UPOV } 1991 \text { is not } \\
\text { provided for. }\end{array}$ \\
\hline $\begin{array}{l}\text { Conditions for } \\
\text { protection }\end{array}$ & $\begin{array}{l}\text { Novelty, distinctness, } \\
\text { homogeneity, and } \\
\text { stability. }\end{array}$ & $\begin{array}{l}\text { Novelty, distinctness, } \\
\text { uniformity, and } \\
\text { stability. }\end{array}$ & $\begin{array}{l}\text { Conditions similar to } \\
\text { UPOV 1978. In addition } \\
\text { agro-ecological value of } \\
\text { the variety must surpass } \\
\text { that of existing varieties. }\end{array}$ \\
\hline $\begin{array}{ll}\text { Scope of } \\
\text { protection }\end{array}$ & $\begin{array}{l}\text { Production for purposes } \\
\text { of commercial } \\
\text { marketing; offering for } \\
\text { sale; and marketing of } \\
\text { the propagating material } \\
\text { of the plant variety. } \\
\text { Protection covers } \\
\text { vegetative or } \\
\text { reproductive propagating }\end{array}$ & $\begin{array}{l}\text { Production or } \\
\text { reproduction; } \\
\text { conditioning for the } \\
\text { purposes of } \\
\text { propagation; offering } \\
\text { for sale; selling or } \\
\text { other marketing; } \\
\text { exporting; importing } \\
\text { or stocking for any }\end{array}$ & milar to UPOV 1991. \\
\hline
\end{tabular}




\begin{tabular}{|c|c|c|c|}
\hline & $\begin{array}{l}\text { material, as such, of the } \\
\text { variety. }\end{array}$ & $\begin{array}{l}\text { of these purposes, of } \\
\text { propagating materials } \\
\text { of the variety. }\end{array}$ & \\
\hline $\begin{array}{l}\text { Minimum } \\
\text { exclusive } \\
\text { rights in } \\
\text { harvested } \\
\text { material }\end{array}$ & $\begin{array}{l}\text { No such obligation, } \\
\text { except for ornamental } \\
\text { plants used for } \\
\text { commercial propagating } \\
\text { purposes. }\end{array}$ & $\begin{array}{l}\text { Protection may also } \\
\text { cover the harvested } \\
\text { product, if obtained } \\
\text { through } \\
\text { unauthorized use of } \\
\text { propagating material, } \\
\text { and if the breeder } \\
\text { has had no } \\
\text { 'reasonable } \\
\text { opportunity' } \\
\text { exercise his right in } \\
\text { relation to the } \\
\text { propagating material. } \\
\text { Protection may also } \\
\text { extend to products } \\
\text { made directly from } \\
\text { harvested material of } \\
\text { the protected variety. }\end{array}$ & Similar to UPOV 1991 \\
\hline $\begin{array}{l}\text { Prohibition on } \\
\text { dual } \\
\text { protection } \\
\text { with patent }\end{array}$ & $\begin{array}{llr}\text { Allowed } & \text { for } & \text { same } \\
\text { botanical } & \text { genus } & \text { or } \\
\text { species. } & & \\
& & \end{array}$ & Not prohibited & Not prohibited. \\
\hline $\begin{array}{l}\text { Breeder's } \\
\text { exemption }\end{array}$ & $\begin{array}{l}\text { Recognized. Breeders } \\
\text { free to use protected } \\
\text { variety to develop a new } \\
\text { variety. However, when } \\
\text { the repeated use of the } \\
\text { variety is necessary for } \\
\text { the commercial } \\
\text { production of another } \\
\text { variety, the breeder's }\end{array}$ & $\begin{array}{l}\text { Recognized. But } \\
\text { breeding and } \\
\text { exploitation of } \\
\text { varieties "essentially } \\
\text { derived" from earlier } \\
\text { variety and varieties } \\
\text { not distinguishable } \\
\text { from the protected } \\
\text { variety require right }\end{array}$ & $\begin{array}{l}\text { Recognized. Breeder free } \\
\text { to use protected variety } \\
\text { for research purposes in } \\
\text { his own nursery. But } \\
\text { breeding and exploitation } \\
\text { of varieties "essentially } \\
\text { derived" from earlier } \\
\text { variety and varieties not } \\
\text { distinguishable from the }\end{array}$ \\
\hline
\end{tabular}




\begin{tabular}{|l|l|l|l|}
\hline \multirow{2}{*}{ privilege } & authorization is required. & holder's & $\begin{array}{l}\text { protected variety require } \\
\text { right } \\
\text { authorization. }\end{array}$ \\
\hline authorization.
\end{tabular}

Author's analysis and also adaptation from Helfer, L.R., Intellectual Property Rights in Plant Varieties: an Overview with options for National Governments, FAO Legal Papers Online 31, July 2002 and also from Santilli, J. (2012). Agrobiodiversity and the Law: Regulating Genetic Resources, Food Security and Cultural Diversity. Earthscan, Oxon.

\subsection{Conclusion}

This chapter has analyzed the Kenyan PBRs regime against international obligations in relation to smallholder farmers in Kenya. It finds that whereas the objective of amending the PBRs regime has been to comply with UPOV 1991, this objective is not entirely met. Not fulfilled entirely also is the initial objective of introducing PBRs legislation to Kenya: to enable local farmers access, high value more yielding foreign varieties. The process of compliance with UPOV 1991 is also constitutionally questionable for not having followed the laid out procedures.

In the process of complying with UPOV 1991, the 2012 SPVA Amendment seems oblivious to other international obligations in place, particularly those concerning farmers' rights as imposed by the IT. Thus previously de facto permissible activities such as seed selling and exchange by 
farmers from their own harvests are now prohibited. Seed saving is also allowed subject to conditions that have not been elaborated. Yet, other countries that have brought their legislation in line with UPOV 1991 have still found ways to accommodate the interests of various categories of farmers and different seed systems that are in place. While innovatively, the legislation on one hand provides for protection of indigenous seeds and plant varieties, on the other hand, it fails to elaborate mechanisms in which this protection may be actualized, and in a manner that also takes into account the PBRs system in place.

The fact that the 2012 SPVA Amendment has not made provision for among others, private and non-commercial use- a compulsory exception under UPOV 1991 presents a chance for review. Such a review would provide an opportunity for all international obligations that Kenya is a party to as well as implications that the legislation may have on smallholder farmers to be taken into account. 


\title{
Chapter 4: Opportunities and threats to barmonization of national plant breeders' rights legislations through regional agreements: ARIPO and SADC. ${ }^{111}$
}

\begin{abstract}
Currently, there are two separate initiatives to establish regional PBRs registration systems in Africa. In one of the initiatives under the aegis of the African Regional Intellectual Property Organization (ARIPO), a PBRs registration instrument was adopted in July 2015, while in the other initiative under the Southern African Development Community (SADC), negotiations are underway. These developments are occurring notwithstanding that most of the countries that are members to these regional organisations, being least developed, are not under obligation to provide for this protection under the 1995 World Trade Organization Agreement on Trade Related Aspects of Intellectual Property Rights (TRIPS Agreement) until 2021. So far, the regional instruments are in accordance with the 1991 Act of the International Union for the Protection of New Varieties of Plants (UPOV 1991), whose standards were developed to fit developed country seed systems. The processes for the development of these regional PBRs instruments have each received criticisms, as the views and practices of smallholder farmers appear not to bave been sufficiently taken into account. In particular, an unaddressed issue is that 21 of the 26 ARIPO and SADC countries are parties to the International Treaty on Plant Genetic Resources for Food and Agriculture (IT), which demands its member states to take measures to protect and promote farmers' rights. Furthermore, serious implementation hurdles are looming ahead in the light of dual memberships to ARIPO and SADC by some countries, and conflicts between the newly developed and proposed instruments and already existing national PBRs legislations in some of these countries. This chapter examines the opportunities and threats to implementation of these two regional instruments and makes some recommendations on how the emerging problems may be addressed.
\end{abstract}

\subsection{Introduction}

Africa's plant breeders' rights (PBRs) landscape currently consists of a few scattered national systems across the continent, ${ }^{112}$ and two regional regimes one under the umbrella of the Organisation Africaine de la Propriété Intellectuelle (OAPI) serving seventeen mainly Francophone

\footnotetext{
${ }^{111}$ This Chapter is based on the article published as: Munyi Peter, Bram De Jonge and Bert Visser (2016). Opportunities and Threats to Harmonisation of Plant Breeders' Rights in Africa: ARIPO and SADC. African Journal of International and Comparative Law, Volume 24 Issue 1, Page 86-104.

112 These include Egypt, Kenya, Mozambique, South Africa, Tanzania, Morocco, Tunisia, Zambia and Zimbabwe.
} 
countries $^{113}$ and the other under the African Regional Intellectual Property Organisation (ARIPO). The OAPI PBRs registration regime has been in place since 2006. However, the ARIPO instrument- the Arusha Protocol for the Protection of New Varieties of Plants (the Arusha Protocol) was adopted in July 2015 and according to its Article 40(3) will enter into force twelve months after at least four countries deposit their instruments of ratification or accession. While no such instruments have been deposited as at $1^{\text {st }}$ October 2015, five countries have signed the Protocol. ${ }^{114}$ A third regional PBRs system, under the aegis of the Southern African Development Community (SADC) is also under negotiations. ARIPO and SADC have a combined membership of 26 countries. Should the negotiations towards the conclusion of the regional instrument under SADC be successful and all ARIPO and SADC member states each ratify its respective protocol, a regional PBR system will become available in at least 40 African countries. The Arusha Protocol and the proposed Protocol for the Protection of New Varieties of Plants in the SADC Region (the SADC draft), do not intend to replace the national PBRs registration systems already in place in some ARIPO and SADC member countries.

The United Nations classifies 17 out of the 26 countries constituting the ARIPO and SADC blocs as Least Developed Countries (LDCs) (see Table 5). Fourteen of these LDCs are also members of the World Trade Organization (WTO). In view of their special needs, and the desire to create a viable technological base, LDCs who are members of the WTO are under no obligation to put in place measures to protect PBRs as required under the WTO Trade Related Aspects of Intellectual Property Rights (TRIPS Agreement) until 1 July $2021 .{ }^{115}$ In this context, it is not surprising that only three out of the 14 LDCs, -Mozambique, Tanzania and Zambia, currently have in place national legislation to protect PBRs. The emerging regional PBRs systems may lead to a situation in which, - should the 11 other countries adopt either the Arusha Protocol $^{116}$ or the SADC draft; these countries would unnecessarily comply with international

\footnotetext{
113 Established under the Bangui Agreement in 1977, OAPI is an intellectual property organisation whose member states include Benin, Burkina Faso, Cameroon, Central Africa Republic, Chad, Congo, Ivory Coast, Equatorial Guinea, Gabon, Guinea, Guinea-Bissau, Mali, Mauritania, Niger, Senegal, Togo and Comoros. Annex $X$ of the Bangui Agreement covers plant breeders' rights. It is notable that in 2014, OAPI became a member of UPOV.

${ }^{114}$ The five countries are Ghana; Mozambique; Sao Tome \& Principe; Tanzania; and, The Gambia. The Protocol will remain open for signature to ARIPO member countries, and countries members of the African Union until December 31, 2015.

${ }^{115}$ Council for Trade Related Aspects of Intellectual Property Rights Decision IP/C/64 of 11 June 2013. Note that the extension could also be moved beyond 2021.

${ }^{116}$ It is notable that four of the five countries that have signed the Arusha Protocol (Mozambique, Sao Tome \& Principe, Tanzania and The Gambia) are LDCs. Mozambique and Tanzania have national PBR systems in place.
} 
obligations that may reduce their flexibility in dealing with their various economic constraints, including their divergent agricultural production systems.

It is notable that the PBRs standards proposed for inclusion in the Arusha Protocol and the SADC draft are those contained in the 1991 Act of the International Convention on the Protection of New Varieties of Plants (UPOV 1991). The PBRs standards of UPOV have been set by the largely developed countries membership of UPOV in 1991 in response to the needs of their agricultural systems. The majority of agricultural systems in the ARIPO and SADC countries are significantly different from those in developed countries. Until now, only two of the ARIPO and SADC member countries are a party to UPOV $1991 .{ }^{117}$ South Africa is a party to a 1978 version of UPOV. ${ }^{118}$ The PBR standards of this older convention are not as strict as those of UPOV 1991, and therefore may be more suitable to African countries. However, UPOV 1978 is no longer open for new members. Although both the ARIPO and SADC draft regional instruments seek to provide standards for protection of PBRs at par with UPOV 1991, the standards so proposed are not identical. For the countries that are members of both ARIPO and SADC this is likely to present an implementation challenge.

At the same time, 21 of the countries constituting ARIPO and SADC are parties to the International Treaty on Plant Genetic Resources for Food and Agriculture (IT) ${ }^{119}$ (see Table 5). The objectives of the IT are the conservation, sustainable use and fair and equitable sharing of benefits arising from the use of plant genetic resources for food and agriculture. ${ }^{120}$ These objectives are fulfilled through among others, the exercise of farmers' rights. Farmers' rights refer to the "enormous contribution that local and indigenous communities and farmers of all the regions of the world have made and will continue to make for the conservation of plant genetic resources for food and agriculture, recognizing that these genetic resources are the basis for food production." ${ }^{121}$ The exercise of farmers' rights includes protection of traditional

However, The Gambia and Sao Tome \& Principe do not while Ghana-a developing country, has a PBR system under development.

${ }^{117}$ The United Republic of Tanzania deposited its instrument of accession to the UPOV Convention on October 22,2015 , and became the $74^{\text {th }}$ UPOV member on November 22, 2015. Kenya on the other hand, deposited its instrument of accession to the UPOV Convention on April 11, 2016 with the UPOV 1991 Convention entering into force for Kenya on May 11, 2016.

118 Notwithstanding that South Africa is a member of UPOV 1978 its PVP law as amended in 1996 closely mirrors UPOV 1991.

${ }^{119}$ Only Botswana, Gambia, Mozambique, Somalia and South Africa are not parties to the International Treaty on Plant Genetic Resources for Food and Agriculture.

${ }^{120}$ International Treaty on Plant Genetic Resources for Food and Agriculture (IT), Article 1.

${ }^{121}$ IT, Article 9. 
knowledge, the right to participate in the sharing of benefits arising from the use of plant genetic resources for food and agriculture, and the right to participate in making decisions, at the national level, relevant to the conservation and sustainable use of plant genetic resources for food and agriculture. ${ }^{122}$ The rights of farmers to save, use, exchange and sell farm-saved seed/propagating material are also considered fundamental to the realisation of farmers' rights. ${ }^{123}$ Yet, these rights are "subject to national law and as appropriate." ${ }^{124}$ As PBRs may restrict certain activities being undertaken by farmers where protected varieties are concerned, this presents a potential conflict between farmers' rights and PBRs.

A similarity shared between ARIPO and SADC countries concerns the characteristics of their farmers. $80 \%$ of the farmers in most of these countries are smallholders (Livingston et al, 2011). With over $75 \%$ of Sub-Saharan Africa consisting of rural populations, and rural communities being home to $75-80 \%$ of the poor (Livingston et al, 2011), it may be concluded that a majority of the farmers in these countries is deprived and poor. Traditional practices regarding saving, using, exchanging and selling farm-saved seed occur widely in these countries and these practices are the basis upon which smallholder farmers rely to obtain seed for most of their crops. In this context it can be noted that the process towards the development of the two regional instruments has been controversial, and has been challenged by a number of civil society organisations and farmers associations. These organisations have persistently claimed that the process is not inclusive and that the intended outcome will not serve the benefit of smallholder farmers. ${ }^{125}$ According to these organisations, these regional instruments "will have significant adverse consequences for small-scale farmers... as well as for food security, agricultural biodiversity... in Africa." 126

From a comparison between the Arusha Protocol and the SADC draft, their relation to the national PBRs registration systems already in existence, plus the farmers' rights provision of the IT, four key issues emerge. These issues are: (a) uncertainty whether the Arusha Protocol and the

\footnotetext{
122 IT, Article 9.

${ }^{123} \mathrm{IT}$, preamble.

${ }^{124}$ IT. Article 1.

${ }^{125} \mathrm{http}$ ///www.grain.org/bulletin board/entries/4802-aripo-s-plant-variety-protection-law-criminalisesfarmers-and-undermines-seed-systems-in-africa (last accessed on 17 July 2014) and http://www.acbio.org.za/index.php/media/64-media-releases/424-new-seed-legislation-spells-disaster-forsmall-farmers-in-africa (last accessed on 17 July 2014).

${ }^{126}$ http://www.grain.org/bulletin board/entries/4802-aripo-s-plant-variety-protection-law-criminalisesfarmers-and-undermines-seed-systems-in-africa (last accessed on 17 July 2014) and http://www.acbio.org.za/index.php/media/64-media-releases/424-new-seed-legislation-spells-disaster-forsmall-farmers-in-africa (last accessed on 17 July 2014).
} 
SADC draft are intended to have a direct legal effect in their respective countries; (b) difficulties arising from an intended uniform application and prohibition of cumulative protection; (c) complexities in the implementation of a farmers' privilege vis-à-vis the IT provision on farmers' rights; and, (d) the relationship with farmers' rights, at the regional and national levels. These four issues are likely to present challenges to the implementation of the Arusha Protocol and the SADC draft (if adopted). This chapter aims to elaborate and discuss these challenges, which so far seem to have been overlooked by academics and policy makers alike, and to provide suggestions on how these challenges may be addressed.

\subsection{Uncertainty on whether the Arusha Protocol and the SADC Draft are intended to have a direct legal effect}

The question whether the Arusha Protocol and the SADC draft are each intended to have a direct legal effect ${ }^{127}$ is fundamental to how the regional PBRs regimes will function for two reasons. First, whether each of these instruments will have direct legal effect is essential in determining the extent to which they will confer rights to individuals in each member state. Second, it is important to determine whether each of these two instruments is capable of conferring UPOV membership to the ARIPO and SADC themselves or member states.

The uncertainty in relation to whether each of the instruments are intended to have direct legal effect stems from the fact that ARIPO and SADC member states consist of both monist and dualist states in relation to how they integrate international treaty law into national provisions. This arises from the legal systems that these countries inherited at the dawn of independence. According to the legal principles of dualist states international law and national law function at two different levels, i.e., international law originating from the intentions of and regulating the relationships between states; and national law regulates the conduct of individuals in a state, or between a state and the individual (Maniruzzaman, 2001). Amongst dualist countries in ARIPO and SADC are those, which inherited a common law or Roman Dutch law system, such as Botswana, Kenya, South Africa, Uganda, Zambia and Zimbabwe. In these countries national implementing legislation is necessary to give the international or regional treaties and conventions effect. In monist states, notably Angola, Mozambique and the Democratic Republic of Congo the situation is different. Here, translation into national law of international obligations is not necessary, and the regional PBRs systems may upon adoption by the country apply directly

127 Article 37 of the Arusha Protocol provides that "breeders' rights shall have uniform effect within the territories of the designated Contacting States where the breeder's rights have been granted." 
to them. This uncertainty stemming from these different legal principles is compounded further by the fact that the regional parent treaties to the Arusha Protocol and the SADC $\mathrm{draft}^{128}$ do not provide specific direction on whether the parent treaties themselves, or Protocols adopted from these treaties such as the regional PBRs instruments, should have a direct legal effect or not.

The parent treaties to which the Arusha Protocol and the SADC draft are anchored, - the Lusaka Agreement and the SADC Treaty, each establish judicial bodies for adjudication of disputes. However, these judicial mechanisms are not open to individual citizens, but only to member states. ${ }^{129}$ From this it can therefore be inferred that direct legal effect was not intended. In other words, it suggests that implementing legislation at the national level is required. However, this issue again is neither explicitly addressed in the parent treaties themselves nor in the Arusha Protocol and the SADC draft. While Article 42 of the SADC draft concerns settlement of disputes among others, between persons in the Member States or between persons and Member States in relation to interpretation and application of the proposed PBRs instrument, the proposed dispute resolution system is not satisfactory. Inasmuch as it provides for negotiation as the first port of call in resolving a dispute, the procedure for negotiation is not provided for. Where negotiation fails and the dispute is submitted to an ad hoc committee appointed by the Ministers, no prescription is made on enforcement of the decision arising. Therefore, discerning the extent and limits of individual rights and obligations to be conferred by the SADC draft is difficult.

As one of the objectives of both the Arusha Protocol and the SADC draft is to create conformity to UPOV 1991, examining the provisions of UPOV 1991 may also aid in unravelling whether direct legal effect is intended. This question is closely related to the question whether conformity of the Arusha Protocol and the SADC draft to UPOV 1991 can confer UPOV membership to ARIPO and SADC themselves or their respective member countries. This was discussed by the UPOV Council in March $2014^{130}$ and it was also the subject of an opinion of the

\footnotetext{
128 The Arusha Protocol is anchored upon the 1976 Agreement on the Creation of an African Regional Intellectual Property Organisation as amended (Lusaka Agreement) and the SADC draft on the 1992 Treaty establishing the Southern African Development Community (SADC Treaty).

${ }^{129}$ Article XIII of the Lusaka Agreement, provides a hierarchical approach towards settlement of disputes relating to application and interpretation of the Agreement first by the Administrative Council and if any party is dissatisfied, by the Council of Ministers. It is upon these two bodies to determine for themselves their own procedures. Similarly, under the SADC Treaty, dispute settlement functions and Treaty interpretation questions are exercised by the Tribunal established under Article 17 thereof.

130 Document C (Extr.)/31/2 dated March 14, 2014. Examination of the Conformity of the draft ARIPO Protocol for the Protection of New Varieties of Plants with the 1991 Act of the UPOV Convention.
} 
World Trade Institute, on behalf of civil society organizations. ${ }^{131}$ Two tests can be applied to assess whether the Arusha Protocol is capable of conferring UPOV membership to ARIPO itself or its member states.

The first test relates to whether through the Arusha Protocol ARIPO is capable of fulfilling implementation measures outlined in Article 30 (1) (i) of UPOV 1991 and therefore attain the status of a Contracting Party. According to Article 30(1)(i) of UPOV 1991, one of the measures necessary to implement the Convention is provision for appropriate legal remedies for the effective enforcement of breeders' rights. According to the World Trade Institute, to effect this measure a country must provide legal measures for the enforcement and implementation of rights. ${ }^{132}$ Where a country wishes to rely on an international treaty such as the Arusha Protocol (or the SADC draft) to fulfil the first test, it must also show that by means of granting direct legal effect through constitutional and domestic case law, effective protection is granted under general procedural rules applicable to intellectual property rights. The UPOV Council when reviewing the draft ARIPO Protocol in 2014, took the view that through Article 35 of the then draft (which is exactly similar in wording of Article $35^{133}$ of the Arusha Protocol), this test was fulfilled. However, the World Trade Institute was of the opinion that ARIPO, comprising the territory of all its member States needs demonstrating that these requirements are met by all its member States either by domestic legislation or by granting direct effect to UPOV Convention rights and, was far from making this demonstration. ${ }^{134}$

The answer whether the Arusha Protocol provides appropriate legal remedies for the effective enforcement of breeders' rights lies in Article 35. Under this article the responsibility to ensure that appropriate enforcement measures are available is left to ARIPO Contracting States, not to ARIPO itself. At present, the Arusha Protocol itself contains no enforcement measures. Of the countries that are ARIPO members that have PBR measures in place, only Kenya and Tanzania can be said to have measures that fulfil Article 30(1)(i) of UPOV 1991. The other ARIPO

\footnotetext{
${ }^{131}$ Letter dated 3 April 2014 from the World Trade Institute to The Berne Declaration available at http://www.apbrebes.org/files/seeds/files/ARIPO\%20UPOV\%20Legal\%200pinion\%200414 0.pdf (last accessed on 31 July 2015).

${ }^{132}$ Letter dated 3 April 2014 from the World Trade Institute to The Berne Declaration available at http://www.apbrebes.org/files/seeds/files/ARIPO\%20UPOV\%20Legal\%200pinion\%200414 0.pdf (last accessed on 31 July 2015).

${ }^{133}$ This Article provides that "The Contracting States shall ensure that accessible and appropriate enforcement measures and dispute settlement mechanisms, sanctions and remedies are available for the effective enforcement of breeders' rights and any other breach of the Protocol."

${ }^{134}$ Document C (Extr.)/31/2 dated March 14, 2014. Examination of the Conformity of the draft ARIPO Protocol for the Protection of New Varieties of Plants with the 1991 Act of the UPOV Convention.
} 
countries cannot completely fulfil this test. Therefore, as presently framed, the Arusha Protocol does not by itself arrange that ARIPO fulfils the requirements of Article 30(1)(i) of UPOV 1991.

The second test relates to the question whether ARIPO as an intergovernmental organization fulfils all the conditions set out in Article 34(1)(b) of UPOV 1991 and therefore acquire capacity to become a party to UPOV. Under Article 34 (1)(b) for an intergovernmental organization such as ARIPO or SADC to become a party it must (1) have competence in respect of matters governed by UPOV 1991 (2) have its own legislation providing for the grant and protection of breeders' rights binding on all its member States and (3) has been authorized, in accordance with its internal procedures, to accede to UPOV 1991.

On this issue, the UPOV Council on the basis of the then draft ARIPO Protocol took the view that the draft ARIPO Protocol fulfilled all the requirements of Article 34(1)(b). It is notable that at the time, the draft ARIPO Protocol provided in its Article 4 that a breeder's right granted under the Protocol would be valid in all contracting states. This provision was further buttressed by another Article (Article 37), which required the breeders' rights to have uniform effect within the territories of all contracting States with any grants, transfers or termination of rights across all territories occurring on a uniform basis. In other words, breeders' rights once granted were to apply in all territories. ${ }^{135}$

As adopted, Article 4 of the Arusha Protocol provides for a designation system, whereby an applicant is now able to designate the Contacting State in which rights may be granted and with the designated country having powers to grant or refuse the right. Furthermore, Article 37 of the Arusha Protocol as adopted while providing that breeders' rights shall have uniform effect in the designated countries, it does not provide unlike at the time the UPOV Council examined the draft protocol on conformity, that breeders' rights may only be granted, transferred or terminated on a uniform basis. This situation has now weakened the ability of the territory for which a right may be enforceable to be identifiable. ${ }^{136}$ As a consequence, ARIPO itself cannot become a member of UPOV.

In sum, if the Arusha Protocol and the SADC draft would each intend to have direct legal effect with a view to provide certainty of rights and obligations accruing to individuals, better clarity

\footnotetext{
135 It is notable that the World Trade Institute took another view again and argued that the draft ARIPO Protocol was not capable of conferring UPOV membership to ARIPO itself as the then draft Protocol would have a limited effect across the ARIPO territory.

136 UPOV 1991 defines a territory where the Contracting party is an intergovernmental organisation, the territory in which the constituting treaty of that intergovernmental organization applies.
} 
should be provided to meet such requirement in these instruments. ARIPO and SADC, as organisations aspiring to UPOV membership, should be able to demonstrate that they have effective mechanisms for the enforcement of breeders' rights. At present such mechanisms are not available, either in the parent treaties or in the Arusha Protocol and the SADC draft.

\subsection{Difficulties arising from intended uniformity application and prohibition of cumulative protection}

While breeder's rights granted under the Arusha Protocol are intended to be protected in the Contracting States an applicant designates, under the SADC draft the rights are intended to apply to all member countries that will ratify the instrument. ${ }^{137}$ Further, the breeder's rights in the SADC draft are intended to have a uniform effect. ${ }^{138}$ Thus while under the Arusha Protocol, an applicant will be able to designate the Contracting States to which the breeder's rights may apply, and the Contracting State may refuse to grant the right, this will not be the case in the proposed SADC PBRs system. Once adopted in the present form, the SADC draft will not enable an applicant for PBRs to choose countries where grants may be applied, akin to what is currently the case in applying for grants of patents and trademarks under the established ARIPO processes. Although it may have been assumed that a breeder interested in registration of PBRs within SADC will be interested in seeking protection in the region as a whole and not in specific countries in a region, this may not always be the case. Where an applicant for PBRs wishes to have the rights available only in some member countries, the national PBRs registration systems in place in these countries should allow for such option. Currently, this will only be the case in seven countries, five of which are in SADC, i.e.- Mozambique, South Africa, Tanzania, Zambia and Zimbabwe, which have such national systems in place. To rely on national registration in few countries rather than on regional registration can hardly be regarded as an effective protection strategy. Yet, due to capacity constraints and implementation costs, enactment of the regional PBRs registration systems may not take place in the short run in those countries with no national systems in place yet.

In the SADC draft, the concept of uniform application is reinforced further by prohibition of cumulative protection, ${ }^{139}$ meaning that where dual registration of PBRs exists national rights shall

\footnotetext{
${ }^{137}$ Arusha Protocol, Articles 4 and 37; SADC draft, Article 3.2.

138 Ibid.

${ }^{139}$ SADC draft, Articles 3.4 and 3.5.
} 
remain ineffective. ${ }^{140}$ This concept is not contained in the Arusha Protocol, and as such within ARIPO countries regional as well as national PBRs can co-exist. ${ }^{141}$

Cumulative protection is normally prohibited on the rationale that unnecessary stacking and duplication of rights in the same jurisdiction should be avoided. Each of these two regional instruments approach the question of cumulative protection as it may result from the granting of rights at the national and regional level differently. While the Arusha Protocol allows cumulative protection of rights at the national and regional levels, this is prohibited in the SADC draft. However, the two instruments appear not to regulate situations where cumulative protection may arise as a result of granting of rights following applications made under each of the two regional instruments themselves. Such case would be realistic, given the Arusha Protocol is not only open for signature to ARIPO member states, but also to others that are members of the African Union. ${ }^{142}$ Already nine countries are parties to both the ARIPO and SADC Agreements, and could potentially, together with others, ratify both of the two regional PBRs instruments. ${ }^{143}$ It is also notable that five of these nine countries do not at present have national PBRs registration systems in place, and should they adopt the regional systems are unlikely to enact national systems in the near future.

An option to enable applicants for PBRs to designate specific countries within each system for which PBRs should apply is therefore important. While the Arusha Protocol provides for such designation, the SADC draft does not. Such designation would reduce conflicts of rights that may arise in situations where an application is filed under both regional systems simultaneously, as the applicant will then be at liberty to choose the preferred regional system to apply in the countries of choice. Further a designation system will also enable countries with robust or near effective PBRs systems at present such as South Africa ${ }^{144}$ (in SADC) and Kenya ${ }^{145}$ (in ARIPO), to keep current national PBRs systems relevant. A designation system is already in place for the registration of patents, trademarks and designs under the ARIPO through and the Harare and Banjul Protocols, and it appears parties are not dissatisfied with it.

\footnotetext{
${ }^{140}$ SADC draft, Articles 3.4 and 3.5.

${ }^{141}$ Article 38 of the Arusha Protocol provides that the Protocol shall be without prejudice to the right of the Contracting States to grant national plant breeder's rights for plant varieties.

${ }^{142}$ Arusha Protocol, Article 42.

${ }^{143}$ Botswana, Lesotho, Malawi, Mozambique, Namibia, Swaziland, Tanzania, Zambia and Zimbabwe. In fact, Mozambique has already signed the Arusha Protocol.

${ }^{144}$ As at 21 July 2014, 7,033 PBR grants were registered in South Africa. Information available from http://www.upov.int/pluto/en/ (last accessed on 1 August 2014).

${ }^{145}$ As at 21 July 2014, 1,338 PBR grants were registered in Kenya. Information available from http://www.upov.int/pluto/en/ (last accessed on 1 August 2014).
} 
Another issue to be addressed is that the aspired uniformity application of the Arusha Protocol and the SADC draft suggests that a single enforcement action will apply to all countries. However, as post-grant PBRs enforcement is left to the competencies of national authorities of the respective member states, there is no guarantee that at the national level uniform interpretation of each of these instruments will be achieved. Evidence of infringement is an essential condition for pursuing civil claims. Collecting such evidence may not be equally feasible in the different member countries. Accessing information necessary to prove infringement forms a prerequisite for action, and information may be accessible at varying degrees from plant quarantine and customs authorities in the different member countries. In other words, it is unclear whether already existing national measures and standards may be effectively applied in enforcing rights arising from these regional instruments. For example, in Kenya the anticounterfeiting legislation ${ }^{146}$ is capable of being applied to deal with infringements arising from nationally granted PBRs, and could potentially be extended to cover those PBRs granted under the Arusha Protocol. In summary, an instrument may receive varying interpretations between countries and this may affect the exercise of rights across borders.

In order to make the Arusha Protocol and the SADC draft more effective, enabling provisions could be developed in these instruments dealing with enforcement measures ${ }^{147}$ and civil proceedings ${ }^{148}$ respectively with a view to provide for specific details relating to evidence and preservation thereof, the right to information and the nature and extent of corrective measures. At the time of enactment of a directive on enforcement of intellectual property rights in $2004,{ }^{149}$ the European Union was confronted with disparities among its member states on enforcement of intellectual property rights, including on PBRs. These disparities were found to result in fragmentation and weakening of the internal market, thus reducing business confidence. ${ }^{150}$ Despite the enactment of the directive a study commissioned by the European Commission later found that disparities between EU member states still existed in enforcement of PBRs, particularly in dealing with compensation, restitution and damages. ${ }^{151}$ This experience in the European Union demonstrates that achieving uniformity of enforcement is a demanding task

\footnotetext{
${ }^{146}$ Anti-Counterfeit Act, 2008.

${ }^{147}$ Arusha Protocol, Article 35.

${ }^{148}$ SADC draft, Article 43.

${ }^{149}$ Directive 2004/48/EC of the European Parliament and of the Council of 29 April 2004 on the enforcement of intellectual property rights.

150 Ibid.

${ }^{151}$ Evaluation of the Community Plant Variety Right Acquis-Final Report. A report by GHK Consulting with ADAS UK for DG SANCO, April 2011. Report available at http://ec.europa.eu/food/plant/plant property rights/evaluation/docs/cpvr evaluation final report en.pdf (last accessed on 1 August 2014).
} 
requiring intervention at different levels, and some for example, judicial systems lie beyond the realm of intellectual property rights legislation.

\subsection{Challenges in implementation of the farmers' privilege}

The rights that accrue to a breeder following the granting of PBRs are not absolute but subject to limitations, and the scope of rights granted to a breeder has been changing over time. Through its various conventions on PBRs since 1961, UPOV has been setting the standards in this regard.

In UPOV 1991, whose standards the regional instruments seek to meet, the exemptions to the breeder's right are laid out in Article 15. The farmers' privilege is one of the exemptions provided for under this Article and states that "each Contracting party may, within reasonable limits and subject to the safeguarding of the legitimate interests of the breeder, restrict the breeder's right in relation to any variety in order to permit farmers to use for propagating purposes, on their own holdings, the product of the harvest which they have obtained by planting, on their own holdings, ...”. In order words, through this exemption countries may allow farmers to use farm-saved seed of a protected variety on their own holding only (i.e. no bartering, gift, exchange or sell of farm-saved seed is permissible) and subject to safeguarding the interest of the breeder (e.g. this may entail remuneration to the breeder). Because of its narrow scope, the UPOV's farmers' privilege has been extensively criticised by civil society organisations, which hold that this narrow exemption favours the interests of commercial breeding companies above the interests of smallholder farmers in developing countries who depend on the use and exchange of farm-saved seed for their seed and food security. Introduction of UPOV 1991 standards is therefore feared to undermine farmers' rights as formulated under Article 9 of the IT (as discussed in the next section). ${ }^{152}$

In implementing the farmers' privilege, the Arusha Protocol includes a "list of agricultural crops and vegetables with a historical common practice of saving seed in Contracting States." ${ }^{, 153}$ Fruits, ornamentals, other vegetables or forest trees do not qualify for this exemption. ${ }^{154}$ Further details

\footnotetext{
${ }^{152}$ Alliance for Food Sovereignty in Africa: media briefing AFSA appeal to ARIPO, AU and UNECA for protection of farmers' rights and right to food. See http://www.acbio.org.za/index.php/media/64-media-releases/462alliance-for-food-sovereignty-in-africa-media-briefing-afsa-appeals-to-aripo-au-and-uneca-for-protection-offarmers-rights-a-right-to-food (last accessed on 11 September 2014).

${ }^{153}$ Arusha Protocol, Article 22(2).

${ }^{154}$ Arusha Protocol, Article 22(2).
} 
by which this exemption may be applied, such as setting levels of remuneration to the breeder by different categories of farmers is left to the Protocol implementing regulations. ${ }^{155}$ Taking into account historical practices in Contracting States it is likely that there will be variation in the ARIPO countries between the types of crops and nature of farmers that will qualify for the farmers' privilege.

In the SADC draft, breeder's rights do not extend to "acts done by a farmer to save, use, sow, re-sow or exchange for non-commercial purposes his or her farm produce including seed of a protected variety, within reasonable limits subject to the safeguarding of the legitimate interests of the holder of the breeder's right..."156 What constitutes reasonable limits and means of safeguarding the legitimate interests of the breeder has not been prescribed in the draft instrument. Other than stating that these shall be prescribed, the draft instrument does not mention whether they will be prescribed in the implementing regulations to the draft, or at the national level in member countries. Should the latter interpretation be made in member countries, then between-country variation of what is considered to be 'reasonable limits' and 'legitimate interests of the holder of breeder's right' is likely to arise.

In addition to the potentially different interpretations of the UPOV's farmers' privilege in both regional instruments, the national PBRs systems already in place indeed all take different approaches to implementing the farmers' privilege. Most in line with the Arusha Protocol provision is the Tanzanian legislation, which is similar in words but leaves the responsibility of specifying the qualifying agricultural crops (which exclude fruits, ornamental crops, most vegetables and forest trees) to the Minister. Setting reasonable limits and the means of safeguarding the legitimate interests of the holder of the breeder's right is left to be provided for by the implementing regulations. ${ }^{157}$ In Kenya and South Africa, their current legal provisions on the farmers' privilege mirror UPOV 1991, which is similar but not exactly the same as the Arusha Protocol and quite different from the SADC one, particularly with respect to the possibility for exchange which is upheld in the latter draft instrument. ${ }^{158}$ In addition, where the 2015 version of the proposed South Africa PBR legislation mirrors UPOV 1991 it requires the Minister to specify the following criteria with respect to the farmers' privilege: category of farmers; plants; uses to which the protected variety may be put; and, where applicable conditions

\footnotetext{
${ }^{155}$ Arusha Protocol, Article 22(3).

${ }^{156}$ SADC draft, Article 28(d).

157 Tanzania 2012 Plant Breeders' Rights Act, section 31(3).

${ }^{158}$ Kenya Seeds and Plant Varieties (Amendment) Act 2012, section 17; South Africa Plant Breeders' Rights Act of 1976 , section $26(3)(d)$.
} 
of royalty payments and labelling requirements. ${ }^{159}$ This proposed provision creates the possibility of the regulator providing more space for smallholder farmer practices within the farmers' privilege in South Africa. The other two SADC countries that have a national PBRs system in place (Zambia and Zimbabwe) have instead incorporated provisions that resemble more closely the farmers' rights provisions of the IT (see next section).

These differences are likely to cause implementation problems at three levels. At the level of the regional systems themselves, this differentiation is likely to bring about problems for countries that are members of both ARIPO and SADC. These countries will be confronted with a dilemma on which standard regarding the farmers' privilege to adopt at the national level. The second level of implementation problems may emerge in those countries that already have in place national standards for the implementation of the farmers' privilege, which may not be in line with what is now proposed at the regional level by their respective member organisations. The third level of implementation problems in relation to the farmers' privilege will be in relation to regulating farmers' rights. Farmers' rights are the subject of analysis in the next section.

In light of the above, it may appear difficult to uniformly implement the farmers' privilege across the member states. The Arusha Protocol provides that the Administrative Council shall draw up a list of 'agricultural crops... with a historical common practice of saving seed' in order to implement the farmers' privilege. Such a list is likely to reveal that variation exists among ARIPO countries regarding the role of such crops. This may lead to a situation in which a variance of implementation of the farmers' privilege between countries will occur. Similarly, in setting levels of remuneration to be paid by small-scale and large-scale farmers, a uniform definition of size and income of these categories of farmers may not be feasible across the ARIPO countries, given the economic differences that exist between these countries. Similarly, under the SADC draft, the use of the phrases 'reasonable limits' and 'legitimate interests of the holder of the breeder's right' may form a basis for variances between countries in interpreting these principles, given the huge differences in economic conditions between SADC countries. ${ }^{160}$ Regarding uniform interpretation between the two instruments, finding a level of uniformity at the regional level in order to accommodate dual-membership countries may not be feasible given that the two instruments do not refer to each other.

\footnotetext{
${ }^{159}$ South Africa Plant Breeders' Rights Bill of 2015, section 9(1)(d) and (2).

${ }^{160}$ For example, SADC encompasses both Malawi and South Africa. While Malawi is classified as an LDC, South Africa is already for years a middle income country. According to the World Bank, in 2013, Malawi had a GDP per capita of USD 226 while South Africa in the same year had a GDP per capita of USD 6,617.
} 


\subsection{Challenges in the implementation of farmers' rights}

The UPOV's farmers' privilege has been subject to strong criticism amongst, in particular, civil society organisations, which hold that this provision undermines the traditional practices of farmers to save, use, sell and exchange seed, and for that manner, does not recognise farmers' rights as formulated under Article 9 of the IT. In this international agreement, farmers' rights refer to the "enormous contribution that local and indigenous communities and farmers of all the regions of the world... have made and will continue to make for the conservation and development of plant genetic resources for food and agriculture..."161, recognising that these genetic resources are the basis for food production. The IT outlines some of the measures that should be taken to protect farmers' rights at the national level. In brief these measures are: protection of traditional knowledge relevant to, the right to equitably participate in sharing benefits arising from utilisation of, and the right to participate in decision making at the national level, on all matters related to the conservation and sustainable use of plant genetic resources for food and agriculture. ${ }^{162}$ National measures may also include allowing farmers to save, use, exchange and sell farm saved seed/propagating material. ${ }^{163}$ However, it is left to countries to take such protective measure "subject to national law and as appropriate." This would allow countries to implement the concept of farmers' rights subject to their national needs and priorities. It is obvious that some of these measures, and in particular those concerning saving, using, exchanging and selling farm-saved seed, present a serious tension between the IT's provisions on the one hand, and the Arusha Protocol and the SADC draft on the other, in as far as protected varieties are concerned (De Jonge, 2014). At present, 21 out of the 26 ARIPO and SADC member states are also member of the IT and, thus, are under the obligation to take measures to implement farmers' rights in their countries.

The challenge in implementing farmer's rights first arises at the regional level, with each of the two regional instruments. Regarding the Arusha Protocol, one of the criticisms levelled against this instrument has been that it does not adequately take into account farmers' rights (African Centre for Biosafety (ACB), 2012). ARIPO's response has been that farmers' rights are addressed in a separate instrument, i.e., the Swakopmund Protocol on the Protection of Traditional Knowledge and Expression of Folklore (the Swakopmund Protocol). ${ }^{164}$ Yet, the Swakopmund Protocol addresses farmers' rights in the narrower context of protection of

\footnotetext{
161 IT, Article 9.1.

162 IT, Article 9.2.

163 IT, Article 9.3.

164 Document ARIPO-CM-XIV-8-ANNEX 1.
} 
traditional knowledge but it does not address farmers' right to save, use, exchange and sell farmsaved seed. The SADC draft has apparently, and under pressure of civil society organisations, tried to integrate some aspects of farmers' rights in the context of its farmers' privilege in Article 28(d) (Alliance for Food Sovereignty in Africa, AFSA, 2014). However, the right of a farmer to save, use, sow, re-sow or exchange seed is not absolute but is subject to three conditions: the act must be (a) for non-commercial purposes, (b) within reasonable limits, and (c) subject to safeguarding the legitimate interests of the holder of the breeders' right.

In addition to the consequences of these ITPGRFA obligations, all country members of ARIPO and SADC, being also members of the African Union will have to deal with the African Model Legislation for the Protection of the Rights of Local Communities, Farmers and Breeders, and for the Regulation of Access to Biological Resources. This model legislation was endorsed by the Heads of States of the then Organisation of African Unity in 1998 with a view to ensure that breeders' rights should not undermine, among others, farmers' rights. To that end, the model law describes in detail the rights of farmers and with respect to farmer-saved seed allows farmers to "collectively save, use, multiply and process farm-saved seed of protected varieties." 165 It further states that farmers shall not sell farm-saved seed of a protected variety in the seed industry on a commercial scale. Although some African countries have incorporated parts of the (non-binding) African Model Law in their (draft) PBRs laws, the model legislation has been ignored in most countries (Munyi, et al, 2012).

In dealing with both regional and national level implementation of farmers' rights, countries are likely to face challenges in two scenarios. The first scenario will confront the 19 countries that have no PBRs systems in place (see Table 5). In these countries, farmers' practices regarding the saving, using, exchanging and selling of seed and propagating material are a norm, providing the main source of seed and planting material for smallholder farmers (Andersen, 2006). These countries will, by subscribing to either or both of the two regional instruments, be required to limit these practices to the extent permissible by the respective instruments. In other words, the countries will be required to prevent farmers from undertaking some age-old practices that have been part of their culture for many years with respect to protected varieties. In addition, countries that have already incorporated farmers' rights measures in their national regimes and are also members of either ARIPO or SADC, or both will be confronted with the tensions between the respective national and regional clauses. Zambia and Zimbabwe fall in this category.

\footnotetext{
${ }^{165}$ Africa Model Legislation for the Protection of the Rights of Local Communities, Farmers and Breeders, and for the Regulation of Access to Biological Resources, Article 26.
} 
The Zambian legislation provides in explicit terms that "a farmer may save exchange or use part of the seed from the first crop of a plant which the farmer has grown for sowing in the farmer's farm to produce a second and subsequent crop." ${ }^{166}$ In Zimbabwe any farmer who derives at least $80 \%$ of his annual gross income from farming on communal land or resettlement land ${ }^{167}$ may save, use, exchange and sell farm-saved seed. In these countries uncertainty on the standards allowable for farmers' rights will only increase.

There are some approaches that these regional instruments could take with a view to address these challenges. First, an appreciation is necessary that the subject matter for breeders' rights and farmers' rights is one and the same: seeds and planting material. Thus, making provisions for PBRs and farmers' rights in a single instrument with a view to create the right balance between breeders and farmers is recommended as opposed to providing for the same in two different instruments. Also, none of these rights are absolute and instead are subject to limitations. Inasmuch as the individuals exercising these rights are different, either of these rights is subject to limitations to the extent that the other is prevailing. This is even a more important reason why provision of these rights in a single instrument is necessary. Dissimilarities in memberships to the Swakopmund Protocol on the one hand, and the Arusha Protocol and the SADC draft on the other may arise, as a country may be a party to one and not to the other instruments. This may lead to imbalances regarding the respective rights in member countries.

Second, the Arusha Protocol and the SADC draft need to take into account that breeders' rights as described in UPOV 1991 were crafted for a specific category of farmers, i.e. commercial farmers, mainly taking into account the situation in developed countries. None of the ARIPO and SADC members are developed countries, and the vast majority of farmers in these countries are smallholders that do not participate in commercial value chains. As such, ARIPO, SADC and their member states should consider restricting the breeders' rights to apply to those commercial farmers who formed the reference during the adoption of UPOV 1991. Mahop et al (2013) and Louwaars and De Boef (2013) have argued that this could for example, be done by differentiating between restrictions on the use of protected varieties for different farmers and/or crops. Commercial farmers, for instance, may only be allowed to use farm-saved seed for some crops subject to paying a reduced royalty to the breeder, while smallholder farmers that do not produce for commercial markets would be allowed to use, exchange and sell on the local market farm-saved seed of protected food crop varieties among each other. Given the fact that the

\footnotetext{
${ }^{166}$ Zambia Plant Breeder's Rights Act (2007), section 8(1)(c).

${ }^{167}$ Zimbabwe Plant Breeders Rights Act (2001), section 17(3)(d).
} 
Arusha Protocol has already been adopted the proper place for this differentiation to be made would be in the implementing regulations to the Protocol. Article 28(d) of the SADC draft also needs to be specified with a view to provide more clarity to this differentiation, which may also be done through the implementing regulations once the SADC protocol has been adopted. ${ }^{168}$

Third, it is necessary to recognise that farmers' rights are broader than simply the right to save, use, sell and exchange seed and planting material. Sharing benefits arising from the utilisation of plant varieties incorporating farmers' varieties, as well as participating in making decisions relating to conservation and sustainable use of plant genetic resources for food and agriculture are equally important provisions. Mechanisms to realize these farmers' rights could also be built in the implementation regulations to the Arusha Protocol and in the SADC draft. Already, it is important that farmers' participation is strengthened in the current negotiation processes of both the SADC draft and the implementing regulations to the Arusha Protocol as that would itself be a realisation of farmers' rights. Civil society organisations have been complaining that the negotiations of the Arusha Protocol and the SADC draft have not been transparent neither inclusive. Also, given that 21 out of the 26 ARIPO and SADC countries are parties to the IT should mean that these two organisations should consider at the very least becoming observers to the IT with a view to acquaint themselves with and also participate in the discussions relating to plant genetic resources for food agriculture, which are used for the development of commercial varieties whose granting of PBRs these organisations seek to facilitate.

\subsection{Conclusions}

Africa is in the process of establishing regional PBRs regimes. These regimes are at par with the highest international protection standards available under UPOV 1991. In this process, many African countries will be complying in an early phase with the provisions of the WTO TRIPS Agreement in adopting sui generis mechanisms for the protection of new plant varieties.

As this chapter shows, several concerns can be and have been raised with respect to the process of development of the PBRs regimes in ARIPO and SADC member countries. These concerns mainly relate to how the two regimes will relate to each other and, to the existing national legislation. Given that each of these regimes is developing its own standards and that there appears to be minimal interactions between the parties developing these instruments, it is likely that conflicts will arise during the implementation phases. Countries that will be affected most

\footnotetext{
${ }^{168}$ How this can be done is further elaborated upon in Chapter 6.
} 
are particularly those that will adopt both instruments, which is likely to happen in the case of nine countries that are parties to both ARIPO and SADC. Two factors that compound the arising challenge are the uncertainty whether the Arusha Protocol and the SADC draft are each intended to have a direct legal effect in the member states (being a mix of dualist and monist countries) or not, and the various difficulties arising from intended uniform application and prohibition of cumulative protection.

In spite of the intention of ARIPO and SADC policy makers to create a single internal market for protected varieties, the end result may look quite different. On the one hand, some countries may choose to stay with or develop their own national PBRs systems, while other countries may remain without functioning PBRs registration systems. On the other hand, countries that already have national PBRs systems in place may ratify both regional instruments, while others may ratify a single instrument. All these different scenarios will cause questions and uncertainties regarding which regional or national system prevails over the other or whether they may have direct effect in some countries or not, resulting in confusion on which standards will apply in and across the two regional blocs. To the breeder, incorporating a provision enabling applicants for PBRs to specifically designate countries where they wish to claim their rights in the registration process may aid in dealing with problems that may arise from double ratifications. ARIPO has already incorporated a designation option in the Arusha Protocol and an equal provision could be considered in the SADC draft as such designation options will also preserve the relevance of some of the national registration systems already in place. However, it is not at all clear whether designation will ease confusion on the part of the (smallholder) farmer who is too, an intended beneficiary of the regional PBRs instruments.

This chapter also relates to the ambition that a single interpretation and consequent enforcement action would apply to all countries. Currently, in both the Arusha Protocol and the SADC draft, post-grants enforcement is left to the national authorities of the member states. As a result, it is unlikely that member states will achieve uniform interpretation of enforcement standards and procedures. This is likely to add to the confusion on which standards will apply in and across the two regional blocs. Whereas it is appreciated that full harmonisation of standards may not be possible, and may in fact not be desirable, it is nevertheless important that variation in the interpretation and enforcement of the law should not be so great, so as to render the system ineffective in some countries and across the region.

Another key challenge that should be considered is the fact that 21 of the 26 ARIPO and SADC countries are party to the IT, which requires its member states to protect and promote farmers' 
rights. In this context, it is relevant that strong criticisms have been made regarding both regional PBRs instruments by civil society organisations which are particularly concerned that the needs and practices of smallholder farmers will not be sufficiently taken into account. To address this issue, an appreciation is necessary that the subject matter for breeders' rights and farmers' rights is one and the same, and that it is of crucial importance that the rights of breeders and those of farmers are balanced.

Furthermore, policy makers should be aware of the fact that the standards of rights set in UPOV 1991 were established with the professional breeding and commercial farming sectors of developed countries in mind. Such commercial farmers form a small minority in the ARIPO and SADC member states, and relate mainly to particular crops that are traded over longer distances. For that reason, a differentiated approach to PBRs could be established in the region by setting varying levels of rights for different groups of farmers and crops. This approach could be established in the implementation regulations to the Arusha Protocol and the SADC draft. This approach may, for example, set UPOV 1991-type protection standards for commercial farmers while smallholder farmers may be allowed to save and exchange farm-saved seed of protected varieties unconditionally. In this context it is relevant to note that while the standards of rights and exemptions can be harmonised throughout the regional blocs, what constitutes a smallholder farmer may vary across countries and require national definition.

Finally, both ARIPO and SADC should consider providing for the full range of farmers' rights, beyond the rights of farmers to save, use, sell and exchange seed and propagating material. A relevant step in such direction would be to make the negotiation process (for the SADC draft, and in making implementation regulations under the Arusha Protocol) more transparent and inclusive, allowing for more interaction with and input from farmers and their organisations in the process. Participation of ARIPO and SADC in the IT processes would also contribute to ensuring that farmers' rights are taken into account in the process of providing for PBRs.

While the Arusha Protocol and SADC draft are set to be compliant to the UPOV 1991 standards, it is necessary for the countries concerned to take into account their own national needs, concerns and status of development, with particular attention to the interests of smallholder farmers who make up the vast majority of farmers in the 26 member states. Finally, taking into account the discussions on plant breeders' rights, countries in the region may also review their patent law in respect to plant based innovations, and their possible effects on farmers' ability to save, reuse, exchange and sell farm saved seed. 
Table 5: ARIPO and SADC countries and their memberships to UPOV, WTO and the IT as well as whether they are designated as LDCs and have national PBRs systems in place.

\begin{tabular}{|c|c|c|c|c|c|c|c|c|}
\hline & & ARIPO & SADC & IT & $\begin{array}{l}\text { UPOV } \\
\text { member } \\
(1978 \\
\text { or } \\
1991)\end{array}$ & $\begin{array}{l}\text { WTO } \\
\text { member }\end{array}$ & $\begin{array}{l}\text { Least } \\
\text { Developed } \\
\text { Country } \\
\text { designation }\end{array}$ & $\begin{array}{l}\text { National } \\
\text { PBRs } \\
\text { law } \\
\text { in place }\end{array}$ \\
\hline 1 & Angola & & $\sqrt{ }$ & $\sqrt{ }$ & & $\sqrt{ }$ & $\sqrt{ }$ & \\
\hline 2 & Botswana & $\sqrt{ }$ & $\sqrt{ }$ & & & $\sqrt{ }$ & & \\
\hline 3 & DR Congo & & $\sqrt{ }$ & $\sqrt{ }$ & & $\sqrt{ }$ & $\sqrt{ }$ & \\
\hline 4 & Djibouti & & & $\sqrt{ }$ & & $\sqrt{ }$ & $\sqrt{ }$ & \\
\hline 5 & Gambia & $\sqrt{ }$ & & & & $\sqrt{ }$ & $\sqrt{ }$ & \\
\hline 6 & Ghana & $\sqrt{ }$ & & $\sqrt{ }$ & & $\sqrt{ }$ & & \\
\hline 7 & Kenya & $\sqrt{ }$ & & $\sqrt{ }$ & $\sqrt{ }$ & $\sqrt{ }$ & & $\sqrt{ }$ \\
\hline 8 & Lesotho & $\sqrt{ }$ & $\sqrt{ }$ & $\sqrt{ }$ & & $\sqrt{ }$ & $\sqrt{ }$ & \\
\hline 9 & Liberia & $\sqrt{ }$ & & $\sqrt{ }$ & & & $\sqrt{ }$ & \\
\hline 10 & Madagascar & & $\sqrt{ }$ & $\sqrt{ }$ & & $\sqrt{ }$ & $\sqrt{ }$ & \\
\hline 11 & Malawi & $\sqrt{ }$ & $\sqrt{ }$ & $\sqrt{ }$ & & $\sqrt{ }$ & $\sqrt{ }$ & \\
\hline 12 & Mauritius & & $\sqrt{ }$ & $\sqrt{ }$ & & $\sqrt{ }$ & & \\
\hline 13 & Mozambique & $\sqrt{ }$ & $\sqrt{ }$ & & & $\sqrt{ }$ & $\sqrt{ }$ & $\sqrt{ }$ \\
\hline 14 & Namibia & $\sqrt{ }$ & $\sqrt{ }$ & $\sqrt{ }$ & & $\sqrt{ }$ & & \\
\hline 15 & Rwanda & $\sqrt{ }$ & & $\sqrt{ }$ & & $\sqrt{ }$ & $\sqrt{ }$ & \\
\hline 16 & Sao Tome \& & $\sqrt{ }$ & & $\sqrt{ }$ & & & $\sqrt{ }$ & \\
\hline
\end{tabular}




\begin{tabular}{|c|c|c|c|c|c|c|c|c|}
\hline & Principe & & & & & & & \\
\hline 17 & Seychelles & & $\sqrt{ }$ & $\sqrt{ }$ & & & & \\
\hline 18 & Sierra Leone & $\sqrt{ }$ & & $\sqrt{ }$ & & $\sqrt{ }$ & $\sqrt{ }$ & \\
\hline 19 & Somalia & $\sqrt{ }$ & & & & & $\sqrt{ }$ & \\
\hline 20 & South Africa & & $\sqrt{ }$ & & $\sqrt{ }$ & $\sqrt{ }$ & & $\sqrt{ }$ \\
\hline 21 & Sudan & $\sqrt{ }$ & & $\sqrt{169}$ & & & $\sqrt{ }$ & \\
\hline 22 & Swaziland & $\sqrt{ }$ & $\sqrt{ }$ & $\sqrt{ }$ & & $\sqrt{ }$ & & \\
\hline 23 & Tanzania & $\sqrt{ }$ & $\sqrt{ }$ & $\sqrt{ }$ & & $\sqrt{ }$ & $\sqrt{ }$ & $\sqrt{ }$ \\
\hline 24 & Uganda & $\sqrt{ }$ & & $\sqrt{ }$ & & $\sqrt{ }$ & $\sqrt{ }$ & $\sqrt{ }$ \\
\hline 25 & Zambia & $\sqrt{ }$ & $\sqrt{ }$ & $\sqrt{ }$ & & $\sqrt{ }$ & $\sqrt{ }$ & $\sqrt{ }$ \\
\hline 26 & Zimbabwe & $\sqrt{ }$ & $\sqrt{ }$ & $\sqrt{ }$ & & $\sqrt{ }$ & & $\sqrt{ }$ \\
\hline & TOTAL & 19 & 15 & 21 & 2 & 21 & 17 & 7 \\
\hline
\end{tabular}

${ }^{169}$ Excludes South Sudan. 


\title{
Chapter 5: Plant breeders' rights licensing as a tool to facilitate access of seed for smallholder farmers: observations from Keny ${ }^{170}$
}

\begin{abstract}
Licensing is a tool commonly used by intellectual property owners to transfer a set of their private rights to their inventions to the users. It is normally deployed in commercial agricultural settings where crop production is not for subsistence purposes. This enables breeders to recoup their costs of investments, or obtain rewards on their efforts prior to the expiration of their rights. Licensing is dependent upon several common factors regardless of the market conditions in which it is deployed. Using three examples of licensing in the agricultural sector in Kenya, this chapter investigates whether licensing of plant breeders' rights is a mechanism that can facilitate access to seeds and planting material for smallholder farmers in conditions prevailing in markets such as Kenya.
\end{abstract}

\subsection{Introduction}

Licensing is the most common vehicle by which intellectual property rights (IPRs) are transferred from inventors to users (Payumo, et al, 2012). As inventors, plant breeders utilize licensing as a tool for introduction of protected varieties of plants. This is preconditioned upon plant breeders' rights (PBRs) also known as plant varieties protection (PVP) being taken out by the breeder against the new variety. According to Louwaars et al (2009), as plant breeding is part of an innovation chain reaching from fundamental research through to the production and marketing of seed and planting material it therefore follows that the process through which breeders introduce new varieties of seeds and planting material to farmers is often not direct. This process normally involves a number of intermediaries in the seed enterprise such as seed multipliers, dealers and stockists.

As PBRs constitute a set of private rights conferred to a breeder, licences then are contracts between parties. However, licence agreements are not the only contracts that a breeder may enter into in relation to a protected variety. Other contracts may include material transfer agreements in relation to accessing varietal material for research purposes, and seed production agreements where a breeder contracts a third party in multiplication of seed.

\footnotetext{
${ }^{170}$ This chapter is based on an article submitted to the Queen Mary Journal of Intellectual Property as: Munyi, P; Bram De Jonge and Niels Louwaars. Plant breeders' rights licensing as a tool to facilitate access of seed for smallholder farmers: observations from Kenya.
} 
Licence agreements are tools normally deployed in commercial agricultural settings, where crop production is targeted for sale in markets, and not for subsistence purposes. In these settings, plant breeding is usually private sector-led and licence agreements could comprise almost all rights of the breeder, or can be limited to certain acts or 'uses' and/or territories. ${ }^{171}$ Whether one licensing mechanism is applied as opposed to another in managing breeder strategies varies depending on various factors including (i) the general legal structure of the national PBRs system; (ii) source of, and policies attendant to the income for the breeder; (iii) type and market of crop, including the seed system operating ${ }^{172}$; and, (iv) royalties collection mechanisms that may be available to the breeder.

Kenya's economy is agriculture driven. It provides employment to over $75 \%$ of the population and contributing up to $25 \%$ of the country's gross domestic product (Deverajan \& Kasekende, 2011). Compared to other African countries such as Morocco and Tunisia (and except for South Africa) Kenya has for the last 15 years had a fairly vibrant PBRs registration system. ${ }^{173}$ As at August 2016, 1,458 applications for grants of PBRs had been filed through the system, with ornamental crops accounting for over $60 \%$ of the applications, and food crops $34 \%{ }^{174}$ The PBRs registration system notwithstanding, Kenya's domestic seeds market is relatively small. According to the International Seed Federation (2011), this market was estimated to stand at USD 60 million as compared to Morocco's at USD 140 million, and South Africa's at USD 454 million. Ayieko \& Tschirley (2006) have observed that most farmers access seed from informal sources. The 2010 National Seed Policy buttresses this fact by acknowledging that whereas the source and quality of seed obtained by the informal seed sector may not be known, it is the major source of planting material for the farmers. ${ }^{175}$

Whether a variety is protected or not, a key feature of the domestic seed market for new varieties in Kenya is that the commercial market for most crops-except in horticulture, is very small as the predominant group of farmers has low purchasing power. Breeders and breeding companies in Kenya are operating in a market environment where most farmers are poor and do not invest in

\footnotetext{
${ }^{171}$ UPOV document UPOV/SYM/GE/08/4 dated 21 October 2008.

172 In this chapter the term seed is used to refer to all kind of propagating material including tubers and cuttings.

${ }^{173}$ While Kenya has had a plant breeders' rights regime since 1972, the same was not implemented until 1996 enabling the first application relating to a rose variety, to be made. South Africa's plant breeders' rights registration system has been in place since 1976 and had as at 8 October 2014, 2,607 grants in its register, compared to Kenya's 317; Morocco's 217; and, Tunisia's 113. See UPOV document C/48/7 dated 8 October 2014.

${ }^{174}$ See chapter 3 of this thesis. A summary of the applications made in Kenya is at Table 8 of this thesis.

${ }^{175}$ Government of Kenya (2010), National Seed Policy.
} 
purchased seed when other acceptable sources exist. This market condition cannot be ignored and has to be taken into account when breeders consider their licensing strategies.

Taking into account the market conditions prevailing in Kenya, this chapter analyses whether licensing of PBRs is a mechanism that can facilitate access to seeds and planting material to smallholder farmers. In answering this question, the chapter begins by examining factors that influence breeder licensing strategies. The factors considered are those that cut across all market conditions that a breeder is confronted with-from strong commercial export markets to settings (such as in Kenya) where food crop farming is normally for subsistence purposes and seed saving and exchange between farmers is prevalent. Thereafter, three Kenyan seeds licensing cases in the food crops sector are described. In choosing these cases it is recognized that the food crops involved are not only grown for commercial and subsistence purposes but also that PBRs have or are being taken out for these crops either in Kenya or elsewhere. Licensing conditions and strategies that emerge from these three cases provide a basis for discussions whether and how licensing of plant breeders' rights can be a tool to facilitate access to seeds and planting material for smallholder farmers. Thereafter a conclusion follows.

The subject matter of this chapter is among the first scholarly work that address licensing of PBRs in relation to smallholder famers. Most of the scholarly work and studies in this area address agricultural biotechnology licensing for smallholder farmers from a patents, not plant breeders' rights perspective. ${ }^{176}$ As such not much literature on the subject matter of this chapter exists.

In undertaking this study, the author conducted qualitative interviews over a period of three years amongst a wide range of stakeholders and informants. These included policy makers; seed companies; seed traders; seed associations; seed multipliers; commercial and smallholder farmers; public and private sector plant breeders; agricultural technology brokers; researchers and scientists in agricultural research centres of the Consultative Group on International Agricultural Research (CGIAR); officials of the International Union for Protection of New Varieties of Plants (UPOV); and, non-governmental organizations. Additional data is complemented through literature review, and discussions during workshops held in Kenya, South Africa and the

\footnotetext{
${ }^{176}$ See for example, TJ Lybbert, (2002) 'Technology Transfer for Humanitarian Use: Economic Issues and Market Segmentation Approaches', IP Strategy Today No. 5-2002 17, 25.
} 
Netherlands where preliminary data were discussed. An anonymized list of the informants interviewed is appended to this thesis.

\subsection{Factors that influence breeder licensing strategies}

As a private arrangement between the breeder and other parties, licensing is first and foremost a business decision. Therefore factors that affect licensing are essentially dependent upon strategic decisions the breeder takes with a view to enable a variety reach as many farmers as possible, at the right price and, at the right time. A commercial breeder may thus optimise profits or have other commercial goals. For a public breeder outreach to farmers may be the first development goal, but royalty income may also play an increasing role depending on institution policies. From research undertaken in this study, it appears that the following are some of the factors that affect licensing strategies: (i) the general legal structure of the national PBRs system; (ii) source of, and policies attendant to the income for the breeder; (iii) type and market of crop, including the seed system operating; and, (iv) royalties collection mechanisms that may be available to the breeder.

\subsubsection{The general legal structure of the national plant breeder's right system}

A PBRs system provides the basis upon which rights are granted and enforced. The system consists not only of the rules granting the rights but also the institution administering these rights, as the efficiency with which the rights of a breeder are responded to is important.

Where a country is a member of the International Union for the Protection of New Varieties of Plants (UPOV), whether its PBRs system is based on UPOV 1978 or UPOV 1991 models is an important consideration for a breeder in crafting a licensing strategy for the market in that specific country. This is because the rights and exceptions to the rights granted to a breeder within each of these two UPOV systems differ. For example, under a UPOV 1978 based PBRs system, farmers may save, re-use, exchange and, for small quantities, even sell farm-saved seed of protected varieties obtained from their own harvests. However, under a UPOV 1991 based PBRs system, the use by a farmer of the product of the harvest of a protected variety for propagating purposes may be allowed ${ }^{177}$ but only within reasonable limits and subject to the safeguarding of the legitimate interests of the breeder. This means that the farmer can only use farm-saved seed of a protected variety on his own holdings, while exchange and local trade of

\footnotetext{
${ }^{177}$ This is an optional exemption within the UPOV 1991 Convention and included in most plant breeders' rights laws of the countries that are members to this convention. The exemption is only meant for crops "where, for the member of the Union concerned, there was a common practice of farmers saving harvested material for further propagation." See document UPOV/EXN/EXC/1 of 22 October 222009.
} 
farm-saved seed amongst farmers is forbidden. Also, a farmer who plants farm-saved seed on his own holding may have to pay a (reduced) royalty to the breeder. This is referred to as the farmer's privilege. ${ }^{178}$ There is another compulsory exception under UPOV 1991 for acts done privately and for non-commercial purposes. While this exception is not further defined, on its website UPOV has published a FAQ stating that "Contracting parties have the flexibility to consider, where the legitimate interest of the breeders are not significantly affected, in the occasional case of propagating material of protected varieties, allowing subsistence farmers to exchange this against other vital goods within the local community."179

These differences between UPOV 1978 and UPOV 1991, and, in particular, the way the relevant provisions are legislated and implemented on the national level, dictate the precise nature of the PBRs legislation in a country. This in turn dictates whether or not plant breeders in a UPOV member country have the necessary legal means to enable collection of royalties particularly for farm-saved seed (Curtis \& Nilson, 2012).

In Kenya, the general legal structure of the PBRs system is founded upon the Constitution. This constitutional basis then gives anchorage to the statutory framework for its implementation, including enforcement. Two statutes-the 1972 Seeds and Plant Varieties Act ('the SPVA') and the 2012 Seeds and Plant Varieties (Amendment) Act ('the 2012 SPVA Amendment') deal with the substance of grants of PBRs. A third statute, the Anti-Counterfeiting Act, 2008 complements the SPVA and the 2012 SPVA Amendment in enforcement of PBRs in instances where it is considered that counterfeiting of protected varieties has taken place. The body that administers PBRs-the Kenya Plant Health Inspectorate Service (KEPHIS), is established through complementary legislation ${ }^{180}$ as its functions extend beyond plant breeders' rights to include seed certification and phytosanitary matters.

On establishment, Kenya's PBRs system was based on UPOV 1978. It has since been upgraded through the 2012 SPVA Amendment, in its aspiration to conform to UPOV 1991, which has not quite been achieved. The upgraded legislation does not for example, provide for private and non-

\footnotetext{
${ }^{178}$ The farmers' privilege has been implemented in the European Union through Commission Regulation (EC) No. 1768/95. With the exception for a defined category of small farmers, others who save and re-use seeds of a protected variety from their own harvests must pay remuneration to the breeder. The amount of the remuneration has to be agreed upon between the breeder and the farmer (or his representative), and in the absence of an agreement, this has been set at $50 \%$ of the royalty normally included in the seed price.

${ }^{179}<$ https://www.upov.int/about/en/faq.html\#300 > accessed on 12 November 2015

${ }_{180}$ KEPHIS was originally established in 1996 through a regulation - the Kenya Plant Health Inspectorate Order, 1996. This regulation is set to be repealed by the Kenya Plant Health Inspectorate Service Act, 2012 (Act No. 54 of 2012) which is yet to come into force.
} 
commercial use exception, which is a compulsory exception under UPOV $1991{ }^{181}$ While the legislation provides for the farmer's privilege exception in wording exactly similar to that in UPOV 1991, no regulation has been put in place to facilitate implementation of this provision. As Kenya is a party to the African Regional Intellectual Property Organization (ARIPO), it is also likely that should the country ratify the Arusha Protocol for the Protection of New Varieties of Plants, then should this regional PBRs system come into force, it will also become available in Kenya. $^{182}$

Related to the presence of the rules on PBRs themselves is the overall effectiveness of the institutions responsible for administration of these rules. The institution responsible for grant of PBRs is required to be efficient and effective in this process, as well as in its involvement in enforcement actions, should this be necessary. In Kenya, KEPHIS is the responsible institution for grant of PBRs. Whereas it is considered to be efficient and effective in dealing with applications and grants of PBRs, a perception exists that it may not be robust, particularly in making available information necessary to enable a breeder pursue infringement actions. This is attributed to the fact that at the national level, no legislation on access to information exists that would obligate KEPHIS to provide relevant information in its possession, notwithstanding constitutional recognition of this right. Some breeders therefore consider that access to information such as data on varietal certification quantities from KEPHIS may not be with ease. $^{183}$

The overall effectiveness and efficiency of both the PBRs system and its attendant institutions as well as other ancillary institutions such as courts are key considerations in the determination by breeders of the choice of law of contract of the country that will apply in interpreting licence agreements. In choosing the law of contract of the country in which a licence agreement will be interpreted and enforced, the breeder must be aware of the totality of legal tools made available by the law of the country. Curtis \& Nilsson (2012) have found that plant breeders in different countries adopt different attitudes to the enforcement of their rights and this leads to widely differing policies and strategies in the collection of royalties from farm-saved seeds. The tools available to assist collection of royalties may include obligations on farmers to provide

\footnotetext{
${ }^{181}$ UPOV 1991, Article 15(1)(i).

182 The Arusha Protocol for the Protection of New Varieties of Plants was adopted in July 2015. It will come into force one year after it receives four ratifications or accessions. It is open for signature until 31 December 2015. As at 1 October 2015, five countries had signed the Protocol but none had ratified it.

${ }^{183}$ Communication to author by Informant 12, 13 and 14.
} 
information on the seed they have saved, certification systems and penalties for evasion of royalty payments. ${ }^{184}$

Taking the case of the breeders in the ornamental crops sector that are operating in Kenya, the licences issued would mostly provide for the choice of law of contract applicable being a European jurisdiction-mostly the Netherlands as breeders hold the view that Dutch law of contract affords them more legal tools for enforcement than Kenyan law of contract. ${ }^{185}$ This is not surprising also given that most of the Kenyan licensors in the ornamental crops sector are of Dutch if not European origin. On the other hand, AATF licences in the WEMA project (discussed in section 5.3.1 below) stipulate that the applicable law of contract is that of England and Wales, notwithstanding that all parties (including AATF) entering into the licence agreements may all be based in Kenya. An outcome of this choice is that the law of contract of the country that is not selected then becomes irrelevant to the extent that it is not applicable in governing licensing relationships between parties.

The nature and effectiveness of the PBRs system in place is therefore an important consideration for a breeder in laying out a licensing strategy. Whether the PBRs system is based on UPOV 1978 or UPOV 1991 dictates the stack of rights available not only to the breeder but also to the farmer. To implement a smallholder farmer-focussed breeding strategy, a breeder may for example, have to forgo some of his rights where such a strategy is implemented in a UPOV 1991-based plant breeders' rights environment.

\subsubsection{Source of, and policies attendant to the income for the breeder}

The breeder landscape in Kenya consists of public and private institutions. Within the public institutions are two main categories: national agricultural research centres; public universities; and, state owned seed companies on the one hand, and, the international agricultural centres of the CGIAR on the other. As regards private institutions, these are comprised of international seed companies in the food crops, vegetables and floricultural sectors, and national seed companies participating more in seed multiplication than plant breeding.

\footnotetext{
184 Ibid.

${ }^{185}$ Communication to author by Informant 2 and 3.
} 
For national public institutions undertaking plant breeding activities, the source and policies attendant to the funding, and breeder income is important. Except for instances where these institutions engage in contract research for which funding may be from private sources, often they rely on public funding. Use of public funds in research and development brings about two things: the first, is the notion that the resultant product following use of these funds is often considered a public good, which should be available and accessible to all (Kaul et al, 1999; Muraguri, 2010). Secondly, the use of public funds is usually subject to wider policy directions and limitations such as rural development and smallholder farmers' needs that may be set out either by statute or institutional mandates, particularly on ownership and deployment of these research results. Next to that there may be policy directions on obtaining and managing intellectual property. The United States Bayh-Dole Act, ${ }^{186}$ which among others allows private and public institutions to own inventions developed with federal funding unlike in the past when such inventions were assigned to the government, is one typical statutory example. Another example is the South African Intellectual Property from Publicly Financed Research and Development Act, ${ }^{187}$ which requires among others, that publicly funded research must be used and commercialised for the benefit of South Africans. ${ }^{188}$ The enactment of the Bayh-Dole Act led to a sharp increase in the number of public institutions taking out patents and other IPRs on the results of their research thereafter leading to launching of technology commercialization and licensing programmes (Graff \& Bennett, 2006). The South African statute has led to some of the public institutions such as the Agricultural Research Council instituting technology deployment policies with a view to include participation of smallholder farmers, for example in citrus value chains. $^{189}$

In Kenya, whereas there is no statutory or other national policy explicitly dealing with stewardship of publicly funded research results, public funded institutions, by a combination of statutes and subject to institutional policies, own IPRs generated by them. Whether these IPRs may be used for the benefit of the public is left to institutional discretion. ${ }^{190}$ The University of Nairobi's intellectual property policy is an apt example. The object of the policy of this public institution is to make intellectual property "available to industry and others for the public benefit,

\footnotetext{
${ }^{186}$ Patent and Trademark Law Amendment Act of 1980.

${ }^{187}$ Act No. 51 of 2008.

${ }^{188}$ Section 2 of the Intellectual Property from Publicly Financed Research and Development Act, 2008.

189 UPOV Symposium on the benefits of plant variety protection for farmers and growers, November 2, 2012, Geneva, Switzerland. Available at <http://www.upov.int/edocs/pubdocs/en/upov pub 357 4.pdf $>$ accessed on 12 November 2015.

${ }^{190}$ Section 25 of the Science, Technology and Innovation Act (Act No. 28 of 2013).
} 
while providing recognition to individual inventors and encouraging the prompt and open dissemination of research results." 191 This objective appears to be in line with Kenya's Science, Technology and Innovation Act whose section 25 vests all rights in any inventions in respect of processes, apparatus and machines made on behalf of an institution to the institution, and leaves the availability of such inventions to the public to the discretion of the institution.

For international agricultural centres of the CGIAR their main mandate is the production of public goods. The CGIAR Principles on the Management of Intellectual Assets ${ }^{192}$ allow Centres to grant limited exclusivity for commercialization, and to apply for patents or PBRs over their intellectual assets, but only if "necessary for the further improvement of such Intellectual Assets or to enhance the scale or scope of impact on target beneficiaries, in furtherance of the CGIAR Vision". ${ }^{193}$ This is to facilitate collaboration with the private sector while safeguarding the international public goods nature of the results of its research and development activities.

As for private entities undertaking breeding activities, the primary source of breeder research funding is usually internal. Therefore company policies relating to the overall business strategiesincluding public image and sustainability issues determine how these resources are deployed taking into account the need to maximize returns to the owners or shareholders. Company policies may also include commitments and strategies to help improve the situation of smallholder farmers, based on their portfolio, assets and capabilities. One initiative that aims to make this transparent is the Access to Seeds Index, which measures and compares the efforts of the world's leading seed companies to enhance the productivity of smallholder farmers. ${ }^{194}$ What emerges however is that at the core of all these strategies is the fact that breeding companies have to look at a product development horizon of several to many years. It may take 4-6 years to bring a new maize or tomato hybrid variety to market, and dozens of years for potato or fruit trees. ${ }^{195}$ However, new breeding technology continue to emerge that may variedly reduce product development horizons between crops.

\footnotetext{
191 University of Nairobi Intellectual Property Policy, 2006 (Revised 2013).

192 CGIAR Consortium (2012), CGIAR Principles on the Management of Intellectual Assets ("CGIAR IA Principles").

193 Ibid., Article 6.

${ }^{194}$ Methodology Report for the Access to Seeds Index 2015. Available at http://www.accesstoseeds.org/wpcontent/uploads/Methodology-Report-for-the-Access-to-Seeds-Index-2015-Final.pdf > accessed on 12 November 2015.

${ }^{195}$ Communication to the author by Informants 3, 4 and 11.
} 
From the above, it is apparent that where a breeder institution, whether private or public puts in place a smallholder farmer-focussed breeding policy, implementation of a such a policy would be confronted with considerations such as institutional and individual income and investor returns. These considerations have to be taken into account by the breeder in determining licensing strategies to employ in order to effect the policy.

\subsubsection{Type and market of crop, including the seed system operating}

How a crop is propagated is important in determining the licensing strategy to be deployed. In Kenya, a wide range of crops is cultivated: hybrids; open pollinated varieties (OPVs); and vegetatively propagated crops (VPCs).

Taking the case of maize whose seed is produced by private and public actors, both hybrid seeds and open pollinated varieties (OPVs) are available in the market. Hybrid varieties are made by crossing selected parents (often inbred lines) while OPVs are broad populations created whether by crossing many known parents (synthetics), or by recurrent selection in freely pollinating populations (Setimela \& Kosina, 2006). There are a number of advantages and disadvantages to growing each. While OPVs show greater variability than hybrids, their seeds may also be saved for re-planting without much yield loss. ${ }^{196}$ Further, hybrids are characteristically higher yielding than OPVs, but generally require much higher standards of field management than OPVs to achieve their yield potential. ${ }^{197}$ Thus because seed saved from hybrid harvests are low yielding, seed saving is not usually a concern for hybrid maize breeders. When PBRs are taken out in respect of hybrids it is the inbred lines of these varieties that are usually protected along with the hybrid itself. ${ }^{198}$ For OPVs the end product, the OP-variety is protected. Licensing of PBRs may then take different forms. For example, a licence may be given to produce the hybrid and in some cases the multiplication of the inbred. A seed producer may also be licensed to multiply one parent but is sold the other. That way quantities produced can be controlled particularly when the second parent is a hybrid itself (three-way cross).

For vegetatively propagated crops (VPCs) such as potato, evidence from Ayieko \& Tschirley (2006) is that over 95\% of seed in Kenya is obtained from informal channels. This is in part

\footnotetext{
196 Ibid.

197 Ibid.

198 The hybrid is protected with a view to make sure that competing new hybrids have to be sufficiently distinct.
} 
because there is basically no genetic difference between the crop harvested and seed production. Seed potatoes are also bulky and transportation often is a problem, particularly in areas where road infrastructure is not available or poor. For potato breeders even where plant breeders' rights are taken out, controlling the crop value chain is important as well. This is to increase opportunities for collecting royalties on the use and sale of farm-saved seed of the protected varieties by third parties. In Kenya, foreign private breeders are gradually introducing their varieties, taking caution to ensure that the task of controlling the value chain is passed on to local intermediaries or, if that is not possible, by collecting royalty payments only from the first cycle of seed production.

Most of the licensing of protected plant varieties that is occurring in Kenya relates to ornamental crops, mainly cuttings and bedding plants. Given that over $60 \%$ of all plant varieties protected are ornamental plants, this is not surprising. Furthermore, as ornamental growers multiply the basic stock obtained from the breeder, licensing is a necessary tool for controlling the ornamentals value chain. In this sector, the main strategy breeders employ is licensing varieties to a single agent (as opposed to multiple agents) who in turn, sub-licences the varieties to the growers. That agent is then bestowed with the responsibility of collecting royalties from the growers and remitting the same to the breeder. The centralized nature of the ornamental crops market is an enabler for the value chain to be closely controlled.

Seed systems operating with respect to a particular crop are also a factor to be considered. At least six seed systems have been identified to operate in Kenya- farmer based seed systems; community-based seed systems; relief-based seed systems; public formal systems; mixed private public seed systems; pure private seed systems and, closed value chains. ${ }^{199}$ Different crops may fall under different seed systems, some crops operating in more than one. A farmer is likely to participate in different seed systems depending on the number of crops under cultivation on his land holding. For example, a farmer may receive seed as a contract grower in respect of a cash crop such as tobacco (closed value chain); buy maize seed from a local seed trader (mixed public private seed system); buy tomato seed directly from a multinational seed company (pure private seed system); and use farm-saved planting materials for growing some cassava (farmer based seed system).

${ }^{199}$ See chapter 2 of this thesis. 
For a breeder whose plant variety can easily be disseminated through the use and exchange of farm-saved seed in a farmer-based seed system such as OPV maize and for a number of potato varieties, there is a tendency to either licence these varieties to the seed producers on a royaltyfree basis ${ }^{200}$ or to purely not licence them at all but multiply and sell the seed to the market at the lowest cost possible. For closed value chains and some pure private seed systems, the seed markets are well organized and the breeder is able to control the value chain for the seed and may therefore employ a different strategy such as exclusive licensing to a single agent who in turn sub-licences the varieties. This is the case with ornamental crops discussed above. In relief seed supplies and community based seed systems, the breeder is normally hardly involved in these systems and may, for example, be requested to provide royalty free licences for multiplication of seed with a view to replenish varietal stock following a calamity such as drought or plant disease burden. While licensing per se is not normally taking place in these seed systems, authority to exclusively multiply seeds may be granted in order to ensure that the quality of the seed reaching the farmer is maintained. An example here is cassava where under the Great Lakes Cassava Initiative (GLCI) few farmers in western Kenya have been trained by an NGO-Catholic Relief Services (CRS) to multiply disease-free cassava cuttings for others. ${ }^{201}$

Type and market for a crop, including the seed system the crop operates in are important factors for consideration in breeder licensing strategies. Some types of crops are easily reproducible making plant breeders' rights important in steering access to protected material. Markets for crops and the seed systems the crops operate in also influence actions that farmers will take to access seed.

\subsubsection{Royalties collection mechanisms that may be available to the breeder}

Royalties provide the main mechanism through which a breeder recoups his investments on the protected variety. Even in instances where a farmer, through exploitation of the farmers privilege exception saves and reuses seed from his own harvest, on his own holdings (farm saved seeds), in some situations which vary from country to country, a reasonable payment is to be made to the breeder. This section discusses royalties collection mechanisms arising both from commercial seed production and farm-saved seeds of protected varieties.

\footnotetext{
${ }^{200}$ This does not mean that seeds are given out for free, but rather the breeder does not charge any royalty fees from the licensees.

${ }^{201}$ Communication to the author by Informant 5 .
} 
A variety of royalty collection mechanisms exist. These include extended royalties system (ERS), end-point royalties system (EPR) and others pegged upon units of cuttings or area propagated with the crop in question. All these royalty collection systems find their foundational basis on a PBRs law, backed by contractual arrangements, through licensing agreements. An ERS system when applied to certified or protected varieties operates in the form of a licence agreement with a payment being made at the point of sale of seed. An ERS system is very efficient in collecting royalties for certified seed, but this efficiency is eroded significantly in collecting royalties from farm-saved seed, especially in situations where either it is in the law, or, farmers believe that it is within their right, to save and re-use seeds without compensating the breeder (Curtis \& Nilsson, 2012). With respect to EPR systems, these concern collecting royalties not at the point of sale of the seed, but rather at the point of selling the harvest arising from the seed. EPR systems are therefore very efficient in collecting royalties for harvests whose markets are highly organized and centralized, and a culture of varietal declaration at the point of delivery to the market exists. ${ }^{202}$ According to Thomson (2013), the Australian grain market is one example where an EPR system has been very efficient in collecting royalties for protected varieties and farm-saved seeds. ERS and EPR systems are mostly used to collect royalties in cereals crops. As regards royalties collections based on units of cuttings or areas cultivated with a particular crop, this system is mostly used for ornamental crops, backed by licensing agreements and market surveillance mechanisms to confirm actual areas planted with the crop, or units planted. ${ }^{203}$ Some mechanisms such as EPR carry more risks than upfront payment systems as in the former, the royalty payable is proportionate to the crop harvest while in the latter, it is simply pegged on seed sales. The risk notwithstanding, EPR are also considered to be equitable to the extent that they capture the whole market. Therefore even harvests produced from farm-saved seed do not escape the royalties net. ${ }^{204}$

Cereal crops and VPCs present the most dilemma to a breeder in determining the most appropriate royalty collection mechanism as morphologically, seeds for these crops are very similar to their harvests. Therefore, seed saving is easy for these crops, with the exception of hybrid varieties. How then a breeder decides the appropriate mechanism to employ in collecting royalties varies from market to market. For crops whose markets are well structured and centralized, breeders have the freedom to choose whichever mechanism is most preferable.

\footnotetext{
202 Ibid.

${ }^{203}$ Communication to the author by Informant 2.

204 <http://www.grainsa.co.za/inputs-research-and-development/insetnavorsing-en--ontwikkeling> accessed on 1 March 2015.
} 
Royalties collection being a private activity it behoves the breeder to be organised enough in the market place. Breeder associations, seed producers associations and farmer producers cooperatives therefore play a key role in facilitating royalties collection. In France, South Africa and the United Kingdom, SICASOV, ${ }^{205}$ the South African National Seed Organisation (SANSOR) ${ }^{206}$ and Grain SA; ${ }^{207}$ and, the British Society of Plant Breeders ${ }^{208}$ are respectively, instrumental in organizing royalties collecting mechanisms for grain crops whether from certified or farm-saved seed. This situation generally remains in most countries with long established PBRs systems.

Experiences in collection of breeder royalties for protected varieties in Kenya can be found in both the ornamental crops and food crops sectors. The ornamental crops sector produces mostly for the export market, which is well structured. Breeders in this sector who are predominantly foreign employ global agents such as Royalty Administration International in licensing their protected varieties and collecting royalties from licensees. Incidences of payments default are low as surveillance throughout the supply chain is possible. ${ }^{209}$ With food crops, experience in licensing and subsequent collections of royalties, revolves mainly around KARI (now part of KALRO) as the licensor. Initially, KARI had an exclusive licensing agreement with Kenya Seed Company, a state-owned agency with authority to further sub-licence varieties to other companies. However, in implementing the KARI Strategic Plan 2005-2015, this model was abandoned, with KARI establishing a seed unit to promote own technologies and maximize revenue (Rangnekar, 2006). Concurrent with establishing a seed unit was also adoption of nonexclusive licensing models for different crops, with beneficiary licensees either making upfront

\footnotetext{
${ }^{205}$ SICASOV is an organization that was created in 1976 by French rights owners from the public and private sectors with a view to protect and manage cost-effectively, vegetal variety rights. See <http://www.sicasov.com/info/pages/internet/en/grpPresentationOrigine.html > accessed on 2 March 2015. ${ }^{206}$ SANSOR is a body that represents the South African seed industry. It was created in 1989 as an amalgamation of the ANSO (Association of National Seed Organizations) and ASASA (Association of South African Seed Analysts). See SANSOR 2013/2014 Annual Report. < http://sansor.org/wpcontent/uploads/2012/08/sansor-commemorative-issue-2014.pdf > accessed on 2 March 2015.

${ }^{207}$ Grain SA is a voluntary association of grain farmers and was established in 1999 to represent the interests of its members. Grain SA members grow maize, soybeans, sunflower, groundnuts, wheat, barley, oats and grain sorghum. See <http://www.grainsa.co.za/pages/about-grain-sa/overview> accessed on 2 March 2015. ${ }^{208}$ The British Society of Plant Breeders is an association of plant breeders in the United Kingdom and undertakes among others, royalties collection for protected varieties and payments on farm saved seeds on behalf of the plant breeders. See $<$ http://www.bspb.co.uk/farmsavedseed/index.php $>$ accessed on 2 March 2015.

${ }^{209}$ Communication to author by Informant 2.
} 
payments for seeds, or paying royalties based on gross sales on an annual basis- a combination of ERS and EPR. ${ }^{210}$

Use of seed trader associations, breeder associations and centralized markets for grains and cereals especially, in royalty collection mechanisms is hardly present in Kenya. This can be attributed to three reasons: first, except for very few seed companies, most are involved in seed multiplication activities, not plant breeding and therefore do not own varieties themselves. Therefore even as self-organized as they are through the Seed Traders Association of Kenya (STAK), royalties collection is not one of the priority issues for consideration by seed companies. Secondly, most plant breeders are employees of public institutions- KALRO, Kenya Seed Company or public universities. Debate on whether public plant breeders as salaried employees, should be receiving additional compensation for developing new and protected varieties has been ensuing for years and is yet to be settled. As such the national breeders association- Plant Breeders Association of Kenya (PBAK), is not mandated to collect royalties on behalf of the owners of the varieties, that is the public institutions themselves. Thirdly, markets for most crops are poorly structured and co-ordinated. The National Cereals and Produce Board, another state agency with the mandate to provide a ready market for grain crops is not efficient in providing farm inputs and guaranteeing markets for harvests. The overall appearance is on there being more priority and emphasis in controlling the quality of seed available in the market, and less on creating efficient seed market channels. As such there are multiple and uncoordinated marketing strategies for seed by various seed producers. These strategies are not effective to enable collection of end-point royalties, mainly because registration of the source of the variety for which royalties could be collected from the harvested product at the point of sale is not a requirement.

One factor that has emerged in royalties collection is the perceived role of government through a state agency- the Agriculture, Fisheries and Food Authority (AFFA) in this process. Whereas royalties collection is intended to be a private activity, through the Crops Act, 2013 AFFA is given responsibility to among others "charging of ...breeder royalties on all scheduled crops..."211 While AFFA is yet to commence implementation of this provision, this would clearly give owners of protected varieties a helping hand in collection of royalties. Whether this helping

\footnotetext{
${ }^{210}$ Communication to author by Informant 24, 27 and 28. See also Thornstrom, CG, I Virgin, E Thorn and M Ericsson (2013). Science, Genetic Resources and Regulation. Sida ITP-Program Final Report: The GRIP experience 2003-2014 with focus on GRIP-12 and 13. SLU and Sida.

${ }^{211}$ Section 6(1)(a) of the Crops Act, 2013.
} 
hand will be extended to all owners of protected varieties and if so, how, remains to be seen, suffice to say it is an important factor to consider in royalties collection processes in the future.

Royalties provide one of the basic tools through which a breeder recoups investments. Mechanisms that may be available for collection of seed royalties from farmers are a useful consideration to be had by a breeder, and these may have an influence on how licensing of protected material occurs, as between the breeder and other intermediaries.

The totality of the factors stated above all influence in one way or another, the PBRs licensing strategy a breeder takes in order to make a variety available. In countries where the commercial seed market is not well developed, these factors are extra important as obtaining returns on investments is not necessarily assured. Yet, whereas licensing strategies are normally aimed at recouping breeders' investments in the protected variety, this chapter aims to explore whether licensing of PBRs can also be a tool to facilitate access to seeds and planting material to smallholder farmers. This is done by presenting and analyzing three specific licensing examples in Kenya in the remainder of this chapter.

\subsection{Examples of PBRs licensing and smallholder farmers' access to seeds in Kenya}

In this section, three examples of PBRs licenses in Kenya are described. One example concerns development of a water efficient maize variety. This variety targets smallholder farmers in five African countries (including Kenya). The other two examples concern seed potato deployment for smallholder farmers. Each example exhibits strong commercial breeder company involvement, and registration of plant breeders' rights either in Kenya or in other jurisdictions. Further, in each example, a specific licensing strategy aimed at facilitating access of seed and planting material to smallholder farmers who cannot afford to pay full commercial prices is observed.

\subsubsection{Maize- The Water Efficient Maize for Africa project (WEMA)}

WEMA is a public private partnership with a charitable objective. ${ }^{212}$ It is funded by the Bill and Melinda Gates Foundation, the Howard G. Buffett Foundation and, the US Agency for International Development (USAID) ${ }^{213}$ and led by the African Agricultural Technology Foundation (AATF). AATF is a not-for profit organisation that facilitates and promotes public

\footnotetext{
${ }^{212}<$ http://wema.aatf-africa.org > accessed on 2 December 2015.

${ }^{213}<$ http://wema.aatf-africa.org/partners-donors/funding-partners > accessed on 2 December 2015.
} 
private partnerships for the access and delivery of appropriate agricultural technologies for sustainable use by smallholder farmers in sub-Saharan Africa. WEMA project partners include Monsanto, a US-based agrochemical and agricultural biotechnology corporation. Monsanto is donating its commercial drought-tolerance and insect-protection traits royalty free to the consortium. The International Maize and Wheat Improvement Centre (CIMMYT) a CGIAR Centre, and the national agricultural research centres from Kenya, Mozambique, South Africa, Tanzania and Uganda are also in the research consortium. The project seeks to develop and deliver conventionally bred or genetically modified maize varieties with improved drought tolerance and/or insect resistance to smallholder farmers in South Africa, ${ }^{214}$ and to the rest of sub-Saharan Africa. ${ }^{215}$

Conventionally bred water efficient hybrid varieties from the project are already available for licensing in Kenya, Uganda, Tanzania and South Africa. However, due to biosafety regulatory requirements, genetically modified drought tolerant hybrid maize varieties in the project are undergoing confined field trials in the partner countries, with each country evaluating whether these varieties are suitable for their drought or insect conditions. ${ }^{216}$ An application for environmental release of the insect protection event has also been filed in Kenya.

A number of IPRs are being deployed in the WEMA project. First, the drought tolerant trait is patented in South Africa. Secondly, consideration is being made to apply for PBRs on the improved conventional lines in some of the project countries that have functional plant breeders' rights laws in place. Further, AATF has also registered trademarks in the partner countries, as WEMA varieties will be commercialized in all countries under a single brandDroughtTEGO ${ }^{\mathrm{TM}} \cdot{ }^{217}$

The main licensing strategy in this project is delivery of seed to the targeted farmers on a royalty free basis. Here, targeted farmers have been defined as "farmers in South Africa who plant up to three hectares of land for the production of maize and all farmers in the rest of sub-Saharan Africa." ${ }^{218}$ As such, parties involved in WEMA-the licensed companies and seed producers will

\footnotetext{
${ }^{214}$ In the project, smallholder farmers in South Africa are defined as those who plant maize in up to three hectares.

$215<$ http://wema.aatf-africa.org > accessed on 2 December 2015.

${ }^{216}<$ http://wema.aatf-africa.org/about-us/confined-field-trial-faq $>$ accessed on 2 December 2015.

${ }^{217}$ http://wema.aatf-africa.org/files/wema/Drought-TEGO-Branding-guidelines.pdf $>$ accessed on 2 December 2015.

${ }^{218}$ http://www.aatf-africa.org/userfiles/wema-ip-policy.pdf > accessed on 2 December 2015.
} 
not collect or receive a royalty from the farmers, the idea being to minimize the costs of seed to farmers. ${ }^{219}$ However, there is recognition that some of the technology innovation that may be developed could have considerable commercial value for large-scale farmers in South Africa and outside Africa. It is for this reason that the target project beneficiary is delineated to exclude commercial farmers in South Africa. These farmers will access the technology at full commercial scale, subject to conditions yet to be determined as the project's current focus is reaching the target farmers.

\subsubsection{Potato- HZPC, Kisima Farm and Syngenta Foundation for Sustainable Development}

This example involves three actors- HZPC, a seed potato company based in the Netherlands exporting seed potato to most parts of the world; Kisima Farm, a private Kenyan seed potato multiplier; and, Syngenta Foundation for Sustainable Development, a not-for-profit organization. This not-for-profit organization is established by Syngenta AG, a global agrochemicals and seed company. ${ }^{220}$ It aims to work with pre-commercial farmers- a term used by the Foundation to refer to small-scale producers, with a view to create value for them through innovation in sustainable agriculture and the activation of value chains. ${ }^{221}$

The main activity herein is the introduction of new potato varieties in Kenya by HZPC through Kisima Farm, with Syngenta Foundation facilitating the licensing discussions of these varieties between HZPC and Kisima Farm, and the actual introduction of the varieties into Kenya.

While the Kenyan market for potato processing varieties ${ }^{222}$ appears promising for HZPC due to an emerging middle class market, the company has so far not been ready to introduce these varieties. This has been due to the fact that in the company's view, the Kenyan potato market value-chain is not well co-ordinated and there is rampant saving of seed by smallholder farmers. ${ }^{223}$ This is not the case in northern Africa - Egypt, Tunisia and Libya where HZPC is also operating in. According to HZPC, the potato market value chains in these countries are

\footnotetext{
${ }^{219}<$ http://www.aatf-africa.org/userfiles/wema-ip-policy.pdf > accessed on 2 December 2015.

$220<$ http://www.syngentafoundation.org/index.cfm?pagelD=30> accessed on 2 December 2015.

$221<$ http://www.syngentafoundation.org/ temp/Syngenta Bericht 2009 2010.pdf $>$ accessed on 2 December 2015.

222 These are potato varieties used for processing either as chips or fries as opposed to ware or table varieties which are used for mashing or cooking in other ways.

${ }^{223}$ Communication to author by Informant 11, 20 and 21.
} 
well-organised and seed savings and re-use by farmers is not as rampant. As such in HZPC's view, the cost of enforcing plant breeders' rights would be higher in Kenya than in these other African countries, yet the company would not wish to be seen to be harassing smallholder farmers. ${ }^{224}$

HZPC had by July 2015, officially released nine varieties into the Kenyan market ${ }^{225}$ besides applying for PBRs on these varieties.

Notwithstanding the PBRs applications, the main licensing strategy that HZPC is pursuing is foregoing royalties with respect to the seed bulked and multiplied of the processing varieties it is introducing. ${ }^{226}$

Every cropping season, Kisima Farm purchases in vitro potato tubers from HZPC, which through an aeroponics system produces microtubers. The microtubers are thereafter transferred to the seed farm for reproduction and bulking. This takes up to three cycles whereafter the seed produced is sold to farmers. HZPC only collects a royalty on the in vitro potato tubers, which royalty is built into the purchase price and does not concern itself with the seed quantities that are bulked and multiplied for sale to farmers. ${ }^{227}$ According to the Syngenta Foundation ${ }^{228}$ the licence arrangement between HZPC and Kisima Farm thus permits Kisima Farm to commercially produce seed of modern processing varieties in Kenya in return for a one-time only royalty payment and a waiver of right to collect seed multiplication royalties from Kisima and re-plant fees (farmer fees otherwise collectible from farm saved seeds).

The approach by HZPC, Kisima Farm and Syngenta Foundation puts smallholder farmers in an advantageous position as the agreement to waive the right to collect seed multiplication royalties and re-plant fees enables the cost of access to seed by farmers to be at a minimum. While farmers are free to use farm-saved seed they are encouraged to purchase new seed every season due to quality issues. HZPC is not necessarily turning a profit in this arrangement. However, it

\footnotetext{
224 Ibid.

${ }^{225}$ Kenya National Crop Variety List. List available at $<$ http://www.kephis.org/images/VarietyList/varietylistjuly2015.pdf > accessed on 2 December 2015. ${ }^{226}$ Ibid, note 239.

${ }^{227}$ Communication to the author by Informant 31.

${ }^{228}$ Ian Barker submission to the $10^{\text {th }}$ Meeting of the CGIAR Fund Council -November 6 and 7, 2013 in Nairobi titled, Scaling Technology Transfer through Private Seed Channels: Experience from East Africa. Also seeKisima, CIP and Syngenta Foundation for sustainable Agriculture (2014), Potato seed impact study report: interim study report on the impact of adopting certified potato seed in Meru County, Kenya (2011-2014).
} 
has gained a position in the Kenya market whereby the company is able to study the potato value chain and weigh the potential for introducing its other varieties that are not part of the current arrangement.

\subsubsection{Potato- Mayan Gold case}

Mayan Gold is a potato variety originally bred in the United Kingdom by James Hutton Instituteformerly the Scottish Crop Research Institute (SCRI), a public research institution. Amongst its attributes is resistance to late blight on foliage (Phytophthora infestans), powdery scab (Spongospora subterranean) and potato T. tricovirus and potato leafroll virus. ${ }^{229}$ Further it has low dormancy and as such can be cropped twice a year; fast cooking time thereby saving charcoal and wood fuel; and, resistance to bruising and splitting thus increased yields. ${ }^{230}$

A research grant by the Monsanto Fund, a charity formed by Monsanto Co. has enabled James Hutton Institute, Greenvale Plc-a licensee of the variety, and Masinde Muliro University of Science and Technology (MMUST)- a Kenya public university, through an agreement to undertake research in Kenya evaluating the variety on its susceptibility to a number of potato diseases. ${ }^{231}$ Following the National Performance Trials, Mayan Gold was officially released in Kenya in June $2014 .^{232}$

One of the conditions contained in the agreement between the parties on the research over the variety in Kenya is that the variety shall be made available in Kenya on a not-for-profit basis. This condition has been carried over from the agreement and included as one of the variety conditions, in the national variety release register. ${ }^{233}$ To put a regulatory condition that seed should only be made available to farmers on a not-for-profit basis is innovative. Not only is making the seed of the released variety available on a commercial basis an infringement of the agreement, but also of variety release conditions. This effectively transfers the costs of enforcing the agreement from the parties to public authorities.

\footnotetext{
229 Ibid.

$230<$ http://www.hutton.ac.uk/news/potato-variety-mayan-gold-successfully-released-kenya> accessed on 10 January 2016.

$231<$ http://www.scri.ac.uk/research/pp/plantpathogeninteractions/monsanto > accessed on 10 January 2016.

${ }^{232}$ Vol. CXVI-No. 80, Kenya Gazette Notice No. 4711 dated 14 June 2014.

${ }^{233}$ Ibid.
} 
It is notable that in the UK and other parts of the world, this potato variety is available on full commercial scale. ${ }^{234}$ However, as stated the parties have agreed that the variety shall not be available to the Kenyan farmers on commercial terms. ${ }^{235}$ This does not mean that the variety will be available to the farmers for free, but rather, that the price the farmers will pay for the seed will only be sufficient to meet its production costs. The price is yet to be set as the variety is currently being multiplied at two centres of the Kenya Agricultural and Livestock Research Organisation (KALRO), ${ }^{236}$ and at the Agricultural Development Corporation- a public seed multiplier. It is expected that the varieties will be available to the farmers in 2017.

Whereas PBRs on Mayan Gold have been taken out in the UK and other parts of the world, in Kenya the rights have not been applied for either by the licensee or licensors. The agreement to have the variety availed to farmers on a not-for-profit basis precludes the possibility of third parties offering the variety to farmers on commercial terms. This is then expected to lower the cost of production of the variety and thereby lowering seed purchase price for the farmers. Furthermore, MMUST acknowledges that once Mayan Gold is available to farmers, they may well save and re-use seeds of the variety. MMUST cannot, and does not intend to explicitly restrict farmers from saving and re-using the seed of the improved variety. Moreover, it is hoped that the net result will be a reduction on costs of accessing seed which in itself will encourage farmers to purchase new and, thus, clean planting material after every cropping cycle rather than save and re-use from their own harvests.

The three examples described above concern breeding efforts whose results are aimed to (also) reach smallholder farmers. The next section discusses some observations on the PBRs licensing strategies that emerge from these three cases, and reflects on the question whether and how licensing can be used as a mechanism to facilitate access to seeds and planting material for smallholder farmers.

\footnotetext{
${ }^{234}<$ http://greenvale.co.uk/seed/worldwide/> accessed on 10 January 2016.

235 Notation on the Kenya Gazette No. 4711 dated 14 June 2014.

${ }^{236}$ KALRO Tigoni and Njabini Centres.
} 


\subsection{Reflections on licensing as a tool to facilitate access to seeds for smallholder farmers}

\subsubsection{Observations on the three licensing strategies utilised.}

A number of observations on the licensing strategies utilised emerge from the three examples described above.

One important observation is that all three examples apply some form of market differentiation. Market differentiation is an important consideration in order to ensure that the target beneficiary- the smallholder farmer is reached. Hence in the WEMA case, the target farmer is defined in a manner to exclude commercial farmers in South Africa; in the Mayan Gold case, the variety is released on a not-for-profit condition only in the Kenyan market; and, in the HZPC case, only a select number of varieties suitable for the market discerned by the breeder have been made available under the arrangement in place. The process of differentiating the market involves understanding and defining the characteristics of the targeted beneficiary-recipient farmer, by the right holder.

The differentiation of market conditions in these three cases exhibit characteristics of what in patents licensing is known as humanitarian use licensing. Humanitarian use licensing has come about in order to deal with transfer of technology- in particular pharmaceuticals to developing countries, which has become more problematic due to among others, research inputs and outputs being protected by patents and unaffordable for the poor (Spillane, 2002). Thus to overcome problems caused by patents, creative and novel technology transfer mechanisms-such as market differentiation combined with reduced or royalty free licensing, have been developed. The creativity and novelty lies in the fact that these mechanisms reconcile poor peoples' access to new technologies with proprietors' ability to maintain control over their technology and reap a return on their investment in more profitable markets (Lybbert, 2002).

Whereas humanitarian use licensing strategies have received considerable attention in the field of pharmaceuticals as a tool to facilitate access to medicine for the poor (van Genugten \& Meijknecht) this is much less the case in the agricultural sector. A notable exception is the Golden Rice case, which has broadly advertised the humanitarian use licensing strategy of the 
technology. ${ }^{237}$ In this case, the inventors of the technology assigned their exclusive rights to Syngenta, which also negotiated licences with other companies to use supplementary technologies needed to create Golden Rice. While maintaining the commercial rights (although, at a later stage, the plans to commercialise Golden Rice were abandoned), Syngenta has given the inventors a humanitarian licence to the full set of technologies with the right to sublicence public research organisations and low-income farmers in developing countries. ${ }^{238}$ However, this example concerns patent protected technologies in particular.

The WEMA project provides an apt example of humanitarian use licensing in the field of plant breeders' rights, and applies a clear differentiation between its target beneficiaries and the commercial market. However, the project appears to be lagging behind in putting in place mechanisms to determine terms and conditions for which the untargeted farmers ${ }^{239}$ will access varieties. It is important for both the humanitarian use and the commercial markets to be considered in tandem so that a delay does not arise in realization of profits that could otherwise be obtained by making the improved varieties available to the commercial market. Such profits earned could invariably be used to support the humanitarian use market, ploughed back into research or simply repatriated by the parties involved for their shareholders. The two seed potato case studies appear to be satisfying their commercial objectives in other markets outside Kenya already. ${ }^{240}$ Presumably then, in these two seed potato cases, they have already made considerations in differentiation between the under-served Kenyan farmers and commercial farmers outside Kenya. Another reason to carefully consider both markets in tandem is because the release of improved varieties to the targeted farmers may carry with it the risk of these seeds finding their way to commercial farmers without there being in place mechanisms to deal with such situations.

\footnotetext{
${ }^{237}$ See <http://www.goldenrice.org/Content1-Who/who4_IP.php> accessed on 10 November 2015.

${ }^{238} \mathrm{Ibid}$. Humanitarian use was defined as (i) use in developing countries (low-income, food-deficit countries as defined by the FAO) (ii) resource-poor farmer use (earning less that USD\$10,000 per year from farming) (iii) the technology must be introduced into public germplasm only (iv) national sales are allowed by low-income farmers (in this way urban needs are also covered) (v) reusing the harvested grain as seed for the following season is allowed (the farmer is deemed to be owner of his seeds).

${ }^{239}$ These are farmers in South Africa who plant maize in more than three hectares of land, and farmers in the rest of the world outside Sub-Saharan Africa. Most large scale or commercial farmers in South Africa already have access to such varieties. According to AATF, most large scale or commercial farmers in South Africa already have access to such varieties. However, the problem might be with those South African farmers farming more than 3 hectares but who are not exactly large scale or commercial farmers.

${ }^{240}$ A perusal of the 2012 and 2013 Reports and Financial Statements of Produce Investments plc, whose subsidiary -Greenvale owns Mayan Gold, and HZPC Holland BV indicate that these entities made profits, and there is no loss that occurred or was attributed to a particular variety.
} 
Considering these factors, it is interesting to look at the licensing strategies of the other two cases. In the Mayan Gold case, for example, the parties involved differentiate the market by applying for PBRs in some countries and not in others. Not taking out PBRs coupled with the parties agreeing to not-for-profit conditions which are thereafter embedded on to national variety release procedures appear to be the main strategy. Not taking out PBRs obviously reduces the costs attendant to maintaining the variety whereas embedding agreed conditions to national variety release procedures has the effect of transferring enforcement costs from the parties to the public authorities. These two elements enable seed multiplication arrangements to be put in place in a way that ensures that seed ultimately reaches a farmer at the least cost possible.

Another approach is applied by HZPC, whose licensing strategy is mainly about waiving some if its rights against seed producers and farmers. While HZPC is aware that smallholder farmers will save, re-use and exchange harvests from their protected varieties, the company will neither prevent farmers from doing so nor claim reasonable compensation from them. This is notwithstanding that the company has a right to do so as under the Kenya PBRs law farmers are only allowed to use farm-saved seed on their own holding, within reasonable limits and subject to safeguarding the legitimate interests of the breeder. ${ }^{241}$ The option by HZPC to only collect royalties from the sale of in vitro potato tubers and waive seed multiplication royalties on the amount of propagation material produced and sold to the farmers is obviously of benefit to the farmers as well. In this way, the price of seed is kept to a minimum.

Before comparing the pros and cons of these various licensing strategies, it is important to note, as described in section 5.2, how the different types of crops and the seed systems they operate in influence the licensing strategies that breeders deploy. In the WEMA case, the maize varieties are all hybrids. Since the yielding capacity of farm-saved hybrid seed is significantly lower than the original seed, farmers prefer to buy new seed for every cropping season. In order to facilitate access, the WEMA parties aim for the delivery of seed to be multiplied by companies in each project country for the targeted farmers on a royalty free basis. Potato is vegetatively propagated which means that seed production is very easy and farm-saved seed, despite an increased probability of getting diseased, will maintain its qualities and yielding capacity. Therefore, to facilitate access to seed, potato breeders may simply allow smallholder farmers to use and

\footnotetext{
${ }^{241}$ Section 20 of the Seeds and Plant Varieties Act, 1972 as amended by section 17 of the Seeds and Plant Varieties (Amendment) Act, 2012.
} 
exchange farm-saved seed of a protected variety, a strategy that cannot equally be applied in the case of hybrids.

Another observation is that plant breeders' rights are not necessarily the only IPR tool that a breeder may deploy in order to facilitate access of seed to smallholder farmers. From the WEMA case, it can be discerned that trademarks are also important IPR tools both to farmers and breeders. Trademarks enable farmers to easily identify and differentiate seeds in a market and in the process also build the breeder's market reputation. ${ }^{242}$

\subsubsection{Advantages and disadvantages of the main PBRs licensing strategies}

From the licensing examples discussed above, one can extrapolate three main strategies a breeder can utilise in order to facilitate smallholder farmers' access to a new variety. These can be summarised as follows:

- Not applying for PBRs in a particular country;

- Taking out PBRs and waive some rights in subsequent licenses;

- Taking out PBRs and applying a humanitarian use licensing strategy.

Whereas this chapter focuses on licensing of PBRs, it must be acknowledged that a right holder may also choose to simply not enforce its rights on smallholder farmers without explicitly waiving its rights or including humanitarian use provisions in its licenses. Actually, many right holders may probably do so on a daily basis, as it simply makes no business sense to spend time and resources on enforcing PBRs on those smallholder farmers whose farming practices do not target commercial markets. Yet, the downside of this approach is that without a formal waiver of rights, smallholder farmers that use and, in particular, exchange or trade farm-saved seed of a protected variety will likely be in breach of the national plant breeders' rights law. ${ }^{243}$

This may have varying consequences, depending on the country in question. In many countries, PBRs fall under private law, which means that the responsibility for enforcement of the breeders'

\footnotetext{
${ }^{242}$ In addition, the cost of acquiring trademark rights is much less than that of acquiring PVP. Furthermore, trademark rights unlike PVP remain available to the breeder as long as the trademark is in use and as such, there is no risk of expiry of the rights unless the breeder ceases to use the mark.

${ }^{243}$ It must be noted that some farming practices like the exchange and trade of farm-saved may also be governed by other laws than plant breeders' rights such as seed certification regulations.
} 
rights is left to the right holder itself. This implies that smallholder farmers do not run any risks under the PBRs law if the breeder decides not to enforce its rights on them. By publishing such policy on its website, a breeder would both create legal certainty for smallholder farmers and improve its public image.

Few countries, however, have introduced criminal law provisions in their PBRs law to specify protection measures against infringements. Section 34 of the Tanzanian 2012 Plant Breeders' Rights Act, for example, specifies that "Breeders' rights are protected by both civil and criminal law measures stipulated in any written law". This implies that smallholder farmers can be prosecuted irrespective of a right holder deciding not to enforce its breeders' rights on them. In Kenya, the PBRs legislation contains general criminal provisions relating to enabling public authorities undertake actions such as inspections and prevention of provision of false information to the public authorities. However, the anti-counterfeiting law- the Anti-Counterfeit Act, 2008 defines counterfeiting ${ }^{244}$ so liberally to include certain activities against goods protected by plant breeders' rights, which essentially are, plant varieties. This means that all offences in relation to counterfeit goods, such as selling, possession, barter or exchange, ${ }^{245}$ apply to plant varieties as well.

Turning back to the three main strategies listed above, a brief discussion of their main advantages and disadvantages follows.

The main advantage of the first strategy- not applying for PBRs, is probably that it is the cheapest of the three as it precludes PBRs application, maintenance and enforcement costs. For breeding programs that first and foremost target smallholder farmers in developing countries, this strategy is likely to be the most attractive. This observation is confirmed by, for example, the very low number of PBRs applications applied for by the international agricultural research centres of the CGIAR. ${ }^{246}$

\footnotetext{
${ }^{244}$ Section 2 of the Anti-Counterfeit Act, 2008 defines counterfeiting to include the manufacture, production or making, whether in Kenya or elsewhere, the subject matter of that intellectual property without the authority of the owner of intellectual property subsisting in Kenya, with intellectual property right being said to include plant breeders' rights.

${ }^{245}$ Kenya Anti-Counterfeit Act, 2008, Section 32.

${ }^{246}$ No CGIAR centre applied for plant variety protection in the period 2012-2014. During this period, only three centres entered into an agreement with third parties containing provisions authorizing the third party to apply for PVP in specific countries. See Intellectual Assets Report for Year 2013, prepared by the CGIAR Consortium Office and the Fund Council IP Group.
} 
An important disadvantage is that the breeder has few instruments to control the use of its variety in the marketplace. For example, it may be difficult to incentivize seed companies to multiply and market the variety if no market exclusivity can be provided.

The second strategy- waiving of some PBRs, does provide the breeder with control over its variety in the marketplace. This position allows the right holder to decide on the best marketing strategy. By waiving its rights to collect seed multiplication royalties from the seed producer, HZPC aims to keep the seed price to a minimum. By doing so, HZPC hopes that farmers start buying new and clean planting material every cropping season. In a seed system where seed saving, re-use and exchange by farmers is rampant, this is a first and crucial step towards building a viable seed business. An added advantage of this licensing strategy, together with the waiver of farmer re-plant fees, is that it enhances the companies' reputation while allowing the company to obtain a market position and a better understanding of the Kenyan seed potato market.

The main disadvantage relates to the costs involved. Next to the costs of applying and maintaining the PBRs, licensing involves other costs in the form of time and resources that need to be invested in negotiating, monitoring and implementing the licence conditions. Normally, these costs are divided over the various parties to the licence, and all expect to make a return on their investments in the market place. However, when the market is composed of smallholder farmers who predominantly access seed through informal channels, neither the licensor nor the licensee are likely to make a profit from the arrangement or even recoup their licensing costs. As demonstrated in the three cases, this has brought forth a third set of entities into the process. This third set consists of not-for-profit technology facilitators or brokers- AATF; Monsanto Fund; and, Syngenta Foundation for Sustainable Development with their role being to link the licensor and licensees and in the process, absorb some or all of these costs on behalf of the parties.

The third strategy- humanitarian use licensing, can be a tool to mitigate the costs of providing for the non-commercial market by simultaneously protecting and exploiting one's rights in commercial markets. Experiences drawn by Steven \& Effort (2008) from humanitarian use licensing in respect of pharmaceuticals suggest that universities and companies alike can facilitate access to medicine in developing countries without this "loss of market share in the developing world [to] diminish the company's value". Yet, these lessons cannot easily be extrapolated to the agricultural sector for various reasons. One is the fact that a new variety cannot be marketed 
across the globe but needs to be adapted to local environments. Also, the market value of most crops is significantly smaller than of pharmaceuticals not only in developed countries, but globally as well. In 2011, the global seed industry was estimated to be valued at USD 45 billion ${ }^{247}$ while the pharmaceutical market estimated value was at USD 956 billion. ${ }^{248}$ During the same period, Kenya's domestic seed market was estimated to be worth USD 60 million $^{249}$ against a domestic pharmaceutical market estimated at USD 659 million. ${ }^{250}$

Whether a humanitarian use licensing strategy with respect to a protected variety would indeed allow the licensor to mitigate its costs and recoup investments depends, amongst others, on how effectively the strategy separates humanitarian from commercial use. A repeated concern is that low priced versions of a product may undermine sales of the same in the commercial market. Putting in place legal and practical mechanisms to keep markets apart always come with a price and that may be the main reason why humanitarian use licensing has hardly been applied in the agricultural sector, and when it is, the licensing strategy is often sponsored by a philanthropic organisation as in the three cases described above.

Despite the costs, there may also be advantages to applying a humanitarian use licensing strategy. One is the aforementioned public image gain, as the strategy can be used to show a licensor's social responsibility and increase its reputation. Another advantage is that through market differentiation, a right holder can provide clarity on the various conditions to which different groups of farmers can make use of its variety. This can be useful especially in countries like Kenya where despite there being a farmers' privilege in the law, the same is not implemented through regulation. For example, next to spelling out the category of farmers that can access the variety on a royalty-free basis, the licensor can clearly define the conditions for royalty payments on the use of farm-saved seed for commercial farmers.

\footnotetext{
${ }^{247}$ International Seed Federation, 2012.

${ }^{248}$ Information available at $<$ https://www.imshealth.com/files/web/Corporate/News/TopLine\%20Market\%20Data/Global Pharma Market by Spending 2003-2011.pdf> accessed on 10 November 2015 .

${ }^{249}$ International Seed Federation, 2012.

250 IMS Health. Africa: a ripe opportunity. Understanding the pharmaceutical market opportunity and developing sustainable business models in Africa. A report available at $<$ http://www.imshealth.com/files/web/Africa/IMS-Africa_WP 101212final.pdf > accessed on 10 November 2015.
} 


\subsection{Conclusion}

As a tool to transfer technology and inventions between parties and across geographies, licensing has not received much attention in PBRs especially in market conditions that predominantly involve smallholder farmers such as those found in Kenya. When licensing is deployed in PBRs generally, there are a number of factors that come into play. These factors include the general legal structure of the national PBRs system and the source of, and, policies attendant to the income of the breeder. Also key are the type and market of crop, including the seed system operating as well as the royalties collection mechanisms that may be available to the breeder.

Kenya's PBRs system was recently the subject of efforts to upgrade the same to the UPOV 1991 standards. As observed, these standards were not met to the letter, mostly by the omission of the private and non-commercial use exception. No specific policies that could explicitly dictate the licensing conditions exist at the national level as well. Farmer based seed systems in which smallholder farming is key, are dominant in the food crops sector. This is the background against which licensing in plant breeders' rights is taking place.

From the three licensing cases described in this chapter, market differentiation emerges as a key issue in licensing in market conditions such as those prevailing in Kenya. Market differentiation enables the breeder to identify the targeted beneficiary in licensing. The type of crops the subject of the licence -whether hybrids or vegetatively propagated crops also influence specific strategies that may be deployed. It is also observed that not taking out PBRs also constitutes part of the strategy, as also taking out plant breeders' rights. Where PBRs are taken out, breeders either also opt to waive their rights in some of their subsequent licences or employ humanitarian use licensing in their strategies to enable seed reach smallholder farmers. While licensing of PBRs in market conditions such as those prevailing in Kenya has some advantages, the main disadvantage relates to costs. This is the case as the market is hardly sufficient to enable all parties recoup their investment costs. This has brought about not-for-profit third party technology facilitators or brokers who bear some of the costs associated with the licenses.

The use of licensing as a tool to facilitate access to seed and planting material for smallholder farmers in market conditions such as those prevailing in Kenya, appears limited to very few crops. Given that markets such as those in Kenya are dominated by smallholder farmers, who can ill-afford to pay for seeds at market prices this diminishes the possibility for breeders being able to recoup costs attendant to enabling seed and planting materials reach the smallholder 
farmers market. This has brought about the emergence of not-for-profit technology brokers in the licensing field. Breeders where they consider as part of their licensing strategy to smallholder farmers, a waiver of some of their rights with respect to protected varieties, should publicly provide this information. This way the specific category of farmers for which activities such as seed saving, exchanging and re-using is permissible despite the law providing otherwise will remain known. 


\title{
Chapter 6: A differentiated approach to plant breeders' rights in Africa ${ }^{251}$
}

\begin{abstract}
Several African countries and regional organizations are investing in the establishment of a plant breeders' rights system modelled on the UPOV 1991 Convention, which currently provides the strongest, international standard for plant breeders' rights. Whereas proponents argue that strong protection of breeder's rights will incentivize breeding and the introduction of new varieties for farmers, opponents fear that the proposed legal framework is unsuitable for African countries as it may hamper traditional farming practices of using and exchanging farmsaved seed. These informal or farmer-managed seed systems supply more than $80 \%$ of the total food crop seed used by farmers. The challenge for African countries is to strike a balance between protecting the interests of breeders through the incentive function of plant breeder's rights for the commercial market, and the leeway that needs to be provided to smallholder farmers that depend on informal sources for their seed security and survival; and to do so in a practical and legally enforceable manner. This chapter explores how African countries and regional organizations can establish such balance through a differentiated approach to plant breeders' rights, which sets different levels of protection for different crops in relation to different categories of farmers.
\end{abstract}

\subsection{Introduction - Plant Breeders' Rights in Africa}

Plant breeders' rights (PBRs) aim to encourage plant breeding by granting breeders of new plant varieties an exclusive right to commercialize their varieties, once registered for PBRs. Most African countries are members to the World Trade Organization (WTO), which has established minimum standards of intellectual property (IP) protection for all its member states through the Agreement on Trade-Related Aspects of Intellectual Property Rights (TRIPS). With respect to plant varieties, TRIPS in its Article 27.3(b) obliges members to provide for the protection of plant varieties either by patents or by an effective sui generis system or by any combination thereof. No African country grants patent protection on new plant varieties ${ }^{252}$ and few countries have so far established an operational sui-generis system for that purpose. ${ }^{253}$

\footnotetext{
${ }^{251}$ This Chapter is based on the article published as: De Jonge, B. and Munyi, P. (2016). A Differentiated Approach to Plant Variety Protection in Africa. World Intellectual Property, 19: 28-52. doi:10.1111/jwip.12053 ${ }^{252}$ Some countries, like South Africa, allow for patenting of plant material.

253 This is not surprising since 34 African countries are classified as Least Developed Countries (LDCs), which have till 2021 to comply with the TRIPS provisions or until the moment that they cease to be a LDC. This
} 
However, this situation is about to change as several African regional organizations are in the process of establishing PBRs systems modelled on the 1991 Act of the International Union for the Protection of New Varieties of Plants (UPOV), which currently provides the strongest, international standard for plant breeders' rights. UPOV is an intergovernmental organization, which was established by six European countries in 1961 through the International Convention for the Protection of New Varieties of Plants in order to "provide and promote an effective system of plant variety protection, with the aim of encouraging the development of new varieties of plants, for the benefit of society." ${ }^{254}$ This Convention has been revised in 1972 (UPOV 1972), 1978 (UPOV 1978) and most recently in 1991 (UPOV 1991), in particular to remain consistent with developments in the professional breeding and farming sectors of its member countries, which, at that time, were almost all major industrialised countries (Louwaars et al, 2013). Despite the fact that the agricultural sector in most African countries looks very different from those of the industrialised countries in 1991, new UPOV members can only sign onto UPOV 1991.

In 2014, the Organisation Africaine de la Propriété Intellectuelle (OAPI), the regional IP organization for French- speaking western Africa countries, joined UPOV as its 5th African member, following the depositing of an instrument of accession to UPOV 1991. In that same year, the African Regional Intellectual Property Organization (ARIPO) consisting of mainly eastern and southern African countries had its draft PBRs law approved by the UPOV Council to be in conformity with UPOV 1991, and the ARIPO PBRs Protocol was adopted in Arusha in 2015. Other regional organizations, such as the Southern African Development Community (SADC), the Common Market for Eastern and Southern Africa (COMESA), and the East African Community (EAC) are similarly planning to either enact their own PBRs legislation or have their member states harmonize their national legislations in line with UPOV 1991. Altogether, these regional organizations encompass 48 African countries ${ }^{255}$.

By establishing a PBRs system at par with UPOV 1991, African countries hope to incentivize breeding and the introduction of new varieties, allowing farmers to access "a wide range of improved varieties to contribute to the attainment of the regional goal of economic development and food security" (ARIPO, 2015, Preamble). Yet, these developments are strongly criticised by several academics (Haugen, 2015; Oguamanam, 2015) and Civil Society Organizations (CSOs)

transition period can be further extended according to Article 66.1 of the TRIPS Agreement (WTO document IP/C/64, 12 June 2013).

254 UPOV's mission statement, see http://www.upov.int/about/en/mission.html accessed on 5 June 2015.

${ }^{255}$ Algeria, Cape Verde, Morocco, Nigeria and Tunisia are not members of any of these regional blocs that have or are in the process of developing regional PVP systems. 
from across Africa and the world. ${ }^{256}$ Generally, they are of the opinion that the proposed legal framework is unsuitable for most countries in the region as it exclusively favours "commercial breeders' interests and marginalises the small-scale farmers that for centuries have been the backbone of Africa's agricultural system" (CSOs, 2012). One of the key concerns is that a UPOV 1991 system "outlaws centuries old practices of farmers freely using, exchanging and selling seeds/propagating material" (Via Campesina, 2014).

These farmer practices are often referred to as informal or farmer-managed seed systems. Farmer-managed seed systems are of crucial importance for seed security in Africa because they supply more than $80 \%$ of the total food crop seed used by farmers (World Bank, 2008; FAO, 2010; Lipper et al, 2010). These same farmer practices are also considered important in realization of farmers' rights in the International Treaty on Plant Genetic Resources for Food and Agriculture (IT). ${ }^{257}$ In its Preamble, the IT affirms "that the rights recognized in this Treaty to save, use, exchange and sell farm-saved seed and other propagating material, (...), are fundamental to the realization of Farmers' Rights, as well as the promotion of Farmers' Rights at national and international levels" (FAO, 2001). 36 African countries are party to the IT and are thus, under the obligation to take measures to protect and promote farmers' rights. ${ }^{258}$ The relationship between UPOV and the provisions on farmers' rights in the IT is increasingly the subject of debate. ${ }^{259}$

\subsubsection{An ISSD perspective on plant breeders' rights in Africa}

This chapter explores the contours of a PBRs system that recognizes the importance of both commercial and farmer-managed seed systems. Integrated Seed Sector Development (ISSD) is an approach to seed sector development that builds upon the diversity of seed systems in African countries, recognizing that all play an important role in providing farmers with seed. ${ }^{260}$ By recognizing that each seed system has its own benefits and limitations and requires a unique

\footnotetext{
${ }^{256}$ See for example http://www.acbio.org.za/index.php/media/64-media-releases/409-aripospvp-lawundermines-farmers-rights-a-food-security-in-africa accessed on 5 June 2015.

${ }^{257} \mathrm{IT}$, preamble and Article 9.

${ }^{258}$ For more information on the different legal obligations of African countries that are member of various international treaties and regional (IP) organization, see chapter 4 of this thesis.

${ }^{259}$ During the 5th session of the ITPGRFA's Governing Body in Oman, 2013, a resolution was adopted to invite "UPOV and WIPO to jointly identify possible areas of interrelations among their respective international instruments." See Resolution 8/2013.

${ }^{260}$ The ISSD approach is endorsed by the African Union as contributing to the implementation of the African Seed and Biotechnology Program (ASBP) and the seed agenda of the Comprehensive Africa Agriculture Development Program (CAADP). In several African countries, national ISSD programs have been established and an African-wide ISSD pilot program was launched in 2014.
} 
approach in strengthening it, ISSD aims to foster pluralism and guide policies in their design to strengthen multiple seed systems. The main objective of ISSD is to guide the design of seed sector interventions that are coherent with farmers' agricultural practices, in order to enhance farmers' access to quality seed ${ }^{261}$ of superior varieties (ISSD, 2014). 'Superior varieties' are understood to refer to both formally improved varieties (e.g. new varieties released by public research institutes or seed companies) and locally improved varieties (e.g. traditional varieties or landraces adapted to local conditions and preferences) most preferred by farmers (ISSD Africa, 2014).

When approaching plant breeders' rights from an ISSD perspective it is important to look at the potential benefits and drawbacks of a PBRs system for all the different seed systems. As explained above, ISSD aims to contribute to improved access to quality seed of better (adapted) varieties of food and cash crops. This requires investment in plant breeding in which PBRs can play an important role, in particular with respect to the formal and above all the commercial seed systems. Indeed, breeding companies consider strong and effective IP protection a neccesity for continued investments in their breeding programs and commercial farmers have an interest in obtaining better varieties through an efficient formal seed system that allows them to compete and to cater for standardized markets. Many smallholder farmers in Africa, however, have difficulty in accessing quality seed of improved varieties directly from these formal seed systems due to physical and financial constraints, as well as due to limited availability of locally adapted varieties. Therefore, smallholder farmers access new varieties mainly through the same informal channels' of saving and exchanging seed (Louwaars and de Boef, 2012). It is important that a PBRs system protecting new varieties does not create extra impediments to their accessibility for smallholder farmers (The Crucible II Group, 2001; De Jonge, 2014; De Jonge et al, 2015).

The challenge for African countries is to strike a balance between protecting the interests of breeders and seed producers through the incentive function of plant breeder's rights for the commercial market, and the leeway that needs to be provided to smallholder farmers that depend on informal sources for their seed security and survival. ${ }^{262}$

\footnotetext{
${ }^{261}$ In this chapter, the term 'seed' refers to any kind of plant reproductive material, such as seeds, cuttings, tubers, etc.

${ }^{262}$ Although this is one of the main challenges African countries face when considering to establish plant variety protection, it is not the only one. Two other important challenges that need to be addressed relate the need to improve transparency and democratic accountability in decision-making processes on PVP (see e.g. Dutfield, 2011; Deere, 2009), and the compatibility of the PVP system with national and international
} 
This chapter explores how African countries and regional organizations can establish such balance through a differentiated approach to plant breeders' rights, which establishes different levels of protection for different crops in relation to different categories of farmers. Given the current interest of the African regional IP and trade organizations in UPOV 1991, this Convention will be the main reference point in this analysis.

Before discussing the possible contours of a differentiated approach to PBRs in detail, this chapter starts with an analysis of the benefits and drawbacks a PBRs system based on UPOV 1991 may have for different seed systems. In the second section, the potential incentive function of PBRs for stimulating breeding in formal seed systems is discussed. Here, three general categories of seeds systems, namely: private, public, and mixed public-private seed systems are distinguished. Briefly, the rights and obligations of commercial farmers in light of the incentive function of breeders' rights are reflected upon followed by a discussion about the farmers' privilege as included in UPOV 1991. In the third section, the potential impact of plant variety protection on farmer-managed seed systems (or informal seed systems) will be analysed. In the end, it is shown how legal space can be created for smallholders' farming practices by elaborating upon the exceptions to the breeders' right in UPOV 1991. This will set the foundation for a detailed analysis of a differentiated approach to PBRs.

As stated above, a differentiated approach to PBRs establishes different levels of protection in relation to different categories of farmers. In order to make such approach legally and practically operational, a careful definition of the various categories of farmers, as well as the specific rights or exemptions each category would be entitled to is necessary. This will be the focus of analysis in the fourth section. Here, an exploration of the pros and cons of three ways in which different categories of farmers can be defined, namely by reference to 1) farm size or cropping area, 2) production or production capacity, and 3) profits or income is made. In this chapter, an attempt to define the boundaries between the two different categories of farmers is also made. The first category is the group of 'smallholder farmers' that due to their strong dependency on informal sources of seed for their seed and food security, are to be exempted from the breeders' rights. This means that this group of 'smallholder farmers' will be allowed to use, exchange and sell farm-saved seed of protected varieties for certain crops. All other farmers, which - for the sake of simplicity - are referred to as 'commercial farmers', will have to respect the breeder's right. ${ }^{263}$

legislation on Access and Benefit Sharing (see e.g. Lawson, 2015; Berne Declaration et al, 2014). These challenges are not further looked into in this chapter.

${ }^{263}$ The terms 'smallholder farmers' and '(small) commercial farmers' will further be reflected upon in the fourth section of this chapter. 
This means that these farmers are not allowed to sell or exchange farm-saved seed of any protected variety. However, for certain crops these farmers can be allowed to use farm-saved seed on their own holding while paying a reduced royalty to the breeder, in line with the 'farmers' privilege' included in UPOV 1991. The second category aims to distinguish and define the group of 'small commercial farmers' that can be exempted from the obligation to remunerate the breeder for the use of farm-saved seed.

The fifth and final section briefly summarizes the three main recommendations for policymakers that can be drawn from this chapter.

\subsection{Incentivising Plant Breeding Through PBRs}

As indicated above, African regional organizations hope to incentivize breeding and the introduction of new varieties in order "to contribute to the attainment of the regional goal of economic development and food security", by establishing a PBRs system at par with UPOV 1991 (ARIPO, 2015, Preamble). UPOV 1991 is indeed, strongly supported by the international seed industry, which considers that "strong and effective intellectual property protection is necessary to ensure an acceptable return on a research investment and to encourage further breeding and research" (ISF, 2012).

Plant breeder's rights, like any intellectual property right, are intended to stimulate innovation and development by regulating rights and obligations amongst parties involved in commercial trade (Blakeney, 2009). Intellectual property rights are market tools that help the right holder to recoup investments by providing both a trade monopoly and the legal means to protect it against infringers (i.e. to fight those who aim to copy and commercialise the right holder's invention). However, prior to successful exploitation of an IP-protected invention, investment in the original product development, creation of demand for the invention through marketing, and organization of distribution channels amongst other things are necessary. In addition to the costs of applying for and maintaining the IPR, it normally is the right holder that bears the costs of tracking down and prosecuting infringers in the market place (Maskus, 2000). This has important implications with respect to the potential benefits and drawbacks of introducing a PBRs system in many African countries. For example, as noted by UPOV itself, the introduction of such a system does not incentivize breeding in crops for which there is no commercial market:

"In an effective system of PVP the development of new varieties of plants will be encouraged where there is commercial viability, but in cases where there is no existing, or potential, commercial market for 
varieties, the presence of a PVP system should not be expected to encourage the development of new varieties" (UPOV, 2005a).

There is plenty of evidence to support this conclusion on the African continent. In francophone Africa for example, the conclusion of Annex X of the Bangui Agreement in 1999, which enabled registration of plant breeders' rights under the OAPI system and in line with UPOV 1991 appears not to have served as a catalyst to the development of new varieties in that region for by 2013, only 12 PBRs certificates had been granted (Mahop et al, 2013). Furthermore according to UPOV statistics, no applications for PBRs were received at OAPI between 2009 and 2013. ${ }^{264}$ This implies that the 12 PBRs certificates were all pre-2009 applications. Also when looking at the numbers of PBRs applications made in Kenya - one of the few African countries that has been a UPOV member for several years, a clear pattern demonstrating the commercial rationale behind the PBRs system can be seen. As at June 2015, ornamental crops led in terms of the total number of PBRs applications made in Kenya with 692, out of a total of 1156 applications. ${ }^{265}$ Yet, the country is not a market destination for cut flowers but only a source of production of ornamentals. As such all the owners of these PBRs-protected varieties are of foreign origin. The number of applications made for food crops for which a commercial market exists in Kenya such as maize and wheat is much higher (153 and 32 respectively) as opposed to low commercial value food crops such as pumpkin (1), sweet potato (1), millets (4), cowpea (4) and cassava (8). ${ }^{266}$

In order to protect the interests of private breeding companies and seed producers that cater for the needs of commercial farmers, and to stimulate further investments and (international) trade in commercial (export) crops, African countries may decide to establish a PBRs system based on UPOV 1991. The UPOV 1991 system is the seed industry's preferred PBRs system, both in and outside of Africa (ISF, 2012; AFSTA, 2008). UPOV and other international organizations can provide assistance to countries for setting up an efficient PBRs system that conforms to international standards. However, it should be realised that the introduction of such an intellectual property system will only serve a minor share of the existing seed systems in most African countries. Even within the formal seed sector, for those crops with little commercial seed market, plant breeder rights are unlikely to play an important role for many years to come.

\footnotetext{
${ }^{264}$ UPOV Document C/48/7 dated 08 October 2014.

${ }^{265}$ Worldwide, over $70 \%$ of all the Plant Breeders Rights granted in UPOV members states are on ornamentals and fruits according to the International Community of breeders of asexually reproduced ornamental and fruit plants (CIOPORA). See http://www.ciopora.org/fileadmin/assets/pageDownloads/Press Releases/2014-4CIOPORA PR 42014 Breeders vision for the future.pdf. Accessed on 5 June 2015. ${ }^{266}$ Information as at 31 December 2013. Retrieved from KEPHIS Annual Reports (2008-2013) and National Crop Variety List (2014). Reports with the author.
} 


\subsubsection{The incentive function of plant breeder's rights differ amongst formal seed systems}

The ISSD literature distinguishes three main categories of 'formal' seed systems, namely (i) private, (ii) public and (iii) mixed public-private seed systems. In public formal seed systems the public sector undertakes all the activities in the seed value chain - from breeding to seed distribution. Mixed public-private seed systems are characterized by participation of both the public and private sector in the seed value chain with the public sector usually undertaking breeding research while the private sector multiplies and distributes seed to farmers. In regard to the "pure" private seed systems, the private sector is engaged in all the operations of the seed value chain (chapter 2 of this thesis). A fourth category are the closed-value chains, in which the seed value chain is completely closed and integrated in the product value chain with the farmers being contracted to produce and sell their harvests to a company or state entity, which also provides the farmers with seed. For this reason, this fourth category of formal seed systems is not included below where the incentive function of plant breeder's rights is analyzed.

\subsubsection{Private seed systems}

Commercial farmers have an interest in obtaining better varieties through efficient private seed systems. In many countries, effective PBRs protection is necessary to support these private seed systems and to have a regular supply of new varieties that cater for the needs of commercial farmers and the value chains (e.g. supermarkets and consumer demands) they operate in. Private seed companies typically focus on hybrids or higher value cereal and horticultural crops and commodities and often involve closed-value chains (e.g. for ornamentals, fruits, tobacco, sugar cane, tea and coffee). In order to get a return on their investments in breeding and variety release, and to facilitate (international) trade, an efficient system of plant breeders' rights which is at par with the international standards provided by UPOV, is often considered a necessity (Jefferson et al, 2014; ISF, 2012). The African Seed Trade Association considers a strong PBRs system "necessary to ensure the development of new varieties that will help to overcome the new challenges that African agriculture is facing, all the more that public research in that domain is shrinking.". Ratification by African countries of UPOV 1991 "would certainly encourage private investment in Africa" according to the organization (AFSTA, 2008).

Many breeding companies and public institutions in developed countries consider the UPOV 1991 system a prerequisite for marketing or licensing their elite varieties in a particular country. The University of California-Davis for example, only licenses its varieties in jurisdictions where a 
UPOV based PBRs system is in place and together with potential licensees, encourages countries to establish one where not available (Bennett \& Carriere, 2007). Similarly, foreign breeding companies take a cautious approach to the kind of varieties they introduce into a particular country, depending not only on whether a UPOV-based PBRs system is present but also on its perceived effectiveness. In Kenya, some European seed companies and breeders in the seed potato industry have indicated they are more comfortable introducing varieties that are attractive to industry for products such as French fries and crisps rather than for ware or table varieties. The argument these companies proffer is that for processing varieties the value chain is better organised, making it easier to collect royalties, while for ware varieties where farmers have a propensity to save and re-sow seed, this is much more difficult. ${ }^{267}$

\subsubsection{Public seed systems}

The importance and functioning of PBRs in relation to public seed systems can, however, be very different. This is mainly because these seed systems often involve crops for which there is no (strong) commercial seed market and where, as a consequence, investments in formal breeding are fully dependent on public breeding programs (Tripp, 2001). Legumes and sweet potato research in Kenya serves as a good example. Public universities, the Kenya Agricultural Research Institute (KARI) - the predecessor to the Kenya Agricultural and Livestock Research Organization (KARLO), and international agricultural research centres of the CGIAR such as ICRISAT either independently or in collaboration, have been conducting legumes and sweet potato research for many years. Yet, these institutions are not major utilizers of the national PBRs system. For example, in 2013 PBRs applications were filled for only 12 of the 31 released varieties of common bean (KEPHIS, 2013), which is the most important grain legume for human consumption (Schmutz et al, 2014) and a major source of protein for the poor in Eastern and southern Africa (Katungi et al, 2009). For pigeon peas, with 8 national variety releases since 1996, no PBRs applications have been made. ${ }^{268}$ In the case of sweet potatoes, despite the official release of 21 varieties since 1996, only one PBRs application has been made. ${ }^{269}$

Some public breeders or research institutions may expect some extra income streams once a PBRs system is implemented. However, a plant breeders' right does not guarantee making money by itself and the fulfilment of this expectation depends on many more factors than just the introduction of such rights per se (De Jonge et al, 2011). In 1994, upon the passage of the

\footnotetext{
${ }^{267}$ Communication to the author by Informant 11,12 and 87.

268 Ibid, Note 265.

${ }^{269}$ Ibid, Note 265.
} 
Kenyan Seeds and Plant Varieties (Plant Breeders' Rights) Regulations, KALRO (then KARI) projected an 8\% contribution of their operating income from breeder royalties (Ndii and Byerlee, 2004). This appears to have been a very optimistic projection for in 2011 breeder royalties contributed only about $0.031 \%$ of KALRO's operating income. ${ }^{270}$

A related concern that has been raised is whether a focus on IP protection for revenue generation could potentially shift public research organizations from developing crop varieties for smallholder agriculture such as beans and millets to high value commercial crops such as maize (Louwaars et al, 2005). Looking at KALRO again, no signs justifying this concern can be found. KALRO's biggest crops research programs have been related to maize, but this has historically been the case due the importance of this crop for food security. Over time, KALRO has maintained breeding programs in place for so-called 'orphan crops', which also has been a requirement of the Kenyan government.

\subsubsection{Mixed public-private seed systems}

The role and impact of PBRs can be different again in relation to mixed public-private seed systems. In these seed systems, the public sector usually undertakes the breeding while private partners multiply and distribute seed to farmers. In such public-private partnerships, (semi-) exclusive licenses can play an important role in getting new varieties out into farmers' fields. A concern is that when a public research organization gives a newly developed variety to all seed companies operating in a particular region the risk is that, due to competition between the seed companies and low effective demand, ${ }^{271}$ the expected revenues will be too low to incentivise the uptake of the new variety by any of the seed companies. In addition, seed companies may not be keen to make investments in the marketing of a variety that has also been licensed to others as such an investment may end up benefitting competitors. So, in order to create more incentives for seed companies, the public research organizations may decide to license a new variety to only one company in a particular region. By taking out PBRs on the new variety, a public research organization is better positioned to enforce the license in the marketplace, which adds to the incentive function it wants to create. This way, public research institutes do not (only) use PBRs

\footnotetext{
${ }^{270}$ In 2011, KALRO's total internally generated revenue -inclusive of breeder royalties, seed sales and services offered to third parties for a fee, was Kenya Shillings 94.2 million (about USD 1 million) out of a total income of Kenya Shillings 3.4 billion (about USD 41.1 million). Out of the Kenya Shillings 94.2 million, revenue from breeder royalties was about Kenya Shillings five hundred thousand (about USD 5,400). Communication to the author by Informant 17.

${ }^{271}$ For example in the case of public-private seed systems catering for smallholders, who do not constitute a strong commercial market and are likely to save and re-use their seed for the next planting season.
} 
for income generation, but primarily to increase the distribution of their varieties and use by farmers.

\subsubsection{Rights and obligations of commercial farmers: the farmers' privilege}

As explained above, plant breeder's rights are intended to stimulate innovation and development in breeding by regulating rights and obligations amongst parties involved in the commercial trade of seed. Given this prime objective, it would be illogical for countries that are setting up a PBRs system to introduce exceptions that allow commercial farmers to sell, trade or exchange farm-saved seed of a protected variety as these activities would deplete the incentive function of the breeders' right and with that the whole rationale for implementing a PBRs system. A country may, however, decide to include an exception to the breeder's right that allows commercial farmers to re-use their farm-saved seed.

Under Article 15.2, UPOV 1991 includes such exception in the form of the "farmers' privilege", which is a provisional exemption that permits its members to allow farmers "to use for propagating purposes, on their own holdings, the product of the harvest which they have obtained by planting, on their own holdings, the protected variety". According to the nonbinding UPOV guidelines, the farmers' privilege should only be implemented in relation to food crops where farmers have a tradition of using farm-saved seed for the next planting season (UPOV, 2009). In other words, the use of farm-saved seed for the production of non-food crops and food crops without such a tradition is not permitted. UPOV member states are expected under Article 15.2 of UPOV 1991 to implement the farmers' privilege "within reasonable limits and subject to the safeguarding of the legitimate interests of the breeder". This implies that farmers that use farm-saved seed of a protected variety can be required to pay remuneration to the breeder.

Article 14 of the European Council Regulation on Community Plant Variety Rights, 1994 for example, includes a list of crops for which farmers are allowed to use their own farm-saved seed for which they "pay an equitable remuneration" to the PBRs holder, which is normally about $50 \%$ of the commercial royalty (Wurtenberger et al, 2006). Interestingly, small commercial farmers are exempt from such payment, with small farmers being defined as "farmers who do not grow plants on an area bigger than the area which would be needed to produce 92 tonnes of cereals" (European Council, 1994, Article 14), or comparable criteria for other plant species (e.g. 185 tons for potatoes (European Council, 1995, Article 7.3)). 
So, with respect to the rights and obligations of commercial farmers that use protected varieties, UPOV 1991 does provide its member states with flexibilities in relation to the use by farmers of their farm-saved seed. Countries are in principle free to decide for which crops the farmers' privilege will be available and how to interpret the requirement to take "the legitimate interests of the breeder" into account. The exchange and selling of farm-saved seed is, however, strictly forbidden. In the next section this chapter discusses the potential impacts this may have on smallholder farmers.

\subsection{The Potential Impact of PBRs on Farmer Managed Seed Systems: The Informal Sector}

Since in most African countries the formal sector only caters for $10 \%$ to $20 \%$ of total seed demand, African farmers are highly dependent on the customary practices of using farm-saved seed, exchanging seed amongst themselves, and trading and selling seed on local grain markets, next to practices of crossing and selection in order to improve the adaptation of crop varieties to local needs and respective environmental conditions (Almekinders and Louwaars, 1999; World Bank, 2008; Lipper et al, 2010). These farming practices are of crucial importance for the millions of smallholder farmers on the continent, who contribute up to $90 \%$ of food production in some Sub-Saharan Africa countries (Wiggins, 2009; Livingston et al, 2011). Farmer managed seed systems often safeguard the availability and affordability of seed. This is why smallholder farmers acquire seed from formal varieties mainly from the informal sector as well (Louwaars and De Boef, 2012). Apart from over-the-fence exchange of farm-saved seed, many farmers buy seed at local grain markets (Lipper et al, 2009; Sperling and McGuirre, 2010; Smale et al, 2011). By selling their surplus seed after a good season, smallholder farmers can earn a little extra income.

Looking at Kenya, for example, Ayieko and Tschirley (2006) estimate that approximately fourfifths $(78 \%)$ of all seed used comes from the informal sector. The proportions of seed either being saved, exchanged or obtained from informal markets is relatively low for maize (34\%) and rice $(15 \%)$, while for bananas, beans, pigeon peas and groundnuts, this proportion stands at $80 \%$; and for cassava, millet, Irish potato and sweet potato, it is well over 90\% (Ayieko and Tschirley, 2006). It is interesting to note that the use of farm-saved seed and buying seed from local markets is not necessarily most preferred by farmers. Potato farmers in the Njabini region of Kenya, for example, have indicated a strong preference for buying certified varieties from the formal sector, but due to the low accessibility (nearest seed potato distribution centre is 150 kilometres away) and affordability (the cost of certified seed is twice the cost of buying seed on 
the local market) of these varieties the farmers indicated to be highly depended on informal sources for their planting material. ${ }^{272}$

A further recognized benefit of farmer-to-farmer practices of saving and exchanging seed in combination with crossing and selection is that they contribute to the development of locally adapted crops that fit the specific and often challenging agro-ecological conditions in which these farmers operate (Lipper et al, 2010). Another important benefit is that these traditional farming practices are crucial for the in-situ conservation of agro-biodiversity (Zimmerer et al, 2015). This is particularly important taking into account, on the one hand, the global decline in biodiversity and on the other hand, the dependence on this biodiversity for farmers and breeders alike to cope with the challenges of feeding a growing world population in the face of climate change (Burke et al, 2009; Mercer and Perales, 2010). Since climate change is responsible for increasing both biotic (e.g. fungi; insects) and abiotic stresses (e.g. drought; salinity), farmers and breeders' access to crop diversity will be more important than ever in the years to come (Villanueva et al, 2015).

So what will be the likely impact on farmer managed seed systems once a PBRs system based on UPOV 1991 is adopted by African countries? Obviously, only new plant varieties that are eligible for a plant breeder's right will be protected by a UPOV-type PBRs system. ${ }^{273}$ This means that all varieties currently in use by farmers will remain available without restrictions on their use, exchange and sale of farm-saved seed. The real question is whether varieties protected by a plant breeder's right will be accessible to smallholder farmers? As explained above, smallholder farmers have difficulties in accessing new varieties originating from the formal sector due to several reasons, including inadequate access to markets and to financial resources to buy the seed (Rangnekar, 2002; Louwaars and de Boef, 2012). As a consequence, new and improved varieties coming from the formal sector reach smallholder farmers mainly through the same channels of exchange and local trade of farm-saved seed. Given the importance of these farming practices for seed and food security in many African countries, the introduction of a PBRs system should not further impede the accessibility of such varieties for smallholder farmers (The Crucible II Group, 2001; De Jonge, 2014; De Jonge et al, 2015). In the next section the discussion concerns how countries or regional organizations, in particular those that want to join UPOV, can create the necessary space for smallholder farmers on the basis of the exemptions included in UPOV 1991.

\footnotetext{
${ }^{272}$ Communication to the author by Informants 52 to 73. See also Braunschwig,T. (et al), 2014.

${ }^{273}$ See Articles 5 to 9 of UPOV 1991 on UPOV's conditions for the grant of the breeder's right.
} 


\subsection{Exemptions in UPOV 1991}

Next to the farmers' privilege described above, UPOV 1991 contains two other exemptions that are relevant for farmers operating in farmer managed seed systems. These are the breeders' exemption and the private and non-commercial use exemption. ${ }^{274}$ The breeders' exemption provides that the breeder's right does not extend to acts done for the purpose of breeding and exploiting other varieties. UPOV recognizes that real progress in breeding relies on access to the latest improvements and new variation and is only possible if protected varieties are available for further breeding. This can be done by any breeder using any methodology, be it a rival company that applies molecular technologies or a farmer who does basic crossing and selection. However, a licence must be negotiated with the initial breeder if the new variety is 'essentially derived' from the protected variety, meaning that the new variety was hardly changed compared to the parent variety, ${ }^{275}$ or that one requires the repeated use of the protected variety for producing the new variety. A farmer who selects for particular traits following natural or man-made crosses is developing a new variety which is not essentially derived and therefore will be exempted from the breeder's right. ${ }^{276}$

The exemption for "acts done privately and for non-commercial purposes" is not further defined in the Convention text. However, a non-binding, explanatory note from UPOV clarifies that:

"propagation of a variety by a farmer exclusively for the production of a food crop to be consumed entirely by that farmer and the dependents of the farmer living on that holding, may be considered to fall within the meaning of acts done privately and for non-commercial purposes" (UPOV, 2009).

The explanatory note continues stating that:

'Therefore, activities, including for example 'subsistence farming', where these constitute acts done privately and for non-commercial purposes, may be considered to be excluded from the scope of the breeder's right, and farmers who conduct these kinds of activities freely benefit from the availability of protected new varieties" (UPOV, 2009).

\footnotetext{
${ }^{274}$ Articles 15.1 (iii) and (i) of UPOV 1991 respectively.

${ }^{275}$ That is, the new variety retains or conforms to the initial variety in the expression of the essential characteristics that result from the genotype or combination of genotypes of the initial variety. See Article 14. 5 of UPOV, 1991.

${ }^{276}$ In the unlikely case the variety can be considered an essentially derived variety (EDV) smallholder farmers' use and production of the EDV would fall under the private and non-commercial use exemption as discussed below.
} 
This explanation does not clarify whether the exchange of seed amongst smallholder farmers would be permissible. Because it only refers to the propagation of a variety by a farmer for the production of a food crop "to be consumed entirely by that farmer and the dependents of the farmer living on that holding" (UPOV, 2009, italics added), it appears that the exemption is not meant to allow part of that food crop (e.g. grain to be used as seed) to be exchanged with anyone beyond the holding of the farmer that propagates it. More significantly, civil society organizations understand the wording of the explanatory note to imply that "even the use of the protected variety to produce food crop [sic] to be consumed by a neighbor (not living on the holding) is not seen as falling within the scope of the exception" (APBREBES, 2014). So, according to them farmers are not even allowed to share food derived from a protected variety with anyone not living on the same farm.

In 2014, however, the UPOV Council at its $31^{\text {st }}$ Extraordinary Session added two new Frequently Asked Questions (FAQs) on its website that specifically deal with exchange of seed. ${ }^{277}$ The first question is whether it is possible for subsistence farmers to exchange propagating material of protected varieties for other vital goods within the local community. Since UPOV does not specifically address or define subsistence farmers the answer to this question refers the reader to the legislation of each UPOV member country. However, it adds that:

"Within the scope of the breeder's right exceptions provided under the UPOV Conventions, UPOV Contracting Parties have the flexibility to consider, where the legitimate interests of the breeders are not significantly affected, in the occasional case of propagating material of protected varieties, allowing subsistence farmers to exchange this against other vital goods within the local community" (UPOV, 2014).

This is a small but significant sign that the UPOV Council is willing to accept a broader interpretation of the private and non-commercial use exemption as for the first time the issue of seed exchange is being positively considered, albeit under rather narrow conditions. The description suggests that the exchange of farm-saved seed with farmers from outside the local community is not allowed, which is problematic since the continued re-use of seed within the same environment favours the build-up of biotic stresses (FAO, 2011; Zegeye et al, 2014).

In addition, the references to 'vital goods' and the condition that 'the legitimate interests of the breeders are not significantly affected' seem to imply that the sale on a local market of a surplus

$\overline{277}$ Similar to UPOV's explanatory notes, these FAQs are not legally binding for UPOV members. 
harvest by a subsistence farmer is not allowed. On that point UPOV is very clear indeed: The authorization of the breeder is required for the selling of seed of a protected variety by any person. ${ }^{278}$ Yet, in the second UPOV FAQ dealing with seed exchange it is observed that under the UPOV system it is the breeders who decide the conditions and limitations under which they authorize the exploitation of their protected varieties. Therefore, on the question whether "farmers, for instance, [can] be allowed to exchange seeds of protected varieties freely within the local community?", the answer reads that "any breeder may decide on the conditions and limitations under which he authorizes the exploitation of his/her protected variety. The breeder may, for instance, allow the farmer to exchange seeds of protected varieties freely within the local community." 279 It follows that a breeder or breeding company may as well allow the sale of farm-saved seed on the local market.

It is interesting to note the European Seed Association's interpretation of UPOV's private and non-commercial use exemption in this regard. In one of its position papers, it is stated that:

"Subsistence farmers in developing countries however are not probibited to exchange seed with or sell seeds to other subsistence farmers as according to the UPOV 1991 Convention the protection conferred by a plant breeders' right does not extend to acts done privately and for non-commercial purposes" (ESA, 2011).

This interpretation of the exemption appears to be more liberal than that indicated in UPOV's explanatory note and FAQ's, and much more liberal than how some civil society organizations have interpreted the exemption. Next to being a sign of the industries' willingness to take responsibility towards the poor, there also is a cost-benefit rationale underling this position since it simply is practically and economically not feasible for a breeding company to enforce its rights on, and collect royalties from, subsistence farmers. Indeed, some foreign seed companies operating in Kenya acknowledge that collecting breeder royalties for crops such as potatoes is a costly and daunting task, more so where smallholder farmers are involved. ${ }^{280}$ In addition to the question of the practicality of enforcing royalty rights, there is a public relations issue. Even where it would be possible due to legislation available to enforce their rights against smallholder farmers, seed companies are reluctant to act for they would not want to be seen to obliterate and harm the smallholder farmer. ${ }^{281}$

\footnotetext{
${ }^{278}$ See http://www.upov.int/about/en/faq.html\#Q24 accessed on 5 June 2015.

${ }^{279}$ See http://www.upov.int/about/en/faq.html\#Q31 accessed on 5 June 2015.

${ }^{280}$ Communication to the author by Informant 11.

${ }^{281}$ Communication to the author by Informant 11.
} 


\subsection{Creating legal space for smallholders' farming practices}

The above assertions from the breeding industry show that breeding companies prefer to not enforce their rights on smallholder farmers. This implies that, when setting up a PBRs system, smallholder farmers can be exempted from the strict obligations in UPOV 1991 without this having a negative impact on the incentive function of the PBRs system and the protection of the 'legitimate interests of the breeder'. The private and non-commercial use exemption provides UPOV 1991 members with an opportunity to create space for certain categories of farmers and their farming practices to be exempted from the breeders' right. An important aspect to take into account in this respect is that UPOV's explanatory notes and FAQs, as discussed above have no legal force. The only binding obligations on UPOV member countries are those contained in the Convention text itself. And since the UPOV 1991 Convention does not define private and noncommercial use member countries are free to define the farming practices that they consider to fall within the scope of this exception (De Jonge et al, 2015).

In other words, African countries themselves and their regional organizations can include additional provisions in their legislations to allow smallholder farmers to freely save, exchange and sell farm-saved seed of protected varieties, if they wish to do so. Such interpretation of the private and non-commercial use exemption can be included in the national or regional implementation rules that complement the primary legislation (i.e. the PBRs law).

Most countries have secondary legislation to specify the way particular provisions in their PBRs laws should be implemented. ARIPO's PBRs Protocol-the Arusha Protocol for example, refers to "the list of agricultural crops and vegetables with a historical common practice of saving seed in the Contracting States specified by the Administrative Council" to indicate that in the secondary legislation the crops for which the farmers' privilege applies will be specified (ARIPO, 2015, Article 22.2). It continues to state that:

"The conditions for the implementation of the provisions underparagraph (2), such as the different level of remuneration to be paid by small scale commercial famers and large scale commercial farmers and the information to be provided by the farmer to the breeder, shall be stipulated in the implementing Regulations”. (ARIPO, 2015, Article 22.3).

Unfortunately, the Arusha Protocol only refers to the practice of seed saving and does not cover possibilities for seed trade or exchange, but these could be incorporated as well. 
Some countries have incorporated a broader farmers' privilege in their PBRs law. The recent Ugandan PBRs statute for example, includes as one of the exemptions to the breeders' rights that a farmer may "exchange seeds, plants or propagation material of plants of that variety with another farmer for purposes other than commerce" (Republic of Uganda, 2014, Article 15.c). The draft SADC PBRs treaty formulates the farmers' privilege as follows:

"... acts done by a farmer to save, use, sow, re-sow or exchange for non-commercial purposes his or her farm produce including seed of a protected variety, within reasonable limits subject to the safeguarding of the legitimate interests of the holder of the breeder's right. The reasonable limits and the means of safeguarding the legitimate interests of the holder of the breeder's right shall be prescribed" (SADC, 2014, Article 28.d).

The Ugandan PBRs legislation and the proposed SADC PBRs treaty are clearly based on the UPOV 1991 despite having incorporated a broader farmers' privilege. This may cause a problem if the country or regional organization in question want to become a member of UPOV. Because the farmers' privilege is clearly defined in UPOV 1991, any deviation from the set standard in the UPOV Convention may therefore easily be rejected by the UPOV Council, which has to approve the PBRs law of each country or regional organization that wants to become a member. Before the UPOV Council, which consists of all UPOV members, votes on the approval of a candidate member's PBRs law, the UPOV Office normally provides written feedback on the applicant's legislation. In the case of Malaysia, for example, the UPOV Office recommended several amendments that it considered necessary to bring the submitted laws in line with UPOV 1991 (UPOV, 2005b). The Arusha Protocol on the other hand, was found by the UPOV Council to be in compliance with UPOV 1991 and was approved by the UPOV Council on 11 April 2014 (UPOV, 2014).

Obviously, it is up to a country or regional organization to choose whether they should become a UPOV member. Some countries have drafted alternative sui generis systems for the protection of plant varieties which, while in compliance with the TRIPs agreement, do not comply with the UPOV '91 Convention. Examples of these sui generis systems include the Thailand (Thailand, 1999) and Indian PBRs laws (India, 2001), while on the regional level there is the African Model Legislation for the Protection of the Rights of Local Communities, Farmers and Breeders, and for the Regulation of Access to Biological Resources (Organization of African Unity, 2000). These laws provide interesting examples for those countries and regional organizations that do not want to become a member of UPOV, and they have been extensively discussed in the literature (Lertdhamtewe, 2013; Berne Declaration et al, 2014; Koonan, 2014; Correa et al, 2015). 
However, since the regional trade and IP organizations in Africa explicitly aim to establish a harmonized PBRs law on the basis of UPOV 1991, this chapter will further explore how these organizations and their member states can create space for farmer-managed seed systems within the contours of a UPOV 1991 compliant PBRs system.

As explained above, one provision that offers such space is UPOV's private and non-commercial use exemption. Since this provision itself needs no elaboration in the primary legislation (i.e. the elaboration is provided in the secondary legislation) in the event of a country submitting its primary legislation to the UPOV Council for approval, a positive decision is likely to result. The other possibility is broadening the farmers' privilege. However, this will require altering the existing UPOV provision thus making approval dependent on the decision of the UPOV Council.

Whatever option a candidate UPOV member opts for, in both cases one will have to clearly define the scope of the exemption in the secondary legislation. The challenge for African countries is, indeed, to delineate the exemption in such a way as to strike a balance between protecting the legitimate interests of breeders in order to maintain the incentive function of plant breeder's rights in the commercial market, and the leeway provided to farmers that depend on informal sources for their seed security and survival; and to do so in a practical and legally enforceable manner. How countries or regional organizations can do so will be discussed in the next section.

\subsection{Defining Different Categories of Farmers}

\subsubsection{Subsistence farmers, smallholder farmers and commercial farmers}

A differentiated PBRs system establishes different levels of protection for different crops in relation to different categories of farmers. In order to make such PBRs system legally and practically operational, a careful definition of the various categories of farmers, as well as the specific rights or exemptions each category will be entitled to is necessary. In Africa as well as globally there is a broad spectrum of farmers, ranging from very small subsistence farmers to very large commercial farmers. Clearly defining subsistence and commercial farmers could thus create two different categories of farmers, which may well be treated differently under one PBRs system. 
The Cambridge Dictionaries define commercial farming as "the production of crops and farm animals for sale, usually with the use of modern technology". ${ }^{282}$ Subsistence farming is defined as "farming that provides enough food for the farmer and their family to live on, but not enough for them to sell". ${ }^{283}$ In reality, however, any person farming for subsistence needs is likely to trade some of his or her harvest after a good harvest, which means that very few farmers can technically be regarded subsistence farmers according to the dictionary definition. The term 'smallholder farmers' does not exclude those subsistence farmers that sell their (occasional) seed surpluses on the local market. The downside of this term, however, is that the term has been used interchangeably in the literature with 'resource-poor', 'small-scale', 'family', 'peasant', 'lowincome', 'low-input', or 'low-technology' farming (Heidhues and Bruntrup, 2003). As a consequence, many different definitions exist (Nagayets, 2005; Hazell et al, 2007). The African Development Bank, for example, has in some studies defined a smallholder farmer as an individual owning less than 2.5 hectares of land (Salami et al, 2010). Dixon et al, (2004) in a FAO study defines the term 'smallholder' to refer to a farmer's limited resource endowments relative to other farmers in the sector. Others, including the fair trade movement, refer to smallholders as those who "don't depend on hired workers all the time, but run their farm mainly by using their own and their family's labour." 284

Some countries have tried to define smallholders more precisely in their PBRs laws. For example, the EU Council Regulation on Community Plant Variety Rights defines a small farmer in terms of production capacity (European Council, 2015), while the Malaysian PBRs law defines a small famer as a "farmer with the size of land of holding for farming operations not exceeding 0.2 hectare." (Malaysia, 2008, p. 14). The smallholder farmer can also be defined in terms of earnings. For example the license agreement of Syngenta on Golden Rice refers to resource-poor farmers as those earning less than US $\$ 10,000$ per year from farming, ${ }^{285}$ while the draft Ethiopian PBRs law defines a smallholder farmer as someone whose total earnings from sales of crops produced do not exceed the average household income (De Jonge, 2014). The Zimbabwean

\footnotetext{
${ }^{282}$ See http://dictionary.cambridge.org/dictionary/business-english/commercial-farming accessed on 5 June 2015.

${ }^{283}$ See http://dictionary.cambridge.org/dictionary/british/subsistence-farming. The Oxford dictionaries define a subsistence farmer in as similar way as "a person who owns or manages a farm on which they grow crops or raise livestock sufficient only for their own use, without any surplus for trade". See http://www.oxforddictionaries.com/definition/english/subsistence-farmer?q=subsistence+farmer accessed on 5 June 2015.

${ }^{284}$ See http://www.fairtrade.net/aims-of-fairtrade-standards.html\#c3948 accessed on 5 June 2015.

${ }^{285}$ See http://www.goldenrice.org/Content1-Who/who4 IP.php accessed on 5 June 2015.
} 
PBRs law refers to farmers who derive at least $80 \%$ of their annual gross income from farming on communal land or resettlement land (Zimbabwe, 2001, Article 17.3.d).

In summary, there appear to be three different ways a smallholder farmer can be classified in a PBRs law: namely with reference to 1) farm size or cropping area; 2) production or production capacity; 3) profits or income. In the remainder of this section, the pros and cons of these three approaches in relation to the two categories of farmers distinguished is discussed. The first category is the group of 'smallholder farmers' that, due to their strong dependence on informal sources for their seed and food security, are to be exempted from the breeders' rights, allowing them to use, exchange and sell farm-saved seed of protected varieties for certain crops. The second category relates to the 'commercial farmers' that are not exempted from the breeders' right but who are allowed - for certain crops - to use farm-saved seed on their own holding while paying a reduced royalty to the breeder, in line with the 'farmers' privilege' in UPOV 1991. Here, a boundary can be drawn that specifies the group of 'small commercial farmers' that could be exempted from the obligation to remunerate the breeder for the use of farm-saved seed.

\subsubsection{Farm size or cropping area}

Many studies on smallholder farming define small farms as those with less than 2 hectares of crop land (IFAD, 2006). Looking at the number of farms and their land size worldwide, this definition would include the vast majority of farmers in the world. Lowder et al (2014) in a background paper for the FAO State of Food and Agriculture 2014 estimate that there are more than 570 million farms in the world, of which more than 71\% (i.e. 410 million) have a land size of less than 1 hectare, and more than 83\% (i.e. 475 million) are less than 2 hectares in size. In Sub-Saharan Africa, according to this study, $82 \%$ of all farms are smaller than 2 hectares, and $95 \%$ is smaller than 5 hectares.

A study from Kenya by Kamau (2000) indicates that $81 \%$ of all Kenyan farms are smaller than 2 hectares, while 98\% are smaller than 10 hectares, all of which are considered small farms. Yet, according to Kamau (2000) the remaining 2\% of medium (10-60 hectares) and large (60-200+ hectares) scale farms cover about $54 \%$ of the total area farmed (see Table 6).

Table 6: Distribution of farm holdings by size and percentage of total land area in Kenya

\begin{tabular}{|l|l|l|}
\hline Size of holding (in hectares) & Percentage of total holdings & Percentage of total land area \\
\hline Under 2 ha & $81 \%$ & $46 \%$ \\
\hline
\end{tabular}




\begin{tabular}{|l|l|l|}
\hline $2-10$ ha & $17 \%$ & \\
\hline $10-20$ ha & $1.2 \%$ & $15 \%$ \\
\hline $20-60$ ha & $0.7 \%$ & \\
\hline $60-200$ ha & $0.05 \%$ & $39 \%$ \\
\hline Over 200 ha & $0.06 \%$ & \\
\hline
\end{tabular}

Source: Kamau, 2000

For monitoring purposes it seems easier to define a smallholder farmer in terms of land size. Yet, the size of a farm does in itself give no indication of the farmer that maintains it. For example, a 2 hectares farm may be situated in an isolated, low margin area where the farmer grows low rainfall crops for subsistence means, or it may be situated in a fertile area well connected to (export) markets with the farmer growing cash crops or having a greenhouse for cut flower production. In addition, many smallholder farmers are involved in contract farming growing crops like tea or coffee for closed-value chains. Next to these permanent crops, which often involve a much larger area than 2 hectares, these farmers tend to grow food crops for subsistence purposes on the side. To be able to take these dissimilarities into account, one could define a 'smallholder farmer' in terms of cropping area instead of farm size, setting parameters for different crops and in relation to different agro-ecological zones in a country or region.

Next to a definition that aims to specify the group of 'smallholder farmers' that are to be exempted from the breeders' right, one can define a second category to distinguish the group of 'small commercial farmers' that can be exempted from paying royalties on the use of farm-saved seed (i.e. the farmers' privilege). For several crops, the private sector takes the cropping area as a yardstick to calculate royalty payments for the use of protected varieties and/or farm-saved seed. In doing so, there can be a differentiation in land area or acreage for the purpose of exempting certain farmers from the obligation to remunerate the breeder for the use of farm-saved seed. ${ }^{286}$ Obviously, any such threshold needs to be tailored to the specific crop in question. In Europe, different land area thresholds apply to particular crops in various countries in defining who is a small farmer and therefore exempted from paying remuneration to the breeder (Rutz, 2008). Table 7 compares these variances between cereals and potatoes in seven European countries:

\footnotetext{
${ }^{286}$ This is also acknowledged in UPOV's explanatory note on exceptions, which states that '“small farmers' with small holdings (or small areas of crop) might be permitted to use farm-saved seed to a different extent and with a different level of remuneration to breeders than 'large farmers'." (UPOV, 2009, p. 9).
} 
Table 7: Parameters for the definition of small farmers in Europe

\section{Parameters for the definition of small (commercial) farmers in Europe}

\begin{tabular}{|l|l|l|}
\hline Country & Maximum ha (cereals) & Maximum ha (potato) \\
\hline Bulgaria & 1 & - \\
\hline Germany & 15 & 5 \\
\hline Denmark & 18 & 5 \\
\hline Estonia & 10 & 1 \\
\hline Finland & 10 & 2 \\
\hline Lithuania & 30 & 10 \\
\hline Poland & 10 & 10 \\
\hline Sweden & $18-33$ & 4 \\
\hline Slovenia & 20 & 8 \\
\hline
\end{tabular}

Source: Rutz, 2008.

ARIPO is planning to implement the same approach to determine the "different levels of remuneration to be paid by small scale commercial famers and large scale commercial farmers" (ARIPO, 2015, Article 22.3), and has asked member countries to share information on the acreage or tonnage $e^{287}$ that defines a small scale commercial farmer in their territory.

\subsubsection{Production or production capacity}

The collection of royalties on the use of farm-saved seeds under the UPOV 1991 framework can also be regulated in terms of production or production capacity. In many parts of the world, breeders use crop production levels as a parameter to determine the amount of royalties to be collected for the use of a protected variety. Most often, this involves royalty collection from (seed) producers that have a license to produce and sell the protected variety either as (certified) seed or as produce on the market. In Australia and South Africa, for example, collection of

\footnotetext{
${ }^{287}$ This is similar to the approach taken by the EU Community Plant Variety Office, which links the acreage to production capacity, see the section on production capacity.
} 
royalties of protected varieties at the point of sale of the produce is becoming increasingly common particularly in the cereal grains sector (Curtis and Nilsson, 2012). Thus instead of having the royalty included in the price of the seed that is sown, the royalty is calculated on the basis of the farm produce arising therefrom. A similar system is employed with respect to certain varieties of flowers that are grown in Eastern Africa and marketed in the Netherlands, wherein royalties are determined and collected at the point of sale, which normally is at the flower auction FloraHolland (FloraHolland Import, 2010).

This system for collecting royalties, known as end-point royalty collection, is best suited for those crops (whether ornamentals or food crops) where the value chain is well organised and (export) markets can easily be monitored. An inherent advantage of this approach is that it targets yields that are traded in commercial markets. As such, the system can be used to differentiate between farmers growing crops mainly for subsistence purposes and those farming for commercial purposes. For example, the commercial market for maize produce is fairly well organized in Kenya, with commercial millers and the National Cereals and Produce Board-a state agency, being the main market. In this way, end-point royalties could be collected from those farmers selling their maize produce to these entities. However, those farmers growing the crop for subsistence purposes and selling their produce on the local market would naturally fall outside the royalty collection system. In other words, the end-point royalty collection system will lower the seed price of protected varieties, making such varieties more accessible to smallholder farmers. Once these farmers manage to produce larger quantities they can enter the commercial market where they will pay royalties.

An important characteristic of a royalty collection mechanism at the point of sale of the produce is that it automatically covers the use of farm-saved seed. Normally, the seed (grain) that is retained for future planting is exempt from end-point royalties but the produce that will be derived from that farm-saved seed will be charged the same end-point royalty as the produce that results from purchased seed. Farmers still benefit financially from the use of farm-saved seed as they have to buy less seed for the next sowing season.

As mentioned earlier, in Europe the Community Plant Variety Office differentiates the farmers that should remunerate the breeder for the use of farm-saved seed as being those that grow plants on an area bigger than that which would be needed to produce 92 tonnes of cereals or 185 tons of potatoes (European Council, 1994; 1995). Here, production capacity is linked to cropping area. This approach allows for applying a more uniform threshold across the European Union as climatic and other agro-ecological conditions can influence the production capacity per 
hectare, which can vary considerably between countries. Another way to safeguard the legitimate interests of the breeder in relation to the use of farm-saved seed is "to specify the maximum percentage of the harvested crop which a farmer may use for further propagation." (UPOV, 2009, p. 10).

A reference to production or production capacity seems less suitable for setting the boundary of the first category that functions to exempt a certain group of 'smallholder farmers' from the breeders' rights. This is mainly because of the varying farming systems and agro-ecological conditions these farmers are operating in, which may have strong and fluctuating effects on their production capacity and actual yields.

\subsubsection{Profits or income}

The licensing example of Syngenta mentioned earlier refers to annual earnings from farming that determines which farmers may freely use the golden rice varieties (i.e. without paying a surcharge for the golden rice trait). ${ }^{288}$ Countries could take a similar approach by defining the group of 'smallholder farmers' that are exempted from the breeders' rights in terms of a particular threshold based on total income or profits from farming. This approach seems less useful for distinguishing the group of 'small commercial farmers' that can be exempted from the payment of royalties on farm-saved seed since breeders would need to have access to information on farmers' incomes. The exception being the case of contract farming.

With respect to setting an income threshold to distinguish the 'smallholder farmers' that are exempted from the breeders' right, a reference to a fixed amount as utilised in the Syngenta license may be problematic in light of steep inflation rates. To overcome this problem and to even out the potentially strong fluctuations in purchasing power over time, the Ethiopian draft PBRs bill sets the threshold in relation to the average household income, i.e. a smallholder farmer is defined as a farmer whose total earnings from sales of crops produced do not exceed the average household income. This approach is more precise than one referencing farm size in distinguishing the resource-poor farmers that one wants to allow free use of protected varieties. In addition, by linking to a country's average income, this approach can equally be applied to different countries and is independent of agro-ecological differences between regions. A major disadvantage, however, is that the monitoring and enforcement of a threshold that is defined in terms of earnings or income levels depends on a reliable system of income registration, which can be problematic when it comes to earnings derived from the informal sector.

\footnotetext{
${ }^{288}$ See http://www.goldenrice.org/Content1-Who/who4 IP.php accessed on 5 June 2015.
} 


\subsubsection{Separating commercial from smallholder farmers}

Taking into account the pros and cons of the three approaches described above, it is clear that a country will have to decide for itself what definitions for the different farmer categories will suit its agricultural conditions and administrative structures best. Also for regional organizations, a country-specific approach appears the best way forward given the huge agro-ecological variations and economic disparities that exist between countries that are members of the same regional organization. ${ }^{289}$ When drafting a legal framework to implement a differentiated PBRs system it is important to keep in mind that the primary responsibility for enforcement of breeders' rights will not be in the hands of the government but of private actors (i.e. the right holder itself or a designated institution). Such actors will need easy access to the information that is required to verify in what category a certain farmer belongs.

With respect to royalty collection on the use of farmer-saved seed, several countries exempt 'small commercial farmers' from the obligation to remunerate the breeder for using farm-saved seed on their own holding. This is mainly done on the basis of cropping area, where countryspecific thresholds are set in relation to particular crops. When implementing a regional PBRs system, the country-specific variables for cropping area can be derived from a region-wide production capacity threshold in order to come to a more even standard across different agroecological environments. Setting a threshold in terms of income or profits from farming seems less suitable because of the privacy sensitive data involved. A country may decide that the use of farm-saved seed is not allowed for all crops and exclude, for example, cut flowers and other nonfood crops from the farmers' privilege. ${ }^{290}$

The ways in which the seed and crop value chains are organised in a specific country will to a large extent determine the most practical mechanisms for royalty collection. One interesting mechanism is end-point royalty collection. Despite the fact that this approach does not normally include a differentiation in the royalty rates for purchased and farm-saved seed, it essentially targets farmers that supply national or international markets. Farmers selling their harvest surplus on the local market in addition to using the protected variety for subsistence purposes will escape the royalty collection system while benefitting from lower seed prices.

\footnotetext{
${ }^{289}$ For example, SADC encompasses both Malawi and South Africa. While Malawi is classified as a LDC, South Africa is already for years a middle-income country. According to the World Bank, in 2013, Malawi had a GNI per capita of USD 270 while South Africa in the same year had a GNI per capita of USD 7,410 (Atlas method, current US\$), see http://data.worldbank.org/country accessed on 5 June 2015.

${ }^{290}$ In case a crop, e.g. cassava, can be used for both food and non-food applications, the actual or foreseen usage of the crop may trigger different rights and obligations.
} 
The other category discussed in this section aims to define the group of 'smallholder farmers' that are to be exempted from the breeders' rights, allowing them to use, exchange and sell farmsaved seed of a protected variety. To define this category in a legally and practically enforceable manner will be a pioneering task because no country has yet implemented such exemption. From the above, it is concluded that there may be two options to choose from. The first is to define a 'smallholder farmer' in terms of cropping area (instead of total farm size) by setting boundaries for different crops and in relation to different agro-ecological zones in a country or region. The second option is to set the parameters in terms of a farmer's annual income from the sale of his or her crop produce, for example linked to the average household income in a country.

To decide on the most practical definition of a 'smallholder farmer' and the farming activities (e.g. seed saving, exchange, local trade) that should be allowed for under the private and noncommercial use exemption, it is worthwhile to also look at the issue from a breeding company's point of view. As stated above, a breeder is responsible for the enforcement measures and royalty collections in relation to the use, production and sale of those varieties he or she is the rightholder of. As a bottom-line, breeders need to be able to enforce their rights in the marketplace and a PBRs law should provide legal certainty that rightholders can stop a competitor from commercializing a protected variety. However, collecting royalties from smallholder farmers who save, exchange and locally trade relatively small amounts of seed of a protected variety is rarely worthwhile, as the cost of collecting will quickly outweigh the royalties that can be reclaimed. More importantly, forcing smallholder farmers that struggle to make a decent living to pay royalties or obstructing them from exchanging or locally trading the seed they save is morally reprehensible and would, as a consequence, seriously damage a company's reputation. It is when a farmer or farming community starts producing for a 'considerable' market that a breeder or seed producer will have an interest to enforce its rights.

The definition of 'smallholder farmer' should separate those farmers that produce for a 'considerable commercial market' from those that do not. Also, the definition applied should take into account the possibility of multiple smallholder farmers (i.e. a farming community) collaborating and producing together for such a market. Giving the huge social inequalities that proliferate in most African countries, this task may not be so difficult in respect of the vast majority of farmers after all. The division of farmland in Kenya, for example, shows that $98 \%$ of the farms are not larger than 10 hectares, while just over $0.1 \%$ of the farms are larger than 60 hectares, with both groups covering a similar share of the total land area. This major divide makes it relatively easy - with a bit of extra research on crops grown, value chains, or household 
income levels - to draw a line that separates the commercial farmers from those smallholders whose (informal) farming practices do not damage the commercial interest of a breeder's right holder. Establishing a division criterion on the basis of income levels or cropping area will also provide guidance to draw a line amongst the remaining $1.9 \%$ of Kenyan farms, which in terms of size fall in between the 'big' and 'small' farms.

\subsection{Recommendations}

African countries and regional organizations are investing in the establishment of PBRs systems across the continent. Given the importance of both commercial and farmer-managed seed systems for economic development and food security on national and household levels, the challenge for African countries is to implement a PBRs system that incentivises investments in breeding without creating extra impediments to the accessibility of formally improved but protected varieties for smallholder farmers. The goal of this chapter has been to explore the possibilities for, and describe the contours of a differentiated PBRs system that can achieve that challenge, in particular in relation to UPOV 1991 since the regional trade and IP organizations in Africa explicitly aim to establish a harmonized PBRs law on the basis of this Convention. From this review, three main recommendations for policymakers can be drawn.

Firstly, policymakers need to realise that PBRs, like any intellectual property rights, are intended to stimulate innovation and development by regulating rights and obligations amongst parties involved in commercial trade. A PBRs system will not incentivize breeding in crops for which there is no commercial market. This implies that in many African countries a PBRs system will only serve a minor share of the existing seed systems, in particular those that cater for the needs of commercial farmers linked to national and international markets. In the case of public-private seed systems, where a commercial seed market may be emerging but investments in breeding are still predominantly done by the public sector, thoughtful IP management is of crucial importance. For example, plant breeders' rights taken out by a public research organization can strengthen the incentive function of a (semi-) exclusive license to be provided to a seed company for distributing a new variety to farmers in a particular region. Yet, when public organizations work with local seed businesses in an effort to strengthen the production of quality seed in a marginalised area (e.g. by providing improved and clean propagation material for multiplication), any increase in the seed price due to costs of IP protection may negatively affect business vitality. For many crops and farming areas, breeding will continue to depend on public investments and farmer-breeding without PBRs playing an incentivizing role for many years to come. 
Secondly, African countries should seize the opportunity to establish a PBRs system that suits their specific needs. As has repeatedly been emphasized, the WTO TRIPS Agreement does not prescribe a specific PBRs system and LDCs (i.e. 35 of the 53 African countries) are still exempted from compliance with the TRIPs provisions either until 2012 or until a country ceases to be an LDC, with a possibility of this period being extended. For countries and regional organizations that aim to stimulate investments and (international) trade in commercial (export) crops by joining UPOV 1991, this chapter has identified the possibility of creating legal space for smallholder farmers and their so-called, 'informal' farming practices. One provision that offers such space is the private and non-commercial use exemption, which is not defined in UPOV 1991. Because of this African countries are free to define, in their secondary legislations the farming practices which they consider to fall within the scope of this exception. The other possibility is to broaden the farmers' privilege but this would require altering the existing UPOV provision. Since UPOV candidate members need to submit their PBRs law for review to the UPOV Council, this would make approval of a broadened farmers' privilege dependent on the decision of the UPOV Council.

Thirdly, in order to clearly define in the secondary legislations the scope of the private and noncommercial use exemption and/or a broadened farmers' privilege, policymakers should select the parameters (based on farm size or cropping area; production or production capacity; profits or income) that best fit the seed systems, agricultural conditions, administrative structures and crop value chains that exist in their country. In this way, one can distinguish different categories of farmers having different rights and obligations in relation to different crops, and do so in a practical and legally enforceable manner. This chapter explored various ways of defining 'smallholder farmers' as a category of farmers that can be exempted from the breeder's right without significantly affecting the incentive function of PBRs in the commercial market. In addition, it is analysed how countries can exempt 'small commercial farmers' from an obligation to remunerate the breeder for the use of farm-saved seed. In this way, African countries can put a differentiated PBRs system in place that protects the interests of breeders and seed producers in the commercial markets while providing leeway to those farmers that simply cannot afford to buy seed for every cropping season. This will promote formal breeding while not disrupting smallholders' farming practices of saving, exchanging and trading seed of protected varieties amongst themselves or using such varieties for crossing and selection in order to improve their adaptation to local needs and respective environmental conditions. 


\section{Chapter 7: Conclusions}

The main results of this research have been presented in the preceding five chapters, with each of these chapters containing a conclusion. This chapter does not intend to reproduce these individual conclusions but rather to collate major findings, and provide some general conclusions that can be derived from this collation.

The overarching objective of this thesis was to investigate whether the current plant breeders' rights system in Kenya is designed in a manner that enables smallholder farmers access seed and planting material of protected varieties and in so doing enabling them to positively contribute towards Kenya overcoming its food security problems. In order for this objective to be investigated in detail, it was then broken into the following three sub-objectives: (i) identifying how plant breeders' rights in Kenya operate and their implications for different seed systems in the country, (ii)mapping out legal frameworks governing plant breeders' rights and their implications for smallholder farmers taking into account international treaties and regional processes and (iii) enquiring into whether there are any existing legal spaces within the current national plant breeders' rights frameworks for right holders and policy makers that could facilitate access to seed and planting material for smallholder farmers with a view to enabling them to positively contribute towards Kenya overcoming its food security problems. These objectives are reflected in the main research question, which is whether the current plant breeders' rights system in Kenya is designed in a manner which enables smallholder farmers to access seed and planting material of protected varieties.

This chapter is arranged in four parts with each of the first three parts presenting the major findings and general conclusions that can be derived from each sub-objective. The fourth and last part contains final conclusions, recommendations and a number of questions for research that remain.

\subsection{Plant breeders' rights framework in Kenya and their implications for smallholder farmers}

Plant breeders' rights in Kenya have been in place since 1972. Whereas it took over 20 years for these frameworks to be implemented, since the commencement of implementation there has been a rapid acceleration of their function with the number of applications filed being on the face of it, evidence of their perceived utility. The ornamental crops sector in particular has been 
at the forefront in utilizing the plant breeders' rights systems in place. Of the 1,458 applications for granting plant breeders' rights that have been made since $1999^{291}, 60 \%$ of these concern carnations, roses, Alstroemeria, Chrysanthemum or other ornamental crops. Nearly all of these applications are from foreign breeders. The leading food crop in the applications - maize accounts for only 156 applications, a mere 10.6\% of the total applications made. Other food crops such as rice, wheat, Irish and sweet potato, dry bean and cassava account for a combined total of 47 applications-a paltry 3.2\%. A vast majority of the breeders for the food crop applications are local, more so public entities. Yet, these crops are the main backbone to Kenya's diet and its food security.

The number of applications for plant breeders' rights received as described above only suggests that the number of actual grants made over the applications for all crops can only be fewer. This situation suggests that the initial objective of the system, which was to among others enable farmers in Kenya to access improved foreign varieties of food crops may yet to be realized. It is noteworthy to recall that the plant breeders' rights policy was designed as a component of food policies and economic programmes of the 1980s, which emphasized increased food crop productivity for self-sufficiency purposes. ${ }^{292}$ Against this backdrop, that the plant breeders' rights system is hardly utilized for food crops may appear surprising given the policy's intention. However, once it is borne in mind that since pre-independence Kenya, legal and policy frameworks whether in relation to agricultural production, economic development, poverty alleviation or food security have been geared towards supporting commercial seed systems to which smallholder farmers appear to be incidental benefactors, then this outcome could be expected. As stated in chapter 2 of this thesis, in post-independence Kenya, Sessional Paper No. 10 on African Socialism and its Implications to Planning in Kenya (1965) set the foundation for a post-colonial policy that would see public resources deployed in activities and sectors where they would yield the most. It would appear then that by practice, remnants of this initial policy document have been carried over to subsequent ones over the years. As a result, smallholder farmer activities and sectors which mainly concerned food production for subsistence purposes did not receive public sector investments because they did not yield the most in terms of economic returns, as opposed to other activities and sectors.

\footnotetext{
${ }^{291}$ See Table 8 for a summary of these applications. Information available on https://www3.wipo.int/pluto/user/en/index.jsp (accessed on 13 May 2016). ${ }^{292}$ Sessional Paper No. 4 of 1981 on National Food Policy and Sessional Paper No. 1 of 1986 on Economic Management for Renewed Growth.
} 
Therefore, a continued pattern of disconnection between plant breeder's rights policies and smallholder farmer practices can be observed, right from the onset of the use of plant breeders' rights system in place to date. The amendments to the 1972 Seeds and Plant Varieties Act in 2012 through the Seeds and Plant Varieties (Amendment) Act, 2012 appear not to have taken into account smallholder practices on the ground. It is worth noting that the 2012 amendments to the 1972 Seeds and Plant Varieties Act were intended, amongst others, to upgrade the standards of plant variety protection from those set by UPOV 1978 to UPOV 1991. Whether these standards of protection were achieved has been a question of debate. Suffice to say, on the basis of these amendments Kenya subsequently in April 2016, deposited its instrument of accession to UPOV 1991 with UPOV 1991 entering into force for Kenya on 11 May $2016 .{ }^{293}$

The implications for smallholder farmers of the current design of the plant breeders' rights system have been the subject of direct and indirect criticisms, with civil society organizations being at the forefront. The first argument provided concerns the fact that a UPOV 1991 based plant breeder's rights system denies smallholder farmers opportunities to continue exercising some of their age old cultural practices, e.g. saving, re-using, exchanging and selling farm-saved seed, whether of protected varieties or not. This is especially the case since in implementation of UPOV 1991 based plant breeders' rights systems, no developing country has taken a crop by crop approach in its application of farmers' privilege. Therefore while these practices may provide channels for access to a diversity of seeds for farmers for many crops that are not protected, the fact that in its application there is no differentiation between protected and unprotected varieties of seeds then leads to the opportunity to access seeds of unprotected varieties in this manner being lost due to the associated risk of accessing protected varieties in a similar manner. A likely result in restricting or prohibiting smallholder farmers from exercising these age-old cultural practices is food insecurity.

A second criticism that is leveled against plant breeders' rights systems that are designed similar to Kenya's system relate to compliance with other international obligations that concern the conservation, sustainable use and access to and benefit sharing in relation to plant genetic resources for food and agriculture. Whereas Kenya is a party to the International Treaty on Plant Genetic Resources for Food and Agriculture (Plant Treaty) and has even contributed material to

\footnotetext{
${ }^{293}$ Information available from http://www.upov.int/edocs/pressdocs/en/upov pr 105.pdf (accessed on 13 May 2016).
} 
the Multilateral System of the Plant Treaty ${ }^{294}$, its national policy and legislative framework does not support all provisions of the Treaty. The most notable of all provisions of the Treaty for which no policy or legislative framework exists in Kenya concerns Farmers' Rights. It is without a doubt that Farmers' Rights are an inalienable feature of smallholder farmers' practices. The Plant Treaty provides a non-exhaustive list of measures that countries may take to protect and promote Farmers' Rights and a brief examination of each of these measures against Kenya's national policy and legislative framework is imperative. The first measure is protection of traditional knowledge relevant to plant genetic resources for food and agriculture. ${ }^{295}$ Article 11 (3) (c) of The Kenyan Constitution requires the State to enact legislation that recognizes and protects the ownership of indigenous seeds and plant varieties, their genetic and diverse characteristics and their use by communities in Kenya. This Constitution was promulgated in 2010 and the expectation would have been that the Seeds and Plant Varieties (Amendment) Act, 2012 would have had a hand in implementation of this constitutional provision, which is very much in line with Article 9.2(a) of the Plant Treaty. However, there is nothing in the national policy and legislation on plant breeders' rights that gives effect to Article 9.2(a) of the Plant Treaty and Article 11 (3) (c) of the Kenya Constitution and therefore traditional knowledge relevant to plant genetic resources for food and agriculture remains unrecognized within the plant breeders' rights framework. In 2016, the Protection of Traditional Knowledge Act was passed by Parliament. While the objective of this statute is to among others give effect to Article 11 of the Kenya Constitution, it does not make any reference to seeds or para-reference the national plant breeders' rights framework in place. Furthermore, the mechanism this legislation provides for the protection of traditional knowledge is quite burdensome and almost impossible to implement for it requires each of the 47 county governments in the country to establish a traditional knowledge register and repository. Given that many communities traverse across numerous counties implementability of such a protection measure would be an arduous task.

The second measure to protect Farmers' Rights relates to the right to equitably participate in sharing benefits arising from utilization of plant genetic resources for food and agriculture. Article 69(1) (a) of the Kenya Constitution requires the State to ensure among others, equitable sharing of benefits accruing from sustainable exploitation of natural resources. Taken in the context of seeds and plant varieties, there is nothing in the national policy and legislation on plant breeders' rights that makes provision for this to occur. Section 24 of the Traditional

\footnotetext{
${ }^{294}$ Information available at http://www.planttreaty.org/sites/default/files/inclu kenya.pdf (accessed on 13 May 2016).

${ }^{295}$ IT, Article 9.2(a).
} 
Knowledge Act, 2016 recognizes the right to sharing of benefit arising from the commercial or industrial use of traditional knowledge and may provide solace in implementation of Article 9.2(b) of the Plant Treaty. However, difficulties will arise in the practical implementation of this right, as administratively this could potentially involve consultations with as many county governments as there may be registered and claimants of the right to the traditional knowledge being exploited.

The third measure to protect Farmers' Rights that is prescribed in the Plant Treaty relates to the right to participate in making decision, at the national level, on matters related to the conservation and sustainable use of plant genetic resources for food and agriculture. ${ }^{296}$ Public participation in decision making is an entitlement that is enshrined in the Kenya Constitution in various contexts such as in the management, protection and conservation of natural resources; ${ }^{297}$ and in legislative affairs both at the national and county levels. ${ }^{298}$ In effect, based on these constitutional provisions the State ought to have consulted the public prior or during the process of ratification of UPOV 1991. However, the silent manner in which the government took the decision to join UPOV 1991 is evidence of non-implementation of Article 9.2 (c) of the Plant Treaty and of an open flout of the constitutional provisions on public participation. The Protection of Traditional Knowledge Act, 2016 does not come in aid of the State action for its provision on public participation is narrowed to apply only to instances where access decisions have to be made and in that event, follows the traditional process for decision making. ${ }^{299}$

As demonstrated above, the conflicting implementation of these international obligations related to the granting of plant breeders' rights on the one hand, and Famers' Rights on the other hand, influences smallholder farmers' access to seed and planting material in several ways. Most notable is the fact since the enactment of the 2012 SPVA Amendment, seed saving, use, exchange and sale of farm-saved seed of a protected variety is by law illegal. Although a farmers' privilege provision exists in the 2012 SPVA Amendment, its non-elaboration through regulations do not aid in curing this illegality.

An unintended consequence of the conflicting implementation of these international obligations relating to the grant of plant breeders' rights on the one hand, and Farmers' Rights on the other

\footnotetext{
${ }^{296}$ IT, Article 9.2(c).

${ }^{297}$ Constitution of Kenya, Article 69(1).

${ }^{298}$ Constitution of Kenya, Articles 118 (1) and 196.

${ }^{299}$ The Protection of Traditional Knowledge Act, 2016, section 25.
} 
hand is that both rights stand at a conflict. This is because what is considered to be a right in one is an infringement in the other. This conflict has not gone without notice at the international level. The respective governing bodies of the two instruments concerned - the Governing Body of the Plant Treaty and the UPOV Council are exploring possible interrelations between the two instruments. ${ }^{300}$ A number of outcomes in this thesis provide a glimpse of some of the solutions that could be found in resolving this conflict. These are discussed in more detail in section $\mathrm{C}$ below. Let it suffice to say that providing a differentiated approach to plant variety protection would entail the utilization of legal space by setting limitations and exceptions to plant breeders' rights. This legal space includes the full utilization of the so-called farmers' privilege and the exceptions from protection for private and non-commercial use. Holding this conflict against Kenya's plant breeders' rights legislation, it can be concluded that whereas a farmers' privilege provision is now included in Kenya's plant breeders' rights legislation, further elaboration of this provision through implementing regulations is necessary so as to render any exchange and sale of farm-saved seed of protected varieties legal. Furthermore, in its quest to upgrade the plant breeders' rights regime to UPOV 1991 through the 2012 SPVA Amendment, provision for a private and non-commercial use exception was not made. Yet, the private and non-commercial use exception is one of the compulsory exceptions contained in Article 15(1) of UPOV 1991. It is important to note that the UPOV Council has in its explanatory ${ }^{301}$ and $\mathrm{FAQ}^{302}$ documents interpreted private and non-commercial use activities to include subsistence farming, which is a common form for agriculture in Kenya especially in relation to most food crops.

An inevitable question that now arises with Kenya's ratification of UPOV 1991 is whether its framework for plant breeder' rights complies with Article 30(2) of UPOV 1991. In a nutshell, Article 30(2) of UPOV 1991 provides that a country depositing an instrument of ratification of the UPOV 1991 is understood to ensure that its laws conform to the provisions of UPOV 1991. Article 30(2) of the UPOV 1991, when read together with Article 30(1), imply that in implementing UPOV 1991, a country must adopt all measures necessary for the implementation of this Convention. Given that the private and non-commercial use exception is a 'compulsory' exception under Article 15(1), it can only be read that this exception is one of the 'measures necessary for the implementation of this Convention'. Consequently, it appears that Kenya has deposited its instrument of accession to UPOV 1991 when its national legislation did not yet

\footnotetext{
300 UPOV-ITPGRFA/SYM/GE/16. Symposium on Possible Interrelations between the International Treaty on Plant Genetic Resources for Food and Agriculture (ITPGRFA) and the International Convention for the Protection of New Varieties of Plants (UPOV Convention).

${ }^{301}$ Document UPOV/EXN/EXC/1 dated October 22, 1999.

302 Information available from http://www.upov.int/about/en/faq.html (accessed on 13 May 2016).
} 
comply with the provision of this Convention.

\subsection{Harmonization of plant breeders' rights frameworks at the regional level: risks, concerns and opportunities for smallholder farmers in Kenya.}

At a first glance, the process of harmonization of plant breeders' rights regimes at the regional level, particularly through the Arusha Protocol for the Protection of New Varieties of Plants appears unlikely to have any direct effect on Kenyan smallholder farmers' access to seeds and planting material. However, this process may still pose some risks to smallholder farmers in Kenya should the country accede to the Protocol, and the Protocol enters into force. ${ }^{303}$ At the same time, the Protocol does offer some opportunities.

The risks and concerns to smallholder farmers mainly arise from the mismatch there is between the Arusha Protocol and Kenya's plant breeders' rights provisions on the farmers' privilege. The Arusha Protocol takes a listing approach, providing that a list of agricultural crops and vegetables with a historical common practice of saving seed in the Contracting States specified by the Administrative Council of ARIPO shall form the basis of the farmers' privilege. ${ }^{304}$ This list excludes fruits, ornamentals, vegetables and forest tress. The Protocol further states that the function of setting different conditions of implementing the farmers' privilege by various levels of remuneration to be paid by small-scale commercial farmers as opposed to large-scale commercial farmers and different information requirements to be met by the farmer in relation to the breeder, shall be stipulated in the regulations. ${ }^{305}$

Kenya's approach to implementing the farmers' privilege is by a simple regurgitation of Article 15(2) of UPOV 1991. A question therefore remains whether fruits, ornamentals, vegetables or forest trees would otherwise qualify for farmers' privilege under Kenyan law. Another mismatch occurs, as the Kenyan regime does not give a hint or direction on which conditions may have to be fulfilled in order to qualify for the privilege. These mismatches would bring about uncertainties both to breeders and (smallholder) farmers in their quest to exercise their rights in Kenya in case Kenya would accede to the Arusha Protocol and consequently the Protocol would enter into force.

\footnotetext{
${ }^{303}$ As at 20 October 2016, 5 countries had signed the Protocol, with none having deposited any instrument of ratification or accession. Kenya was not among these five countries.

${ }^{304}$ Arusha Protocol, Article 22(2).

${ }^{305} \mathrm{Ibid}$, Article 22(3).
} 
The absence of the private and non-commercial use exception in the Kenyan plant breeder's rights regime also contains risks and concerns, as well as opportunities in the context of harmonization of its national regime with the Arusha Protocol. In Article 22(1)(a), the Arusha Protocol provides for a private and non-commercial use exception exactly similar to UPOV 1991 as provided in its Article 15(1)(i). The UPOV Council through a FAQ has elaborated one manner in which this exception may be utilized at the national level and how it should be understood. As UPOV has stated, "UPOV Contracting Parties have the flexibility to consider, where the legitimate interests of the breeder are not significantly affected, in the occasional case of propagating material of protected varieties, allowing subsistence farmers to exchange this against other vital goods within the local community. ${ }^{306}$ This interpretation by UPOV could therefore carry and be applied to interpretation of the private and non-commercial use provision in the Arusha Protocol. However, the absence of this exception in the Kenya regime obviously brings about the absence of the opportunity to give a similar interpretation to the exception at the national level. This mismatch as between the Kenya regime and the Arusha Protocol on this element is also likely to cause legal uncertainty and bring about more confusion on those subsistence-farming activities that smallholder farmers may engage in without breaking the law.

The above notwithstanding, it is worthy to note that the presence of the private and noncommercial use exception under the Arusha Protocol provides an opportunity for its availability at the national level in Kenya. However, this opportunity must be preconditioned upon all of the following: (i) Kenya depositing an instrument of accession to the Arusha Protocol; (ii) the Arusha Protocol coming into force; and, (iii) the Arusha Protocol defining and implementing the exception through its regulations. The Special Rapporteur on the Right to Food ${ }^{307}$ and African civil society organizations ${ }^{308}$ have been urging the ARIPO to take into account the needs of smallholder farmers when giving meaning to the private and non-commercial use exception in the implementing regulations to the Arusha Protocol. However, the ARIPO Secretariat appears to be unresponsive to these requests. Without proper definition and implementation of the exception in the implementing regulations to the Arusha Protocol, no benefit for smallholder farmers would result from the Protocol coming into force even if Kenya was to accede to it.

\footnotetext{
${ }^{306}$ www.upov.int/about/en/faq.html (accessed on 13 May 2016).

307 Open Letter dated 24 November 2016 to the Member States of the African Regional Protocol for the Protection of New Varieties of Plant from the Special Rapporteur on the Right to Food.

${ }^{308}$ Open Letter dated 11 April 2017 to the Director General of the African Regional Intellectual Property Organization (ARIPO) from the African Centre for Biodiversity, the Alliance of Food Sovereignty in Africa and Pelum Association.
} 
ARIPO member countries each subscribe to different international treaties and instruments that provide for different standards for protection of or in dealing with plant breeders' rights. The different subscriptions also provide some risks, concerns and opportunities to the Kenyan smallholders in the context of the intended harmonization of plant breeders' rights at the regional level. Of the nineteen ARIPO member countries nine (to which Kenya is not among them) are members of the Southern African Development Cooperation (SADC). SADC is developing a separate and different regional plant breeders' rights regime for its member countries. At the same time, only two of the ARIPO member countries-Kenya and Tanzania, are parties to UPOV 1991 and therefore, notwithstanding some of the gaps contained in Kenya's plant breeders' rights regime they are expected to hold the UPOV 1991 standards. While most of the ARIPO member countries are parties to the WTO, a vast majority of those are designated as Least Developed Countries, meaning that they are currently under no obligation to put in place plant breeders' rights regimes. However, should these countries accede to the Arusha Protocol, they will by implication comply with this WTO obligation. While Kenya is not a Least Developed Country, all its neighbours and members of the East African Community (EAC) to which it is a member are. At the EAC, discussions concerning plant breeders' rights and seed trade issues are taking place as well. Yet, while all EAC members are members of ARIPO, their membership is also scattered between UPOV (Kenya and Tanzania) and SADC (Tanzania). The risk of different standards arising in the harmonization processes is therefore real. To smallholder farmers and small seed traders selling seed in a local market, the risk is in the difficulty of finding out under which regime a particular variety is protected and thus what exemptions may apply, if any.

The process of harmonizing regional plant breeders' rights frameworks carries with itself some risks, concerns and opportunities for smallholder famers in Kenya. These risks, concerns and opportunities should be taken into account as Kenya being a member of ARIPO continues to engage with the Arusha Protocol process. Without taking these into account, the country may not progress efforts to overcome the food security problems

\subsection{Existing legal spaces within the current national plant breeders' rights frameworks to facilitate access to seeds for smallholder farmers}

As this thesis has shown in chapter 2 there are at least six seed systems operational in Kenya with smallholder famers mostly relying on farmer-based seed systems and community based seed 
systems to access seed for many crops. According to the 2010 National Seed Policy, these two seed systems fall under the informal domain and receive least policy and legislative support. This implies that a disengagement exists between policy that government sets and smallholder farmer activities on the ground. A number of legal spaces within the current plant breeder's rights framework exist. These legal spaces if utilized, could facilitate access to seeds for smallholder farmers and contribute towards bridging the gap that currently exists between policy and practices on the ground.

Some narrow legal space is to be found within the national plant breeders' rights framework itself, which consists mainly of the 1972 Seeds and Plant Varieties Act, and the Seeds and Plant Varieties (Amendment) Act, 2012. The latter statute has domesticated the farmers' privilege. The existence of this provision in itself creates no legal space at all since on the face of it, it rendered exchange and sale of farm saved seed illegal. However, it is possible to find a gap through implementing regulations, if drafted. Crafted to take into account different factors such as categories of farmers that exist in Kenya, defined on the basis of farm size or cropping area, yield or production capacity, profits or income, such regulations can provide for a differentiated mechanism through which different sets of farmers could enjoy the breadth of plant breeders' rights differently. As the economic wellbeing of smallholder farmers changes so will be their rights and obligations.

In Kenya as anywhere else in the word, a broad spectrum of farmers is found, ranging from pure and small subsistence ones to huge commercial enterprises. ${ }^{309}$ The existence of different seed systems is only but part of wider evidence of the existing variance of different categories of farmers. It is also notable that farmers can use and operate in different seed systems to access seeds for different crops, and in some cases even one and the same crops. For example, a farmer could access hybrid and OPV seed for maize from different sources, or purchase protected seed for wheat while at the same time replanting seed saved from the previous harvest. In furthering implementation of the farmers' privilege or the private and non-commercial use exception it is possible, taking the different categories of farmers that are available, to then differentiate the set of rights and obligations that will apply to each. Already, studies on farm size distribution in Kenya have been undertaken (Kamau, 2000) and could be used as a parameter in making decisions how to allocate different rights and obligations to farmers in relation to access to seeds for protected varieties. Cropping area linked to yields of specific set of crops across different countries in the European Union has been used as a parameter to define different categories of

${ }^{309}$ A report of a High Level Round-Table Meeting on Plant Variety Protection in Africa 27-28 November, 2014. 
farmers and thereafter determining the obligation to pay royalties for farm saved seed of protected varieties.

Legal space is also to be found within the regional plant breeders' rights framework as contained in the Arusha Protocol for the Protection of New Varieties of Plants. The legal space in question is in the form of the private and non-commercial use exception in the Arusha Protocol. The existence of this legal space however, is dependent upon (i) Kenya's accession to the Arusha Protocol; (ii) the Arusha Protocol entering into force, and; (iii) the Arusha Protocol defining and implementing the exception through its regulations. Kenya's national plant breeders' rights legislation does not make provision for this exception. While the availability of this exception is preconditioned upon a host of factors which render the possibility of it being available to be rather narrow, it is worth to note that the exception itself has the possibility of a wide interpretation. To begin with, the UPOV Convention itself does not define the meaning of 'private and non-commercial use exception'. Secondly, UPOV Explanatory Notes and FAQ only provide a possible interpretation of this exception and have no legal force. It is therefore implied that ARIPO countries could choose to make a broad interpretation of the private and noncommercial use exception in a way that creates space to accommodate the needs of smallholder farmers. A broad interpretation of this exception could enable smallholder farmers access seeds and planting material for subsistence purposes without being found to infringe upon the rights of holders of protected varieties.

Finally, legal space may be found within the contractual arrangements that plant breeders enter into for the purpose of making their varieties available. It has emerged that plant breeders do not necessarily exercise their rights to the full extent, but may contractually waive some of their rights with seed multipliers in favour of smallholder farmers. Thus, breeders are by contracts foregoing collection of their royalties especially in relation to food crops where smallholder farmers are involved. As a result, even where subsequent to accessing seed of protected varieties smallholder farmers save, reuse, exchange and sell it in local markets, there is no risk of a breeder enforcing rights against these farmers.

Though only exercised at their discretion, these waivers of rights by plant breeders appear to create legal space through which smallholder farmers may access and use seeds of protected varieties. While this waiver of rights provides an alternative legal space to smallholder farmers, the challenge that comes with it is that the applicability or availability of this space is dependent upon the views of the plant breeder. How farmers may know for which variety there is a waiver is subject to the extent to which the breeder may wish to communicate. Furthermore, the 
presence of third party intermediaries who cover some transactional costs relating to making a protected variety reach the smallholder farmer at the least costs possible dilutes the efficacy of the space available, as the decision of the breeder has to also take into account the interests of other parties involved in the process. Thus this space is only on a case-by-case basis and to the extent that it satisfies the strategic interests of the breeder, taking into account the interests of other intermediaries involved.

\subsection{Final Conclusions and Recommendations}

Through three objectives, this thesis set out to answer the question whether the current plant breeders' rights system in Kenya is designed in a manner that enables smallholder farmers to access seed and planting material of protected varieties. A study into the seed systems in place finds that a diversity of seed systems exists. However, the legal and policy framework in place in particular with respect to plant breeders' rights is designed to make provision for only some, not all of them.

A key finding in this thesis is that the need for Kenya to put in place a plant breeders' rights framework is partly driven by the necessity to comply with international trade obligations resulting from the country's membership to the World Trade Organization. However, the manner in which the country has implemented the plant breeder's rights framework is in conflict with (a) the farming practices on the ground especially those of the smallholder farmers who are majority of the farming community and (b) other international obligations relating to conservation, sustainable use and access and benefit sharing of plant genetic resources for food and agriculture. Plant breeders' rights inherently aim to create incentives for investments in breeding with a view to deliver better varieties in the hands of farmers. In a country such as Kenya where the commercial market for protected varieties is limited for many crops, it is necessary for a balance to be found between intended incentives for investment in breeding, and the needs of smallholder farmers. The public sector may come in aid in finding this balance. As this thesis shows in Chapter 5, the role of plant breeders' rights in incentivizing breeding in the public seed systems functions very differently. Plant breeders' rights are applied for in respect of very few crops in which public breeding investments are made. If public investments in breeding are only to be made in crops for which revenue generation will be highest, this is likely to lead to crops which are important for human consumption yet less profitable being neglected. Continuous investment in public breeding for all crops including those that are less profitable is likely to lead to the genetic resources for these crops being conserved and sustainably used, thus creating some balance in the dealing with some of the needs of smallholder farmers. 
This thesis also finds that regional processes in sub-Saharan Africa to harmonize plant breeders' rights regimes are likely to exacerbate conflicts between plant breeders' rights policies and smallholder farmer practices in Kenya. While this brings about risks and concerns, it also presents some opportunities for smallholder farmers. All these require to be weighed with a view to ensure that smallholder farmers can access seed and planting material for home consumption, livelihood improvement, and food security purposes.

This thesis makes a number of recommendations for policy makers. First, there is need for the national plant breeders' rights framework to be changed with a view to accommodate the private and non-commercial use exception to plant breeders' rights. This provision could also be introduced through Kenya acceding to the Arusha Protocol on the Protection of New Varieties of Plants inasmuch as this route would be subject to the Arusha Protocol entering into force, and at the same time defining and implementing the exception through its regulations. Secondly, implementing regulations to farmers' privilege should be introduced taking into account a list of crops for which farmers may be allowed to use their own farm saved seeds. In such regulations, exemption from payment of an equitable remuneration to the holder of the right may be granted to smallholder farmers. A likely outcome of introduction of the private and non-commercial use exception and of regulation to implement the farmers' privilege would be an increase in legal certainty amongst smallholder farmers on access to protected varieties. This is essential for food security.

With respect the processes to harmonize plant breeders' rights regimes at the regional level, this thesis would recommend that the ARIPO and SADC do hold joint discussions with a view to harmonize their provisions as much as possible. Such harmonization is likely to lead to lesser conflicts in national implementation of the adopted plant breeders' rights instruments.

Plant breeders often exercise their rights in a manner that is conscious of the needs of smallholder farmers. By waiving some of their rights in respect of protected varieties, plant breeders enable smallholder farmers to freely access these varieties without having the fear of being accused of infringement. Such waivers may play either complementary or alternative roles to policy responses with the smallholder farmer being the ultimate benefactor. If the government does not take its responsibility to look at the needs of smallholder farmers who are amongst the most vulnerable or how Farmers' Rights can be implemented, plant breeders and seed companies can still do so in the process of making decisions on when to protect their rights. This thesis would therefore recommend that plant breeders be more open and explicit in doing so, and in a manner that is conscious of the needs of the smallholder farmers. 
Finally there are a number of questions that remain for research which if pursued, would greatly contribute towards this debate.

The first question is whether patents in plants are likely to limit or increase access to seeds for smallholder farmers in many developing and African countries including Kenya. The threats to food security posed by climate change in the face of an ever-increasing human population have brought about the need to use increasingly advanced breeding technologies to improve crop yields. When protected through Kenyan patents, such technologies may greatly limit incremental research in plant breeding. In Kenya and much of Africa, the use of patents in plant breeding is rising as evidence is abound in the development of water efficient maize varieties. Given the fact that the exceptions of plant breeders' rights are not applicable to the Kenyan patent law, it is likely that this increased use of patents in plant breeding will affect how farmers will access seeds to these varieties.

The question of harmonization of plant breeders' rights at the regional level in Africa is also another which requires further research. While international trade commitments have necessitated the need to put in place plant breeders' rights frameworks, it should be borne in mind that many countries in Africa are at different levels of development. This implies that their international trade obligations differ and as a result, so should their commitments. It therefore follows that it is necessary that harmonization of plant breeders' rights be researched further, so as to ensure that further conflicts in national implementation across different countries are minimized.

This thesis demonstrates that plant breeders' rights have the potential to influence important seed systems in Kenya. Policy makers should carefully assess internationally harmonized plant breeders' rights systems before subscribing to them in order to ensure that national implementation of such systems fully concurs with national agricultural development and food security policy objectives. Where national agricultural development and food security objectives are taken into account in their implementation, such plant breeders' rights system can enable smallholder farmers to positively contribute towards Kenya overcoming its food security problems. 
Table: 8 PBRs Applications in Kenya since 1999 to August 2016

\begin{tabular}{|c|c|c|c|}
\hline Common name & Variety description & & \\
\hline Rose & Ornamental crop & 720 & 875 \\
\hline Hypericum & Ornamental crop & 6 & \\
\hline Pelargonium & Ornamental crop & 4 & \\
\hline Eryngium & Ornamental crop & 1 & \\
\hline Marigold & Ornamental crop & 1 & \\
\hline Pyrethrum & Ornamental crop & 23 & \\
\hline Carnations & Ornamental crop & 7 & \\
\hline Gypsophila & Ornamental crop & 14 & \\
\hline Mandevilla & Ornamental crop & 2 & \\
\hline Spider plant & Ornamental crop & 1 & \\
\hline Calla lilly & Ornamental crop & 5 & \\
\hline Limonium (Statice) & Ornamental crop & 6 & \\
\hline Phlox & Ornamental crop & 5 & \\
\hline Pin cushion flower & Ornamental crop & 1 & \\
\hline Chrysanthemum & Ornamental crop & 27 & \\
\hline Zantedeschia & Ornamental crop & 1 & \\
\hline Alstroemeria & Ornamental crop & 38 & \\
\hline Carnation & Ornamental crop & 7 & \\
\hline Milk weed & Ornamental crop & 1 & \\
\hline Golden rod & Ornamental crop & 2 & \\
\hline Aster & Ornamental crop & 2 & \\
\hline
\end{tabular}




\begin{tabular}{|c|c|c|c|}
\hline Birds of paradise & Ornamental crop & 1 & \\
\hline Sugar cane & Grass crop & 6 & 18 \\
\hline Rhodes grass & Grass crop & 6 & \\
\hline Coloured guinea grass & Grass crop & 1 & \\
\hline Setaria grass & Grass crop & 2 & \\
\hline Congo signal grass & Grass crop & 1 & \\
\hline Pepper grass & Grass crop & 1 & \\
\hline Other grass & Grass crop & 1 & \\
\hline Cotton & Oil and fibre crop & 2 & 29 \\
\hline Safflower & Oil crop & 1 & \\
\hline Rape seed & Oil crop & 14 & \\
\hline Sunflower & Oil crop & 12 & \\
\hline Blueberry & Fruit crop & 5 & 33 \\
\hline Raspberry & Fruit crop & 8 & \\
\hline Strawberry & Fruit crop & 6 & \\
\hline Sweet yellow passion fruit & Fruit crop & 5 & \\
\hline Granadilla & Fruit crop & 1 & \\
\hline Pineapple & Fruit crop & 3 & \\
\hline Avocado & Fruit crop & 5 & \\
\hline Mung bean & Legume crop & 3 & 74 \\
\hline Cowpea & Legume crop & 4 & \\
\hline Finger millet & Legume crop & 2 & \\
\hline
\end{tabular}




\begin{tabular}{|c|c|c|c|}
\hline Proso millet & Legume crop & 1 & \\
\hline Pearl millet & Legume crop & 3 & \\
\hline Pigeon pea & Legume crop & 4 & \\
\hline Dolichos bean & Legume crop & 2 & \\
\hline Castor bean & Legume crop & 2 & \\
\hline Pea & Legume crop & 9 & \\
\hline Dry bean & Legume crop & 15 & \\
\hline Runner bean & Legume crop & 3 & \\
\hline Snap pea & Legume crop & 1 & \\
\hline Other beans & Legume crop & 24 & \\
\hline Sunhemp & Legume crop & 1 & \\
\hline French bean & Vegetable crop & 34 & 45 \\
\hline Amaranthus & Vegetable crop & 5 & \\
\hline Cabbage & Vegetable crop & 1 & \\
\hline Crotolaria & Vegetable crop & 1 & \\
\hline Tomato & Vegetable crop & 1 & \\
\hline Pumpkin & Vegetable crop & 1 & \\
\hline Pepper (Capsicum) & Vegetable crop & 1 & \\
\hline Black night shade & Vegetable crop & 1 & \\
\hline Sweet potato & Root and tuber crop & 1 & 38 \\
\hline Cassava & Root and tuber crop & 8 & \\
\hline Irish potato & Root and tuber crop & 29 & \\
\hline
\end{tabular}




\begin{tabular}{|l|l|l|l|}
\hline Maize & Cereal crop & 156 & 215 \\
\hline Sorghum & Cereal crop & 9 & \\
\hline Oats & Cereal crop & 3 & \\
\hline Wheat & Cereal crop & 33 & \\
\hline Barley & Cereal crop & 13 & \\
\hline Rice & Cereal crop & 1 & 30 \\
\hline Macadamia nuts & Tree crop & 22 & \\
\hline Eucalyptus & Tree crop & 8 & \\
\hline Coffee & Plantation crop & 7 & \\
\hline Tea & Plantation crop & 3 & \\
\hline Stevia & Plantation crop & 1 & \\
\hline Clover & Plantation crop & 5 & \\
\hline Grape vine & Vine crop & & \\
\hline
\end{tabular}

Information obtained from the UPOV Plant Variety Database, accessible at https://www3.wipo.int/pluto/user/en/index.jsp (accessed on 27 September 2016). 


\section{References}

A.F.M. Maniruzzaman, 'State Contracts in Contemporary International Law: Monist Versus Dualist Controversies', European Journal of International Law Vol 12, No. 2 (2001): 309-28.

AFIDEP and PAI. (2012). "Population, Climate Change, and Sustainable Development in Kenya", Nairobi and Washington, DC: African Institute for Development Policy (AFIDEP) and Population Action International (PAI).

African Centre for Biosafety (ACB) (2012). Harmonization of Africa's seed laws: a recipe for disasterPlayers, motives and dynamics. Agriculture, Energy and Livelihood Series. Melville: ACB.

African Regional Intellectual Property Organization (ARIPO) (2015).

Arusha Protocol For The Protection Of New Varieties Of Plants. 6 July

2015, Arusha, Tanzania.

Alliance for Food Sovereignty in Africa. AFS A makes small gains for farmers' rights in draft SADC PV P Protocol. A briefing paper. June 2014.

African Seed Trade Association (AFSTA). (2008). AFSTA Position Paper on Informal Seed System. Adopted by the AFSTA General Assembly on 29 February 2008. Retrieved from http://afsta.org/media/newsletter/position-paper// [Accessed on 6 August 2015].

African Union Commission (2011), Communiqué on Integrated Seed Sector Development. Retrieved from https://www.wageningenur.nl/en/show/Integrated-seed-sector-development-inAfrica.htm

Alliance for the Green Revolution in Africa Progress Report 2007-2014. Nairobi (AGRA). March 2015. Almekinders, C.J.M., N.P. Louwaars and G.H. de Bruijn (1994). Local seed systems and their importance for an improved seed supply in developing countries. Euphytica 78: 207-216.

Almekinders, C.J.M. and N.P. Louwaars (1999). Farmers' seed production: New approaches and practices. London, Intermediate Technology Publications. 291pp 
Anatole Krattiger, R.T. Mahoney, L. Nelsen, J.A. Thomson, A.B.Bennett, K. Satyarayana, G.D. Graff, C. Fernandez and S.T Kowalski (Eds) (2006). Intellectual Property Management in Health and Agricultural Innovation: A Handbook of Best Practices. MIHR: Oxford, UK, and PIPRA: Davis, USA.

Andersen, R. (2005). The History of Farmers' Rights: A Guide to Central Documents and Literature. The Fridtjof Nansen Institute, Lysaker.

(2006). Realising Farmers' Rights Under the International Treaty on Plant Genetic Resources for Food and Agriculture: Summary of Findings from The Farmers' Rights Project, Phase 1, The Fridtiof Nansen Institute

Araspostathis, Stathis and Dutfield, G. (Eds) (2013). Knowledge Management and Intellectual Property: Concepts, Actors and Practices from the Past to the Present. Edward Elgar, Cheltenham, UK.

Association for Plant Breeding for the Benefit of Society (APBREBES) (2014). Report on the UPOV Autumn Session, 17 November 2014. Retrieved from http://www.apbrebes.org/news/apbrebes-report-upov autumn-session [Accessed on 6 August 2015].

Ayieko, M.W and Tschirley, D.L. (2006). Enhancing access and utilization of Quality seed for improved food security in Kenya. Working paper No. 27/2006. Nairobi: Tegemeo Institute of Agricultural Policy and Development.

Bedmar Villanueva, A., Halewood, M. and López Noriega, I. (2015). Agricultural Biodiversity in climate change adaptation planning: an analysis of the National Adaptation Programmes of Action. CCAFS Working Paper no. 95. Copenhagen, Denmark: CCAFS.

Bellman, Christophe, Graham Dutfield, Ricardo Melendez-Ortiz (Eds). (2003). Trading in Knowledge: Development Perspectives on TRIPS, Trade and Sustainability Earthscan Publications 357 p.

Braunschweig, Thomas, Francois Meineberg, Carine Pionetti and Sangeeta Shashikant (2014). Owning Seed, Accessing Food: A Human Rights Impact Assessment of UPOV 1991 Based on Case Studies in Kenya, Peru and the Philippines. Zurich, Switzerland: Berne Declaration. 
Blakeney, M. (2009). Intellectual property rights and food security. Oxfordshire, UK: CABI.

Bocci, R. (2009). 'Seed Legislation and agrobiodiversity: conservation varieties', Joumal of Agriculture and Environment for International Development, Vol. 103 (1/2), 31-49.

Borlaug, N.E. (1968). Wheat breeding and its impact on world hunger. In: K.W. Finlay and K.W. Shepherd (Eds): Proc. $3^{\text {rd }}$ Int. Wheat Genetics Symposium. Canberra, Australian Academy of Science, pp 1-36.

Bouckaert, B. (1990). 'What is Property?' Harvard Journal of Law and Public Policy, Vol. 13, pp.275816.

Bremmer, Jason (2012). Population and Food Security: Africa's challenge. Population Reference Bureau, Policy Brief. February 2012.

Burke, M.B., Lobell, D.B. and Guarino, L. (2009). Shifts in African Crop Climates By 2050, and the implications for crop improvements and genetic resources conservation. Global Environmental Change 19, pp. $317-325$.

Civil Society Organizations (CSOs) (2012). Civil society concerned with ARIPO's draft regional policy and legal framework for plant variety protection. Retrieved from http://acbio.org.za/wp content/uploads/2015/02/CSOconcernsonARIPOPVPframework1.pdf [Accessed on 6 August 2015].

Colony of Kenya (1954). Swynnerton Plan. Nairobi: Colony of Kenya.

Commission on Intellectual Property Rights and Development Policy (2002). Integrating Intellectual Property Rights and Development Policy. A report, London, September 2002.

Correa, C.M., Shashikant, S. and Meienberg, F. (2015). Plant Variety Protection in Developing Countries: A Tool for Designing a Sui Generis Plant Variety Protection System: An Alternative to UPOV 1991. APBREBES.

Cromwell, E. (1996). Governments, farmers and seeds. Wallingford, CAB International. 
Crucible II Group (2001). Seeding solutions. Volume 2. Options for National laws governing control over genetic resources and biological innovations. Rome: IDRC, IPGRI \& DHF.

Curtis, F., and Nilsson, M. (Eds). (2012). Collection systems for royalties in wheat -An international study. Bio-Science Law Review, 12(6). p. 215.

Daniel Gervais, (2008). The TRIPS Agreement: Drafting History and Analysis, Sweet \& Maxwell, UK.

Deere, C. (2009). The Implementation Game: The TRIPS Agreement and the Global Politics of Intellectual Property Reform in Developing Countries. New York, USA: Oxford University Press.

De Jonge, B. What is fair and equitable benefit-sharing? Journal of Agricultural and Environmental Ethics (2011) 24: 127-146 DOI 10.1007/s10806-010-9249-3

De Jonge, B. (2014). Plant Variety Protection in Sub-Saharan Africa: Balancing Commercial and Smallholder Farmers' Interests. Journal of Politics and Law 7(3), pp 100-111.

De Jonge, B., Louwaars, N.P. and Kinderlerer, J. (2015). A solution to The Controversy on plant variety protection in Africa. Nature Biotechnology 33(5). pp. 487-488.

De Jonge, B. and Munyi, P. (2016), A Differentiated Approach to Plant Variety Protection in Africa. World Intellectual Property, 19: 28-52. doi:10.1111/jwip.12053.

Devarajan, S. and Kasekende, L. A. (2011), 'Africa and the Global Economic Crisis: Impacts, Policy Responses and Political Economy' African Development Review, 23: 421-438. doi: 10.1111/j.1467-8268.2011.00296.x.

Dixon G.E. (1960) 'A review of wheat breeding in Kenya', Euphytica 9 (1960): 209-2021.

Dixon, J., Taniguchi, K., Wattenbach, H. and Tanyeri-Arbur, A. (2004). Smallholders, globalization and policy analysis. AGSF Occasional Paper 5. Rome: FAO.

Drahos, P. (1996). A philosophy of intellectual property, Dartmouth. Aldershot, England. 
Dutfield, G. (2011). Food, biological diversity and intellectual property: The role of The international union for the protection of new varieties of plants (UPOV). Intellectual property issue paper no. 9. Geneva, Switzerland: QUNO.

European Council. (1994). Council regulation (EC) no 2100/94 of 27 July 1994 on Community plant variety rights. Retrieved from http://www.cpvo.europa.eu/main/en/home/community plant-variety rights/legislation-in-force [Accessed on 6 August 2015].

(1995). Commission Regulation (EC) No 1768/95 of 24 July 1995 implementing rules on the agricultural exemption provided for in Article 14 (3) of Council Regulation (EC) No 2100/94 on Community plant variety rights. Retrieved From http://www.cpvo.europa.eu/main/en/home/community-plant Varietyrights/legislation-in force [Accessed on 23 August 2015].

European Seed Association (ESA) (2011). Position on Plant IP Protection and Biodiversity. ESA_11.0049, 6 January 2011. Retrieved From http://www.euroseeds.org/esa110049-esa position-plant-ip protection-and biodiversity [Accessed on 23 August 2015].

FloraHolland Import (2010). General Terms and Conditions of FloraHolland Import. Retrieved from

https://www.floraholland.com/media/391410/General $\% 20$ terms $\% 20$ nd $\% 20$ coditions $\% 20$ Flora Holland $\% 20$ Import $\% 20 \% 28$ cross-border $\% 20$ supplies $\% 29$.pdf [Accessed on 5 August 2015].

Food and Agriculture Organization of the United Nations (FAO), (2001). International treaty on plant genetic resources for food and agriculture, Rome, FAO.

(2009). FAOSTAT online database [online]. Food and Agriculture Organization of the

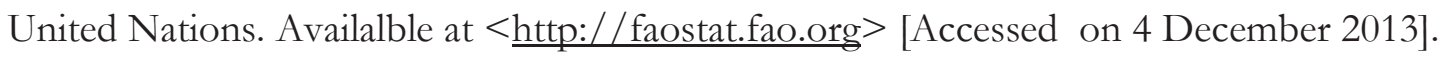

(2010). Second report on the state of the world's plant genetic resources for food and agriculture. Rome, Commission on Genetic Resources for Food and Agriculture.

(2010). Quality declared planting material: protocols and standards for vegetatively propagated crops. Rome, FAO. 
(2010).The State of Food Insecurity in the World-Addressing Food Insecurity in Protracted Crises Rome, FAO.

(2011). Save and Grow. A policymaker's guide to the sustainable intensification of smallholder crop production. Rome, FAO.

(2012). Kenya Economic Indicators, Retrieved from http://faostat.fao.org/.

FAO, International Fund for Agricultural Development (IFAD) and World Food Program (WFP) (2014). The State of Food Insecurity in the World 2014. Strengthening the enabling environment for food security and nutrition. Rome, FAO.

Federation of Malaysia (2008). Background document on Malaysian PVP

Act 2004. Gazette, 20 October 2008.

Fowler, C. (1994) Unnatural Selection. Technology, Politics and Plant Evolution. Gordon and Breach, Yverdon.

Geoffrey Livingston, Steve Schonberger and Sara Delaney. Sub-Sabaran Africa: The state of smallholders in agriculture. Paper presented at the IFAD Conference on New Directions for Smallholder Agriculture 24-25 January 2011, IFAD, Rome.

Gerald Moore and Witold Tymowski (2005). Explanatory Guide to the International Treaty on Plant Genetic Resources for Food and Agriculture. IUCN, Gland, Switzerland and Cambridge, UK. Xii+212 pp.

GHK Consulting \& ADAS UK., Evaluation of the Community Plant Variety Right Acquis - Final Report. A report for DG SANCO, April 2011, available

at http://ec.europa.eu/food/plant/plant property rights/evaluation/docs/cpvr evaluation fin al report en.pdf (accessed 1 August 2014).

Government of Kenya (GOK) (1965). Sessional Paper No. 10 of 1965 on African Socialism and its Implication on Planning in Kenya.

(1981). Sessional Paper No. 4 of 1981 on National Food Policy. (1986). Sessional Paper No.1 of 1986 on Economic Management for Renewed Growth. 
(1999). Sessional Paper No. 2 of 1999 on the Liberalization and Restructuring of the Tea Industry.

(2001). Sessional Paper No. 2 of 2001 on Liberalization and Restructuring of the Coffee Industry.

(2004). Strategy for Revitalisation of Agriculture.

(2010). National Seed Policy.

(2011). National Food and Nutritional Security Policy.

(2011). The Kenya CAADP Compact. Implemented through the Agricultural Sector Development Strategy.

(2013) Commission for the Implementation of the Constitution. 2012-2013 Annual Report. Three years after Promulgation: Tracking Devolution.

Granqvist, B. (2006). Is Quality Declared Seed Production an effective way to address Seed and Food Security in Africa? FAO Plant Production and Protection Paper No. 185. ISSN 0259-2517.

Haugen, H. M. (2015). Inappropriate Processes and Unbalanced Outcomes: Plant Variety Protection in Africa Goes Beyond UPOV 1991 Requirements. The Journal of World Intellectual Property, 18: 196-216. doi: 10.1111/jwip.12037

Hazell, P., Poulton, C., Wiggins, S., and Dorward, A. (2007). The Future of small farms for poverty reduction and growth. International Food Policy Research Institute (IFPRI) 2020 Discussion Paper 42, May 2007. Washington DC: IFPRI.

Heidhues, F., \& Brüntrup, M. (2003). Subsistence agriculture in development: Its role in processes of structural change. In: Abele, S., and Frohberg, K. (Eds.). Subsistence agriculture in Central and Eastern Europe: How to break a vicious yycle? Halle, Germany: IAMO.

Hermitte, M.A. and Kanh, P. (eds) (2004). Les Ressources Genetiques Vegetales et le Droit dans les Rapports Nord-sud. Travaux du Centre Rene-Jean Dupuy pour le Droit et le Developpement et du Centre de Recherche sur le Droit des Sciences et Techniques, v.II, Bruylant. 
Hughes, J. (1988). 'The Philosophy of Intellectual Property' The Georgetown Law Journal, Vol. 77, pp. 287-366.

IMS Health. Africa: a ripe opportunity. Understanding the pharmaceutical market opportunity and developing sustainable business models in Africa. A report available at

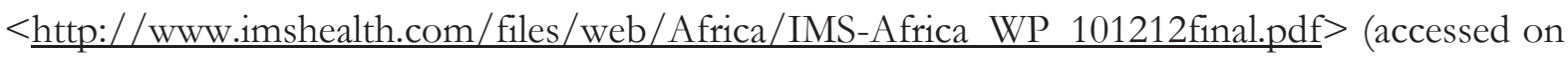
10 November 2015).

Republic of India. (2001). The Protection of Plant Varieties and Farmers' Rights Act. Retrieved From http://www.wipo.int/wipolex/en/details.jsp?id=2401 [Accessed on 16 August 2015].

Institution of Mechanical Engineers (2013). Global Food: Waste Not, Want Not. A Report.

IFAD (2009). Smallholder Farming in Transforming Economies of Asia and the Pacific: Challenges and Opportunities. Discussion Paper prepared for the side event organized during the $33^{\text {rd }}$ session of IFAD's Governing Council, 18 February 2009.

International Seed Federation (ISF). (2012). ISF View on Intellectual Property Adopted in Rio de Janeiro, Brazil, 28 June 2012. Retrieved From

http://www.worldseed.org/isf/on intellectual property.htm [Accessed on 16 August 2015].

Integrated Seed Sector Development (ISSD) (2014). Outline of the Piloting Phase for a Comprehensive Program on Integrated Seed Sector Development in Africa: Sept 2014-Ang 2016. Centre for Development Innovation Wageningen UR, August 2014, Wageningen.

(2014). Introduction to Integrated Seed Sector Development and its Guiding Principles. Retrieved from http://www.issdseed.org/topic/issd guiding principles [Accessed on16 August 2015].

(2015). Report of High Level Round-Table Meeting on Plant V ariety Protection in Africa 27-28

November 2014. Retrieved from http://www.issdseed.org/resource/high-level-round-tablemeeting-plant-variety-protection-africa-27---28th-november-2014 
International Union for the Protection of New Varieties of Plants (UPOV) (1961). Act of 1961 International Convention for the Protection of New Varieties of Plants.

(1972). Act of 1972 International Convention for the Protection of New Varieties of Plants.

(1978). Act of 1978 International Convention for the Protection of New Varieties of Plants.

(1991). Act of 1991 International Convention for the Protection of New Varieties of Plants.

(1992) Records of the Diplomatic Conference for the Revision of the International Convention for the Protection of New V arieties of Plants, UPOV, Geneva.

(1996). Examination of the Conformity of the Legislation of Kenya with the UPOV Convention (Geneva: International Union for the Protection of New Varieties of Plants), $\mathrm{C} / 30 / 13$.

(2005). UPOV report on the impact of plant variety protection. Geneva: UPOV.

(2005). Examination of the conformity of the Protection of New Plant Varieties act 2004 of Malaysia with the 1991 act of the UPOV Convention. Document prepared by the Office of the Union, C(Extr.)/22/2, 2 February 2005.

(2009). Explanatory notes on exceptions to the breeder's right under the 1991 act of the UPOV Convention, UPOV/EXN/EXC. Retrieved from http://www.upov.int/explanatory notes/en/ [Accessed On 12 August 2015].

(2014). Report on the decisions of the Thirty-First Extraordinary Session Geneva, C(Extr.)/31/5, 11 April 2014. Retrieved from http://www.upov.int/meetings/en/details.jsp?meeting id=31768 [Accessed on 12 August 2015].

Jabbar, M.A., Peden, D.G., Mohamed Saleem, M.A. and Li Pun. H. Agro ecosystems, natural resources management and buman health related research in East Africa. Proceedings of an IDRC-ILRI international workshop held at ILRI, Addis Ababa, Ethiopia, 11-15 May 1998. Nairobi, Kenya: ILRI. 
Jefferson, D.J., Camacho, A.B. and Chi-Ham, C.L. (2014). Towards a Balanced Regime of Intellectual Property Rights for Agricultural Innovations. Journal of Intellectual Property Rights 19(6). pp. 395-403.

Katungi, E., Farrow, A., Chianu, J., Sperling, L.,and Beebe, S. (2009). Common bean in Eastern and Southern Africa: a situation and outlook analysis. International Centre for Tropical Agriculture: Patancheru, India.

Kaul, I., I Grunberg and M.A Stern (1999). Global Public Goods: International Cooperation in the $21^{\text {st }}$ Century. UNDP, UN Plaza, New York.

Kenya Plant Health Inspectorate Service (KEPHIS) (2008). Annual Report and Financial Statement, July 2007-June 2008.

(2009). Annual Report and Financial Statement, July 2008-June 2009.

(2011). Annual Report and Financial Statement, 2010-2011.

(2012). Annual Report and Financial Statements for 2011/2012.

(2013). Annual Report and Financial Statement, 2013.

(2014). National Crop Variety List - Kenya.

Kloppenburg, J.R. (1988). First the seed: The political economy of plant biotechnology, 14922000. Cambridge, Cambridge University Press.

Koonan, S. (2014). Developing country sui generis options. India's sui generis system of plant variety protection. Quaker United Nations Office (QUNO) briefing paper on food, biological diversity and intellectual property no. 4. Geneva, Switzerland: QUNO.

Langinger, N. (2011). School Feeding Programs in Kenya: Transitioning to a Homegrown Approach. Stanford Journal of international Relations, 13(1), pp. 30-37. 
La Via Campesina. (2014). ARIPO's Draft Protocol for the Protection of New Varieties of Plants (“DRAFT Protocol”) Undermines Farmers' Rights, Lacks Credibility \& Legitimacy. Open letter to members of the international convention for the protection of new varieties of plants (UPOV), 14 April 2014. Retrieved from http://viacampesina.org/en/index.php/main-issues mainmenu27/biodiversity-and-genetic-resources-mainmenu-37/1591-aripo-s-draft-Protocol forthe-protection-of-new-varieties-of-plants-draft-protocol-undermines-farmers-rights-lacks credibility-legitimacy [Accessed on 12 August 2015].

Lawson, C. (2015). The breeder's exemption under UPOV 1991, the Convention on Biological Diversity and its Nagoya Protocol. Journal of Intellectual Property Law \& Practice, 10(7), pp. 526-535.

Lertdhamtewe, P. (2013). Plant variety protection in Thailand: the need for a new Coherent framework. Journal of Intellectual Property Law and Practice 8(1), pp. 33-42.

Lipper, L., Anderson, C.L., and Dalton, T.J. (Eds.) (2010). Seed trade in Rural markets. Implications for crop diversity and agricultural development. London: Earthscan.

Livingston, G., Schonberger, S., and Delaney, S. (2011). Sub-Saharan Africa: The state of smallholders in agriculture. Paper presented at the IFAD conference on new directions for smallholder agriculture, 24-25 January. Rome: IFAD.

Llewelyn, M. and Adcock, M. (2006). European Plant Intellectual Property. Hart Publishing, Oxford.

Louwaars, N.P. and G.A.M. van Marrewijk (1996). Seed Supply Systems in Developing Countries. Wageningen, CTA, 135p.

Louwaars, N.P., R. Tripp, D. Eaton, V. Henson-Apollonio, R. Hu, M. Mendoza, F. Muhhuku, S. Pal \& J. Wekundah (2005). Impacts of Strengthened Intellectual Property Rights Regimes on the Plant Breeding Industry in Developing Countries: A Synthesis of five case Studies. Centre for Genetic Resources, The Netherlands (CGN).

Louwaars, N.P. (2007). Seeds of Confusion: The Impact of Policies on Seed Systems. PhD dissertation, Wageningen, The Netherlands. ISBN 978-90-8504-793-3. 
Louwaars, N., Dons, H., van Overwalle, G., Raven, H., Arundel, A., Eaton, D., Nelis, Annemiek (2009). Breeding Business: the future of plant breeding in the light of developments in patent rights and plant breeders' rights. Centre for Genetic Resources, the Netherlands (CGN), Wageningen. CGN Report 2009-14(EN).

Louwaars, N.P. and De Boef, W.S. Integrated seed sector development in Africa: a conceptual framework for creating coherence between practices, programs and policies. Journal of Crop Improvement, 26, 39-59. Htt://dx.doi.org/10.1080/15427528.2011.611277.

Lowder, S.K., Skoet, J., \& Singh, S. (2014). What do we really know about the number and distribution of farms and family farms worldwide? Background paper for The State of Food and Agriculture 2014. ESA Working Paper No. 14-02. Rome: FAO.

Lybbert, T.J. (2002). 'Technology Transfer for Humanitarian Use: Economic Issues and Market Segmentation Approaches', IP Strategy Today No. 5-2002 17, 25.

Machlup, F. and Penrose, E. (1959). 'The Patent Controversy in the Nineteenth Century' Journal of Economic History, Vol.x, No.1, pp. 1-29. 1959:11

Mahagayu, M.C., A.C. Ndiema, C.M. Njeru, N. Macharia, and P. Rengine (2010). Smallholder Wheat Production and Marketing in Timau Division Meru County. Presentation made at the $12^{\text {th }}$ KARI Biennial Scientific Conference, 8-12 November, 2010.

Mahop, M.T., B. De Jonge \& P. Munyi. Seed systems and intellectual property rights: an inventory from five Sub-Sabaran African countries (pp 44-54). Report of the Ministry of Economic Affairs, Agriculture and Innovation, The Netherlands.

Maniruzzaman, A.F.M. State Contracts in Contemporary International Law: Monist versus Dualist Controversies, European Journal of International Law (2001), Vol. 12 No. 2, 309-328, at 310.

Maskus, K.E., (2000). Intellectual Property Rights in the Global Economy. Washington DC: Institute for International Economics.

Matanga, D.W and James F. Oehmke (1996). The History of and Returns to Kenya Wheat Research. Mimeo. Department of Agricultural Economics, Michigan State University. 
McMullen, N (1987). Seeds and World Agricultural Progress. Washington DC, National Planning Association, 263p.

Methodology Report for the Access to Seeds index 2015. Available at http://www.accesstoseeds.org/wp-content/uploads/Methodology-Report-for-the-Access-toSeeds-Index-2015-Final.pdf > accessed on 12 November 2015

Moore, G. and Witold, T. (2003). The Explanatory Guide to the International Treaty on Plant Genetic Resources for Food and Agriculture. The World Conservation Union (IUCN). IUCN Environmental Policy Law Paper Number 57. 2005

Mercer, K.L., \& Perales, H.R. (2010). Evolutionary response of landraces to climate change in centers of crop diversity. Evolutionary Applications 3, pp. 480-493.

Mooney, Pat Roy (1979). Seeds of the Earth: A private or Public Resource? Ottawa: Inter Pares.

Munyi, P; Tonye Mahop, M., du Plessis, P., Ekpere J. and Bavikatte, K. (2012). A Gap Analysis Report on the African Model Law on the Protection of the Rights of Local Communities, Farmers and Breeders, and for the Regulation of Access to Biological Resources. A report Commissioned by African Union Commission.

Munyi, P. (2015). Plant Variety Protection Regime in Relation to Relevant International Obligations: Implications for Smallholder Farmers in Kenya. World Intellectual Property, 18: 65-85.

Munyi, P. and De Jonge, B. (2015). Seed Systems Support in Kenya: Consideration For an Integrated Seed Sector Development Approach. Journal of Sustainable Development 8(2). pp. 161173.

Munyi, P., De Jonge, B., and Visser, L. (2016). Opportunities and Threats to Harmonisation of Plant Breeders' Rights In Africa: ARIPO and SADC. African Journal of International and Comparative Law 24.1, pp. 100-118. DOI: 10.3366/ajicl.2016.0142.

Muraguri, L. (2010). The role of intellectual property in agricultural public-private partnerships in the context of development. An unpublished thesis submitted in partial fulfilment of the requirements for the degree of Doctor of Philosophy in Law, University of London. 
Nagayets, O. (2005). Small farms: current status and key trends. Information brief prepared for the Future of Small Farms Research Workshop. Wye College, June 26-29 2005.

Muthoni, J. and Nyamongo, D.O. (2008). Seed Systems in Kenya and Their Relationship to On-Farm Conservation of Food Crops, Journal of New Seeds 9: 4, 330-342.

New Partnership for Africa's Development, African Agriculture, transformation and outlook, November 2013, 72 p.

Niels P. Louwaars \& Walter Simon de Boef (2012). Integrated Seed Sector Development in Africa: A Conceptual Framework for Creating Coherence Between Practices, Programs, and Policies, Journal of Crop Improvement, 26:1, 39-59, DOI: 10.1080/15427528.2011.611277

Niels P. Louwaars, Walter S. de Boef \& Janet Edeme (2013). Integrated Seed Sector Development in Africa: A Basis for Seed Policy and Law, Journal of Crop Improvement, 27:2, 186214, DOI: $10.1080 / 15427528.2012 .751472$

Nyangito, H and Okello, J (1998). Kenya's agricultural policy and sectors performance: 1964-1996.

Retrieved from

http://www.chr.up.ac.za/chr old/indigenous/documents/Kenya/Report/Kenya $\% 27 \mathrm{~s} \% 20$ Agri cultural $\% 20$ Policy $\% 20$ and $\% 20$ Sector $\% 20$ Performance.pdf

Odame, H and E Muange (2010). Can Agro-dealers deliver the green revolution in Kenya? Future Agriculture. Working Paper No. 014.

Oguamanam, C. (2015). Breeding Apples for Oranges: Africa's Misplaced Priority Over Plant Breeders' Rights. World Intellectual Property, 18: 165-195. doi: 10.1111/jwip.12039

Organization of African Unity (OAU) (2000). African model legislation for the protection of the rights of local communities, farmers and breeders, and for the regulation of access to biological resources. Retrieved from http://www.wipo.int/wipolex/en/text.jsp?file id=252153 [Accessed on 6 August 2015]. 
Pammolli, Fabio and Maria Alessandra Rossi (2005). Intellectual Property, Technological regimes and market Dynamics, Economia e Politica Industriale, 2/2005.

Payumo, J.G., H.D. Grimes and K.J. Jones. 'Licensing agricultural intellectual property: how should public R\&D institutions in developing countries respond?' International Journal of Innovation and technology Management. Vol. 9, No. 4 (2012)

Pereira, C. (1996). The Role of agricultural research in development of Kenya before independence, in: Smith, P. D., R.A. Tyler and E.M. Young (Eds). Review of Kenyan Agricultural Research, Nairobi: KARI.

Pinto F.F. and E.A. Hurd (1970). '70 Years with wheat in Kenya', East African Agriculture and Forestry Journal 36 (Special Issue).

Prifti, V. (2013). 'The Breeding Exemption in Patent Law: Analysis of Compliance with Article 30 of the TRIPS Agreement'. World Intellectual Property, Vol. 16, Issue 5-6), pages 218-239.

Poulton, C. and Kanyinga, K. (2014). The Politics of Revitalizing Agriculture in Kenya. Development Policy Review, 32: s151-s172. doi: 10.1111/dpr.12080

PS Setimela and P Kosina (eds) (2006). Strategies for Strengthening and Scaling up Communitybased Seed Production. Mexico, D.F.:CIMMYT

Rangnekar, D. (2002). Access to genetic resources, gene-based inventions and agriculture. London, UK: Commission on Intellectual Property Rights.

Rangnekar, D (2006). Assessing the economic implications of different models for implementing the requirement to protect plant varieties: A case study of Kenya. A report prepared under the European Commission's $6^{\text {th }}$ Framework Programme for Research (Contract No.503613) as part of the Project: Impacts of the IPR Rules on Sustainable development.

Rangnekar, D. (2013). 'Geneva Rhetoric, National Reality: The Political Economy of Introducing Plant Breeders' Rights in Kenya', New Political Economy, DOI: 10.1080/13563467.2013.796445

Rayan, A. (1987). Property, Milton Keynes: Open University Press. 
Robert Lettington (2003). Small-scale Agriculture and the Nutritional Safeguard under Article 8(1) of the Uruguay Round Agreement on Trade-Related Aspects of Intellectual Property Rights: Case Studies from Kenya and Peru [online]. International Centre for Trade and Sustainable Development. Available at < http://ictsd.org/downloads/2008/06/lettingtonfinaldraft.pdf > Accessed in 11 December 2013.

Republic of Uganda (2014). Plant Variety Protection Act, 2014. Retrieved from http://www.seatiniuganda.org/wp-content/uploads/2014/08/The-plant-variety protection-act 2014.pdf [Accessed on 6 August 2015].

Richards, D.G. (2002). 'The Ideology of Intellectual Property Rights in the International Economy', Review of Social Economy, Vol. IX, No.4, pp.521-620.

Rutz, H.W. (2008). Study on Farm saved seed in the European Union. Technical report prepared on behalf of the Community Plant Variety Office (CPVO) Angers, France: CPVO.

Salami, A., Kamara, A.B., \& Brixiova, Z. (2010). Smallholder agriculture in East Africa: trends, constraints and opportunities. Working Paper No. 105. African Development Bank Group.

Salazar, R., Louwaars, N.P and Visser, B. (2007). 'Protecting Farmers' New Varieties: New Approach to Rights on Collective Innovations in Plant Genetic Resources', World Development, Vol.35, No.9, pp. 1515-1528, 2007.

Santilli, J. (2012). Agrobiodiversity and the Law: Regulating Genetic Resources, Food Security and Cultural Diversity. Earthscan, Oxford.

Schmutz, J. (et al.). (2014). A reference genome for common bean and Genome wide analysis of dual domestications. Nature Genetics 46, pp. 707-713.

Smale, M., Byerlee, D., \& Jayne, T. (2011). Maize revolutions in Sub-Saharan Africa. Policy Research Working Paper 5659. Washington, DC: World Bank.

Society for International Development (2006). Readings on Inequality in Kenya: Sectoral Dynamics and Perspectives. Society for International Development Eastern Africa Regional Office, Nairobi. 
Southern African Development Cooperation (SADC). (2014). Draft Protocol For Protection of New Varieties of Plants (Plant Breeders' Rights) in the Southern African Development Community Region, May 2014.

Sperling, L., T. Osborn and D. Cooper. (2004). Towards effective and sustainable seed relief activities. Rome: FAO.

Sperling, L., T. Remington, J. M Haugen, and S. Nagoda (2004). Addressing Seed Security in Disaster Response: Linking Relief with Development. Cali, Colombia: International Center for Tropical Agriculture.

Sperling, L., and McGuirre, S. (2010). Understanding and strengthening Informal seed markets. Experimental Agriculture 46(2), pp. 119-136.

Stevens, A.J. and EA Effort, 'Using Academic License Agreements To Promote Global Social Responsibility' Les Nowvelles June 2008 p. 99.

Swanson, T.M. (ed) (2002). Biotechnology, agriculture and the developing world: the distributional implications of technological change (Cheltenham: Edward Elgar, UK).

Thailand (1999). Plant Varieties Protection Act B.E. 2542 (1999). Retrieved from http:/ /www.wipo.int/wipolex/en/details.jsp?id=3816

Thiele, G. (1997). Informal Potato Seed Systems in the Andes: Why Are They Important and What Should We Do with Them? Cochabamba: PROINPA. MS

Thomson, R. (2013). The yield of plant variety protection, Intellectual Property Research Institute of Australia Working Paper No. 6/13. ISSN 1447-2317.

Thornstrom, C.G., I. Virgin, E. Thorn and M. Ericsson (2013). Science, Genetic Resources and Regulation. Sida ITP-Program Final Report: The GRIP experience 2003-2014 with focus on GRIP-12 and 13. SLU and Sida.

Torremans P.L.C (ed) (2008). Intellectual property and Human Rights, Enhanced Edition of Copyright and Human Rights. Kluwer Law International BV, The Hague. 
Tripp, R. and Van der Burg, W.J. (1997). The conduct and reform of seed quality control, in: Tripp, R. (Ed.), New seed and old laws: regulatory reform and the diversification of national seed systems. Intermediate Technology, London, pp. 121-126.

Tripp, R. (2001). Seed Provision \& Agricultural Development. London: Overseas Development Institute/Oxford: James Curry/Portsmouth (N.H.): Heinemann.

Ulen, T.S.A. Nobel Prize in Legal Science: Theory, Empirical Work, and the Scientific Method in the Study of the Law, University of Illinois Law Review, 2002.

United Nations, Department of Economic and Social Affairs, Population Division (2015). World Population Prospects: The 2015 Revision, Key Findings and Advance Tables. Working Paper No. ESA/P/WP.241.

Waithaka, M., Nelson, G., Thomas, T., and Kyotalimye, M. (2013). Kenya. In: East African Agriculture and Climate Change. Washington, D.C.: International Food Policy Research Institute.

Walter Simon de Boef, Hannes Dempewolf, Jean Marie Byakweli and Johannes Martinus Marie Engels (2010). Integrating Genetic Resource Conservation and Sustainable Development into Strategies to Increase the Robustness of Seed Systems, Journal of Sustainable Agriculture, 34:5, 504-531, DOI: 10.1080/10440046.2010.484689

Watal, J. (2000). Intellectual Property Rights in the WTO and Developing Countries. Kluwer Law International BV, The Hague.

Wiggins, S. (2009). Can the smallholder farmer model deliver poverty reduction and food security for a rapidly growing population in Africa? Paper for the FAO expert meeting on how to feed the world in 2050, 24-26 June, Rome.

Willem van Genugten, Anna Meijknecht, Bernard Maister, Caspar van Woensel, Bram De Jonge, Godber Tumushabe, Julian Barungi, Niels Louwaars, Grant Napier, Sibongile Gumbi and Tobias Rinke de Wit (2011). Harnessing Intellectual Property Rights for Development Objectives: The Double Role of IPRs in the Context of Facilitating MDGs Nos 1 and 6. Wolf Publishers, Nijmegen. 
World Bank (2008). World Development Report: Agriculture for Development. The World Bank, Washington DC: the World Bank.

World Trade Organization Agreement on Trade Related Aspects of Intellectual Property Rights.

WIPO Berne Convention for the Protection of Literary and Artistic Works.

Würtenberger, G., van der Kooij, P., Kiewiet, B., \& Ekvad, M. (2006). European Community Plant Variety Protection. New York: Oxford University Press.

Zegeye, F., Alemu, D., Nishikawa, Y., \& Kiyoshi, S. (2014). Perception of farmers and agricultural experts for farmers' saved seed: The case of East Showa, Ethiopia. Sky Journal of Agricultural Research 3(5). pp. 74-81.

Zhang, Y., \& Wildemuth, B. (2009). Unstructured interview. In B. Wildemuth (Ed.), Applications of Social Research Methods to Questions in Information and Library Science (pp.222-231). Westport, CT: Libraries Unlimited.

Zimbabwe. (2001). Plant Breeders Rights Act (Chapter 18:16). Retrieved from http://www.wipo.int/wipolex/en/text.jsp?file id=214683 [Accessed on 6 August 2015].

Zimmerer, K.S., Carney, J.A., Vanek, S.J. (2015). Sustainable smallholder intensification in global change? Pivotal spatial interactions, gendered livelihoods, and agrobiodiversity. Current Opinion in Environmental Sustainability 14, pp. 49-60. 


\section{Appendix}

\section{Date and place of interview of anonymous informants}

\begin{tabular}{|c|c|c|c|}
\hline No. & Informant & Date & Location \\
\hline 1 & Informant 1 & 02.08 .2012 & Kenya \\
\hline 2 & Informant 2 & 22.05 .2014 & Kenya \\
\hline 3 & Informant 3 & 11.07 .2014 & The Netherlands \\
\hline 4 & Informant 4 & 11.07 .2014 & The Netherlands \\
\hline 5 & Informant 5 & 15.06 .2011 & Kenya \\
\hline 6 & Informant 6 & 15.06 .2011 & Kenya \\
\hline 7 & Informant 7 & 15.06 .2011 & Kenya \\
\hline 8 & Informant 8 & 18.04 .2012 & South Africa \\
\hline 9 & Informant 9 & 18.04 .2012 & South Africa \\
\hline 10 & Informant 10 & 18.04 .2012 & South Africa \\
\hline 11 & Informant 11 & 11.07 .2014 & The Netherlands \\
\hline 12 & Informant 12 & 15.07 .2014 & The Netherlands \\
\hline 13 & Informant 13 & 15.07 .2014 & The Netherlands \\
\hline 14 & Informant 14 & 22.07 .2014 & The Netherlands \\
\hline 15 & Informant 15 & 19.07 .2013 & Kenya \\
\hline 16 & Informant 16 & 19.07 .2013 & Kenya \\
\hline 17 & Informant 17 & 27.06 .2012 & Kenya \\
\hline 18 & Informant 18 & 26.06 .2012 & Kenya \\
\hline
\end{tabular}




\begin{tabular}{|c|c|c|c|}
\hline 19 & Informant 19 & 26.06 .2012 & Kenya \\
\hline 20 & Informant 20 & 03.09 .2012 & Kenya \\
\hline 21 & Informant 21 & 21.06 .2013 & Kenya \\
\hline 22 & Informant 22 & 27.11 .2015 & South Africa \\
\hline 23 & Informant 23 & 27.11 .2015 & South Africa \\
\hline 24 & Informant 24 & 22.04 .2013 & Kenya \\
\hline 25 & Informant 25 & 22.04 .2013 & Kenya \\
\hline 26 & Informant 26 & 22.04 .2013 & Kenya \\
\hline 27 & Informant 27 & 22.04 .2013 & Kenya \\
\hline 28 & Informant 28 & 22.04 .2013 & Kenya \\
\hline 29 & Informant 29 & 22.04 .2013 & Kenya \\
\hline 30 & Informant 30 & 22.04 .2013 & Kenya \\
\hline 31 & Informant 31 & 25.04 .2013 & Kenya \\
\hline 32 & Informant 32 & 26.04 .2013 & Kenya \\
\hline 33 & Informant 33 & 26.04 .2013 & Kenya \\
\hline 34 & Informant 34 & 21.06 .2013 & Kenya \\
\hline 35 & Informant 35 & 21.06 .2013 & Kenya \\
\hline 36 & Informant 36 & 21.06 .2013 & Kenya \\
\hline 37 & Informant 37 & 21.06 .2013 & Kenya \\
\hline 38 & Informant 38 & 21.06 .2013 & Kenya \\
\hline 39 & Informant 39 & 21.06 .2013 & Kenya \\
\hline 40 & Informant 40 & 21.06 .2013 & Kenya \\
\hline
\end{tabular}




\begin{tabular}{|c|c|c|c|}
\hline 41 & Informant 41 & 22.06 .2013 & Kenya \\
\hline 42 & Informant 42 & 22.06 .2013 & Kenya \\
\hline 43 & Informant 43 & 22.06 .2013 & Kenya \\
\hline 44 & Informant 44 & 22.06 .2013 & Kenya \\
\hline 45 & Informant 45 & 22.06 .2013 & Kenya \\
\hline 46 & Informant 46 & 23.06 .2013 & Kenya \\
\hline 47 & Informant 47 & 23.06 .2013 & Kenya \\
\hline 48 & Informant 48 & 23.06 .2013 & Kenya \\
\hline 49 & Informant 49 & 23.06 .2013 & Kenya \\
\hline 50 & Informant 50 & 23.06 .2013 & Kenya \\
\hline 51 & Informant 51 & 23.06 .2013 & Kenya \\
\hline 52 & Informant 52 & 25.04 .2013 & Kenya \\
\hline 53 & Informant 53 & 21.06 .2013 & Kenya \\
\hline 54 & Informant 54 & 23.04 .2013 & Kenya \\
\hline 55 & Informant 55 & 23.04 .2013 & Kenya \\
\hline 56 & Informant 56 & 23.04 .2013 & Kenya \\
\hline 57 & Informant 57 & 23.04 .2013 & Kenya \\
\hline 58 & Informant 58 & 23.04 .2013 & Kenya \\
\hline 59 & Informant 59 & 23.04 .2013 & Kenya \\
\hline 60 & Informant 60 & 23.04 .2013 & Kenya \\
\hline 61 & Informant 61 & 24.04 .2013 & Kenya \\
\hline 62 & Informant 62 & 24.04 .2013 & Kenya \\
\hline
\end{tabular}




\begin{tabular}{|c|c|c|c|}
\hline 63 & Informant 63 & 24.04 .2013 & Kenya \\
\hline 64 & Informant 64 & 24.04 .2013 & Kenya \\
\hline 65 & Informant 65 & 24.04 .2013 & Kenya \\
\hline 66 & Informant 66 & 24.04 .2013 & Kenya \\
\hline 67 & Informant 67 & 24.04 .2013 & Kenya \\
\hline 68 & Informant 68 & 24.04 .2013 & Kenya \\
\hline 69 & Informant 69 & 24.04 .2013 & Kenya \\
\hline 70 & Informant 70 & 23.04 .2013 & Kenya \\
\hline 71 & Informant 71 & 23.04 .2013 & Kenya \\
\hline 72 & Informant 72 & 23.04 .2013 & Kenya \\
\hline 73 & Informant 73 & 23.04 .2013 & Kenya \\
\hline 74 & Informant 74 & 30.01 .2013 & Italy \\
\hline 75 & Informant 75 & 17.03 .2016 & South Africa \\
\hline 76 & Informant 76 & 16.03 .2016 & South Africa \\
\hline 77 & Informant 77 & 30.01 .2013 & Italy \\
\hline 78 & Informant 78 & 25.02 .2016 & Kenya \\
\hline 79 & Informant 79 & 27.11 .2014 & The Netherlands \\
\hline 80 & Informant 80 & 30.01 .2013 & Italy \\
\hline 81 & Informant 81 & 03.07 .2013 & The Netherlands \\
\hline 82 & Informant 82 & 23.10 .2013 & South Africa \\
\hline 83 & Informant 83 & 15.07 .2014 & The Netherlands \\
\hline 84 & Informant 84 & 04.06 .2015 & Kenya \\
\hline
\end{tabular}




\begin{tabular}{|c|c|c|c|}
\hline 85 & Informant 85 & 24.04 .2013 & Kenya \\
\hline 86 & Informant 86 & 07.04 .2013 & Kenya \\
\hline 87 & Informant 87 & 12.07 .2014 & The Netherlands \\
\hline 88 & Informant 88 & 24.04 .2013 & Kenya \\
\hline 89 & Informant 89 & 22.04 .2013 & Kenya \\
\hline 90 & Informant 90 & 22.04 .2013 & Kenya \\
\hline 91 & Informant 91 & 27.11 .2014 & South Africa \\
\hline 92 & Informant 92 & 28.11 .2014 & South Africa \\
\hline 93 & Informant 93 & 28.11 .2014 & South Africa \\
\hline 94 & Informant 94 & 17.03 .2016 & South Africa \\
\hline 95 & Informant 95 & 17.03 .2016 & South Africa \\
\hline 96 & Informant 96 & 27.11 .2014 & South Africa \\
\hline 97 & Informant 97 & 17.03 .2016 & South Africa \\
\hline 98 & Informant 98 & 16.03 .2017 & South Africa \\
\hline 99 & Informant 99 & 16.03 .2017 & South Africa \\
\hline 100 & Informant 100 & 16.03 .2017 & South Africa \\
\hline 101 & Informant 101 & 30.01 .2013 & Italy \\
\hline 102 & Informant 102 & 03.08 .2012 & Kenya \\
\hline
\end{tabular}




\section{Summary}

Seeds perform various functions in society. In agriculture, as the carrier of the genetic makeup of the plant seeds are key tools for technology transfer. In this sense, seeds are widely considered a focal point in agricultural progress. In some societies, seeds are inextricably linked with the culture of the people that develop, select, conserve and use them. In this sense, seeds are the very foundation of life and livelihoods. Seeds also have commercial value and hence scientific and commercial investments are made to increase yields, and reduce disease and pest attacks, all with a view to generate commercial returns on the investments made. The sum total of the various functions of seeds is that they are an essential element in the attainment of the United Nations Sustainable Development Goal 2: end hunger, achieve food security and improved nutrition and promote sustainable agriculture.

Advancement in plant breeding techniques including through use of biotechnology has led to seeds over the years becoming carriers of proprietary genetic information. The need to recoup investments made in breeder research and discoveries through commercialisation of new varieties has brought about the quest to protect the intellectual creations of the breeder. This intellectual property protection of improved varieties of seed has not taken away the fact that many local seeds are an embodiment of communities' traditions, cultures and indigenous knowledge arising from efforts by farmers and communities to conserve and improve them over the years. The intellectual property protection conferred over seed of new crop varieties and at the same time the aim to maintain the traditional and cultural embodiments of seed has brought forth tensions between breeders' commercial interests and unrestricted access to seed by smallholder farmers. Intellectual property protection over seed has also brought about concerns that it is a double edged sword, by not only incentivising breeding, but also blocking access to private sector seed for smallholder farmers and breeders, and by destroying traditional farming practices.

One form of intellectual property rights which provides intellectual property protection to the work of a plant breeder upon fulfilment of certain conditions is plant breeders' rights. A characteristic of intellectual property rights (including plant breeders' rights) is their negative nature, enabling the rights holder to prevent others from utilizing creations protected by them. However, as intellectual property rights are not absolute rights there are limitations and exceptions that are provided for thus enabling third parties to utilize the protected creations without authorization of the right holder. However, these limitations and exceptions do not take 
away the fact that prima facie, intellectual property rights make access to protected products, processes and material which may include seeds subject to the conditions set by the right holder.

This thesis is a study of the relationship between plant breeders' rights on the one hand and access to seed and planting material on the other hand for smallholder farmers in Kenya. The relationship between plant breeders' rights and access to seed has brought about several academic and policy debates which this thesis seeks to contribute to. The scope of the issues under debate include (a) the uncertainty and possible negative consequences of intellectual property protection in plant breeding and more so in least developed and developing countries that are food insecure; (b)the inter-relationship between the International Union for the Protection of New varieties of Plants (UPOV) and the International Treaty on Plant Genetic Resources for Food and Agriculture (IT or Plant Treaty); and, (c) the relevance of utilizing limitations and exceptions in plant breeders' rights with a view to ultimately, promote access to seed for food security purposes. Plant breeders' rights are the predominant mechanism for the protection of breeders' creations in Kenya. Kenya is selected as the study area because agriculture provides the bulk of employment and livelihoods in the country with most of the famers being smallholders obtaining seed and planting material from informal sources.

This thesis focuses on plant breeders' rights, a subset of intellectual property rights and the effects these rights have on access to seeds by smallholder farmers in Kenya. Access to seeds invariably affects food availability and security and ultimately, the right to food. The aim of this research is to ultimately enquire whether the legal spaces that exist within plant breeder' rights legislation can enable smallholder farmers to positively contribute towards Kenya overcoming food security problems.

Chapter 2 of this thesis is a description of the evolution of Kenya's seed policies and regulatory frameworks from the pre-independence era. It deals with research questions relating to the historical evolution of legal and policy frameworks that affect seed systems in Kenya. Using the integrated seed sector development approach, this chapter identifies the seed systems operating in Kenya and exposes a continuous support for the formal seed sector while support given to the informal sector has merely shown the intention to transform it to formal. Seed policy components that influence smallholder farmers' access to new varieties of seed are exposed as well.

Chapter 3 focuses on Kenya's fulfilment of its international obligations in relation to plant breeders' rights and its implications for smallholder farmers. In the process, legal frameworks in 
Kenya that govern plant breeders' rights and the approaches by these frameworks towards exceptions and limitations to the rights are discussed. It is found that the quest to fulfil international obligations has an obvious influence on the legal frameworks' approach towards exceptions and limitations to plant breeders' rights. This quest to fulfil international obligations is oblivious to other related international commitments in place such as those in relation to conservation, sustainable use and fair and equitable sharing of benefits arising from utilization of plant genetic resources for food and agriculture. Furthermore, this quest appears not to fit in with the smallholder farming systems in place, as well as the constitutional requirements in the country.

Chapter 4 builds upon the fulfilment of international obligations and examines two African regional plant breeders' rights initiatives. This chapter deals with questions relating to risks and concerns that arise for smallholders from the processes to harmonise plant breeders' rights in sub-Saharan Africa. It also addresses questions about legal uncertainties that arise in national plant breeders' rights legislations from the regional harmonization processes. The analysis in this chapter reveals that several challenges in relation to implementation of these regional instruments exist and if adopted, the intended outcome may be very different from what is envisioned.

Chapter 5 takes a case study approach examining whether licensing of plant breeders' rights could facilitate access to seeds and planting materials for smallholder farmers in market conditions prevailing in Kenya. Taking into account that licensing is a private activity, it is observed that where breeders are unlikely to recover their costs of investments, licensing can take a humanitarian objective and third party technology facilitators emerge to among others, absorb some of the licensing costs involved.

Chapter 6 explores how through utilization of spaces within the exceptions and limitations to plant breeders' rights as provided in the 1991 Convention of the International Union for the Protection of New Varieties of Plants (UPOV 1991), African countries can balance the needs and obligations of different categories of farmers in the continent. Furthermore the chapter explores how African countries can implement plant breeders' rights systems that incentivise investments in breeding and seed production without creating impediments for access to improved seed for smallholder farmers. It is found that such a balance can be established through a differentiated approach to plant breeders' rights. A differentiated approach to plant breeders' rights by making use of the exemptions contained to the breeders' rights, sets different levels of protection for different crops in relation to different categories of farmers. 
In this thesis a study into the seed systems in place finds that a diversity of seed systems exists in Kenya. However, the legal and policy framework in place in particular with respect to plant breeders' rights is designed to make provision for only some, not all of them. It is also found that the need for Kenya to put in place a plant breeders' rights framework is partly driven by the necessity to comply with international trade obligations resulting from the country's membership to the World Trade Organization. However, the manner in which the country has implemented the plant breeder's rights framework is in conflict with (a) the farming practices on the ground especially those of the smallholder farmers who are the majority of the farming community and (b) other international obligations relating to conservation, sustainable use and access and benefit sharing of plant genetic resources for food and agriculture. This thesis also finds that regional processes in sub-Saharan Africa to harmonize plant breeders' rights regimes are likely to exacerbate conflicts between plant breeders' rights policies and smallholder farmer practices in Kenya. While this brings about risks and concerns, it also presents some opportunities for smallholder farmers.

This thesis demonstrates that plant breeders' rights have the potential to be utilized in a manner that could enable smallholder farmers to positively contribute towards Kenya overcoming its food security problems. However, this will only occur if policy makers carefully assessed internationally harmonized plant breeders' rights systems before subscribing to them in order to ensure that national implementation of such systems fully concurs with the conditions and needs of its farmers and the national agricultural development and food security policy objectives. 


\section{Peter Gitahi Munyi}

Wageningen School of Social Sciences (WASS)

Completed Training and Supervision Plan

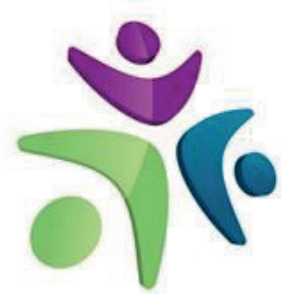

Wageningen School

of Social Sciences

\begin{tabular}{|c|c|c|c|}
\hline Name of the learning activity & Department/Institute & Year & ECTS* \\
\hline \multicolumn{4}{|l|}{ A) Project related competences } \\
\hline $\begin{array}{l}\text { Principles of Dynamic Modeling and } \\
\text { Policy Design }\end{array}$ & $\begin{array}{l}\text { Millenium Institute/University } \\
\text { of Bergen }\end{array}$ & 2011 & 5 \\
\hline Model-based Socioeconomic Planning & $\begin{array}{l}\text { Millenium Institute/University } \\
\text { of Bergen }\end{array}$ & 2011 & 10 \\
\hline $\begin{array}{l}\text { Research Methodology, from Topic } \\
\text { to proposal }\end{array}$ & Wageningen University & 2011 & 4 \\
\hline \multicolumn{4}{|c|}{ B) General research related competences } \\
\hline $\mathrm{PhD}$ Introduction course & WASS & 2011 & 1 \\
\hline Writing PhD research proposal & $\begin{array}{l}\text { WASS/Law and Governance, } \\
\text { WUR }\end{array}$ & $2011 / 2012$ & 6 \\
\hline $\begin{array}{l}\text { 'Plant variety protection experience } \\
\text { in Kenya' }\end{array}$ & $\begin{array}{l}\text { Expert Meeting on the Impact } \\
\text { of Seed Laws on Smallholder } \\
\text { Farming Systems in Africa, } \\
\text { Cape Town }\end{array}$ & 2016 & 1 \\
\hline $\begin{array}{l}\text { 'Towards flexibilities in plant } \\
\text { breeders' rights regimes for food } \\
\text { security' }\end{array}$ & $\begin{array}{l}\text { Towards flexibilities in plant } \\
\text { breeders' rights regimes, } \\
\text { Nairobi }\end{array}$ & 2016 & 1 \\
\hline \multicolumn{4}{|c|}{ C) Career related competences/personal development } \\
\hline $\begin{array}{l}\text { Teaching: Chinese Law on Food and } \\
\text { Agriculture assistance and supervision } \\
\text { (Law 56306) }\end{array}$ & $\begin{array}{l}\text { Law and Governance Group, } \\
\text { WUR }\end{array}$ & $2012 / 2013$ & 2 \\
\hline $\begin{array}{l}\text { Teaching: Intellectual Property Rights } \\
\text { (Law 32806) }\end{array}$ & $\begin{array}{l}\text { Law and Governance Group, } \\
\text { WUR }\end{array}$ & 2012 and 2013 & 2 \\
\hline Total & & & 32 \\
\hline
\end{tabular}

*One credit according to ECTS is on average equivalent to 28 hours of study load 


\section{Acknowledgements}

The journey to writing this thesis must have kicked off one Sunday afternoon in 2003 when my interest in plant breeders' rights was sparked by a casual perusal of Seeding Solutions Volume 1: Policy Options for genetic Resources (People, Plants, and Patents Revisited). I am therefore deeply indebted to those who planted in me, the germ of inquiry into this area. To Robert John Lewis-Lettington and Kent Nnadozie, I take my hat off to you both for having shown faith in me in my very early attempts to come to grasp with this subject.

To my supervisors: Bram De Jonge, Niels Louwaars, Bert Visser and Bernd van der Meulen asante sana for your patience and guidance in this process. This could not have been done without you.

In the course of writing this thesis, I made many visits to the University of Cape Town and colleagues at the Intellectual Property Unit and Environmental Evaluation Unit ever made me feel welcome and at home. To Tobias Schonwetter, Nan Warner, Phyllis Webb, Bernard Maister, Douglas Gichuki and everyone else I encountered at the 'loft' and, Rachel Wynberg, Jaci van Nierkek, and Fahdelah Hartley, I cannot thank you enough.

Germaine Dunsleman, Hannington Odame, Viola Prifti, Dominic Byarugaba, Liz Ng'ang'a, Lois Muraguri, Astrid Mastenbroek, Marc Ghislain, Alhaji Tejan Cole, Veerle van Venckenray, Lumumba Juma, Maria Julia Oliva, Doris Mutta, Nowella Anyango-van Zwieten, Conny Almekinders, Walter de Boef, Moses Matui, Willem van Genugten, Marja Thijssen, Abishkar Subedi, James Mulkerrins, Gareth Borman, Andreas Drews, Suhel al Janabi, Anna Meijknecht, Patricia Kameri-Mbote, Marcelin Tonye Mahop, Michael Halewood, Carine Pionetti, Charlotte Van't Klooster, Susanne von Saint André, Hartmut Mayer, Linda Opati, Caroline Muchiri, Pierre du Plessis, Richard Gold, Nicole Lewis-Lettington, Julian Kinderlerer, Olivier Rukundo, Juliana Santilii, Mohammed Hassena, Isaac Rutenberg, Wanjiru Kamau-Rutenberg, Marisella Ouma, Miltone Ayieko, Wachira Kaguongo, Dan Kiambi, Evans Sikinyi, Shelagh Raubenheimer, Victor Mosoti, Chege Waitara, Lodewijk Van Dycke, Sisule Musungu, Geertrui van Overwalle, Gisella Cloosterman-Kersten, Mugambi Nandi, Francois Meienberg, Jaap Satter, Thomas Braunschweig, Elfrieda Strauss-Pschorn, Leontine Crisson, the Shire Council of Elders, the Series, Capoeira Mamaz, Wambua Kilonzo, Victoria Henson-Apollonio, Kay Chapman (R.I.P), Pauly Nadine, Tobias Dierks, Dwijen Rangnekar (R.I.P), Gino Cocchiaro, Krystyna Swiderska, John Harrington, Fabian Haas, Jean Gapusi (R.I.P), Christa Cepuch, Evans Chege Kamau, Andrew Mushita, Cecilia Githaiga, Harry Jonas and Peter Gildemacher. At several stages of writing this thesis, you were all either eager to test my theories, show me the reality of things, offer valuable criticisms, support this endeavour in various ways and mostly, nudged me on throughout. Thank you very much for standing by and offering your hands when most needed. Emmanuel Kubo and Dasep Wahidin, thank you for tirelessly assisting me through the last steps of this work.

To Mum, Dad, Wambui, Mwangi, Wagura, Johna, Jimmy, Annie, Cathy, Yvonne, Joshua, Eden, Mrs. M, Sally, Brian and Maggie. On many occasions, you had to endure my absence due to this adventure. If for any reason this undertaking was an excuse for my absence, it is now over.

This thesis is dedicated to Sheila, Austin and Rory. I cannot thank you enough for your unwavering support. 


\begin{abstract}
About the author
Born in 1976 in Nyeri, Kenya, Peter G. Munyi obtained his LL.B in 1999 at Moi University, Kenya and in 2008, his LL.M specializing in European Intellectual Property Law from Stockholm University, Sweden. After three years of private legal practice, he joined the International Centre of Insect Physiology and Ecology (ICIPE), an International Agricultural Research Centre based in Nairobi Kenya where his functions included advising the institution on legal and policy matters affecting its work.

During the course of his employment at ICIPE, Mr. Munyi was instrumental in assisting African countries negotiate towards the adoption of the Nagoya Protocol on Access to Genetic Resources and the Fair and Equitable Sharing of Benefits Arising from their Utilization to the Convention on Biological Diversity. In addition, he served as Legal Advisor to the Government of Kenya delegation to the World Trade Organization Ministerial Conference in Mexico in 2003, and advisor to the African Group at the World Health Organization towards the adoption of the Global Strategy and Plan of Action on Public Health, Innovation and Intellectual Property.

Since 2016, Mr. Munyi has been teaching at the Department of Commercial Law, University of Nairobi School of Law.
\end{abstract}




\section{Colophon}

The research described in this thesis was financially supported by the research programme Responsible Innovation, funded by the Netherlands Organisation for Scientific Research (NWO).

Cover design: Peter Munyi, Erwin Hellegering \& Ruben Stoel

Publisher: Digiforce/Proefschriftmaken.nl, Vianen 
